DANILO VICENSOTTO BERNARDO

\title{
Diversidade craniana humana e suas implicações evolutivas
}





\title{
Diversidade craniana humana e suas implicações evolutivas
}

\author{
Tese apresentada ao Departamento de \\ Genética e Biologia Evolutiva do \\ Instituto de Biociências da Universidade \\ de São Paulo, para a obtenção do título \\ de Dr. em Ciências, na área de Biologia \\ (Genética).
}

Orientador: Dr. Walter Alves Neves 

Bernardo, Danilo Vicensotto

Diversidade craniana humana e suas implicações evolutivas.

337 páginas (volumes 1 e 2 )

Tese (Doutorado) - Instituto de Biociências da Universidade de São Paulo. Departamento de Genética e Biologia Evolutiva.

Palavras-chave: 1. Evolução morfológica. 2. Microevolução humana. 3. Deriva genética. 4. Seleção natural. I. Universidade de São Paulo. Instituto de Biociências. Departamento de Genética e Biologia Evolutiva.

\section{Comissão Julgadora:}

$\operatorname{Prof}(a) \cdot \operatorname{Dr}(\mathrm{a})$.

$\operatorname{Prof}(a) \cdot \operatorname{Dr}(\mathrm{a})$.

$$
\operatorname{Prof}(a) \cdot \operatorname{Dr}(\mathrm{a})
$$

$\operatorname{Prof}(a) \cdot \operatorname{Dr}(a)$. 


Para minha mãe,

com todo o amor que sentimos juntos. 

"... from so simple a beginning endless forms most beautiful and most wonderful have been, and are being, evolved".

Charles Darwin 



\section{Agradecimentos}

Até onde eu consigo me lembrar, sempre tive dificuldades em escrever algo que expressasse sentimento ou emoção. Junto com os agradecimentos, peço, então, desculpas às pessoas e instituições que aqui citarei, caso não consiga expressar a sincera gratidão que tenho por elas.

Esta tese representa o fim de um ciclo que se iniciou há aproximadamente dez anos. Foi nessa época que conheci o Prof. Walter Neves, um cientista exemplar, que viria a ser meu orientador no mestrado, um amigo e meu orientador no doutorado. Tudo o que aconteceu na minha vida nesses últimos dez anos sempre teve, de alguma maneira, o reflexo de algo que foi ensinado ou influenciado pelo Walter, razão à qual seria impossível medir a gratidão que tenho por ter podido compartilhar de seu brilhantismo profissional nestes anos. Um desses ensinamentos, sempre proferidos em forma de frases de efeito, foi o de que "fazer ciência demanda generosidade". Prometo me lembrar disso, tanto pelo com o que aprendi com meu orientador quanto com o que recebi graças à generosidade de outros cientistas. Espero um dia poder retribuir tamanha contribuição ao Dr. Tsunehiko Hanihara, responsável pela coleta de dados de mais de 15.000 crânios e que, generosamente, disponibilizou tal base de dados para que pudéssemos realizar pesquisas no âmbito do Laboratório de Estudos Evolutivos Humanos.

Trabalhar no LEEH e diretamente à uma de suas principais atividades na última década, o desenvolvimento do projeto temático "Origens e microevolução do homem na América", representou uma nova perspectiva na minha maneira de encarar a vida acadêmica e minhas obrigações profissionais. As experiências, conhecimentos e amizade compartilhados pelos Professores Rui Murrieta, Renato Kipnis e Astolfo Araujo serão sempre recordadas, também, com muita gratidão. Da mesma maneira com que serão recordados os amigos da "velha guarda" do LEEH: Emil, Puru e Dani, cujas ausências são sempre sentidas.

O convívio no LEEH trouxe também o coleguismo e a amizade de pessoas que participaram do desenvolvimento deste, e de outros, trabalho e também de desenvolvimento pessoal, motivo o qual serei também, sempre grato aos seus gestos. É muito edificante dividir experiências com pessoas do quilate de Mark Hubbe, André Strauss, Mercedes Okumura, Max Ernani, Pedro Tótora e Mariana Inglez. São pessoas que me ajudaram muito nesses anos de IB.

Fora das paredes do LEEH tive também contato com muitos professores durante os anos de pós-graduação. Embora acredite que muitos deles não façam a menor ideia do quanto fui influenciado por suas posturas profissionais e pessoais, não vejo outra alternativa a não ser cita-los, também, nestes agradecimentos, com a esperança de que possamos compartilhar mais experiências no futuro. Dedico essas palavras aos Professores Paulo A. Otto, Francisca Carolina Do Val, Gabriel Marroig, Diogo Meyer, Sérgio Matioli, Sabine Eggers e Eduardo Gorab. A compreensão e o auxílio prestado pelas professoras Célia Koiffman e Regina Célia Mingroni Netto bem como pelos auxiliares acadêmicos Helenice Hirata, Deyse S. de Morais, Helder R. S. Souza, Erika de Camargo e Shirlene F de S. Barros foram fundamentais para o cumprimento das atividades que resultaram nesta tese. 
Fora da USP também conheci pessoas que tornaram a vida acadêmica mais suave, e que contribuíram direta ou indiretamente para a execução deste projeto. Agradeço à Tim Weaver por sua postura sempre prestativa em discutir problemas analíticos nas vezes que nos encontramos durante as AAPA e também pela revisão crítica de uma das metodologias utilizadas neste trabalho. Todos os curadores que responderam prontamente às solicitações de informações de suas coleções osteológicas também merecem um profundo agradecimento, em especial à Giselle Garcia-Pack, por disponibilizar acesso ao catálogo do AMNH. As pessoas que convivi durante a visita ao museu de San Pedro de Atacama, Cristina, David, Emily, Carla e Macarena, também, um muito obrigado.

Minha vida pessoal só é completamente viável devido à existência de três pessoas em especial. Tudo o que sou, penso e faço devo ao estímulo e amor incessante com que minha mãe me presenteou durante toda minha vida. Sua capacidade inesgotável de se admirar com coisas novas, e aprender coisas que parecem impossíveis de se fazer me inspira todos os dias. É muito difícil não desejar ser cientista sendo filho da dona Jeannette. Da mesma maneira que sou grato à minha mãe, sou também à Daniella, minha irmã, a melhor pessoa que já tive a felicidade de encontrar no mundo. Poucas pessoas têm um senso de justiça, camaradagem, lealdade e bondade tão aguçados quanto os da Dani. É um orgulho muito grande ser irmão dela.

A terceira pessoa especial é difícil de descrever. Difícil até de decidir onde ela deveria aparecer nesta lista de agradecimentos. Se existisse a figura do "co-autor" numa dissertação ou tese ela ocuparia, fatalmente, esse posto nos dois trabalhos. Fora isso, o fato de ser minha comparsa intelectual (na verdade, acho que eu sou o comparsa dela), é a minha companheira de vida, de coisas boas, de coisas ruins... É o amor de minha vida. Sem a Tatiana, nada disso teria acontecido.

O apoio da Fundação de Amparo à Pesquisa no Estado de São Paulo (FAPESP), foi fundamental para a execução deste trabalho. Além do, óbvio, apoio financeiro, a responsabilidade agregada à condição de bolsista Fapesp é uma motivação que sempre ocupou uma posição de destaque durante os estudos de pós-graduação. 


\begin{tabular}{|c|c|}
\hline$\mu$ & valor médio de um caráter \\
\hline A.P. & Antes do Presente \\
\hline AIC & Anthropological Institute, Copenhagen \\
\hline AIUO & Instituto Anatômico, Universidade de Oslo \\
\hline AIV & Anthropological Institute, Viena \\
\hline ALUC & Anthropological Laboratory, University of Copenhagen \\
\hline AM & Auckland Museum \\
\hline AMNH & American Museum of Natural History \\
\hline AMS & Australian Museum, Sydney \\
\hline as & Asterion \\
\hline AS & Academia Sinica, Nankang, Taiwan \\
\hline ba & Basion \\
\hline BBM & Bernice Bishop Museum, Honolulu \\
\hline BM & British Museum \\
\hline $\mathrm{br}$ & Bregma \\
\hline C & Matriz de Correlação \\
\hline CAALE & Centro de Arqueologia Annete Laming Emperaire, Lagoa Santa \\
\hline CAM & Duckworth Laboratory for Physical Anthropology, Universidade de Cambridge \\
\hline $\mathrm{CM}$ & Canterbury Museum \\
\hline $\mathrm{CV}$ & Coeficiente de Variação \\
\hline CVM & Coeficiente de Variação Média \\
\hline$D^{2}$ & Distância de Mahalanobis \\
\hline DB & banco de dados agregado por Danilo Bernardo/LEEH \\
\hline$D_{G e n}$ & Matriz de Distâncias Genéticas \\
\hline$D_{G e o}$ & Matriz de Distâncias Geográficas interpopulacionais \\
\hline DHAO & Department of Human Anatomy, Oxford University \\
\hline $\mathrm{dk}$ & Dacryon \\
\hline $\mathrm{D}_{\text {Mor }}$ & Matriz de Distâncias Morfológicas \\
\hline DNA & Ácido Desoxirribonucleico \\
\hline DOA & Distância ao ponto de origem africana \\
\hline$E$ & valor do efeito ambiental em um caráter qualquer \\
\hline $\mathrm{E}_{\text {Con }}$ & Matriz de Efeito Continental \\
\hline EHW & Equilíbrio de Hardy-Weinberg \\
\hline ek & Ectoconchion \\
\hline et al. & et alli (e outros). \\
\hline eu & Euryon \\
\hline Evo-Devo & Biologia evolutiva do desenvolvimento \\
\hline$F$ & componente filogenético de uma variável quantitativa \\
\hline fem & Feminino \\
\hline FM & Field Museum \\
\hline fm:a & Frontomalare anterior \\
\hline $\mathrm{F}_{\mathrm{ST}}$ & índice derivado do coeficiente $\mathrm{F}$ de endocruzamento. \\
\hline
\end{tabular}




\begin{tabular}{|c|c|}
\hline FUMDHAM & Fundação Museu do Homem Americano, São Raimundo Nonato, Piauí \\
\hline$G$ & Matriz de Variância/Covariância Genética Aditiva \\
\hline gb & Glabella \\
\hline$h^{2}$ & coeficiente de herdabilidade \\
\hline HFM & Hipótese dos Fatores Múltiplos \\
\hline HSAN & Homo sapiens anatomicamente moderno \\
\hline HU & Faculty of Medicine, Hokkaido University, Sapporo \\
\hline $\mathrm{i}$ & distância de ligação escalonada ( $\mathrm{i}=$ dist. lig./dist. max.) \\
\hline IB-USP & Instituto de Biociências da Universidade de São Paulo \\
\hline IE & Institute of Ethnography, Academy of Science, Leningrado \\
\hline IHGB & Instituto Histórico Geográfico Brasileiro, Rio de Janeiro \\
\hline IIARMPGLP & $\begin{array}{l}\text { Instituto de Investigações Arqueológicas e Museu Padre Gustavo Le Paige, Universidade } \\
\text { Católica do Norte, Chile }\end{array}$ \\
\hline in & Inion \\
\hline IPD & Isolamento por Distância \\
\hline KU & Kyushu University, Fukuoka \\
\hline la & Lambda \\
\hline LEEH & Laboratório de Estudos Evolutivos Humanos \\
\hline LEEH & Laboratório de Estudos Evolutivos Humanos \\
\hline LEPA & Laboratório de Estudos e Pesquisas Arqueológicas da Universidade de Santa Maria \\
\hline M & Matrizes hipotéticas de modularidade \\
\hline MAEUFPR & Museu de Arqueologia e Etnologia da Universidade Federal do Paraná \\
\hline MAEUSP & Museu de Arqueologia e Etnologia da Universidade de São Paulo, São Paulo \\
\hline MARSUL & Museu Arqueológico do Rio Grande do Sul \\
\hline masc & Masculino \\
\hline MASJSC & Museu Arqueológico de Sambaqui de Joinvile \\
\hline $\mathrm{MH}$ & Musée de l'Homme, Paris \\
\hline MHNJBUFMG & Museu de História Natural e Jardim Botânico da UF MG, Belo Horizonte \\
\hline MHSPJAR & Museu do Homem do Sambaqui Pe. João Alfredo Rohr \\
\hline MNHUK & Museum of Natural History University of Kansas \\
\hline MNUFRJ & Museu Nacional da Universidade Federal do Rio de Janeiro, Rio de Janeiro \\
\hline MO & Banco de dados consolidado por Mercedes Okumura/LEEH \\
\hline MPPR & Museu Paranaense \\
\hline $\mathrm{ms}$ & Mastoidale \\
\hline MSUP & Medical School, University of Phillippines, Manila \\
\hline mtDNA & DNA mitocondrial \\
\hline na & Nasion \\
\hline NHM & Museu de História Natural, Londres \\
\hline NHMB & Museu de História Natural, Busapeste \\
\hline NJT & Neighbor Joining Tree \\
\hline NM & Naturhistorisches Museum, Viena \\
\hline NMM & National Museum Melbourne \\
\hline NMNH & National Museum of Natural History, Smithsonian Institution \\
\hline NTU & National Taiwan University, Taipei, Taiwan \\
\hline op & Opisthocranion \\
\hline os & Opisthion \\
\hline
\end{tabular}




$\begin{array}{ll}\text { OU } & \text { Oxford University } \\ P & \text { Matriz de Variância/Covariância Fenotípica } \\ \text { PMHU } & \text { Peabody Museum, Harvard University } \\ \text { po } & \text { Porion } \\ \text { pr } & \text { Prosthion } \\ \text { QTL } & \text { Loci de Traços Quantitativos } \\ \text { QVM } & \text { Queen Victoria Museum } \\ r & \text { Coeficiente de correlação produto-momento de Pearson } \\ \text { R } & \text { Linguagem e ambiente para computação estatística e gráficos. } \\ \text { RNA } & \text { ácido Ribonucleico } \\ \text { RSM } & \text { Royal Scotish Museum } \\ S & \text { componente específico de uma variável quantitativa } \\ \text { SAM } & \text { South Australiam Museum, Adelaide } \\ \text { SAMCT } & \text { South African Museum, Cape Town } \\ \text { SS } & \text { Subspinale } \\ \text { St } & \text { Stephanion } \\ T & \text { variação total de um caráter } \\ t & \text { Referência à distribuição "t" de Student } \\ \text { TGEM } & \text { Teoria Genética da Evolução Morfológica } \\ \text { TH } & \text { banco de dados consolidado por Tsuneiko Hanihara } \\ \text { TM } & \text { Tasmanian Museum } \\ \text { UCT } & \text { University of Cape Town } \\ \text { UE } & \text { University of Edinburgh } \\ \text { UM } & \text { University of Melbourne } \\ \text { UMTU } & \text { University Museum, University of Tokyo } \\ \text { UNC } & \text { Universidad Nacional de Colombia } \\ \text { UNESC } & \text { Universidade Estadual de Santa Catarina } \\ \text { UOMS } & \text { University of Otago Medical School } \\ \text { USNM } & \text { U.S. National Museum, Washington } \\ \text { UW } & \text { Universidade de Witwatersrand } \\ \text { V/CV } & \text { Matriz de Variância/Covariância } \\ \text { VX } & \text { Vertex } \\ \text { WH } & \text { banco de dados consolidado por William White Howells } \\ \text { WN } & \text { banco de dados consolidado por Walter Neves/LEEH } \\ \text { zm:a } & \text { Zygomaxillare anterior } \\ \text { ZMUC } & \text { Museu de Zoologia da Universidade de Copenhagem } \\ \text { zo } & \text { Zygoorbitale } \\ & \end{array}$




\section{Lista de tabelas}

3.1 Informações primárias sobre as populações do conjuto inicial de dados.

3.2 Informações primárias sobre as populações do banco de dados final.

3.3 Descrição sumária das populações do banco de dados de microssatélites.

3.4 Descrição sumária das populações do banco de dados de mtDNA.

3.5 Distribuição das antiguidades (anos A. P.) das populações amostradas.

3.6 Nível hierárquico-associativo das medidas craniométricas utilizadas neste trabalho.

3.7 Representação das relações entre as variáveis de dois módulos hipotéticos.

3.8 Representação algébrica da construção de uma matriz C.

3.9 Representação algébrica da construção de uma matriz V/CV.

4.10 Valores de CVM, DOA, tamanho amostras e antiguidade das séries analisadas.

4.11 Valores de correlação entre CVM e DOA obtidos de acordo com estratificação cronológica.

4.12 Valores de correlação entre CVM e DOA obtidos de acordo com estratificação geográfico-continental.

4.13 Valores de correlação observados entre as matrizes $D_{G e n}, D_{G e o}$ e $E_{C o n}$.

4.14 Valores de correlação observados entre as matrizes $D_{G e n}, D_{M o r}$ e $D_{G e o}$.

Valores de correlação observados entre as matrizes $D_{G e n}$, $D_{\text {Mor }}$ e $D_{\text {geo }}$ (amostra dividida em América do

4.15 Norte e América Central-Sul).

Valores de correlação observados entre as matrizes $D_{G e n}, D_{\text {geo e }} D_{\text {Mor }}$ (calculada variável-a-variável).

4.16 América toda

Valores de correlação observados entre as matrizes $D_{G e n}, D_{\text {geo e }} D_{\text {Mor }}$ (calculada variável-a-variável).

4.17 América do Norte, apenas

Valores de correlação observados entre as matrizes $D_{G e n}, D_{\text {geo e }} D_{\text {Mor }}$ (calculada variável-a-variável).

4.18 Américas Central e do Sul.

4.19 Distribuição das antiguidades (anos A. P.) das populações amostradas (Tabela 4.10). 


\section{Lista de figuras}

3.1 Landmarks selecionados. Crânio humano, norma frontal.

3.2 Landmarks selecionados. Crânio humano, norma lateral.

3.3 Landmarks selecionados. Crânio humano, norma basal.

3.4 Medidas cranianas do protocolo Howells. Crânio humano, norma frontal.

3.5 Medidas cranianas do protocolo Howells. Crânio humano, norma lateral.

3.6 Medidas cranianas do protocolo Howells. Crânio humano, norma basal.

3.7 Medidas cranianas (raios) do protocolo Howells. Crânio humano, norma lateral.

3.8 Distribuição geográfica das populações amostradas.

3.9 Distribuição mundial das populações agregadas ao banco de dados consolidado.

3.10 Distribuição das antiguidades médias das populações amostradas.

3.11 Mapa do continente americano indicando a localização geográfica de 22 populações nativas americanas.

3.12 Mapa do continente americano ilustrando suposto efeito de escalonamento climático.

3.13 Módulos cranianos da associação desenvolviental.

3.14 Módulos cranianos da associação funcional.

3.16 Representação hipotética de medidas cranianas e suas relações modulares.

4.17 Diagrama de dispersão CVM x DOA.

4.18 Diagrama de dispersão CVM x DOA.

4.19 Diagrama de dispersão CVM $\times$ DOA.

4.20 Diagrama de dispersão CVM x DOA.

4.21 Diagrama de dispersão CVM x DOA.

4.22 Diagrama de dispersão CVM $\times$ Antiguidade das amostras.

4.23 Diagrama de dispersão CVM $\times$ DOA.

4.24 Diagrama de dispersão CVM x DOA.

4.25 Diagrama de dispersão CVM x DOA.

4.26 Diagrama de dispersão CVM $\times$ DOA.

4.27 Diagrama de dispersão CVM x DOA.

4.28 Diagrama de dispersão de $\mathrm{F}_{\mathrm{ST}} \mathrm{x}$ distância geográfica entre as populações amostradas.

4.29 Representação das variáveis craniométricas com sinal neutro (todas as populações amostradas).

4.30 Representação das variáveis craniométricas com sinal neutro (apenas as populações da América do Norte).

4.31 Representação das variáveis craniométricas com sinal neutro (apenas as populações das Américas Central e do Sul).

4.32 Dendrograma gerado a partir de matriz $D^{2}$ calculada sobre as 149 séries utilizadas para a comparação de V/CV.

4.33 Diagrama de dispersão de antiguidade (em anos A. P.) em função de DOA. 



\section{Resumo}

As últimas décadas têm apresentado um crescente número de contribuições para o entendimento sobre quando e onde ocorreu o surgimento do Homo sapiens. Modelos baseados nessas evidências, geralmente, sugerem que a gênese dos humanos modernos ocorreu na África, há cerca de 200.000 anos antes do presente, de onde migraram para as outras partes do mundo. Análises da diversidade genética de populações atuais corroboram esse cenário, ao sugerir que, a partir de uma origem única, a espécie foi, gradativamente, perdendo variabilidade à medida que as populações divergiram, espacial e temporalmente, umas das outras e de suas ancestrais africanas. No que se refere especificamente à morfologia craniana, diversos autores sugerem a existência deste mesmo padrão de decréscimo da variabilidade em função do distanciamento em relação a África, embora seja, também, reconhecida entre os especialistas a partição da diversidade craniana humana entre dois padrões fundamentais: um representado pela morfologia similar àquela que caracterizou os primeiros Homo sapiens, antes que o processo de raciação, no sentido de diversificação, tivesse ocorrido, representado pela denominada "morfologia generalizada"; e outro representado pelas demais variações morfológicas, correspondendo às populações já diversificadas fora da África, denominada "morfologia especializada". Nesse sentido, o entendimento dos processos evolutivos envolvidos nos eventos de diferenciação morfológica gera bastante controvérsia entre os especialistas. Embora a maioria das informações já obtidas aponte para o fato de que a morfologia craniana evoluiu, majoritariamente, por processos estocásticos, algumas evidências sugerem que, ao menos em condições ambientais extremas, algumas regiões anatômicas cranianas específicas tenham uma parcela de sua variabilidade morfológica fixada por seleção natural. Nesse contexto, o objetivo primordial desta pesquisa é caracterizar a evolução da variação craniana humana, abordada a partir de dois tópicos centrais: 1) A investigação da composição, padrão de ocorrência, distribuição e estruturação da diversidade morfológica craniana humana; e, 2) A análise do contexto evolutivo da variação observada no crânio humano, em função de suas características de integração, modularidade e estase evolutiva investigadas a partir da exploração de seus padrões de variância e covariância. Para tanto, foram utilizadas as características métricas cranianas (24 variáveis do protocolo Howells) de 9.287 indivíduos, distribuídos em 161 populações autóctones de dispersão mundial. Apenas indivíduos morfologicamente íntegros constituíram o banco de dados, eliminando qualquer efeito devido à ocorrência de "missing values". Informações adicionais às séries presentes no banco de dados foram utilizadas para uma melhor caracterização geográfica e cronológica dessas populações, e que possibilitou o cálculo das distâncias geográficas entre elas e a estratificação dos dados sob diferentes critérios. Bancos de dados complementares, compostos por marcadores moleculares (mtDNA e microssatélites) também foram utilizados para a análise exploratória comparativa de questões específicas. Os resultados obtidos para as análises da composição, distribuição e estruturação da diversidade craniana humana mostram que grupos populacionais particulares, normalmente associados à alguma região geográfica específica, apresentam padrões de diversificação diversos daqueles observados para todas as populações analisadas de maneira conjunta, o que sugere a ocorrência de respostas evolutivas específicas associadas às condições particulares, como seleção, por exemplo. Em relação às investigações do contexto evolutivo da variação observada, inferida pelos padrões de correlação, covariância e modularidade investigados em diferentes agrupamentos populacionais, os resultados gerados demonstraram que, de maneira geral, os padrões de variância/covariância e a magnitude dos padrões de correlação entre os caracteres apresentam-se de maneira estável, com raras exceções ao estado de estase evolutiva predominante. Em suma, os resultados obtidos através das diferentes estratégias empregadas nesta tese reforçam a ideia de que a evolução da morfologia craniana é melhor explicada por um modelo que assuma a ocorrência de diferentes ditames evolutivos, como deriva genética e seleção natural, por exemplo, que, devido ao recente processo de diversificação da espécie apresentam, de maneira generalizada, em estado de estase.

Palavras-chave: Evolução morfológica; Microevolução humana; Deriva genética; Seleção natural. 


\begin{abstract}
The last decades have seen a growing number of contributions to the understanding of when and where was the emergence of Homo sapiens. Models based on this evidence generally suggests that the genesis of modern humans occurred in Africa some 200,000 years before present, where migrated to other parts of the world. Analysis of genetic diversity of current populations corroborate this scenario, suggesting that, from a single source, the species was gradually losing variability as the populations diverged, spatially and temporally, from each other and from their African ancestors. With regard specifically to the cranial morphology, several authors suggest the existence of this same pattern of decreasing variability as a function of distance from Africa, although it is also recognized among experts partition the human cranial diversity between two fundamental patterns: one represented by morphology similar to that characterized the first Homo sapiens before the process raciação in the sense diversifying, occurred, represented by the so-called "general morphology" and the other represented by other morphological variations, corresponding to the populations already been diversified Africa, called "specialized morphology." In this sense, understanding the evolutionary processes involved in the events of morphological differentiation generates a lot of controversy among experts. Although most of the information already obtained point to the fact that the cranial morphology evolved mostly by stochastic processes, some evidence suggests that, at least in extreme environmental conditions, some cranial specific anatomical regions have a portion of their morphological variability determined by natural selection. In this context, the primary objective of this research is to characterize the evolution of human cranial variation, approached from two themes: 1 ) The investigation of the composition, pattern of occurrence, distribution and structuring of human cranial morphological diversity, and, 2) analysis of the context of evolutionary change observed in the human skull, due to its characteristics of integration, modularity and evolutionary stasis investigated from the exploitation of their patterns of variance and covariance. For this, we used the metric cranial characteristics (24 variables protocol Howells) of 9287 individuals distributed in 161 indigenous peoples worldwide dispersion. Only morphologically intact individuals constituted the database, eliminating any effect due to the occurrence of "missing values". Additional information on these series in the database were used to better characterize geographic and chronological these populations, and that allowed the calculation of geographical distances between them and the stratification of the data under different criteria. Databases additional compounds by molecular markers (mtDNA and microsatellites) were also used for exploratory comparative analysis of specific issues. The results for the analyzes of the composition, structure and distribution of human cranial diversity show that particular population groups, usually associated with a specific geographic region, provide diversification patterns different from those observed for all populations analyzed jointly, suggesting the occurrence of specific evolutionary responses associated with particular conditions, such as selection, for example. Regarding investigations of evolutionary context of the variation observed, inferred by patterns of correlation, covariance and modularity investigated in different population groups, the results generated showed that, in general, the patterns of variance / covariance and magnitude of correlation patterns between characters are presented in a stable manner, with rare exceptions the state of evolutionary stasis predominant. In summary, the results obtained through the different strategies employed in this thesis reinforce the idea that the evolution of cranial morphology is best explained by a model that assumes the occurrence of different evolutionary dictates, as genetic drift and natural selection, for example, that due to the recent process of diversification of species present in a generalized way, in a state of stasis.
\end{abstract}

Keywords: Morphological evolution; human microevolution; Genetic drift; Natural selection. 


\section{Diversidade craniana humana e suas implicações evolutivas}

\section{Apresentação}

Investigar as bases biológicas de um fenômeno particular, a ocorrência (e, consequentemente, suas causas) diacrônica de dois padrões morfológicos distintos em crânios de populações nativas americanas (Neves \& Hubbe, 2005), cujas implicações representam um dos principais focos de debate na Arqueologia: o povoamento do continente americano. Do tema, representado da maneira como foi descrito, decorreu, então, o objetivo de compreender a evolução da diversidade craniana humana e suas implicações para os modelos de povoamento do Novo Mundo. Com essa orientação nasceu o embrião da tese que aqui é apresentada.

Aprofundar-se na investigação do processo de diferenciação e especialização morfológica humana, mostrou-se um exercício crucial para o desenvolvimento do tema proposto. Além do reconhecimento da diversidade e ocorrência de diferentes padrões morfológicos, fez-se necessário investigar os processos envolvidos na gênese dessas diferenças. Tal questão é foco de intenso debate (Lieberman, 2008), e sua solução constitui um ponto crucial para o correto entendimento do processo de dispersão do Homo sapiens a partir da África no final do Pleistoceno (Turner, 1999; Flores, 2007). Tal afirmação se apoia na ideia de que a morfologia de uma característica complexa, como o crânio, retém o histórico evolutivo de seu grupo biológico (Tattersall, 2009).

Somente por volta do início dos anos 1960, as investigações sobre morfologia craniana humana superaram a má reputação a elas atribuída devido à obsessão tipológico-racial que as marcaram durante o século XIX e início do século XX, dentro e fora dos círculos acadêmicos (Washburn, 1963). A Antropologia Biológica, apoiada na popularidade alcançada pela, então nova síntese Neodarwiniana, passou a sinalizar sua crescente necessidade de explicar, dentro 
do arcabouço teórico-metodológico da abordagem evolutiva, as diferenças observáveis na morfologia craniana humana de espécimes fósseis e viventes (Roseman \& Weaver, 2007).

Historicamente, os primeiros trabalhos desenhados sob a ótica neoevolucionista superestimaram a função da seleção natural no processo de diversificação humana (para alguns exemplos ver Wolpoff, 1968; Steegman, 1970; Beals, 1972), desconsiderando, ou subestimando, as outras forças evolutivas que poderiam estar atuando no processo de diferenciação morfológica. Essa afinidade com os modelos baseados na ação da seleção natural refletiu, por cerca de 40 anos, o "programa adaptacionista” ou, simplesmente, “adaptacionismo" (Gould \& Lewontin, 1979), ao qual toda uma geração foi submetida.

A agenda adaptacionista se difundiu por toda a pesquisa biológico-evolutiva realizada a partir da metade do século XX. Diferentes níveis de sucesso e de influência foram alcançados em cada área específica, atingindo seu ápice em dois trabalhos em particular (Pigliucci \& Kaplan, 2000). Em 1975, Edward O. Wilson publicou o livro "Sociobiology", no qual uma nova abordagem sobre o estudo do comportamento animal foi construída sobre o argumento de que cada comportamento, ou funcionalidade, atualmente observado reflete alguma adaptação ao cenário evolutivo passado ao qual a espécie em questão foi submetida (Wilson, 1975). No ano seguinte, o livro The selfish gene, de Richard Dawkins inaugurou uma nova tendência do programa adaptacionista, ao sugerir que a força da seleção natural e sua íntima relação com a produção de novas adaptações seriam tão extraordinariamente fortes que atuariam em todos os níveis da vida, de populações a genes e ideias (Dawkins, 1976).

Impulsionadas pelo trabalho de Gould \& Lewontin (1979) as críticas ao adaptacionismo começaram a ocupar espaço cada vez maior em diversas áreas do pensamento evolutivo (Pigliucci \& Kaplan, 2000). Novas concepções teóricas, como as ideias de dissociação entre adaptação e seleção natural, de exaptação como alternativa à relação "uma forma - uma função", e de deriva genética, em detrimento das outras forças evolutivas como principal agente das mudanças biológicas (Gould \& Lewontin, 1979; Gould \& Vrba, 
1982), conferiram um status inovador à releitura da teoria adaptacionista vigente, desencadeando respostas de diferentes áreas da Biologia Evolutiva e das áreas correlatas.

Assim como o programa adaptacionista atingiu as diferentes áreas da Biologia Evolutiva de maneiras, e em momentos, distintos, a reação, e seu sucesso, também ocorreram de forma diferenciada de acordo com cada área específica. O clímax dessa reação ao adapatacionismo pode ser creditado à consolidação de um novo paradigma evolutivo, a teoria da evolução neutra. Enraizada na teoria estocástica, desenvolvida nos anos 1930 a partir de trabalhos de genética de populações por, principalmente, Ronald A. Fisher (1890-1962), John B. S. Haldane (1892-1964) e Sewall G. Wright (1889-1988), na compreensão e manipulação de modelos matemático-probabilísticos e no desenvolvimento alcançado pela genética molecular a partir dos anos 1950, M. Kimura (1924-1994) publicou, em 1983, "The neutral theory of molecular evolution". Neste livro, o autor expõe e defende a ideia de que a principal causa de mudança evolutiva, tratando-se do nível molecular, é a fixação aleatória de novas variações de caráter seletivo neutro.

O impacto alcançado pela nova visão neutralista foi ampla e rapidamente absorvido pela Biologia Evolutiva em geral, mas, especialmente, nos estudos genéticos e moleculares. A argumentação de que o estudo evolutivo deveria contemplar, a priori, hipóteses alternativas ao adaptacionismo selecionista conquistou destacada posição nas novas investigações empreendidas a partir de então (para uma visão ponderada sobre o assunto ver Mayr, 1983).

Desdobramentos teóricos à parte, o modelo neutro demorou algum tempo até atingir de maneira retumbante os estudos de variação fenotípica humana, mais especificamente os relacionados à evolução da diversidade morfológica craniana. Situação que, hoje, pode ser considerada absolutamente oposta (von Craemon-Taubadel \& Weaver, 2009).

Nesse novo cenário, a diversidade morfológica observada no crânio humano é interpretada como uma entidade evolutiva predominantemente neutra. Embora essa interpretação favoreça e estimule, por um lado, a utilização de traços da morfologia craniana 
como marcadores da história demográfica populacional, como feito com genes de evolução neutra, por exemplo (Relethford, 1994, 2002), por outro desestimula os estudos que investigam as forças seletivas por trás dos processos de diversificação (von Cramon-Taubadel \& Weaver, 2009). Em outras palavras, considerar a morfologia craniana humana como um marcador estritamente neutro pode ser útil para uma parcela das investigações que utilizam a morfologia craniana como objeto de estudo, mas, paradoxalmente, pode ser depreciativa para a compreensão de como o crânio humano foi, de fato, formado. É exatamente essa discussão que representa o pano de fundo que motivou o estabelecimento desta pesquisa.

O desenvolvimento do projeto que originou esta tese, porém, expandiu o escopo inicialmente proposto. Se, num primeiro momento, o objetivo do estudo era compreender a evolução da diversidade craniana humana sob um prisma específico, o problema americano, em outro passou a ser uma compreensão global dos fenômenos envolvidos na diversificação morfológica observada no planeta. Dessa maneira, como uma "exaptação" do primeiro, nasceu o título do trabalho, aqui apresentado: "Diversidade craniana humana e suas implicações evolutivas".

O texto está dividido em cinco capítulos principais: Introdução, Objetivos, Material e Métodos, Resultados e Discussão e Conclusões, organizados de acordo com cada conteúdo específico. Segue-se a esses capítulos principais outros dois adicionais: um contendo a lista de referências citadas no texto e outro com apêndices. De maneira a tornar a leitura mais agradável, tal capítulo de apêndices foi produzido em um volume separado. 


\section{Índice}

INTRODUÇÃO

2 - ObJetivo: CARACTERIZAR A eVolução dA VARIAÇÃo CRANIANA HUMANA

2.1 - QUANTO À DISTRIBUIÇÃO GEOGRÁFICO-TEMPORAL DA VARIAÇÃO CRANIANA HUMANA 39

2.1.1 - Quanto à variação intrapopulacional 40

2.1.2 - Quanto à variação interpopulacional 41

2.2 - QUANTO AO CONTEXTO EVOLUTIVO DOS PADRÕES DE MODULARIDADE, INTEGRAÇÃO E PROPORCIONALIDADE DA VARIAÇÃO CRANIANA HUMANA $\quad 42$

2.2.1 - Quanto à modularidade e à integração morfológica cranianas: 43

2.2.2 - Quanto à estase da variância e covariância dos caracteres morfocranianos: 43

MATERIAL E MÉTODOS

3 - MATERIAL E MÉtodos: ORganizaÇÃo dos dAdOS E PLANEJAMENTO dOS EXPERIMENTOS 47

$\begin{array}{ll}3.1 \text { - BANCOS DE DADOS } & 49\end{array}$

3.1.1 - Banco de Dados de Morfologia Craniana (Morfológico) 50

Definição de "Landmarks" $\quad 53$

Definições das medidas craniométricas $\quad 58$

$\begin{array}{lr}3.1 .2 \text { - Bancos de Dados Moleculares } & 108\end{array}$

$\begin{array}{ll}3.2 \text { - Metodologias AnALíticas } & 114\end{array}$

3.2.1 - Padrões de variação e diversificação humana 117

a) Distribuição da variação intrapopulacional 119

b) Distribuição da variação interpopulacional 121

c) Partição da variação entre fenótipo e genótipo: caso específico de Nativos Americanos 123

3.2.2 - Modularidade, integração e padrões de V/CV da morfologia craniana humana 127

I) Hierarquização morfológica $\quad 136$

II) Hierarquização cronológica $\quad 136$

III) Hierarquização geográfica $r$

IV) Hierarquização molecular $\quad 137$

d) Comparações entre matrizes C, V/CV, e seus padrões de similaridade 138

e) Detecção dos padrões de modularidade e integração morfológica 140

f) Inferência da magnitude de correlação entre caracteres $\quad 140$ 
4.1 - PADRÕES DE VARIAÇÃO E DIVERSIFICAÇÃO HUMANA 143

a) distribuição intrapopulacional 143

b) distribuição interpopulacional $\quad 158$

c) Partição da variação entre fenótipo e genótipo 164

c.1 - Comparação direta entre as matrizes 164

c.2 - Inferência de seleção natural 166

C.3 - assinaturas evolutivas das variáveis craniométricas 169

4.2 - MODULARIDADE, INTEGRAÇÃO E PADRÕES DE (V/CV) DA MORFOLOGIA CRANIANA HUMANA 176

4.2.1 - Critérios de agrupamento 176

I) Hierarquização morfológica $\quad 176$

II) Hierarquização cronológica $r$

III) Hierarquização geográfica $r$

IV) Hierarquização molecular $\quad 186$

4.2.2 - Inferência dos padrões de Variância/Covariância (V/CV) e Correlação (C) 190

d) Comparações entre matrizes e padrões de similaridade $\quad 190$

$\begin{array}{ll}\text { d.1 - Similaridades das matrizes de V/CV } & 190\end{array}$

e) Detecção de módulos cranianos $\quad 203$

\begin{tabular}{ll} 
DISCUSSÃO E CONCLUSÃO & 211 \\
\hline
\end{tabular}

5 - DISCUSSÃO E CONCLUSÃO: INTERPRETAÇÃO E HIPÓTESES 213

\begin{tabular}{lr} 
REFERÊNCIAS & 229 \\
\hline
\end{tabular} 




\section{1 - Introdução: Variação da morfologia craniana humana}

Variação é um fenômeno recorrente em todos os níveis hierárquicos de organização biológica (Hallgrímsson et al., 2005). É razoável supor que o estudo desse fenômeno constitui-se em um tópico extremamente vasto, ocupando posição central, tanto historicamente quanto conceitualmente, para a pesquisa em Biologia Evolutiva (Mayr, 2001; Hallgrímsson \& Hall, 2005). Tal suposição pode ser facilmente justificada e exemplificada através da análise de obras que constituem pilares do pensamento evolutivo. Seguramente, a observação e a interpretação da variação fenotípica, por exemplo, representaram aspectos fundamentais das ideias apresentadas por Charles Darwin (1809-1882) em sua Teoria da Seleção Natural (Bowler, 2005) às quais convergem as raízes do evolucionismo (Mayr, 2006).

Não diferente disso, o estudo das variações intra e interespecíficas, bem como do fenômeno geral da tendência a variar, culminando em aumento de variabilidade - ou, em sentido amplo, diversidade - (Wagner \& Altenberg, 1996), pode ser assumido como fundamental nos pensamentos propostos por Mayr (1970) e Wright (1965), dois dos fundadores da Síntese Moderna (Hallgrímsson et al., 2005; Bowler, 2005). De maneira geral, as diferenças entre indivíduos de uma mesma espécie são observadas em qualquer população, seja ela natural ou artificial. Seres humanos, animais e plantas, domesticados ou selvagens, compartilham essa característica, bem como compartilham a natureza dual, genotípica e fenotípica, da variação (Dobzhansky, 1937).

Segundo Mayr (2005), a produção de variação pode ser considerada como o mais importante passo do processo de Seleção Natural. Para ilustrar esse raciocínio, argumenta que é possível se observar, ao longo do registro fossilífero, períodos que apresentam grandes amplitudes de variação fenotípica alternados com outros de relativa estase, ou, em outras palavras, pouca variabilidade (Gould \& Elderedge, 1993). Admitindo que a Seleção Natural é 
ativa em todos os períodos, Mayr (2001) sugere que as mudanças evolutivas são, então, dependentes mais da disponibilidade de variação do que do processo seletivo propriamente dito, o que explicaria a alternância entre os períodos de mudanças e os de manutenção dos fenótipos dos organismos. De fato, a Seleção Natural apenas pode operar quando existe variação genética associada à variação fenotípica relacionada à aptidão ${ }^{1}$ de um indivíduo em uma população (Templeton, 1999). Consequentemente, depreende-se, sob essa ótica, ser inviável estudar Evolução a partir de uma abordagem que não contemple, ou negligencie, a medida da variação, nos seus componentes genotípico e fenotípico, contida nas populações naturais (Mayr, 1970, 2001).

Nesse sentido, então, pode-se dizer que o estudo da variabilidade em um nível específico da diversificação fenotípica humana, a variação da morfologia craniana, é a questão primordial desta tese. É através da análise de como ocorreu a variação da forma do crânio de populações de Homo sapiens, seguindo uma abordagem metodológica biológicocomparativa (Diniz Filho, 2002), que se pretende aqui investigar os padrões e processos da evolução biológica desta espécie. Assim, de maneira complementar, o tema deste trabalho, como pode ser depreendido a partir de seu título, compreende, de maneira mais ampla, o estudo da evolução da variação morfológica craniana humana.

As últimas décadas têm apresentado um crescente número de contribuições sobre quando e onde nossa espécie surgiu. Baseadas na descrição de novos fósseis, sítios arqueológicos meticulosamente explorados, datações mais refinadas, avanços na biologia molecular, com sequenciamento de ácido desoxirribonucleico (DNA) fóssil e moderno, e ferramentas analíticas cada vez mais poderosas, essas evidências sugerem que os humanos modernos surgiram na África, há cerca de 200.000 anos (McDougall et al., 2005), e dali migraram para as outras partes do mundo (Cann et al., 1987; Manica et al., 2007; Lieberman, 2008), como preconizado pelo modelo proposto por Stringer \& Andrews (1988),

\footnotetext{
1 "Aptidão", aqui, foi o termo escolhido como melhor correspondente em língua portuguesa ao termo "fitness" em inglês. Dado à recorrência da utilização desse termo em textos de Evolução, deve-se assumir que, ao longo deste texto, sempre que a palavra "aptidão" for utilizada remete-se ao termo em inglês.
} 
popularmente conhecido como "Out of Africa" (ver Weidenreich, 1947; Wolpoff et al., 1988, 2000; Eswaran et al., 2005; Templeton, 1993, 2002, 2005 para uma visão contrária). Análises da diversidade genética de populações atuais vêm fornecendo, sistematicamente, argumentos a favor desse cenário, confirmando uma origem única (Liu et al., 2006), embora eventos de mistura genética com espécies próximas (Reich et al., 2010; Green et al., 2010) e interpretações alternativas à essa conclusão (Templeton, 2005, 2010) não possam ser peremptoriamente descartadas.

De maneira simplificada, admitindo-se a origem única africana para o Homo sapiens, a análise da diversidade genética inferida indica uma progressiva perda de variabilidade através de uma série de eventos fundadores ("bottlenecks") a partir da África, demonstrando um declínio progressivo da heterozigosidade proporcional ao aumento da distância em relação ao leste africano (Prugnolle et al., 2005; Ramachandran et al., 2005) de maneira concordante com as predições efetuadas a partir de um modelo evolutivo neutro (Frankham, 1999; Fowler \& Whitlock, 1999; Whitlock, 2002).

O fato de esses resultados convergirem com outros obtidos em estudos a partir de traços craniométricos (Relethford, 1994, 2002; Manica et al., 2007; Betti et al., 2009), indica para a investigação aqui proposta a adoção do modelo neutro como hipótese nula para o padrão evolutivo da diversificação craniana humana. Embora alguns trabalhos tenham indicado divergência quanto à natureza evolutiva desses dados (Hawks et al., 2000; Grine et al., 2007; Hubbe et al., 2009; Bernardo et al., 2009), a interpretação de que a morfologia craniana, como um todo, é determinada por processo estocástico ainda é a mais aceita, historicamente inclusive, entre os especialistas (von Cramon-Taubadel \& Weaver, 2009).

É importante esclarecer, no entanto, que, como brilhantemente enfatizado por Dobzhansky (1937), os fenômenos evolutivos podem ser investigados a partir de duas abordagens distintas. Como Evolução, pode-se averiguar a sequência de eventos e estados que efetivamente possam ter ocorrido ao longo das gerações de um ou mais organismos. Essa 
abordagem trata da reconstituição histórica da linhagem analisada (Mayr, 2001). Por outro lado, como Evolução pode-se também compreender a avaliação analítica dos processos envolvidos e responsáveis pelas mudanças biológicas ocorridas ao longo da história de uma ou mais espécies, ocupando-se, assim, dos fenômenos fisiológicos e desenvolvimentais da linhagem em estudo (Dobzhansky, 1937; Mayr, 1970, 2001).

Sob esse contexto, o estudo dos padrões evolutivos da diversificação humana representa um dos mais importantes e duradouros debates da Antropologia (Relethford, 1998), com especial ênfase para a Antropologia Física, ou Biológica. Embora a partir da segunda metade do século XX tenha sido testemunhada a utilização crescente e massiva de técnicas moleculares para as investigações sobre o tema (Relethford, 1998; Bradley, 2008), estudos executados sobre características morfológicas, em especial as métricas cranianas, continuam desfrutando de destacado prestígio entre os especialistas, uma vez que os remanescentes esqueletais ${ }^{2}$ humanos ainda oferecem a maior e a melhor conexão, em termos quantitativos e demográficos, às informações biológicas relativas às populações humanas pretéritas (Relethford, 2004a; Betti, 2010).

Reflexo da excelência dos estudos que se baseiam na investigação da morfologia craniana para a inferência evolutiva da diversificação humana tal qual observamos nos dias de hoje pode ser testemunhado por uma extensa e já tradicional lista de trabalhos classicamente citados sobre o tema (para apenas alguns poucos exemplos sobre o assunto, veja Howells, 1973, 1989, 1995; Relethford, 1994, 2002; Lahr, 1996; Roseman \& Weaver, 2004). No entanto, além da inferência direta da ocorrência dos diferentes padrões morfocranianos e da comparação entre estes diferentes padrões e suas implicações populacionais e demográficas, ou seja, suas reconstituições históricas (Berry \& Berry, 1967; Sparks \& Jantz, 2002; Neves \& Hubbe, 2005; Bernardo, 2007), pouco têm sido feito, especialmente em relação aos humanos, em favor da investigação e de uma melhor

\footnotetext{
2 Embora o termo "esqueletal" não seja comum à norma da língua portuguesa (a sugestão da língua seria "esquelético") a forma será assim mantida devido a sua melhor adequação ao que se refere em inglês, "skeletal" e não "skeletic".
} 
compreensão dos mecanismos e eventos envolvidos no processo de diversificação do formato do crânio (Lynch, 1990; Marroig \& Cheverud, 2001; Cheverud \& Marroig, 2007; Roseman, 2004; Weaver et al., 2007; Hubbe et al., 2009; Perez \& Monteiro, 2009, para alguns exemplos). É exatamente este tipo de inferência evolutiva a que se propõe a presente tese.

Evolução ${ }^{3}$ é, em geral, frequentemente descrita como "descendência com modificação", o que estabelece uma relação direta, mas imprecisa, entre herança e variação biológica por um lado e continuidade e mudança populacional por outro (Roth, 2005). A análise detalhada (através de observações empíricas, interpretações teóricas e avaliações estatísticas) da relação entre estas duas importantes entidades evolutivas, a variação (Wright, 1984) e as populações (Mayr, 1970), reforça uma das questões fundamentais da síntese moderna, a amplitude da variação intra e interespécies como "matéria-prima" evolutiva (Hallgrímsson \& Hall, 2005). Neste contexto, sob a luz da genética de populações, Evolução pode ser mais precisamente definida como sendo a mudança cumulativa na composição genética de uma população (Hartl, 2008).

Essa definição tem a vantagem de ser curta, simples e eficiente, à medida que contempla as fontes primárias de variação de um deme ${ }^{4}$, seus genes, e permite a contabilização do quanto sua composição muda ao longo do tempo. Assim, por exemplo, uma população local, infinita, em panmixia e sob ausência de seleção, mutação ou migração apresentará frequências gênicas e genotípicas constantes, de geração para geração, obedecendo a uma relação simples e linear entre si. A essa população local, dita em Equilíbrio de Hardy-Weinberg (EHW), é imputada a característica de não apresentar processo de Evolução (Klug et al., 2010).

Nas investigações que envolvem a análise de caracteres cuja base genética esteja num único lócus gênico, e cujos polimorfismos podem ser facilmente identificados, a definição

\footnotetext{
${ }^{3}$ Deve-se assumir, por razões heurísticas, o sentido biológico do fenômeno todas as vezes que a palavra "evolução" aparecer neste texto daqui em diante.

${ }^{4}$ Segundo Hartl \& Clark (2010), populações locais, ou demes, são as unidades fundamentais da genética de populações. Os demes são as unidades evolutivas reais de uma espécie e, salvo em casos especiais, é sobre esses subconjuntos populacionais que os estudos microevolutivos devem se desenvolver.
} 
acima é claramente útil e adequada à inferência do comportamento evolutivo da população em estudo (Arthur, 1984), pois sua frequência gênica, ou alélica, pode ser calculada em uma série de situações particulares5, tanto para uma única quanto para várias populações (ou demes), em determinados intervalos de tempo ou gerações (Otto, 2008). Assim, nesses casos, é possível reconhecer quando um determinado alelo (e o fenótipo a ele associado) muda ou não sua frequência dentro da população, sinalizando, respectivamente, a ocorrência ou não de processo evolutivo (Ridley, 2006).

A expressão fenotípica das características determinadas por um único lócus gênico (ou, no máximo, alguns poucos loci) ${ }^{6}$ se dá, geralmente, de forma qualitativa, através da "ocorrência" ou "não ocorrência" do caráter, assumindo, assim, uma distribuição discreta, ou não métrica (Gottlieb, 1984). Não por acaso, modelos utilizando esse tipo de marcador, como no caso dos clássicos trabalhos de Gregor J. Mendel (1822-1884), por exemplo, obtém sucesso expressivo ao explicar processos de segregação hereditária dos alelos e sua dinâmica nas populações (Glazier et al., 2002). No entanto, a maior parte da variação encontrada na natureza, que efetivamente oferece o substrato biológico que sustenta os processos evolutivos, é de ordem quantitativa, distribuída continuamente (Bowler, 2005). É esta categoria que contém o tipo de variação comumente relacionado à morfologia dos animais (Gottlieb, 1984).

A complexidade inerente aos mecanismos de regulação gênica da expressão de características fenotípicas métricas tem despertado o interesse de investigadores envolvidos em diferentes áreas específicas da biologia evolutiva (Parichy, 2005). De maneira teórica (Wright, 1921a, 1921b; Hill, 1996) e empírica (Sax, 1923) foi aventada uma relativa

\footnotetext{
${ }^{5} \mathrm{O}$ mais popular dos exemplos de aplicação do EHW admite a ocorrência de dois alelos polimórficos $(p, q)$, cuja frequência na população em estudo, quando somados, deva ser de $100 \%$ (ou, em termos relativos, $p+q=1$ ).

${ }^{6}$ De fato, o raciocínio utilizado para se investigar características determinadas por dois (ou alguns poucos) loci gênicos é o mesmo aplicado quando se analisam casos que envolvam apenas um único lócus, embora algumas estratégias, como a contabilização das frequências de haplótipos ao invés das de alelos, por exemplo, sejam adotadas (Ridley, 2006). Esses artifícios, por vezes, alteram algumas propriedades do EHW e diminuem o poder explicativo das análises (Beiguelman, 1995).
} 
incompatibilidade entre os comportamentos observados e esperados (sob a perspectiva Mendeliana) das características fenotípicas de distribuição contínua (Xing et al., 2002).

O conflito entre a teoria de herança particulada de Mendel e o padrão estatístico observado quando se analisam a expressão de características fenotípicas contínuas, levou, no início dos anos 1900, à interpretação de que a herança e a expressão desses traços quantitativos pudessem ser melhor explicadas como sendo resultado da segregação de múltiplos fatores genéticos, modificados por efeitos ambientais (Lander \& Botstein, 1989).

Denominada como Hipótese dos Fatores Múltiplos - HFM (East, 1916), a ideia de que a expressão das características quantitativas seria determinada pela interação entre condições ambientais e componentes genéticos múltiplos (com cada um deles contribuindo apenas para uma pequena parcela do efeito, ou intensidade, sobre tal expressão fenotípica), foi durante um longo tempo assumida como a melhor explicação sobre o mecanismo de controle genético responsável pelo desenvolvimento das características fenotípicas quantitativas, embora já estivesse claro, também, que os efeitos relativos de cada um dos fatores envolvidos, bem como de suas interações, ainda permanecessem desconhecidos (Sax, 1923).

Apesar do sucesso e popularidade da HFM, as investigações realizadas no âmbito de seu arcabouço teórico permaneceram restritas às abordagens fundamentalmente hipotéticas durante a maior parte do século XX, devido à impossibilidade de se revelar as bases genéticas das características quantitativas baseando-se apenas em métodos derivados dos estudos genéticos clássicos (Xing et al., 2002). Algumas novidades metodológicas, como o emprego de um maior número de marcadores moleculares, o desenvolvimento de novas ferramentas analíticas e a disponibilidade de mapas de ligações moleculares com alta resolução (Lander \& Botstein, 1989; Zeng, 1994) facilitaram a análise das bases genéticas de traços quantitativos, demonstrando que mesmo características fenotípicas quantitativas podem estar associadas ao controle de um único lócus gênico (Xing et al., 2002), estabelecendo, assim, as bases 
fundamentais para a detecção, mapeamento, inferências e modelagens dos loci de traços quantitativos, os "QTL's" (Wu et al., 2007).

No entanto, as análises de QTL para lócus único não são suficientes para explicar a base genética do controle de expressão das características fenotípicas quantitativas por um simples motivo: a maioria dessas características está, ainda que de maneira distinta da preconizada pela HFM, sob controle de complexos multigênicos regidos por diferentes fenômenos de interação, como epistasia, baixa penetrância, expressividade variável e pleiotropia, por exemplo (Glazier et al., 2002; Carroll, 2008).

De maneira sintética, a genética de populações e as análises de QTL desenvolvidas para os estudos que envolvem bases genéticas simples, isto é, fundamentadas em lócus gênicos únicos, não se adéquam, ao menos não diretamente, às investigações envolvendo o caráter complexo das características determinadas por complexos multigênicos. Tal inadequação torna-se particularmente dramática quando o produto fenotípico analisado é de natureza morfológico-quantitativa (Arthur, 1984; Carroll, 2008).

Nesse contexto, a biologia evolutiva sustenta duas abordagens especialmente apropriadas para o estudo da variação contínua das características morfológicas: a genética quantitativa evolutiva e a biologia evolutiva do desenvolvimento (Carroll, 2008). Apesar das idiossincrasias de cada uma dessas abordagens, da interação entre elas nasceu uma linha de pesquisa, com diferentes programas (ou tópicos) específicos, capaz de contemplar as necessidades, ou ao menos uma parcela delas, inerentes ao estudo das características morfológicas quantitativas produzidas por complexos multigênicos (Klingenberg, 2005).

A genética quantitativa fundamenta-se na investigação dos padrões de herança entre indivíduos que apresentam variação em termos de grau (ou quantidade) em detrimento a tipo (ou qualidade). A compreensão de como a variação se estabelece entre gerações é essencial para o entendimento da evolução dos organismos, em diferentes níveis 
organizacionais, tanto em estudos teóricos quanto em aplicados (Falconer \& Mackay, 1996; Klingenberg, 2005).

Embora a genética quantitativa tenha sido desenvolvida, e seja completamente adequada, para operar em situações que fogem àquelas usualmente abordadas através das análises baseadas na genética mendeliana clássica, as premissas básicas do programa quantitativo baseiam-se na ideia de que a herança das características contínuas depende das mesmas bases genéticas que controlam a transmissão hereditária das discretas, qualitativas. Isto significa que a genética quantitativa é, primordialmente, uma extensão da genética mendeliana (e da genética de populações aplicável aos caracteres mendelianos). Dois aspectos principais podem ser destacados como sendo as principais diferenças entre a abordagem quantitativa e a mendeliana: i) uma vez que as proporções de segregação de genes não são detectáveis, não faz sentido estudar as situações estáticas a cada geração, fazendo, assim, com que o objeto, ou unidade, de estudo passe de indivíduos (ou famílias) ${ }^{7}$ para populações, compreendendo diversos grupos ou famílias e, consequentemente, muitas proles; ii) a natureza quantitativa da análise impõe que a variação estudada seja medida e não classificada (Falconer \& Mackay, 1996).

Em suma, a genética quantitativa evolutiva baseia-se nas leis mendelianas de transmissão e segregação dos genes, avaliando o comportamento dinâmico desses genes quando inseridos numa população. Com a utilização de avaliações e modelagens apropriadas para cada tipo de interação (por exemplo, dominância, epistasia, pleiotropia, mutação e desequilíbrio de ligação) entre os genes em estudo, a abordagem possibilita a análise conjunta de complexos multigênicos a partir de seus produtos, os caracteres fenotípicos quantitativos. Com esse raciocínio, os estudos baseados em genética quantitativa evolutiva conseguem prever resultados de processos microevolutivos atuando numa população (Falconer \& Mackay, 1996; Klingenberg, 2005).

\footnotetext{
${ }^{7}$ Família, aqui, deve ser compreendida como unidades reprodutivas.
} 
Além da genética quantitativa, outra abordagem bem-sucedida para estudos da variação fenotípica complexa é a biologia evolutiva do desenvolvimento (Parichy, 2005). Popularmente conhecida por "Evo-Devo"s, essa abordagem teve seu momento de grande evidência após a descoberta dos "homeobox"9, a partir de quando se pode demonstrar que parte da diversidade morfológica observada nos seres vivos é devida às alterações e interações gênicas durante o desenvolvimento embrionário (Freeman \& Herron, 2009).

A partir do reconhecimento dessas redes de regulação durante o desenvolvimento embrionário, os estudos de variabilidade fenotípica (como canalização, estabilidade de desenvolvimento e integração morfológica, por exemplo) passaram a considerar a possibilidade de que alterações nessas redes fossem as responsáveis pelas quebras da estase evolutiva (Hallgrímsson et al., 2005; Freeman \& Herron, 2009). A consequência direta desse raciocínio é a obsolescência da definição de Evolução com base nas frequências gênicas (conforme descrita anteriormente), e de todas as outras abordagens que a usam como arcabouço teórico. Uma vez que, o que seria responsável pela expressão de uma determinada característica fenotípica deixa de ser a existência ou não de um gene, ou um alelo, e passa a ser a ativação, ou a expressão, de um conjunto de genes já previamente estabelecidos no organismo, a frequência genética populacional desses alelos deixa de ser diretamente relacionada às mudanças estruturais da população (Carroll, 1995, 2001; Hallgrímsson et al., 2005).

Outra consequência desse fenômeno das redes de regulação durante o desenvolvimento embrionário atinge a ampla, e prolongada, discussão entre micro e macroevolução como principais atores dos processos de diferenciação e especiação (Carroll,

\footnotetext{
${ }^{8}$ Algumas palavras ou expressões, como "Evo-Devo" e "homeobox", por exemplo, serão mantidas na grafia em inglês, por absoluta falta de uma correspondente razoável ou popularmente aceita no Brasil. Nesses casos, as palavras estão grafadas em itálico, entre aspas. Algumas disciplinas, como é o caso da "Evo-Devo" são mais sujeitas a este problema devido à relativa novidade que elas representam na comunidade acadêmica.

9 "Homeobox" são sequências de aproximadamente 180 nucleotídeos que codifica uma sequência de 60 aminoácidos, chamada homeodomínio, que faz parte de uma proteína de ligação ao DNA atuante como um fator de transcrição (Klug et al., 2010). Foi inicialmente descoberto na mosca da fruta e posteriormente foi encontrado em associação a genes Hox em vertebrados e outros animais (Carroll, 2008). Seus produtos atuam como especificadores de diferenciação celular e de posicionamento no embrião (Ridley, 2006; Freeman \& Herron, 2009).
} 
2001). Tradicionalmente, as mudanças intrapopulacionais, baseadas nos fenômenos classicamente reconhecidos como promotores de alterações na estrutura genética dêmica (mutação, seleção, deriva genética e migração) que acontecem em prazos curtos têm sido referidas como microevolução, ao passo que as mudanças que ocorrem entre grupos taxonômicos mais amplos, através de um longo período de tempo e acúmulo dos fenômenos microevolutivos são denominadas macroevolução (Freeman \& Herron, 2009). Alguns autores, Gould \& Eldredge (1993) entre eles, argumentam que os processos microevolutivos são insuficientes para explicar as modificações macroevolutivas, supondo que outros eventos evolutivos devem atuar nesses processos. Para Carroll (2001), esse debate passa a não fazer mais sentido, uma vez que com base nas redes de regulação qualquer grande inovação poderia ser facilmente explicada.

A Teoria Genética da Evolução Morfológica - TGEM, sob a ótica da biologia evolutiva do desenvolvimento, repousa sobre dois pilares: i) a morfologia (ou as formas) evolui majoritariamente através da alteração de expressão, ou funcionalidade, de proteínas conservadas (estáveis durante um longo período ontogenético); ii) essas mudanças ocorrem amplamente através de mutações em regiões regulatórias dos mosaicos pleiotrópicos que controlam a expressão de diversas características (Carroll, 2008). Assim, de acordo com o preconizado por esta abordagem, traços morfológicos que estabeleçam alguma regularidade entre si ao longo do tempo apresentam boas evidências para serem considerados como controlados pelos mesmos genes, ou mesmos complexos genéticos. Com base nessas informações, em diferentes níveis hierárquicos de organização populacional, é possível descrever a dinâmica dos genes nesses grupos e detectar o surgimento das novidades evolutivas presentes na história do grupo (Parichy, 2005).

Como citado anteriormente, da interação entre essas abordagens evolutivas sobre a dinâmica dos caracteres quantitativos resultou uma agenda de pesquisas voltada à investigação e à expansão da TGEM (Cheverud, 1984; Klingenberg, 2005). O crescente interesse em compreender a influência dos processos de desenvolvimento nas mudanças 
evolutivas (Kirschner \& Gerhart, 1998; Arthur, 2001) promoveu a abertura de um programa de pesquisas sobre a evolucionabilidade ${ }^{10}$, ou potencial evolutivo, dos organismos (Wagner \& Altenberg, 1996). Este tópico é um exemplo emblemático da interação entre as duas abordagens evolutivas discutidas anteriormente, uma vez que, claramente, o estudo da evolucionabilidade dos organismos compartilha interesses tanto da genética quantitativa (a investigação dos padrões de mudanças evolutivas através da análise de características morfológicas) quanto da biologia evolutiva do desenvolvimento (avaliar a influência dos fenômenos ocorridos durante o desenvolvimento na expressão fenotípica dos caracteres estudados).

Assim como revelar o potencial evolutivo de uma população ou espécie, a evolucionabilidade pode predizer como um grupo responde à seleção, qual direção assume durante o processo seletivo, ou, ainda, se as mudanças tendem a ocorrer de maneira não adaptativa através de deriva genética (Hansen, 2003; Hansen \& Houle, 2008; Klingenberg, 2005). A partir dessas predições, deriva, em contraste, outro tópico desta abordagem, o estudo das restrições evolutivas (Beldade et al., 2002, Klingenberg, 2005, Roth, 2005). Essas restrições atuam limitando ou enviesando o potencial evolutivo, reduzindo a evolucionabilidade em algumas direções do espaço fenotípico (Maynard Smith et al., 1985).

A maior parte dos estudos sobre restrições evolutivas têm sido focados na discussão de suas funções como limitadoras da evolucionabilidade de traços quantitativos em direções específicas, tornando algumas variações fenotípicas inviáveis, ou inacessíveis, à evolução. Alterações das trajetórias de desenvolvimento derivadas preponderantemente de estudos não moleculares de comparações entre táxons, como a heterocronia, a alometria e a heterotropia

\footnotetext{
${ }^{10} \mathrm{O}$ programa de pesquisas é denominado, em inglês, "evolvability". Embora, intuitivamente, as melhores traduções do termo para a língua portuguesa fossem "evolvabilidade" ou "evolutibilidade", nenhuma das duas formas aparece no dicionário Caldas Aulete como sinônimos gerais para o termo "evolutivo", que é o adjetivo que melhor qualifica o fenômeno relativo à "evolvability", que corresponde à tendência intrínseca dos organismos em produzir novas variações (Wagner \& Altenberg, 1996). No mesmo dicionário, o termo "evolucional" aparece como sinônimo geral, para os dois gêneros, de "evolutivo", justificando a escolha da denominação "evolucionabilidade" neste texto. Durante a produção do texto a decisão de se cunhar, ou adaptar corretamente, o termo ao invés de apenas usar a grafia em língua inglesa (como foi decidido em alguns casos que, como este, apresentaram incompatibilidade entre as grafias línguas portuguesa e inglesa) deu-se devido à relevância do assunto que, apesar de contar com grupos de expressão no Brasil, até onde sabemos ainda não possui um termo em língua portuguesa (com exceção de "evolvabilidade" sendo sistematicamente utilizado).
} 
(Futuyma, 1998), são exemplos primordiais da ação dos efeitos das restrições evolutivas, que atuam ontogeneticamente, promovendo forte direcionamento dentro do espaço de possibilidades fenotípicas de um indivíduo ou grupo. A ação evolutiva através de mudanças no controle de crescimento podem facilmente alterar a trajetória de crescimento de um grupo daquela de seu grupo ancestral, facilitando eventos macroevolutivos (Gould, 1989; Klingenberg, 1998).

Outro tópico de destaque oriundo da interação entre a genética quantitativa e a biologia do desenvolvimento é o estudo da integração morfológica (Klingenberg, 2005). Esse programa, que já apresenta um longo histórico de pesquisas, tem como objeto de investigação a avaliação de como cada parte de um organismo é formada e sofre mudanças em relação às outras partes desse mesmo organismo (Klingenberg, 2005). O termo "integração morfológica" foi introduzido por Olson \& Miller (1958), ao apresentarem a ideia de que cada parte de um organismo é estabelecida de maneira a manter uma relação proporcional a todas as outras. A questão central é determinar se a variação fenotípica observada em um organismo é totalmente coordenada entre seus diferentes caracteres quantitativos, representando, assim, um conjunto completamente integrado, ou se determinado organismo é composto por subunidades relativamente independentes umas das outras, representando conjuntos pouco integrados (Cheverud, 1982, 1996a; Wagner, 1996).

Assim como à inferência de evolucionabilidade se associa a de restrição evolutiva nota-se, através da definição anterior, que à de integração morfológica se conecta uma nova ideia, descritiva de uma série de "conjuntos pouco integrados" (Klingenberg, 2008). A ideia de que partes de organismos são coordenadas de maneira a formar um "todo funcional" remonta ao início do século XIX, quando Georges Cuvier (1769-1832) a sugeriu através do seu "princípio da correlação" (Mayr, 1982). A verificação experimental de que dentro desses "todos funcionais" são encontrados conjuntos de caracteres mais correlacionados entre si do que com outros agrupamentos, também integrados, levou ao conceito das "plêiades de correlação" (Berg, 1960). 
O reconhecimento das plêiades de correlação como resultado de trajetórias comuns ao longo do desenvolvimento dos caracteres agrupados promoveu a interpretação de que esses complexos fenotípicos deveriam ser determinados pelos mesmos genes e fatores ambientais (Olson \& Miller, 1958). A verificação de diferentes níveis de integração entre os grupos de caracteres favoreceu a ideia de "módulos" (daí a denominação do fenômeno ou tópico de pesquisa - modularidade), que de uma maneira mais ampla, além de serem definidos pelas suas trajetórias de desenvolvimento, são determinados também pelas funções desempenhadas no organismo (Cheverud, 1982; Wagner et al., 2007).

A morfologia craniana como um todo, considerada em termos de tamanho e forma, é definitivamente um ótimo exemplo de estrutura biológica complexa (Zelditch, 2005). Em mamíferos, incluindo humanos modernos, o formato do crânio é determinado sob o controle de diversas interações gênicas (epistáticas e pleiotrópicas) influenciadas tanto por fatores ambientais (Cheverud, 1996b) quanto por estímulos de outras células e tecidos do organismo (Smith, 1997; Wilkie \& Morriss-Kay, 2001; Hallgrímsson et al., 2007). Além disso, o crânio é uma estrutura dinâmica, que sofre alterações ao longo da vida do indivíduo (Zelditch et al., 1992, 1993, 2003) em resposta a diferentes condições físico-químicas às quais é submetido durante seu desenvolvimento (Zelditch et al., 1993, Zelditch, 2005).

Não bastasse essa complexidade intrínseca aos sistemas biológicos, caracterizada pela recorrente interação entre diferentes características (Dobzhansky, 1956), investigações centradas na evolução morfológica, quando dependente de fósseis como objeto de estudo, apresentam ainda um problema adicional às dificuldades de natureza teórica já explicitadas anteriormente: o registro fóssil e suas deficiências (Arthur, 1984), que vão desde a completa ausência (ou inexpressividade numérica) de amostras (indivíduos, grupos) essenciais às análises até a impossibilidade de se avaliar um espécime seja por deficiências de seu registro (onde foi coletado, antiguidade e posição estratigráfica, por exemplo) seja por lacunas ou distorções (por vezes de origem tafonômica) de sua morfologia original. Por vezes, quando 
fósseis humanos constituem o objeto de estudo a situação é ainda mais dramática (Bernardo \& Neves, 2009).

Nesse cenário, a utilização das técnicas desenvolvidas sob o escopo da TGEM para os estudos de variação e diferenciação da morfologia, em diferentes escalas de tempo e níveis hierárquicos, torna-se, praticamente, irrefutável. É essa agenda de pesquisa, com a aplicação de suas ferramentas analíticas às questões pertinentes a essa investigação, que será utilizada neste trabalho.

De maneira geral, a morfologia craniana e seus padrões de diversificação refletem diferentes graus de atuação das bases desenvolvimentais de ação e expressão gênica no controle dos processos de mudanças evolutivas (Mitteroecker \& Bookstein, 2008). Exemplos dessas diferentes atuações podem ser observados quando se consideram os padrões de modularidade craniana de diferentes hominídeos, apresentando mudanças morfológicas e alterações na estrutura de integração de maneira compassada (Ackermann, 2005; Mitteroecker \& Bookstein, 2008). Essa estruturação de modularidade e integração pode ser inferida através da correlação entre caracteres morfológicos, medidas cranianas por exemplo, estabelecidas através de matrizes de correlações (Price et al., 1993). Complementarmente a esse estudo dos padrões de correlação entre traços morfológicos, outras estruturações fenotípicas podem ser inferidas com base em alguns conceitos da TGEM.

Alguns desses conceitos, oriundos da genética mendeliana clássica e das técnicas estatísticas uni e multivariadas e depurados pela genética quantitativa, são fundamentais para a abordagem evolutiva do estudo da morfologia (Falconer \& Mackay, 1996). De acordo com Steppan e colaboradores (2002), dentre esses conceitos, pode-se citar como um dos mais populares, importantes, e promissores, a concepção teórica de Matriz de Variância/Covariância Genética Aditiva. 
Tal conceito, na literatura normalmente representada por $G$, corresponde, matematicamente, a uma matriz simétrica ${ }^{11}$, que sumariza a contribuição genética aditiva às variâncias e covariâncias entre os traços, ou características, de um conjunto fenotípico (Steppan et al., 2002). De maneira geral, $G$ sintetiza as relações de interdependência entre pares de caracteres, através da medida de covariação entre eles. A covariância expressa o quanto duas características variam conjuntamente, ou seja, altos valores de covariância entre dois caracteres indicam que ambos apresentam interdependência em suas variações (Ridley, 2006). Partindo-se da premissa de que a intermediação das relações de dependência entre caracteres é desempenhada pela expressão de genes (ou complexos gênicos), é possível elaborar o raciocínio de que, altos valores de covariância indicam alta incidência desses genes, em nível populacional. Dessa forma, $G$ infere a parcela da variação de uma característica que se apresenta disponível para os processos evolutivos, de geração a geração (Falconer \& Mackay, 1996; Steppan et al., 2002). De maneira a dimensionar as covariâncias, a diagonal principal da matriz $G$ é ocupada pelas variâncias de cada característica, ou variável, assumindo, assim, o formato de Variância/Covariância.

No entanto, por conta dessa amplitude evolutivo-temporal, avaliando a frequência dos caracteres geração a geração, a inferência de $G$ é extremamente complexa, exigindo grandes contingentes amostrais com relações genealógicas determinadas (Falconer \& Mackay, 1996). Voltando à situação exposta anteriormente, em estudos que empregam fósseis como objetos de análise, essas condições tornam-se impraticáveis.

De maneira a contornar essa situação, outro conceito emergido da TGEM, trata da contrapartida fenotípica da matriz $G$, a matriz fenotípica $P$. A matriz $P$ é uma matriz de Variância/Covariância medida diretamente dos caracteres morfológicos (fenotípicos) dos indivíduos de uma população, sem a inferência das contribuições genéticas ou ambientais em sua expressão e desenvolvimento (Steppan et al., 2002). Desde que ambas, $G$ e $P$,

\footnotetext{
${ }^{11}$ Por matriz simétrica, entende-se uma matriz quadrada de ordem $\mathrm{n}$ que apresenta os mesmos valores que sua matriz transposta. Em termos matemáticos: $\tilde{A}=a_{i j}=A^{\top}=a_{j i}$ (Duarte Junior, 2008).
} 
apresentem-se significativamente semelhantes, a segunda pode ser usada em substituição à primeira (Cheverud, 1988; Roff, 1995). Para dados representativos da morfologia craniana, essa premissa parece ser satisfatoriamente cumprida (Marroig \& Cheverud, 2001).

As bases quantitativas da investigação proposta neste trabalho repousam sobre a dependência e a interdependência entre características morfológicas, bem como nas matrizes de Correlação - C e Matrizes de Variância/Covariância - V/CV.

Tendo em mente o que acabou de ser apresentado, faz parte do objetivo primevo da pesquisa descrita nesta Introdução a investigação dos padrões de integração e estase morfológica do crânio de populações humanas pré-históricas e recentes (subatuais). A estratégia adotada consiste em explorar as características estruturais particulares e compartilhadas entre as séries em estudo, agrupadas de maneira populacional e metapopulacional, através da análise de seus padrões de Correlação (C) e Variância/Covariância (V/CV) fenotípicas, morfocranianas mais precisamente.

Confrontando-se esses padrões às medidas de inferência da história biológica dessas populações, como cronologias e deslocamentos, por exemplo, espera-se compreender as tendências e as magnitudes dos eventos evolutivos de particular interesse no estudo da diversificação da morfologia craniana humana.

A interpretação dos padrões emergidos dessas análises depende da contextualização da lógica apresentada nesta introdução. Assim, no que se refere à investigação fundamentada nos modelos de genética quantitativa, a variação morfológica do crânio humano será aqui explorada em função de seus padrões de modularidade e à integração e de estase da variância e covariância de seus caracteres.

Para a execução da estratégia descrita, o presente estudo consistirá em explorar os padrões de variação, diversificação, covariância, modularidade e integração morfológica que emergem a partir da morfologia craniana (representada por medidas lineares) de populações 
humanas autóctones de ampla distribuição mundial. Ao avaliar esses padrões, de maneira intra e inter grupos (ou populações), espera-se detectar dois grupos de características (ou estruturações), em termos morfocranianos: a) generalidades comuns a todos os indivíduos, ou grupos; b) particularidades elementares distintivas de grupos específicos, independentemente dos critérios utilizados para o agrupamento (em geral, os critérios utilizados restringem-se à biologia e à localização geográfica dos indivíduos que formam o grupo). O conhecimento desses padrões gerais pode colaborar para a elucidação das interações histórico-estruturais das populações humanas (Gonzaléz-José, et al., 2004). 


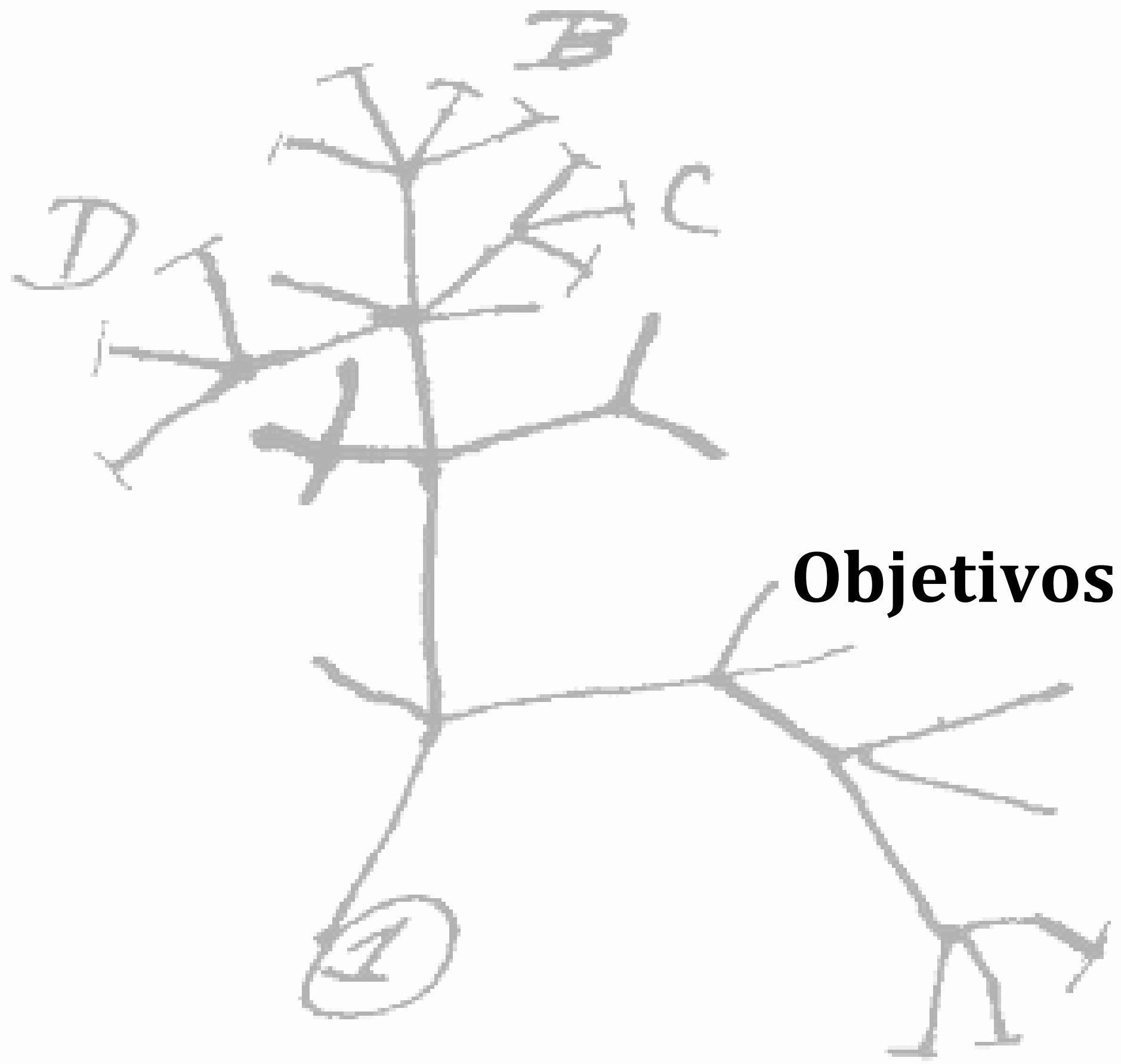
S 



\section{2 - Objetivo: Caracterizar a evolução da variação craniana humana}

Como pode ser depreendido a partir do capítulo anterior, os objetivos centrais da pesquisa proposta podem ser reconhecidos como derivações a partir de duas abordagens principais: 1) A investigação da composição, padrão de ocorrência, distribuição e estruturação da diversidade morfológica craniana humana; e, 2) A análise do contexto evolutivo da variação observada no crânio humano, em função de suas características de integração, modularidade e estase evolutiva investigadas a partir da exploração de seus padrões de variância e covariância. Dessa maneira, tais objetivos podem ser, simplificadamente, relacionados conforme abaixo.

\section{1 - Quanto à distribuição geográfico-temporal da variação craniana humana}

No contexto apresentado ao longo da Introdução, destaca-se que um crescente número de trabalhos têm empregado teoria e métodos desenvolvidos para a genética quantitativa e de populações em tentativas de elucidar nossa compreensão sobre a diversificação da morfologia craniana humana (von Cramon-Taubadel \& Weaver, 2009). A maior parte desses estudos, com raríssimas exceções, demonstra que a morfologia craniana parece evoluir primariamente através de mecanismos estocásticos (Relethford, 1994, 2002; Roseman, 2004; Roseman \& Weaver, 2004; Manica et al., 2007; Weaver et al., 2007; Hubbe et al., 2009), mesmo admitindo-se que a forma do crânio é modulada por um complexo multigenético. Visões contrárias a essa conclusão podem ser encontradas, por exemplo, em Guglielmo-Matessi et al. (1979) e Lieberman (2008, 2011), que sugerem evidências de que, ao menos parcialmente, uma fração da variabilidade morfológica craniana pode ter sido fixada por seleção natural. Com mais precisão, Roseman (2004) e Hubbe et al. (2009) 
também demonstram a possibilidade do crânio ser afetado tanto por uma parcela neutra quanto por uma sujeita à ação seletiva.

Se, por um lado, a natureza neutra do crânio humano possibilita e valida sua utilização para a inferência de filogenias e histórias populacionais, por outro desestimula os estudos que investigam as forças seletivas por trás dos processos de diversificação (von Cramon-Taubadel \& Weaver, 2009). Em outras palavras, considerar a morfologia craniana humana como um marcador estritamente neutro pode ser útil para uma parcela das investigações que a utilizam como objeto de estudo, mas, paradoxalmente, pode ser depreciativa para a compreensão de como o crânio humano foi, de fato, formado.

Assim, no que se refere à investigação da variação da morfologia do crânio de humanos, mais importante do que compreender e descrever quais os padrões de distribuição observados é inferir a natureza evolutiva da variação apresentada. Nesse sentido o presente trabalho objetiva investigar aspectos específicos dessa variação, que podem ser compreendidos quanto à dois aspectos fundamentais:

\subsection{1 - Quanto à variação intrapopulacional}

- Ao se examinar a variação da morfologia craniana intrapopulacional de séries com ampla distribuição geográfica mundial, espera-se constatar, desde que a diversidade observada possa ser fundamentalmente atribuída a processos evolutivos estocásticos, um progressivo decréscimo da quantidade de variação em função do aumento de distância geográfica em relação ao leste da África (Handley et al., 2007; Betti et al., 2010). Tal abordagem objetiva compreender o comportamento da variação craniana humana em diferentes cenários de modo e tempo;

- Adicionalmente, através de tal estratégia espera-se inferir se, como sugerido por alguns autores (Serre \& Päabo, 2004; Manica et al., 2007; Betti et al., 2009, para 
apenas poucos exemplos), a distância em relação à África (como uma estimativa de tempo de divergência) é uma melhor descritora do padrão de variação intrapopulacional do que a localização geográfica continental (como estimativa para as contingências ambientais específicas) de cada população.

\subsection{2 - Quanto à variação interpopulacional}

- Similarmente ao raciocínio empregado para a investigação da diversidade morfológica craniana humana a partir de uma abordagem intrapopulacional, objetiva-se avaliar o comportamento da variação craniana entre diferentes populações sob uma perspectiva evolutiva neutra. Admitindo que caracteres métricos cranianos comportam-se de maneira similar ao observado entre marcadores moleculares não seletivos, cuja variação encontra-se, aproximadamente, $85 \%$ distribuída dentro das populações, $10 \%$ entre populações de um mesmo continente e $5 \%$ entre populações de continentes diferentes (Lewontin, 1972; Barbujani et al., 1997; Relethford, 1994, 2002; Templeton, 1999; Barbujani, 2007) espera-se, de acordo com o modelo de isolamento por distância (Wright, 1943), que, à medida que aumenta a distância geográfica que as separa, as populações amostradas aumentam o grau de divergência entre elas;

- De maneira a investigar como a variação craniana humana é partida em componentes fenotípicos e genotípicos, uma parcela dos dados sobre a variação craniana amostrada será comparada com marcadores evolutivos neutros com o objetivo de analisar a característica evolutiva de cada uma das diferentes variáveis craniométricas analisadas. 


\section{2 - Quanto ao contexto evolutivo dos padrões de modularidade, integração e proporcionalidade da variação craniana humana}

Como inicialmente apresentado, mais do que o reconhecimento descritivo dos padrões de diversidade, o estudo da evolução da variação craniana passa, obrigatoriamente, pela investigação das possíveis causas e fenômenos biológicos envolvidos em tal processo. Como apresentado no capítulo anterior, tal tópico é intimamente relacionado aos modelos de pesquisas de genética quantitativa, modularidade, integração morfológica, evolucionabilidade e restrições evolutivas.

Basicamente, o raciocínio que fundamenta tais modelos baseia-se na detecção, descrição e comparação da organização e proporcionalidade dos padrões de covariância e correlação fenotípica dos grupos analisados.

A proporcionalidade dos padrões de covariância e correlação fenotípica de um grupo, e a correspondência desses à sua estruturação genética, podem estar associadas à ocorrência e à magnitude dos eventos promotores do processo de diversificação morfológica. Essas associações podem ocorrer tanto em termos intraespecíficos quanto em níveis taxonômicos superiores (Oliveira, 2009). Já os padrões de integração morfológica podem indicar o quanto da variação observada intra e intergrupos pode ser associada, ou afetada, por mecanismos de natureza desenvolvimental-funcional (Marroig \& Cheverud, 2001; Ackermann, 2002, 2005; Gonzaléz-José et al., 2004). A forma e a intensidade da interação entre essas características definem a maneira com que o fenótipo, como um todo, evolui (Lande, 1982). Assim, no que se refere à investigação do contexto evolutivo proposta neste trabalho, os principais objetivos propostos podem ser descritos em termos de dois tópicos fundamentais. 


\subsection{1 - Quanto à modularidade e à integração morfológica cranianas:}

- Ao se examinar as matrizes de correlações intrapopulacionais, espera-se encontrar grupos de caracteres (medidas) cranianos mais associados entre si do que com outros caracteres e grupos de caracteres, revelando, assim, uma composição relativa de modularidade/integração craniana intrapopulacional. Se esse raciocínio estiver correto, padrões de associação morfológica entre as populações podem emergir a partir dos padrões de modularidade compartilhados entre as séries analisadas;

- Quando investigadas de maneira interpopulacional, os diferentes padrões de modularidade de uma determinada população podem ser associados, preferencialmente, entre aquelas que apresentam maior similaridade morfológica entre si, reforçando, neste caso, a ideia de origem biológica comum entre elas. $\mathrm{O}$ inverso também é esperado, ou seja, entre populações com maiores dissimilaridades, espera-se encontrar menores níveis de concordância entre os módulos cranianos.

\subsection{2 - Quanto à estase da variância e covariância dos caracteres morfocranianos:}

- Espera-se encontrar uma estrutura geral de variância/covariância entre as populações estudadas, devido à recente origem comum da espécie;

- Entretanto, espera-se encontrar particularidades na estrutura de variância/covariância entre as populações estudadas, com especial concordância entre aquelas que apresentam maior similaridade morfológica e/ou correspondência geográfica e/ou cronológica. A confirmação dessa expectativa pode favorecer a ideia de que o processo de divergência morfológica observada em humanos modernos está associada a rupturas da estase do padrão de variância/covariância da matriz $G$. 



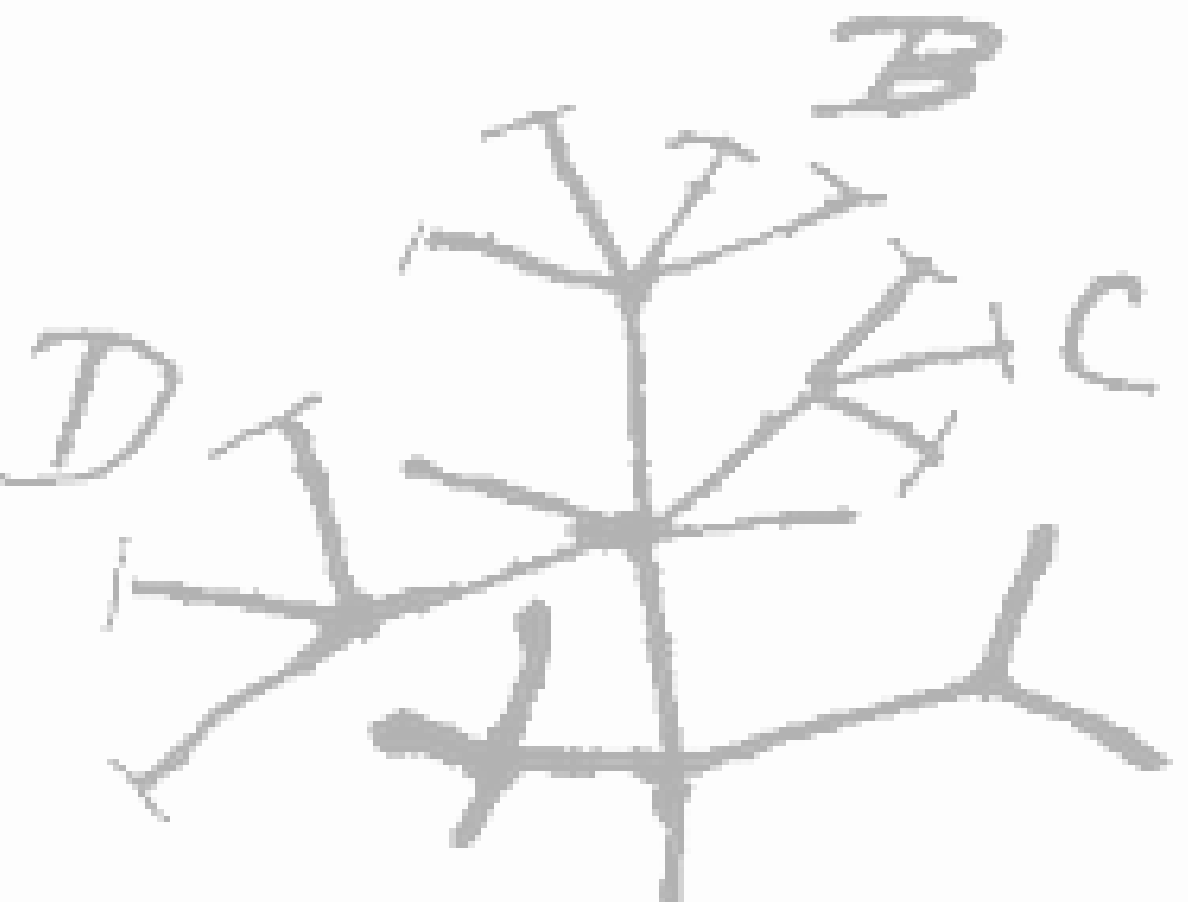

\section{Materiale Métodos}

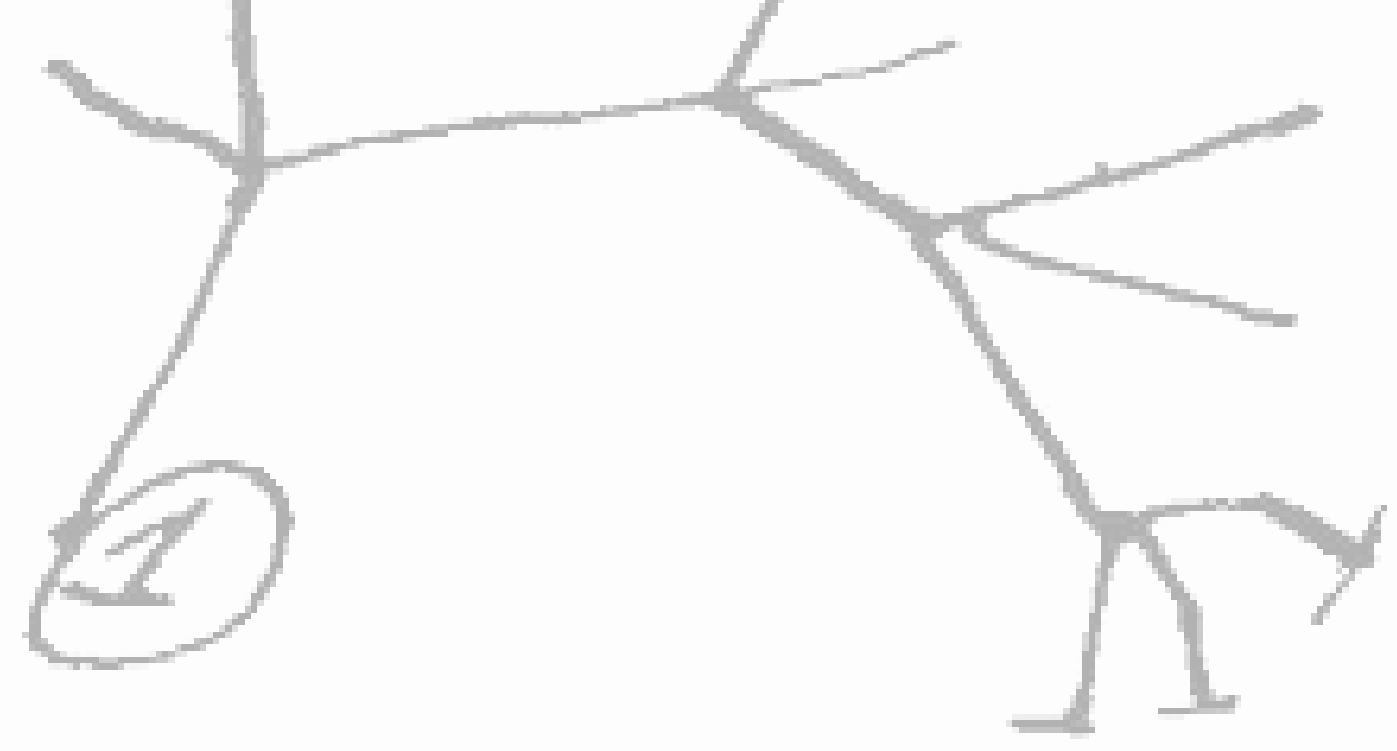

"- Esse nosso rapazinho tem a vista curta. Espera aí, Miguilim... E o senhor tirava os óculos e punha-os em Miguilim, com todo o jeito.

- Olha, agora!

Miguilim olhou. Nem não podia acreditar! Tudo era uma claridade, tudo novo e lindo e diferente, as coisas, as árvores, as caras das pessoas. Via os grãozinhos de areia, a pele da terra, as pedrinhas menores, as formiguinhas passeando no chão de uma distância. E tonteava. Aqui, ali, meu Deus, tanta coisa, tudo..."

João Guimarães Rosa, "Manuelzão e Miguilim". 



\section{3 - Material e Métodos: Organização dos dados e planejamento dos experimentos}

Como discutido por Amorim (2002), e habilmente revisitado por Diniz Filho (2002), o método comparativo vem sendo, desde os tempos de Darwin, uma das principais maneiras de se estudar os padrões e processos da evolução biológica (Diniz Filho, 2002) no nível populacional e de espécie (Amorim, 2002).

De maneira específica às investigações centradas na Biologia Evolutiva, a abordagem comparativa tem como principal objetivo a detecção do processo de adaptação ${ }^{12}$, através da inferência da relação entre variação ambiental e diversidade fenotípica das espécies (Miles \& Dunham, 1993; Pagel, 1999). Para tanto, as técnicas analíticas empregadas pelo método lançam mão da comparação entre conjuntos de dados, de diferentes naturezas, que exprimam as características particulares das espécies, populações e ambientes em análise (Simpson et al., 2003).

Embora implicitamente central ao pensamento evolutivo, as raízes metodológicas, formalmente delineadas, dessa abordagem coalescem nos estudos filogenéticos comparativos baseados no modelo autorregressivo de restrições evolutivas (Cheverud et al., 1985) e no de padrões de evolução correlacionada (Felsenstein, 1985). Tais modelos demonstraram matematicamente o efeito da estruturação dos dados ao longo de uma filogenia, ou, em outras palavras, como ocorre a distribuição de variação intra e interespecífica de determinado caráter. Em decorrência de tal fenômeno, estudos que objetivam a investigação de padrões de evolução e co-evolução de caracteres quantitativos devem, necessariamente, basear-se em métodos comparativos filogenéticos (Miles \& Dunham, 1993; Martins \& Hansen, 1997; Diniz Filho, 2002; Oliveira, 2009).

\footnotetext{
${ }^{12}$ Cabe ressaltar que para fins analíticos, a não ocorrência (ou ausência) de adaptação pode também ser considerada como hipótese nula a ser testada sem que haja prejuízo à lógica intrínseca ao raciocínio biológico-evolutivo.
} 
A discussão sobre a adequação metodológica da interpretação do significado biológico e o estabelecimento de relações evolutivas a partir da inferência da variação morfológicoquantitativa de caracteres remonta aos principais debates envolvendo as diferentes correntes de pensamento de sistematas modernos (Heywood \& McNeill, 1964; Mayr, 1974, 2001).

Mais do que opor cladistas ${ }^{13}$ (filogeneticistas) e gradistas de um lado e feneticistas ${ }^{14}$ de outro quanto aos conceitos interpretativos básicos de cada escola (Sokal \& Camin, 1965), o descompasso causado pela oposição irreconciliável ${ }^{15}$ sobre os princípios a serem utilizados nas classificações biológicas (Amorim, 2002) por cada um desses expoentes colocou em xeque o desenvolvimento de uma agenda de pesquisa que estabelecesse uma relação sinérgica que explorasse tanto as reconstituições históricas, da biologia evolutiva, quanto às modelagens estatísticas, da genética quantitativa, ou, em outras palavras, uma metodologia que combinasse componentes da cladística e da fenética, resultando numa sistemática evolutiva (Mayr, 1974).

No entanto, apesar desse contexto, pode-se observar, à parte das discussões envolvendo as particularidades e as propriedades das diferentes abordagens taxonômicas, o crescimento da literatura cientifica baseada em métodos de análise filogenética apoiados em análises exploratórias de grandes conjuntos de dados quantitativos nas últimas três décadas (Schneider, 2003). O uso desses métodos, aplicados para investigar diferentes relações

\footnotetext{
${ }^{13}$ Cladistas, ou filogeneticistas, é a denominação designada aos sistemátas adeptos dos princípios fundamentais propostos por W. Hennig (1966) para a classificação taxonômica de acordo com as relações de parentesco dos grupos representados (Amorim, 2002). De acordo com os dados e as técnicas utilizadas para reconstruir e interpretar essas relações, os filogeneticistas priorizam a organização da informação sobre a diversidade biológica referenciada ou a relação entre os estágios adaptativos entre os taxa envolvidos. Dessa forma, argumentam, ambas abordagens cladístas representam, inequivocadamente, as relações de ancestralidade e descendência observáveis entre os taxa (Futuyma, 1998; Amorim, 2002).

${ }^{14}$ De acordo com Mayr $(1969,1974)$, fenética é o nome da escola taxonômica que referencia a classificação dos taxa a partir do levantamento do maior número possível de caracteres, mensurados e tratados de maneira quantitativa e analisados a partir de procedimentos estatísticos e modelos matemáticos. Os críticos desta corrente argumentam que seus resultados indicam, apenas, relações de similaridade morfológica (matematicamente representadas) entre os grupos, ou seja, abordam elementos puramente operacionais em detrimento de aspectos evolutivos (Mayr, 1969, 1974; Johnson, 1970; Hull, 1970; de Queiroz \& Good, 1997; Amorim, 2002). Por outro lado, feneticistas argumentam que, apesar da fundamentação de suas classificações se basearem em distâncias desprovidas de bases biológicas (Meyer, 1994) a metodologia por eles adotada apresenta repetibilidadade e imparcialidade analítica, duas qualidades assumidamente desejáveis em ciência, ao contrário da abordagem filogeneticista, assumidamente suscetível às interpretações impostas pelo pesquisador (Heywood \& McNeill, 1964).

${ }^{15}$ Grifo de Amorim (2002).
} 
filogenéticas, como eventos vicariantes, relações de ramificação de endemismo e interações evolutivas e coevolutivas entre espécies e populações, baseados na execução de técnicas analíticas refinadas e na exploração de bancos de dados robustos sedimenta, de maneira cada vez mais sólida, a aplicação dos modelos quantitativos à interpretação filogenética das categorias taxonômicas (Simpson, et. al, 2003; Schneider, 2003).

A partir dessa lógica, a pesquisa proposta nesta tese será executada a partir da investigação analítica comparativa, conciliando as inferências evolutivas e quantitativas, de um conjunto numericamente expressivo de informações composto por um banco de dados morfológico, constituído por medidas lineares representativas da variação mundial da morfologia craniana humana. Adicionalmente, seguindo a mesma lógica anteriormente apresentada, algumas técnicas empregadas na investigação proposta nesta pesquisa serão aplicadas de maneira exploratória a um banco de dados moleculares, consolidado a partir da compilação de dados relativos à variação de fragmentos de microssatélites de DNA e de frequências haplotípicas de mtDNA.

\section{1 - Bancos de dados}

Dada a estratégia adotada de utilizar frações específicas de cada um dos bancos de dados montados de acordo com as necessidades analíticas dos testes propostos, e a consequente complexidade de sua construção, a montagem de cada um dos conjuntos foi realizada em momentos diferentes, adotando procedimentos específicos. Dessa forma, os tópicos a seguir apresentam a descrição geral de cada um desses bancos de dados. 


\subsection{1 - Banco de Dados de Morfologia Craniana (Morfológico)}

A montagem do banco morfológico para a execução das análises propostas foi delineada para que o conjunto de dados represente as características gerais da morfologia craniana humana observada em populações autóctones de ampla distribuição geográfica mundial. Essas características morfológicas são quantificadas através de medidas lineares, tomadas de maneira padronizada, de forma que cubram toda, ou, ao menos, grande parte, a forma do crânio.

Uma das primeiras decisões tomadas para a formação do banco de dados deu-se em relação à expressão numérica desejada para o conjunto de dados. Uma contestação bastante recorrente aos estudos comparativos de Antropologia Biológica, no que compete às afinidades morfológicas inferidas através de medidas craniométricas, reside na crítica em relação à magnitude numérica das séries, ou amostras, contidas nos bancos de dados classicamente utilizados para tal fim, baseando-se no argumento de que a diversidade morfológica coberta por essas séries seria insuficiente para caracterizar a diversidade craniana atual, sobretudo aquela existente no Novo Mundo (Williams et al., 2005; Brace, 2001; Seguchi et al., 2005, 2011).

Nesse contexto, a adoção de um banco de dados mais inclusivo, numericamente representativo e amplamente distribuído do ponto de vista geográfico é uma condição fortemente desejável e aconselhável aos estudos que objetivam investigar as implicações evolutivas da diversidade craniana humana. No entanto, é desnecessário citar que as questões logísticas e a demanda de investimento de tempo e recursos para tal empreitada são consideravelmente incompatíveis com as disponibilidades comuns a uma pesquisa de pósgraduação, como a que trata esta tese. Assim, a estratégia adotada para a formação do banco de dados de morfologia craniana utilizado nessa pesquisa consistiu em agrupar a maior quantidade possível de espécimes, representados por suas medidas craniométricas, oriundos de diferentes fontes de dados e obedecendo a critérios previamente estabelecidos. 
A formação do banco de dados se deu a partir da incorporação de dados provenientes de quatro diferentes fontes: 1) banco de dados Howells (Howells, 1973, 1989, 1995); 2) banco de dados Hanihara (Hanihara, 1993a; Hanihara, 1993b; Hanihara, 1996; Hanihara, 2000), a exemplo do que foi feito por Bernardo (2007); 3) banco de dados do Laboratório de Estudos Evolutivos Humanos - LEEH (Neves \& Hubbe, 2005; Neves et al., 2007a, 2007b; Bernardo \& Neves, 2008; Neves et al., 2011; Bernardo et al., 2011); e, 4) agregação de medidas provenientes de novos indivíduos e séries, tomadas pelo executor desta pesquisa.

Contando com cerca de 3.000 espécimes, distribuídos em 27 populações, o banco de dados coletado e organizado por William W. Howells (1908-2005) é o mais amplamente utilizado como base comparativa nos estudos sobre a diversidade craniana humana (Howells, 1973, 1989, 1995). Entre diversas características que qualificam como a mais consagrada base comparativa de dados de craniometria humana, sendo, inclusive, disponibilizada na internet (Howells, 1996; L. W. Konigsberg's Home Page, 2012), pode-se destacar o fato de que todos os espécimes foram analisados e medidos pelo próprio Howells, seguindo o protocolo por ele adaptado e desenvolvido (Howells, 1973), o que conferiu credibilidade à produção da base de dados. Tal credibilidade, no entanto, revelou-se, conforme anteriormente citado, insuficiente para refutar as críticas em relação à capacidade de cobertura da amplitude de variação morfológica representada pelo grande número de crânios contidos na amostra (Bernardo, 2007).

O Banco de Dados Hanihara, organizado por Tsunehiko Hanihara, do Departamento de Anatomia da Saga Medical School (Saga, Japão), é caracterizado por um grande número de amostras, representando 272 séries masculinas e 179 femininas, de 19 grandes regiões geográficas, abrangendo ampla dispersão mundial (Hanihara, 1993a; 1993b, 1996, 2000; Manica et al., 2007; Bernardo, 2007, Betti et al., 2009, 2010; Hubbe et al., 2009). Composto por 45 variáveis craniométricas, resultante da combinação dos protocolos de craniometria estabelecidos por Martin (1928), Martin \& Saller (1957), Howells (1973), Bräuer (1988) e de medidas de projeção facial (Yamaguchi, 1973; Hanihara \& Ishida, 1995; Hanihara et al, 1999; 
Hanihara, 2000), o banco foi cedido por T. Hanihara para utilização em pesquisas desenvolvidas no LEEH (Bernardo, 2007).

Durantes as últimas três décadas, Walter Neves, à frente do Laboratório de Estudos Evolutivos Humanos (LEEH) do Departamento de Genética e Biologia Evolutiva do Instituto de Biociências da Universidade de São Paulo, e colaboradores investem na consolidação de um banco de dados antropométricos, constituído por dados morfocranianos métricos, não métricos e odontométricos, além de dados provenientes de análises bioarqueológicas sobre materiais pós-cranianos. O conjunto de dados métricos cranianos, tomados seguindo-se o protocolo estabelecido por Howells (1973) em "Cranial Variation in Man", contém séries esqueletais de diferentes populações de distintas cronologias e regiões geográficas. Coleções oriundas de populações arcaicas pré-históricas do sul/sudeste do Brasil (sambaquieiras e do interior), do Brasil Central, da Amazônia e da Colômbia, de populações Paleoíndias do Brasil e da Colômbia além de coleções de nativos recentes do Brasil ditam a tônica do banco de dados do LEEH.

Finalmente, uma pequena parcela do banco de dados morfológico constituiu-se de dados de espécimes analisados (medidos) pelo executante deste trabalho. As séries Lapa do Santo (paleoamericanos de Lagoa Santa, Brasil, depositada no LEEH-IB-USP) e Solcor 3 (períodos pré-Tiwanaku e Tiwanaku do deserto de San Pedro de Atacama, Chile, depositada no Instituto de Investigaciones Arqueológicas y Museo Padre Gustavo LePaige, San Pedro de Atacama, Chile) foram medidas seguindo o protocolo Howells (1973) após intenso treinamento supervisionado por W. Neves. O apêndice 1 apresenta o modelo de ficha craniométrica utilizada para essas análises. As medições provenientes de ambas as coleções serão incorporadas ao banco de dados do LEEH.

O fato de se trabalhar com um banco de dados secundário, alimentado por diferentes fontes, requereu um grande esforço para o correto manuseio dos dados quantitativos dessa base. Além das técnicas estatísticas e computacionais para a identificação de valores 
discrepantes e ausentes, um problema comum às bases extensas de dados, a incompatibilidade entre as variáveis utilizadas em diferentes bases de dados pode impossibilitar a união de dados advindos de bancos distintos (Little, 1988). Dessa forma, o completo conhecimento das fontes de dados utilizadas é imprescindível para a consolidação de um banco de dados único aceitável. Ciente dessa imposição, e focado no objetivo de compreender em detalhes a técnica de medição craniométrica sedimentada por Howells (1973), uma fase fundamental da etapa de adequação de dados foi o estudo do protocolo de medição utilizado. Os resultados desse estudo também refletirão na agregação de novos espécimes à base de dados no futuro.

Os protocolos de medições antropométricas consistem em comparações de contornos e proporções, de órgãos, pontos ou regiões anatômicas (Bass, 1987). Essas comparações devem ser traduzidas em medidas objetivas, para que tais observações possam ser analisadas, em conjunto, em grandes séries, ou grupos de dados (Slice, 2005). O primeiro estágio crítico para o aprendizado da técnica de medição craniométrica é a correta assimilação da determinação dos "landmarks"16 (Bass, 1987).

\section{Definição de "Landmarks"}

"Landmarks" são os pontos referenciais baseados em porções ou estruturas ósseas a partir dos quais as medições podem ser executadas (Slice, 2005). Toda a tradição e desenvolvimento dos diferentes protocolos de medição, que visam diversos tipos de investigação ${ }^{17}$, remontam às convenções inicialmente propostas no Congresso de Craniometria de Munique, em 1877, e depois consolidadas no Congresso Internacional de Antropólogos, realizado em Frankfurt, no ano de 1884. Nesses encontros estabeleceram-se os

\footnotetext{
${ }^{16}$ A meu ver, a melhor tradução para a palavra "landmark" seria "ponto de referência" ou "ponto craniométrico". No entanto, por ser usualmente adotada, tanto nos trabalhos quanto nas discussões técnicas entre falantes de outras línguas que não o inglês, decidiu-se mantê-la, na forma original, sem traduzi-la para o português.

${ }^{17}$ As técnicas comumente utilizadas para os estudos craniométricos clássicos, derivados da antropologia biológica, também são aplicáveis na solução de problemas forenses, odontológicos e cirúrgicos (Moore-Jansen et al., 1994; Águila \& Águila, 1993; Stamm et al., 2002, respectivamente, para um exemplo).
} 
referenciais primordiais da antropometria, com a definição de conceitos fundamentais das técnicas utilizadas até hoje, como o "Plano Horizontal de Frankfurt"18 e o estabelecimento de dois tipos de pontos antropométricos: os não pareados e os pareados. Os "landmarks" não pareados são aqueles que ocorrem no plano sagital médio. Um exemplo dessa classe é o nasion ${ }^{19}$. "Landmarks" pareados são aqueles que ocorrem em duplicata, de maneira equidistante em ambos os lados do plano sagital médio. Um exemplo de ponto para essa classe é o porion (Bass, 1987).

As medidas constantes do protocolo de Howells (1973) são tomadas a partir de 21 "landmarks"20. As definições desses pontos e as subsequentes medidas foram baseadas nos trabalhos de Broca (1875), Buxton \& Morant (1933), Martin (1928), Kherumian (1949) e Vallois (1965). Os "landmarks", demonstrados nas Figuras ${ }^{21} 2.1$ a 2.3, são definidos, de maneira sucinta e objetiva ${ }^{22}$, como segue (em parênteses a abreviatura convencionalmente utilizada para o ponto), de acordo com Howells (1973) e Bass (1987):

\section{Asterion (as)}

"O ponto de encontro comum entre os ossos temporal, parietal e occipital, em ambos os lados".

\section{Basion (ba)}

"É o ponto localizado na borda anterior do forame magno, exatamente na posição sagital média, na posição destacada pelo ápice da superfície triangular na base dos côndilos".

\footnotetext{
${ }^{18} \mathrm{O}$ "Plano Horizontal de Frankfurt" é o plano imaginário traçado através de três pontos: porion esquerdo, porion direito e orbitale esquerdo. O crânio é, normalmente, orientado neste plano quando desenhado, fotografado ou ilustrado com finalidades comparativas. Quando os olhos estão fixados no horizonte, o crânio está, normalmente, posicionado de maneira que os três pontos críticos estejam num plano horizontal (Bass, 1987).

${ }^{19}$ A nomenclatura latina dos "landmarks" será mantida por tratar-se de convenção adotada internacionalmente.

${ }^{20}$ São 14 os "landmarks" destacados por Howells (1973) em seu protocolo. No entanto, algumas medidas, embora não tomadas a partir de "landmarks" precisos, são inferidas a partir de regiões identificadas por pontos tradicionais, como a glabela e o eurion, determinados instrumentalmente, por exemplo. Assim, adotou-se complementar suas definições mesmo não constando na lista apresentada em Howells (1973), perfazendo, assim, 21 "landmarks".

${ }^{21}$ As figuras utilizadas para ilustrar pontos e medidas craniométricas, bem como de estruturas anatômicas e módulos cranianos, ao longo deste texto foram adaptadas a partir dos originais de Steele \& Bramblett, 1988).

${ }^{22}$ De maneira a tornar a leitura desta seção mais fluida, uma série de apontamentos de estruturas anatômicas (nome de ossos, suturas, e regiões anatômicas), imprescindíveis para a compreensão e estudo do protocolo de medição craniométrica, foi deslocada para o final do exemplar, sob a forma de apêndice (Apêndice 2).
} 


\section{Bregma (br)}

"Definido pela borda posterior do osso frontal no plano sagital médio, no ponto de encontro entre as suturas sagital e coronal".

\section{Dacryon (dk)}

"Delimitado pelo ápice da fossa lacrimal, invadindo o osso frontal. Encontra-se em ambos os lados".

\section{Ectoconchion (ek)}

"A intersecção da superfície mais anterior da borda lateral da orbita e sua linha bissecante ao longo de seu maior eixo, em ambos os lados".

\section{Euryon (eu)}

"São dois pontos localizados em lados opostos do crânio que delimitam a linha de maior largura. É instrumentalmente determinado e, normalmente, encontra-se na região superior dos parietais".

Frontomalare anterior (fm:a)

"Encontra-se na posição mais anterior da sutura fronto-malar, em ambos os lados".

\section{Glabella (gb)}

"O ponto mais projetado, localizado na linha média sagital do osso frontal, na região da testa, ao nível das cristas supraorbitais e acima da sutura nasofrontal".

Inion (in)

"Ponto na base da protuberância occipital externa. Localiza-se na tangente da convexidade superior da linha nucal superior".

\section{Lambda (la)}

"Definido pela intersecção das suturas sagital e lambdoidal, na linha média sagital".

\section{Mastoidale (ms)}

"O ponto mais baixo do processo mastoide, em ambos os lados".

\section{Nasion (na)}

"Encontra-se na intersecção da sutura fronto-nasal e do plano mediano sagital". 


\section{Opisthion (os)}

"Localizado na crista inferior da borda posterior do forame magno, no plano médio-sagital".

\section{Opisthocranion (op)}

"O ponto mais posterior do crânio, fora da protuberância occipital. Não é um ponto fixo, sendo instrumentalmente determinado".

\section{Porion (po)}

"Localiza-se no ponto mais alto da margem lateral do meato auditivo externo, em ambos os lados".

\section{Prosthion (pr)}

"É o ponto definido pela proeminência mais anterior, na linha sagital média, na borda alveolar, acima do septo entre os incisivos centrais".

\section{Stephanion (st)}

"Definido pela intersecção da sutura coronal e o limite do músculo temporal, em ambos os lados".

\section{Subspinale (ss)}

"É o ponto mais profundo visto no perfil, abaixo da espinha nasal anterior".

\section{$\operatorname{Vertex}(\mathrm{vx})$}

"É o ponto mais alto no contorno médio sagital, com o crânio em norma lateral (a visão lateral do Plano de Frankfurt)".

\section{Zygomaxillare anterior (zm:a)}

"Localiza-se na intersecção da sutura zigomaxilar e o limite da posição de inserção do músculo masseter, na superfície facial, em ambos os lados".

\section{Zygoorbitale (zo)}

"A intersecção da margem da orbita e da sutura zigomaxilar, em ambos os lados". 


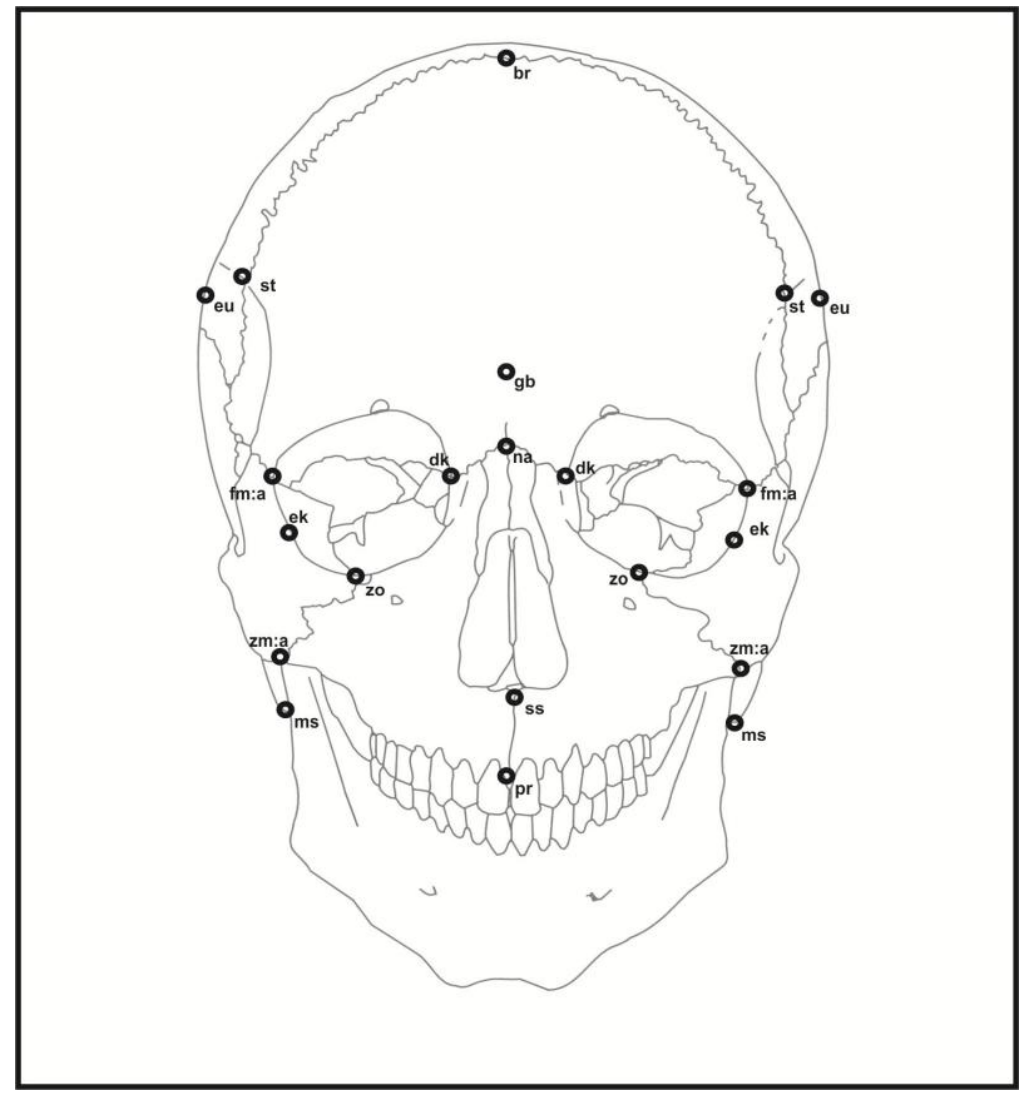

Fig. 3.1 - "Landmarks" selecionados. Crânio humano, norma frontal.

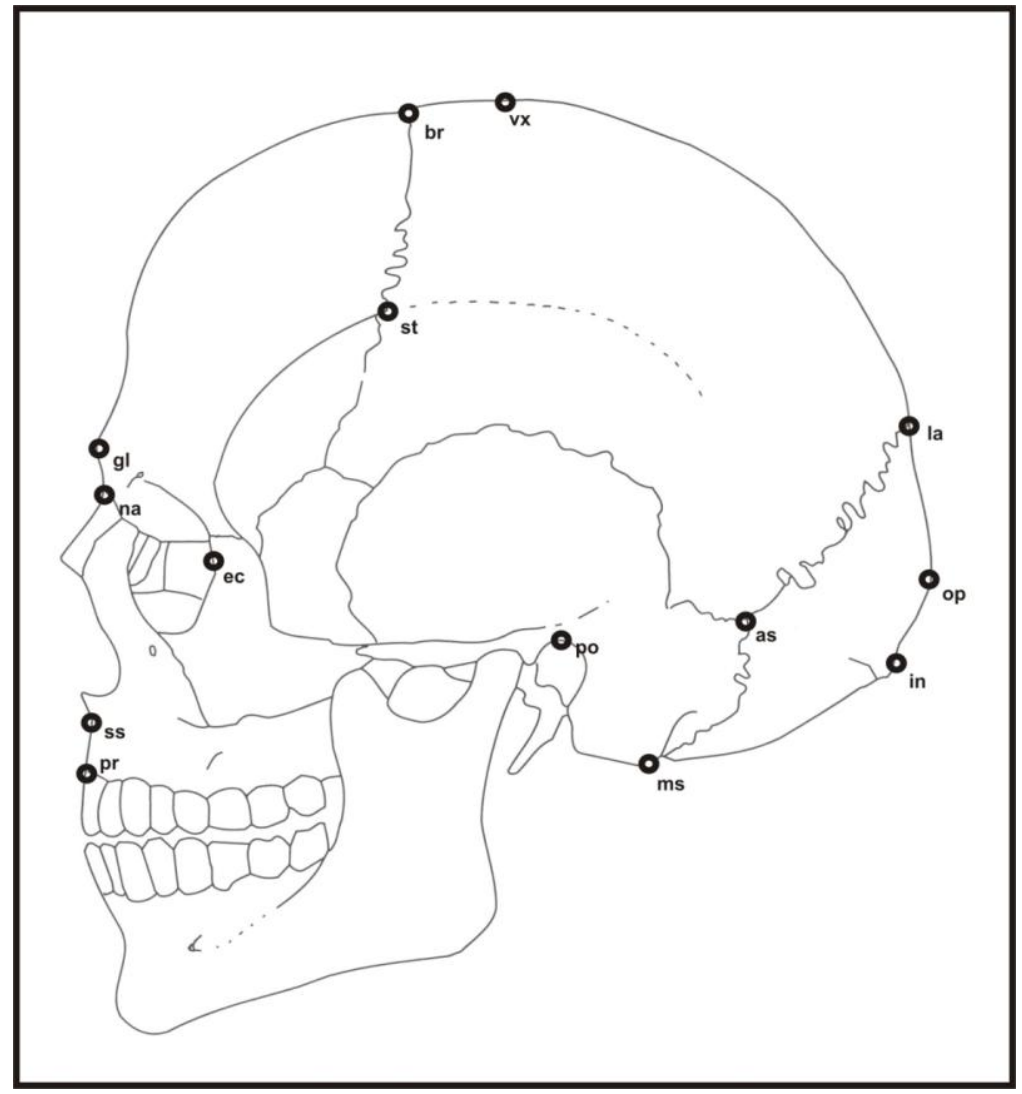

Fig. 3.2 - "Landmarks" selecionados. Crânio humano, norma lateral. 


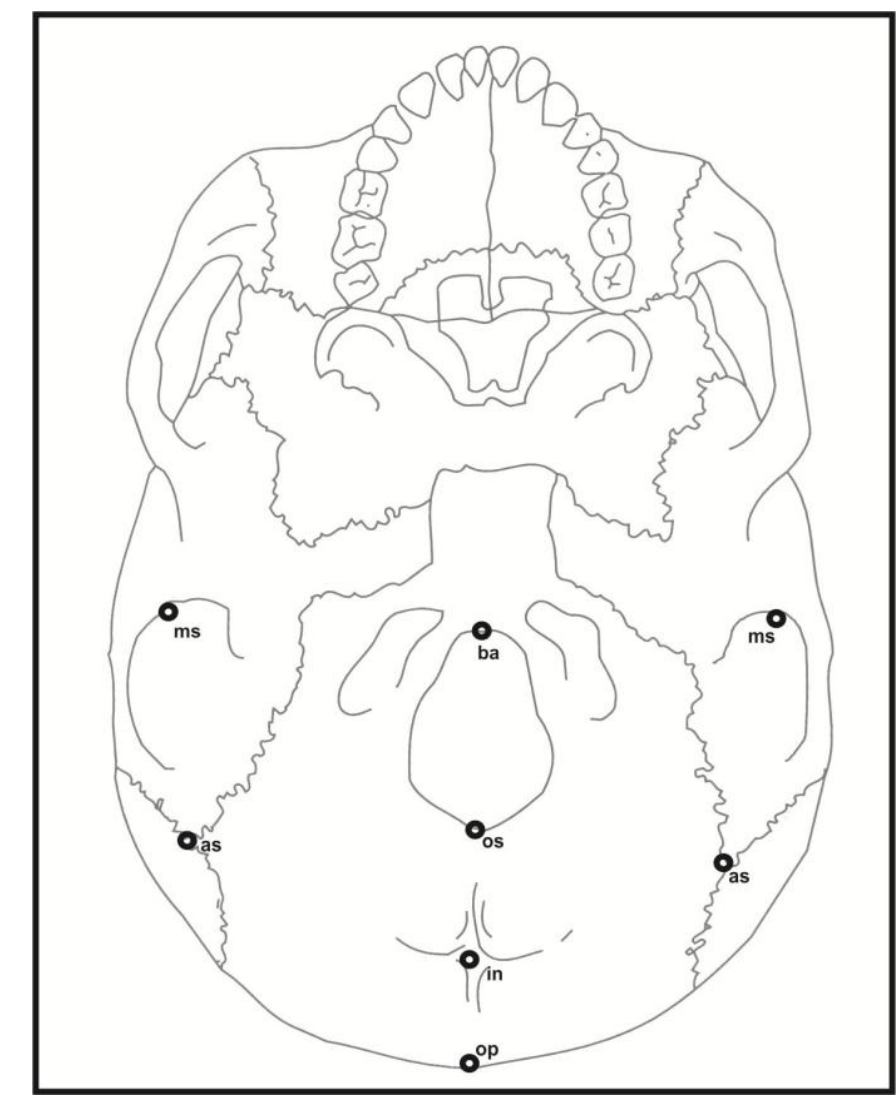

Fig. 3.3 - "Landmarks" selecionados. Crânio humano, norma basal.

Como pode ser depreendida pela leitura de suas definições, a prática de tomada de medidas é intimamente relacionada à determinação e reconhecimento dos "landmarks". Desta forma, após os estudos de definições de pontos craniométricos passa-se, naturalmente, ao estudo das definições das medidas cranianas.

\section{Definições das medidas craniométricas}

O protocolo de medidas desenvolvido e publicado por Howells (1973) é uma decorrência dos protocolos até então classicamente utilizados pelos antropólogos físicos. Como propriamente explicitado em Howells (1973), as definições de cada medida, bem como de suas instruções e seus "landmarks", guardam semelhanças com as técnicas anteriormente 
propostas por Broca (1875), Martin (1928) e Kherumian (1949) e aquelas convencionadas pelo “Acordo de Mônaco de 1906" (Howells, 1973). Apoiado nos incrementos que sua nova metodologia apresentou (uniformidade da tomada de medidas, diminuição da subjetividade de determinação dos "landmarks" e adoção de um sistema lógico de nomenclatura das medidas cranianas), o protocolo proposto por Howells dominou, amplamente, os estudos craniométricos que o sucederam. Por fim, outra tecnicidade do protocolo proposto por Howells que, mesmo que subjetivamente, representa grande contribuição à técnica de medição craniana é a proposição de uma sequência lógica para a tomada dessas medidas. As definições das medidas cranianas do protocolo Howells (1973), na ordem proposta, são as que seguem (note que em negrito encontram-se nome, em inglês, e abreviatura da medida; logo abaixo, em letras menores, encontra-se a tradução literal para o português).

Glabello-occipital length

GOL

Comprimento glabelo-occipital

"O maior comprimento, a partir da região da glabela, ao longo do plano sagital médio".

Nasio-occipital length

NOL

Comprimento nasio-occipital

"O maior comprimento craniano medido sobre o plano sagital médio, a partir do nasion".

Basion-nasion length

BNL

Comprimento basion-nasion

"Distância direta entre o basion e o nasion".

Basion-bregma height

$\mathrm{BBH}$

Altura basion-bregma

"Distância direta, como definida, entre o basion e o bregma".

Maximum cranial breadth

XCB

Largura craniana máxima

"A máxima largura craniana, perpendicular ao plano sagital medial (acima das cristas supramastoidais)". 
Largura frontal máxima

"A máxima largura sobre a sutura coronal, perpendicular ao plano mediano".

Bistephanic breadth

Largura bi-stephanica

"Largura entre as intersecções, em ambos os lados, da sutura coronal e da linha temporal inferior, marcada pelo stephanion".

Bizygomatic breadth

ZYB

Largura bi-zigomática

"Definida pela largura máxima ao longo dos arcos zigomáticos, em qualquer lugar que sejam encontradas, perpendiculares ao plano mediano".

Biauricular breadth

AUB

Largura bi-auricular

"A menor distância entre as duas raízes dos processos zigomáticos".

Minimum cranial breadth

WCB

Largura craniana mínima

"A largura do esfenóide na base da fossa temporal, nas cristas infratemporais".

Biasterionic breadth

ASB

Largura bi-asteriônica

"A medida direta de um asterion ao outro".

Basion-prosthion length

BPL

Comprimento basion-prosthion

"A distância direta entre o basion e o prosthion, como definidos".

Nasion-prosthion height

NPH

Altura nasion-prosthion

"A altura facial superior, medida do nasion ao prosthion, como definidos".

Nasal height

NLH

Altura nasal

"A altura média a partir do nasion até o ponto mais baixo da borda da abertura nasal, em ambos os lados". 
Altura da órbita esquerda

"A altura entre as bordas superior e inferior da órbita esquerda, perpendicular ao seu maior eixo bissecante".

Orbit breadth, left

OBB

Largura da órbita esquerda

"Distância entre o ectoconchion e o dacryon, como definidos".

\section{Bijugal breadth}

JUB

Largura bi-jugal

"A largura externa dos malares, na jugalia, isto é, a posição mais profunda na curvatura entre os processos frontal e temporal dos malares".

\section{Nasal breadth}

NLB

Largura nasal

"A distância entre as bordas anteriores da abertura nasal, na sua maior extensão".

Palate breadth, external

MAB

Largura externa do palato

"A maior largura obtida através das bordas alveolares, no ponto onde for encontrada, perpendicular ao plano sagital mediano".

Mastoid height

$\mathrm{MDH}$

Altura do mastoide

"O comprimento do processo mastoide, abaixo e perpendicular ao plano de Frankfurt, no plano vertical".

Mastoid width

MDB

Largura do mastoide

"Largura do processo mastoide na sua base, através de seu eixo transversal".

Bimaxillary breadth

ZMB

Largura bi-maxilar

"A largura ao longo da maxila, de um zygomaxillare anterior ao outro".

Bimaxillary subtense

SSS

Projeção bi-maxilar

"A projeção (através de paquímetro específico) do subspinale em referência à ZMB". 
Largura bi-frontal

"A largura ao longo do osso frontal, entre os frontomalare anteriores em ambos os lados".

Nasio-frontal subtense

NAS

Projeção nasion-frontal

"A projeção (através de paquímetro específico) do nasion em relação à FMB".

\section{Biorbital breadth}

EKB

Largura bi-orbital

"A distância entre um ectoconchion ao outro".

Dacryon subtense

DKS

Projeção do dacryon

"A projeção (através de paquímetro específico) média (média dos dois lados), do dacryon em relação à EKB".

Interorbital breadth

DKB

Largura interorbital

"A distância medida entre os pontos, de um dacryon ao outro, como definidos".

Naso-dacryal subtense

NDS

Projeção nasion-dacryon

"A projeção (através de paquímetro específico) do ponto mais profundo do contorno dos ossos nasais em relação à DKB".

\section{Simotic chord (least nasal breadth)}

WNB

Corda simótica ou largura nasal mínima

"A largura transversal mínima ao longo dos dois ossos nasais, i. e., a distância mínima entre as duas suturas naso-maxilares".

\section{Simotic subtense}

\section{SIS}

Projeção simótica

"A projeção (através de paquímetro específico) do ponto mais alto da seção transversal que está no ponto mais profundo do contorno nasal em relação à WNB".

Malar length, inferior

IML

Comprimento inferior do malar

"A distância direta entre o zygomaxillare anterior e o ponto mais baixo da sutura zigomaticotemporal, na sua superfície externa, no lado esquerdo". 
Comprimento máximo do malar

"Comprimento total do malar, em direção diagonal, a partir do final da sutura zigomaticotemporal (em seu ponto mais baixo), na face lateral do osso, até ao zygoorbitale".

Malar subtense

MLS

Projeção do malar

"A projeção (através de paquímetro específico) máxima da convexidade do ângulo malar em relação à XML, na altura do forame zigomático-facial, no lado esquerdo.

\section{Cheek height}

WMH

Altura da bochecha ${ }^{23}$

"A distância mínima, em qualquer direção, entre o ponto mais baixo da margem da órbita até a margem mais baixa do maxilar, mesial à posição de inserção do masseter, no lado esquerdo".

Supraorbital projection

sos

Projeção supraorbital

"A projeção máxima do arco supraorbital esquerdo entre a linha medial (na região da glabela) e o osso frontal na porção anterior à linha temporal, em sua região mais proeminente".

\section{Glabella projection}

\section{GLS}

Projeção da glabela

"Definida pela projeção máxima do contorno da linha média, entre o nasion e a região supraglabelar (ou, mais precisamente, a própria glabela), medida como subtense".

Foramen magnum length

FOL

Comprimento do forame magno

"A distância compreendida entre o basion e o opisthion, como definidos".

Nasion-bregma chord (Frontal chord)

FRC

Corda nasion-bregma ou Corda frontal

"Definida como a distância direta entre o nasion e o bregma, tomada sobre o plano sagital médio na superfície externa".

Nasion-bregma subtense (Frontal subtense)

FRS

Projeção nasion-bregma ou Projeção do frontal

"A máxima projeção (através de paquímetro específico) do ponto mais alto na convexidade do osso frontal, sobre a FRC".

\footnotetext{
${ }^{23} \mathrm{O}$ nome da medida, em si, é inadequado. De qualquer forma, a tradução literal é exatamente esta.
} 
Fração da projeção do nasion

"Definida pela distância, ao longo da FRC, do nasion até onde se dá a marcação da FRS".

Bregma-lambda chord (Parietal chord)

PAC

Corda bregma-lambda ou Corda Parietal

"A distância direta do bregma ao lambda, tomada no plano médio sagital ".

Bregma-lambda subtense (Parietal subtense)

PAS

Projeção bregma-lambda ou Projeção do parietal

"A projeção (através de paquímetro específico) máxima, no ponto de maior convexidade dos ossos parietais, sobre a PAC".

Bregma-subtense fraction

PAF

Fração da projeção do bregma

"A distância ao longo da PAC, do bregma até onde se dá a marcação da PAS".

\section{Lambda-opisthion chord (Occipital chord)}

OCC

Corda Lambda-opisthion ou Corda occipital

"A corda occipital externa, ou a distância direta entre o lambda e o opisthion, como definidos, tomados sobre a linha sagital média na superfície externa".

\section{Lambda-opisthion subtense (Occipital subtense) OCS}

Projeção lambda-opisthion ou Projeção do occipital

"A máxima projeção (através de paquímetro específico) do ponto mais proeminente no contorno básico do osso occipital, ao longo da OCC".

Lambda-subtense fraction

OCF

Fração da projeção do lambda

"A distância, ao longo da OCC, do lambda até o ponto onde se dá a OCS".

Vertex radius

VRR

Raio do vértex

"Distância perpendicular ao eixo transmeatal, a partir do ponto mais elevado nos parietais (incluindo o lambda e o bregma), onde quer que seja encontrado".

Nasion radius

NRR

Raio do nasion

"Distância perpendicular ao eixo transmeatal, a partir do nasion, como definido". 
"Distância perpendicular ao eixo transmeatal, a partir do subspinale, como definido".

Prosthion radius

PRR

Raio do prosthion

"Distância perpendicular ao eixo transmeatal, a partir do prosthion, como definido".

Dacryon radius

DKR

Raio do dacryon

"Distância perpendicular ao eixo transmeatal, a partir do dacryon esquerdo".

Zygoorbitale radius

ZOR

Raio do zygoorbitale

"Distância perpendicular ao eixo transmeatal, a partir do zygoorbitale esquerdo, como definido".

\section{Frontomalare radius}

FMR

Raio do frontomalare

"Distância perpendicular ao eixo transmeatal, a partir do frontomalare anterior esquerdo, como definido".

Ectoconchion radius

EKR

Raio do ectoconchion

"Distância perpendicular ao eixo transmeatal, a partir do ectoconchion esquerdo, como definido".

Zygomaxillare radius

ZMR

Raio do zygomaxillare

"Distância perpendicular ao eixo transmeatal, a partir do zygomaxillare anterior esquerdo, como definido".

Molar alveolus radius

AVR

Raio do alvéolo molar

"Distância perpendicular ao eixo transmeatal, a partir do ponto mais anterior do alvéolo do primeiro molar superior esquerdo". 
Essas são as descrições sumárias das $57^{24}$ medidas craniométricas tomadas de acordo com o protocolo Howells. As Figuras 3.4 a 3.6, abaixo, ilustram a posição de tomada dessas medidas $^{25}$, nas normas frontal, lateral e basal, respectivamente. A Figura 3.7 indica a tomada dos raios cranianos a partir do eixo transmeatal, em norma lateral.

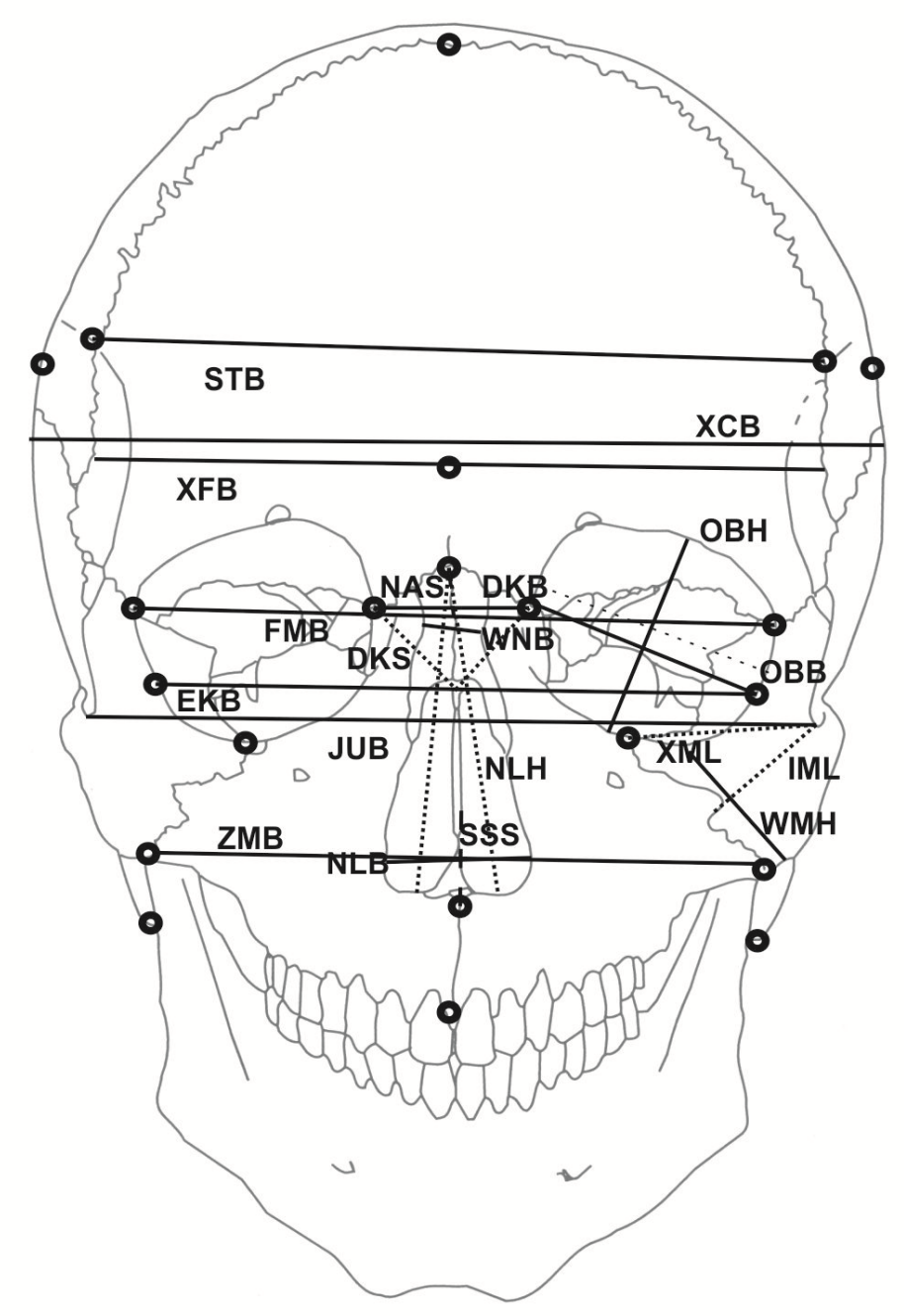

Fig. 3.4 - Medidas cranianas do protocolo Howells. Linhas cheias indicam as medidas diretamente tomadas e representadas; linhas pontilhadas indicam medidas tomadas (medidas que requerem cálculos) ou representadas indiretamente (medidas entre landmarks não representados na figura); linhas tracejadas indicam medidas de projeção. A linha tracejada na órbita esquerda representa a reta bissecante da altura da órbita. Crânio humano, norma frontal.

\footnotetext{
${ }^{24}$ No protocolo publicado em 1973, Howells apresenta 70 medidas cranianas. No entanto, por questões práticas, as 13 medidas angulares (que envolvem, além das medições instrumentais, cálculos geométricos), foram excluídas do protocolo comum, restando, assim, 57 medidas.

${ }^{25}$ As medidas NDS, SIS, MLS, SOS e GLS não estão representadas nas figuras.
} 


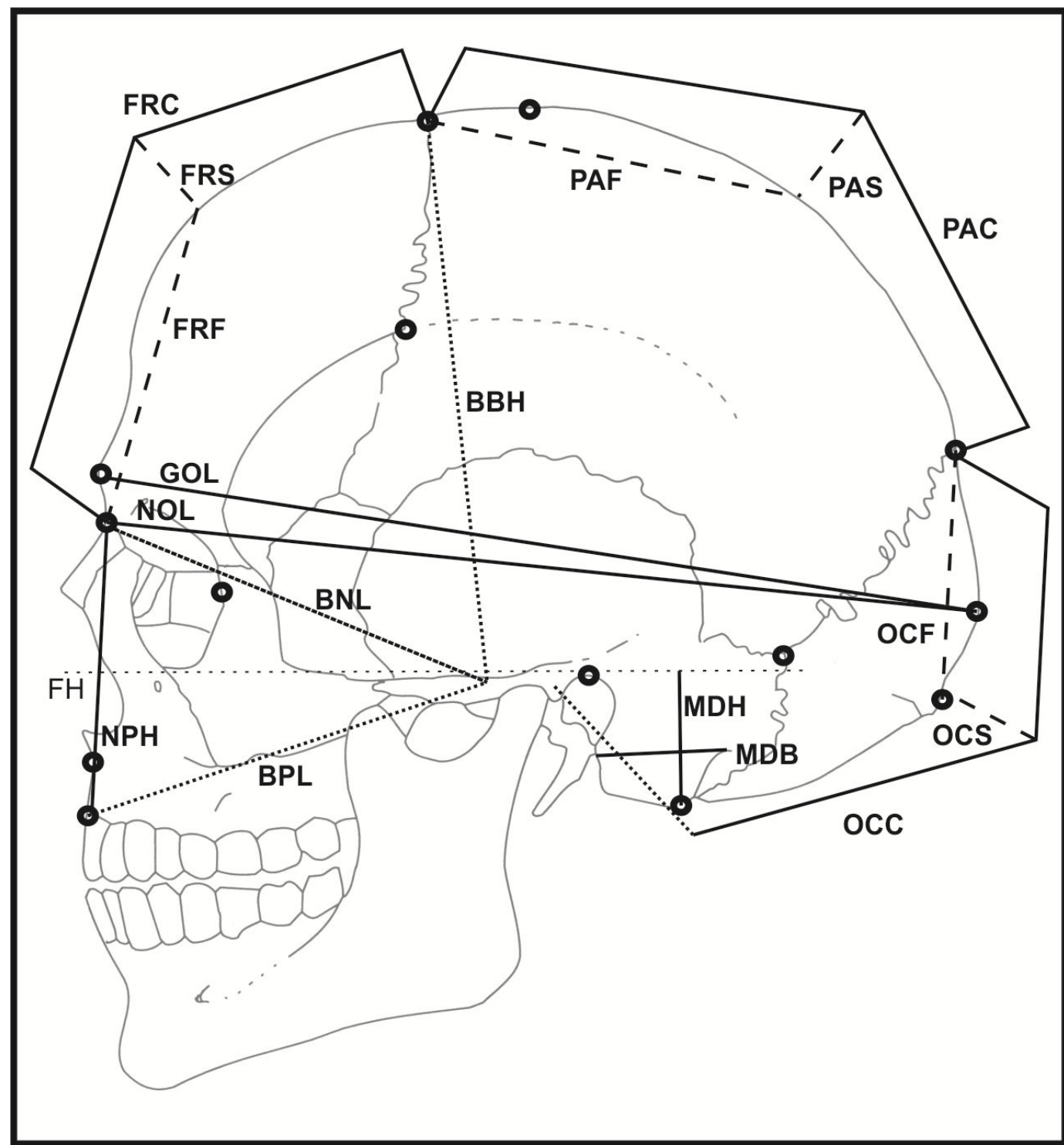

Fig. 3.5 - Medidas cranianas do protocolo Howells. Linhas cheias indicam as medidas diretamente tomadas e representadas; linhas pontilhadas indicam medidas representadas indiretamente (medidas entre "landmarks" não representados na figura); linhas tracejadas indicam medidas de projeções e de projeções de frações. A linha tracejada identificada por FH representa o Plano Frankfurt. Crânio humano, norma lateral.

É desnecessário comentar que a observância e a correta utilização do protocolo, além de possibilitar a adição de novas séries esqueletais aos bancos de dados já consolidados, é uma condição imprescindível para a utilização, bem como sua correta manipulação, de bancos secundários, como o utilizado nesta pesquisa. 


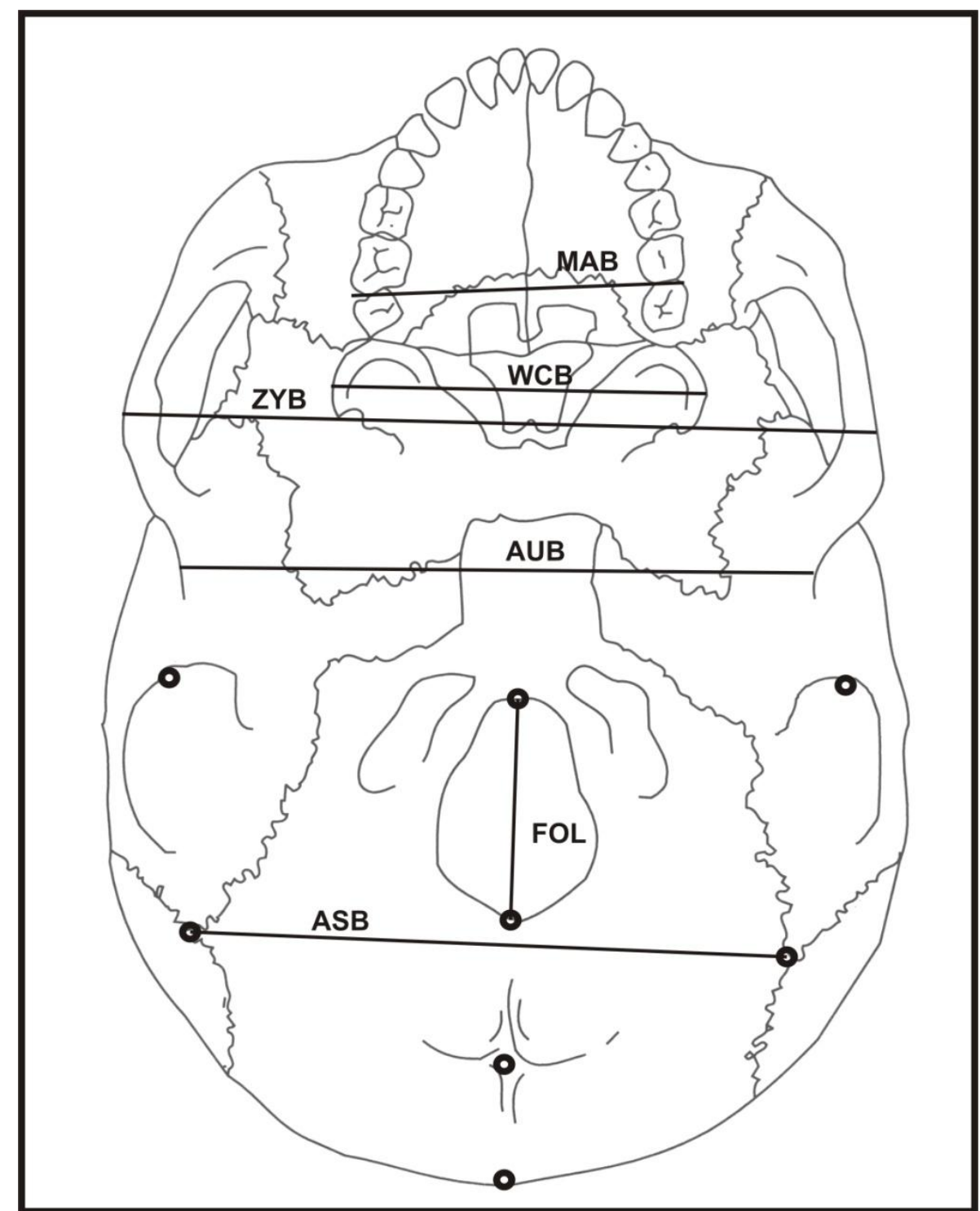

Fig. 3.6 - Medidas cranianas do protocolo Howells. Linhas cheias indicam as medidas diretamente tomadas e representadas. Crânio humano, norma basal.

Como antecipado no início deste capítulo, um dos objetivos da estratégia eleita para o desenvolvimento desta pesquisa é o de adotar a abordagem comparativa como premissa metodológica para a análise quantitativa do objeto de estudo, a variação da morfologia craniana humana. Dessa forma, alguns conceitos biológicos básicos, como o de população²6, por exemplo, precisam ser utilizados de maneira cuidadosa, para que a reconstituição histórico-evolutiva proposta não seja prejudicada ou invalidada.

\footnotetext{
${ }^{26}$ O conceito de população, especificamente como discutido por Vanzolini (1993), pertence também à uma classe de definições ainda mais controversas. Se não bastassem as dificuldades e imprecisões carregadas pelas definições biológicas do conceito há, ainda, aquelas oriundas de suas definições conceituais estatísticas.
} 


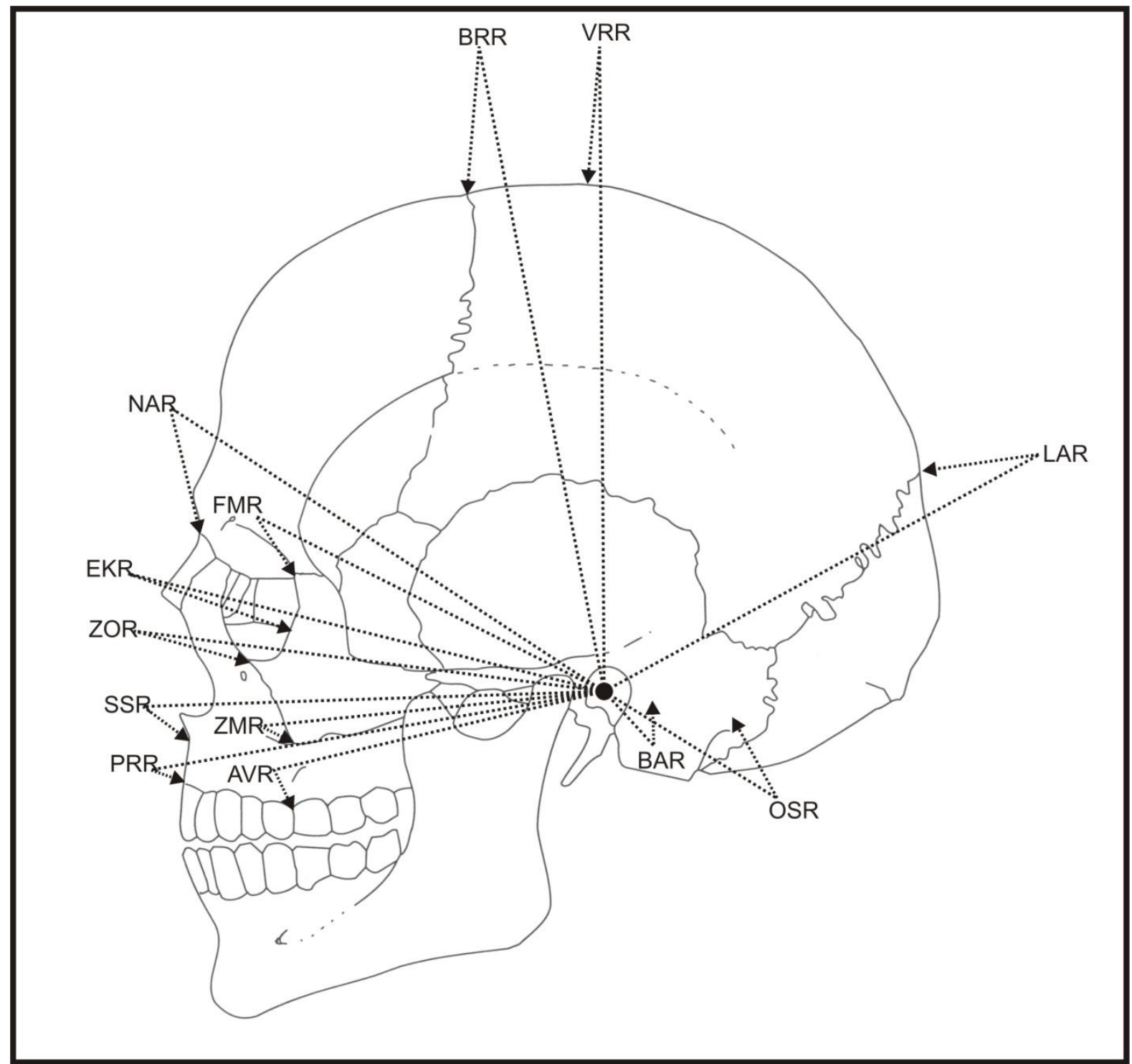

Fig. 3.7 - Medidas cranianas do protocolo Howells. Linhas pontilhadas indicam as medidas dos raios compreendidos entre os landmarks apontados com as setas e o eixo transmeatal. Crânio humano, norma lateral.

Tomando o conceito de população como exemplo, por ser uma concepção biológica fundamental em taxonomia (Vanzolini, 1993), pode-se ilustrar o raciocínio acima apresentado. População local, ou deme²7, pode ser definida como o conjunto de indivíduos, de uma determinada localidade, que formam uma comunidade reprodutiva em potencial (Mayr, 1969). Embora biologicamente ponderada, tanto no sentido ecológico quanto no genético, e lexicamente sensata, no que tange a lógica, o conceito apresenta evidentes problemas práticos, que podem levar a análises e interpretações errôneas de fenômenos

\footnotetext{
${ }^{27}$ Note que na Introdução "deme" é qualificado, também, como unidade fundamental para a genética de populações.
} 
biológicos e seus significados. Qual é a amplitude da ideia de "localidade", ou a precisão da definição de "reprodutiva em potencial", por exemplo?

Obviamente, essas contingências à caracterização das populações atingem as $\operatorname{amostras}^{28}$ em análise de maneira diferencial, ou seja, dependendo da natureza da amostra em questão, o conhecimento de informações necessárias à sua melhor qualificação são mais ou menos difíceis de se conseguir. É intuitivo pensar que, por exemplo, para caracterizar uma população de um organismo endêmico basta que seja amostrada a população do seu local de ocorrência. O mesmo não se aplicaria a um outro tipo de organismo de distribuição territorial mais ampla, por exemplo. Ou ainda, da mesma maneira, obter informações de populações vivas pode ser consideravelmente mais fácil do que obter os mesmos dados de populações extintas. Caracterizar fósseis do ponto de vista populacional é uma tarefa notadamente difícil nesse sentido (Kidwell et al., 1986; Bennington \& Bambach, 1996).

Tais condições ditam a tônica das investigações de Antropologia Biológica, especificamente no que se refere às especialidades da Paleoantropologia e da Bioarqueologia, ou, de outra forma, àquelas que estudam fósseis ou remanescentes ósseos. Em muitos desses casos, conhecer modo e tempo de suas distribuições é virtualmente impossível, o que pode levar qualquer esforço classificatório ao fracasso (Tattersall, 2009). De fato, essa questão já ocupou considerável destaque nas discussões sobre os métodos usados em bioarqueologia, ao questionar a validade de se inferir características populacionais a amostras ósseas de origem arqueológica (Wood et al., 1992; ver Cohen et al., 1994 para uma visão contrária e crítica e Wright et al., 2003 para uma revisão). No entanto, uma vez que os remanescentes esqueletais humanos continuam a oferecer nossa melhor conexão, em termos quantitativos e demográficos, com as informações biológicas relativas às populações humanas extintas (Relethford, 2004a; Betti, 2010), poucas alternativas nos restam para sanar o problema de qualificação das amostras dessa natureza.

\footnotetext{
${ }^{28}$ Não coincidentemente, o próprio conceito estatístico de amostra carrega as mesmas dificuldades quanto à imprecisão de sua definição.
} 
Uma alternativa à essa deficiência é a complementação de informações aos dados, seguindo critérios que propiciem a qualificação adequada aos bancos.

Dessa maneira, a consolidação do banco de dados incorporou uma etapa investigativa adicional durante o desenvolvimento desta pesquisa: a agregação de informações etnográficas, geográficas e cronológicas para cada indivíduo, ou série, incluído no conjunto de dados. Essas informações são de suma importância para a localização geográfico-temporal correta de cada série, o que é imprescindível para a investigação da evolução morfológica ao longo do tempo. Obviamente, no início da execução da pesquisa, já se sabia de antemão que não se conseguiria informações completas para a maioria das séries, o que obrigará a adoção de faixas cronológicas mais amplas para as séries desprovidas desse tipo de informação. Essa estratégia será fundamental para o estudo dos padrões de mudança, considerando-se o tempo, e não apenas a geografia, como é comumente feito nos estudos de afinidades morfológicas.

Vale destacar, ainda, que, além das condições anteriormente expostas, soma-se uma dificuldade extra à qualificação do banco de dados utilizado neste trabalho devido à natureza secundária de sua consolidação, isto é, por conta de sua compilação a partir de diferentes fontes toda e qualquer qualidade atribuída aos dados requereu extremo cuidado.

Assim, foi estabelecido um protocolo para a atribuição de informações e consolidação do banco de dados. A primeira ação deste protocolo consistiu na conferência, indivíduo a indivíduo de todos os espécimes para evitar que ocorresse a inclusão de dados repetidos. Nesta etapa, foram também conferidas a ocorrência de falta de informações, quantitativas e qualitativas, de cada entrada no banco. Esta etapa é fundamental para a detecção de "missing-values"29 no conjunto de dados.

\footnotetext{
29 "Missing-values" poderia ser, facilmente, traduzido para "valores faltantes" ou "valores ausentes". No entanto, como já ocorreu em casos semelhantes ao longo deste texto, optou-se por sua grafia em inglês devido à sua consagrada utilização, mesmo em textos técnicos em língua portuguesa.
} 
Uma vez agregado ao banco de dados, o espécime passou a ter a atribuição de seus dados de qualificação. Obviamente, as informações que já faziam parte de suas descrições foram mantidas e, quando existentes, representaram o ponto de partida para a investigação e aquisição de novas informações. Dessa maneira, através de busca de informações junto às instituições onde as séries esqueletais estão depositadas, comunicações pessoais e consultas a catálogos das coleções (disponibilizados na internet e também solicitados por correspondência30) foi possível levantar as informações a respeito das séries constituintes do banco de dados consolidado para este trabalho.

Ainda assim, em alguns casos, a busca por informações mostrou-se infrutífera e foi necessário complementá-la através de consultas a artigos relacionados, mapas geográficos e históricos, livros de divulgação científica e sítios de internet com informações sobre as populações e regiões de interesse (Vilanova, 1875; Taylor, 1890; Kitson, 1931; Russell, 1965; Lourandos, 1968; Rightmire, 1970; Howells, 1973, 1995; Neel et al., 1977; Lewis, 1983; Young, 1986; Londoño, 1988; Collis, 1990; Steadman \& Kirch, 1990; Drake, 1991; Biddle \& Kjølbye-Biddle, 1992; Lampert \& Steele, 1993; Hanihara, 1993a, 1993b, 1996, 2000; Parker, 1995; Harrington, 1996; Neves et al., 1999; Simielli, 2000; Sayavongkhamdy et al., 2000; O'Rourke et al., 2000; Ulm \& Reid, 2000; Comrie, 2002; Kidd et al., 2003; Morey et al., 2002; Atuí, 2005; Viet, 2005; González-José et al., 2006; Coltrain et al., 2006; Owen et al., 2006; Manica et al., 2007; Martinez \& Martinez, 2007; Johnson, 2007; Bernardo, 2007; Okumura, 2007; Hiscock, 2008; Betti et al., 2009, 2010; Bernardo \& Neves, 2009; Hubbe et al., 2009, 2011; Price \& Bar-Yosef, 2011; Bar-Yosef, 2011; Goring-Morris \& Belfer-Cohen, 2011; Weiss \& Zohary, 2011; Cohen, 2011; Belwood, 2011; Marshall \& Weissbrod, 2011; Rowley-Conwy, 2011; Piperno, 2011; Offenbecker, 2011; AMNH Database, 2011; Tourism and Travellers New Zealand Government Agencies, 2011; South African Government

\footnotetext{
${ }^{30}$ O Apêndice 3 apresenta o modelo de correspondência enviado às instituições nas quais estão depositadas séries utilizadas para alimentar o banco de dados consolidado para esta tese solicitando seu catálogo de informações.
} 
Information, 2011; Andaman \& Nicobar Emerald Islands, 2011)31 ou que guardassem, ao menos, semelhanças mínimas à essas populações alvo. Tal protocolo de investigação de dados possibilitou a compilação do banco formado por 15503 indivíduos distribuídos em 309 séries, cujas características básicas, como sigla, denominação e informações quanto à população e ao banco de dados original, encontram-se apresentadas na Tabela 3.1. Nesta tabela, as séries estão dispostas de acordo com sua posição geográfica latitudinal, no sentido norte-sul. A Figura 3.8 apresenta um mapa-múndi com a distribuição geográfica das 309 séries amostradas.

Tabela 3.1 - Informações primárias sobre as populações constituintes do conjunto inicial de dados.

\begin{tabular}{|c|c|c|c|c|c|}
\hline Sigla & Nome/descrição & $\begin{array}{c}\text { Informação } \\
\text { Etnográfica adicional }\end{array}$ & $\begin{array}{l}\text { Banco } \\
\text { de } \\
\text { Dados } \\
\text { fonte }\end{array}$ & $\begin{array}{l}\text { Instituição } \\
\text { depositária } \\
\text { dos } \\
\text { espécimes }\end{array}$ & Referências bibliográficas \\
\hline ESCA & ESQUIMÓ INUIT (CANADÁ) & $\begin{array}{l}\text { Esquimós Inuit do } \\
\text { Canadá, Nunavut }\end{array}$ & $\mathrm{TH}$ & - & $\begin{array}{c}\text { Hanihara, 1993a, 1993b, 1996, 2000, } \\
\text { Manica et al, 2007, Bernardo 2007, } \\
\text { Betti et al, 2009, 2010, Hubbe et al, } \\
2009\end{array}$ \\
\hline $\mathrm{ESIG}^{\mathrm{b}}$ & $\begin{array}{l}\text { ESQUIMÓ INUIT } \\
\text { (GROELÂNDIA) }\end{array}$ & $\begin{array}{c}\text { Esquimós } \\
\text { Inuit/Kalaallit da } \\
\text { Groelândia }\end{array}$ & $\mathrm{TH}$ & - & $\begin{array}{c}\text { Hanihara, 1993a, 1993b, 1996, 2000, } \\
\text { Manica et al, 2007, Bernardo 2007, } \\
\text { Betti et al, 2009, 2010, Hubbe et al, } \\
2009\end{array}$ \\
\hline LAPO & LAPÔNIA ANTIGA & $\begin{array}{l}\text { Antigos Lapões } \\
\text { pagãos }\end{array}$ & $\mathrm{TH}$ & $\begin{array}{l}\text { NHM, NMNH, } \\
\text { MH }\end{array}$ & $\begin{array}{c}\text { Hanihara, 1993a, 1993b, 1996, 2000, } \\
\text { Bernardo } 2007\end{array}$ \\
\hline ALND & ALASCA NA-DENE & $\begin{array}{c}\text { Nativos do Alasca } \\
\text { (athabascos/Na- } \\
\text { Dene) }\end{array}$ & $\mathrm{TH}$ & - & $\begin{array}{c}\text { Hanihara, 1993a, 1993b, 1996, 2000, } \\
\text { Manica et al, 2007, Bernardo 2007, } \\
\text { Betti et al, 2009, 2010, Hubbe et al, } \\
2009\end{array}$ \\
\hline
\end{tabular}

\footnotetext{
${ }^{31}$ Soma-se, à essas referências, comunicações pessoais de Robert Kruszynski (Natural History Museum), Jude Philp (Sydney University Museums), Keryn Walshe (South Australian Museum), Gisselle Garcia-Pack (American Museum of Natural History), David Hunt (Smithsonian National Museum of Natural History) e Tsuneiko Hanihara (Saga Medical School).
} 


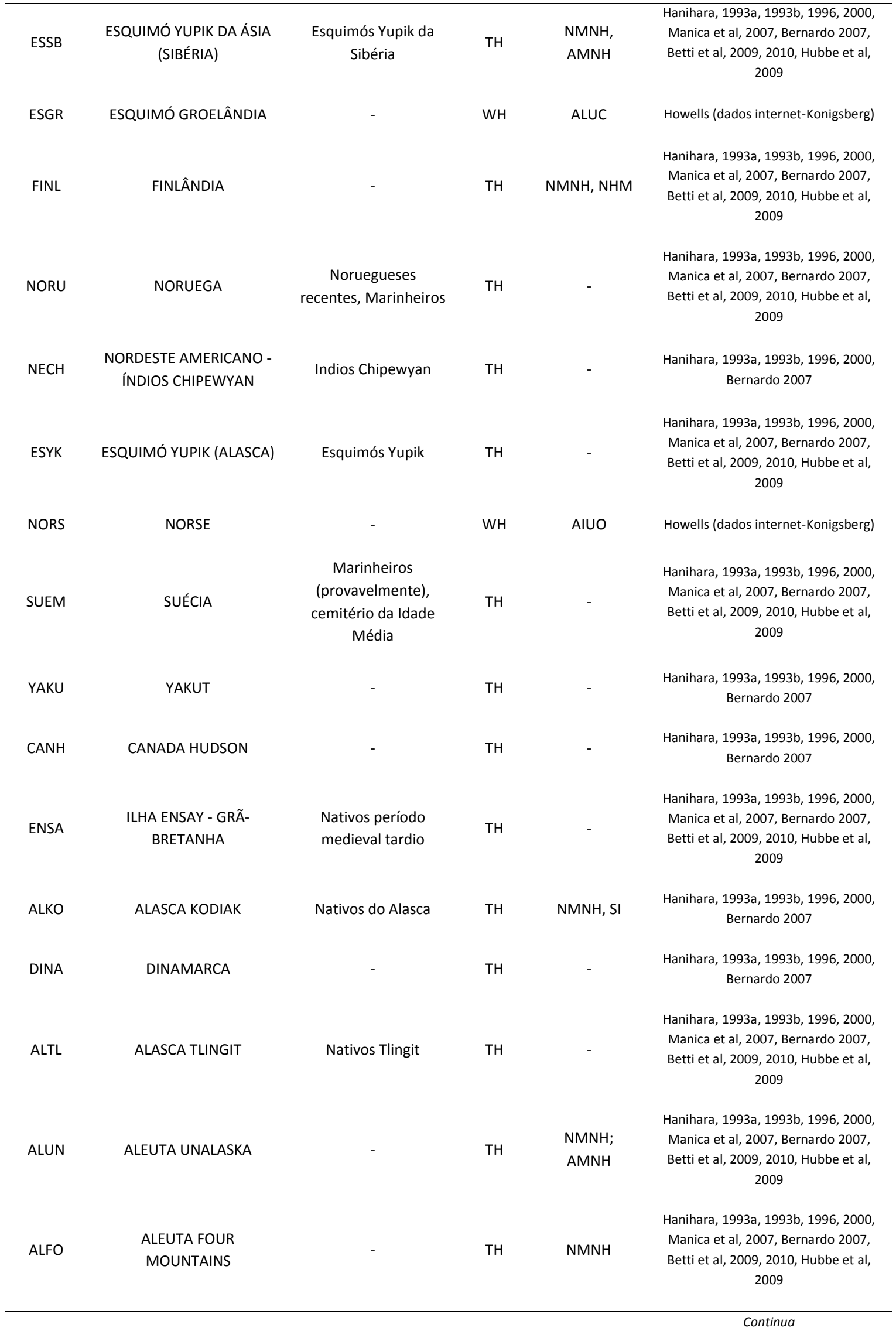




\begin{tabular}{|c|c|c|c|c|c|}
\hline ALAT & ALEUTA ATTU & - & TH & $\mathrm{NMNH}$ & $\begin{array}{c}\text { Hanihara, 1993a, 1993b, 1996, 2000, } \\
\text { Bernardo } 2007\end{array}$ \\
\hline REPT & REPTON GRÃ-BRETANHA & $\begin{array}{l}\text { Nativos da era } \\
\text { medieval, igreja de } \\
\text { Saint Wustans }\end{array}$ & TH & - & $\begin{array}{c}\text { Hanihara, 1993a, 1993b, 1996, 2000, } \\
\text { Manica et al, 2007, Bernardo 2007, } \\
\text { Betti et al, 2009, 2010, Hubbe et al, } \\
2009\end{array}$ \\
\hline NLSI & SIBÉRIA NEOLÍTICO & Período Neolítico & TH & NMNH & $\begin{array}{c}\text { Hanihara, 1993a, 1993b, 1996, 2000, } \\
\text { Bernardo } 2007\end{array}$ \\
\hline HOLA & HOLANDA & - & TH & NHM, NMNH & $\begin{array}{c}\text { Hanihara, 1993a, 1993b, 1996, 2000, } \\
\text { Manica et al, 2007, Bernardo 2007, } \\
\text { Betti et al, 2009, 2010, Hubbe et al, } \\
2009\end{array}$ \\
\hline ALKA & ALEUTA KANAGA & - & TH & $\mathrm{NMNH}$ & $\begin{array}{c}\text { Hanihara, 1993a, 1993b, 1996, 2000, } \\
\text { Bernardo } 2007\end{array}$ \\
\hline NIVK & NIVKH & - & TH & - & $\begin{array}{c}\text { Hanihara, 1993a, 1993b, 1996, 2000, } \\
\text { Bernardo } 2007\end{array}$ \\
\hline NLGB & $\begin{array}{l}\text { NEOLÍTICO GRÃ- } \\
\text { BRETANHA }\end{array}$ & $\begin{array}{l}\text { Nativos do Período } \\
\text { Neolítico }\end{array}$ & TH & - & $\begin{array}{c}\text { Hanihara, } 1993 a, 1993 b, 1996,2000, \\
\text { Bernardo } 2007\end{array}$ \\
\hline SPIM & $\begin{array}{l}\text { SPITALFIELDS GRÃ- } \\
\text { BRETANHA SÉCULOS 16-17 }\end{array}$ & $\begin{array}{c}\text { Indivíduos séculos } 16 \\
-17\end{array}$ & TH & CAM & $\begin{array}{c}\text { Hanihara, 1993a, 1993b, 1996, 2000, } \\
\text { Manica et al, 2007, Bernardo 2007, } \\
\text { Betti et al, 2009, 2010, Hubbe et al, } \\
2009\end{array}$ \\
\hline SPIV & $\begin{array}{l}\text { SPITALFIELDS GRÃ- } \\
\text { BRETANHA ERA } \\
\text { VITORIANA }\end{array}$ & $\begin{array}{l}\text { Indivíduos da Era } \\
\text { Vitoriana (média) }\end{array}$ & TH & NHM & $\begin{array}{c}\text { Hanihara, 1993a, 1993b, 1996, 2000, } \\
\text { Manica et al, 2007, Bernardo 2007, } \\
\text { Betti et al, 2009, 2010, Hubbe et al, } \\
2009\end{array}$ \\
\hline ALAM & ALEUTA AMCHITKA & - & TH & NMNH & $\begin{array}{c}\text { Hanihara, 1993a, 1993b, 1996, 2000, } \\
\text { Bernardo } 2007\end{array}$ \\
\hline BURI & BURIAT & - & WH & IE & Howells (dados internet-Konigsberg) \\
\hline BELG & BÉLGICA & - & TH & NHM, NMNH & $\begin{array}{c}\text { Hanihara, 1993a, 1993b, 1996, 2000, } \\
\text { Bernardo } 2007\end{array}$ \\
\hline POUN & $\begin{array}{l}\text { POUNDBURY GRÃ- } \\
\text { BRETANHA }\end{array}$ & $\begin{array}{l}\text { Nativos do período } \\
\text { Romano tardio. }\end{array}$ & TH & - & $\begin{array}{c}\text { Hanihara, 1993a, 1993b, 1996, 2000, } \\
\text { Manica et al, 2007, Bernardo 2007, } \\
\text { Betti et al, 2009, 2010, Hubbe et al, } \\
2009\end{array}$ \\
\hline ALEH & ALEMANHA (HESSIAN) & $\begin{array}{l}\text { Alemães recentes, } \\
\text { soldados Hessian }\end{array}$ & TH & NHM, NMNH & $\begin{array}{c}\text { Hanihara, 1993a, 1993b, 1996, 2000, } \\
\text { Bernardo } 2007\end{array}$ \\
\hline AMUR & AMUR (RUSSIA/CHINA) & Povo Nanai & TH & AMNH & $\begin{array}{c}\text { Hanihara, 1993a, 1993b, 1996, 2000, } \\
\text { Bernardo } 2007\end{array}$ \\
\hline KYAK $^{\mathrm{b}}$ & BURIAT KYAKHTA & Nativos recentes & TH & - & $\begin{array}{c}\text { Hanihara, 1993a, 1993b, 1996, 2000, } \\
\text { Manica et al, 2007, Bernardo 2007, } \\
\text { Betti et al, 2009, 2010, Hubbe et al, } \\
2009\end{array}$ \\
\hline NLRC & $\begin{array}{c}\text { NEOLÍTICO - REGIÃO } \\
\text { CHECA }\end{array}$ & $\begin{array}{l}\text { Nativos, Idade do } \\
\text { Bronze }\end{array}$ & TH & NMNH & $\begin{array}{c}\text { Hanihara, 1993a, 1993b, 1996, 2000, } \\
\text { Bernardo } 2007\end{array}$ \\
\hline
\end{tabular}




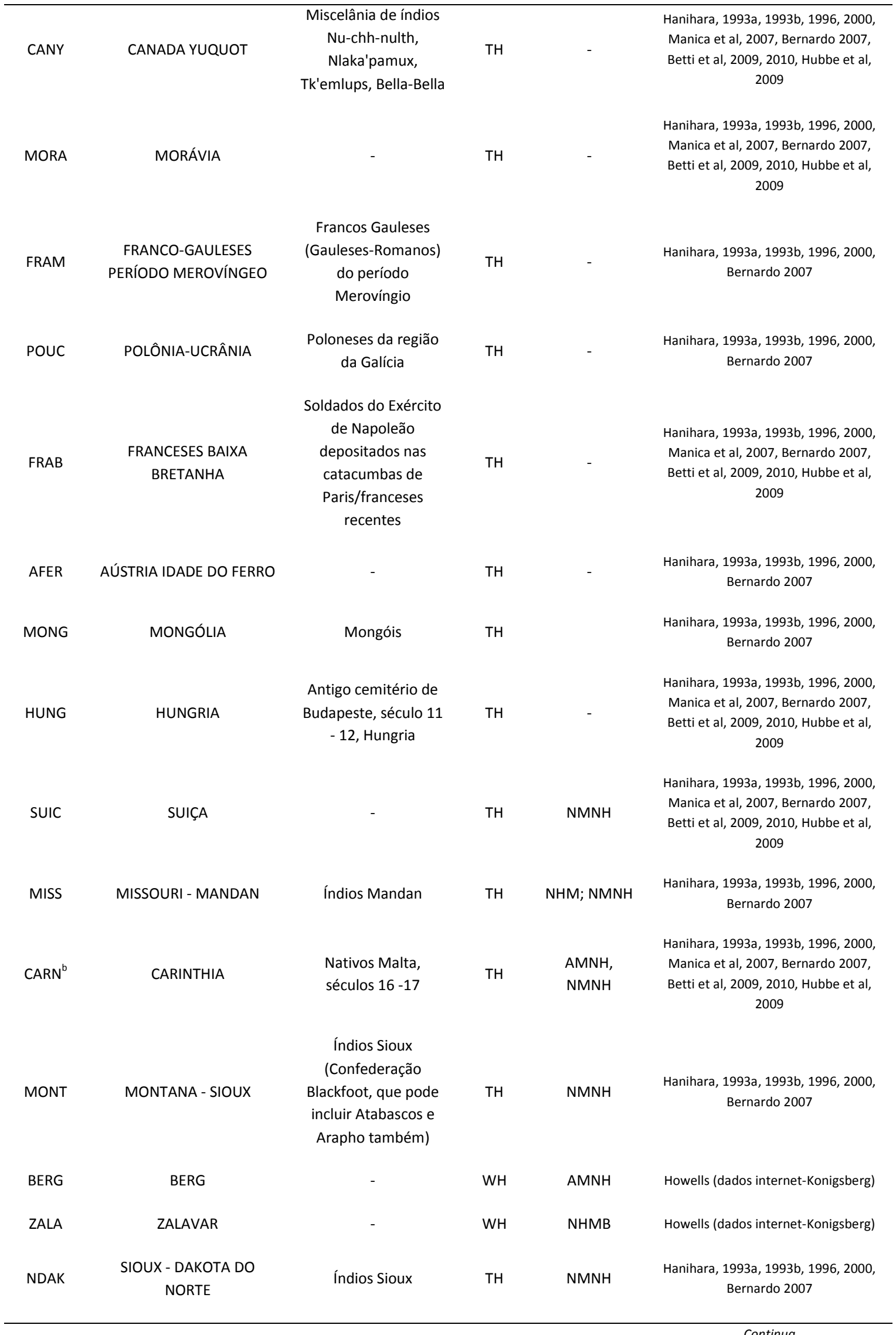




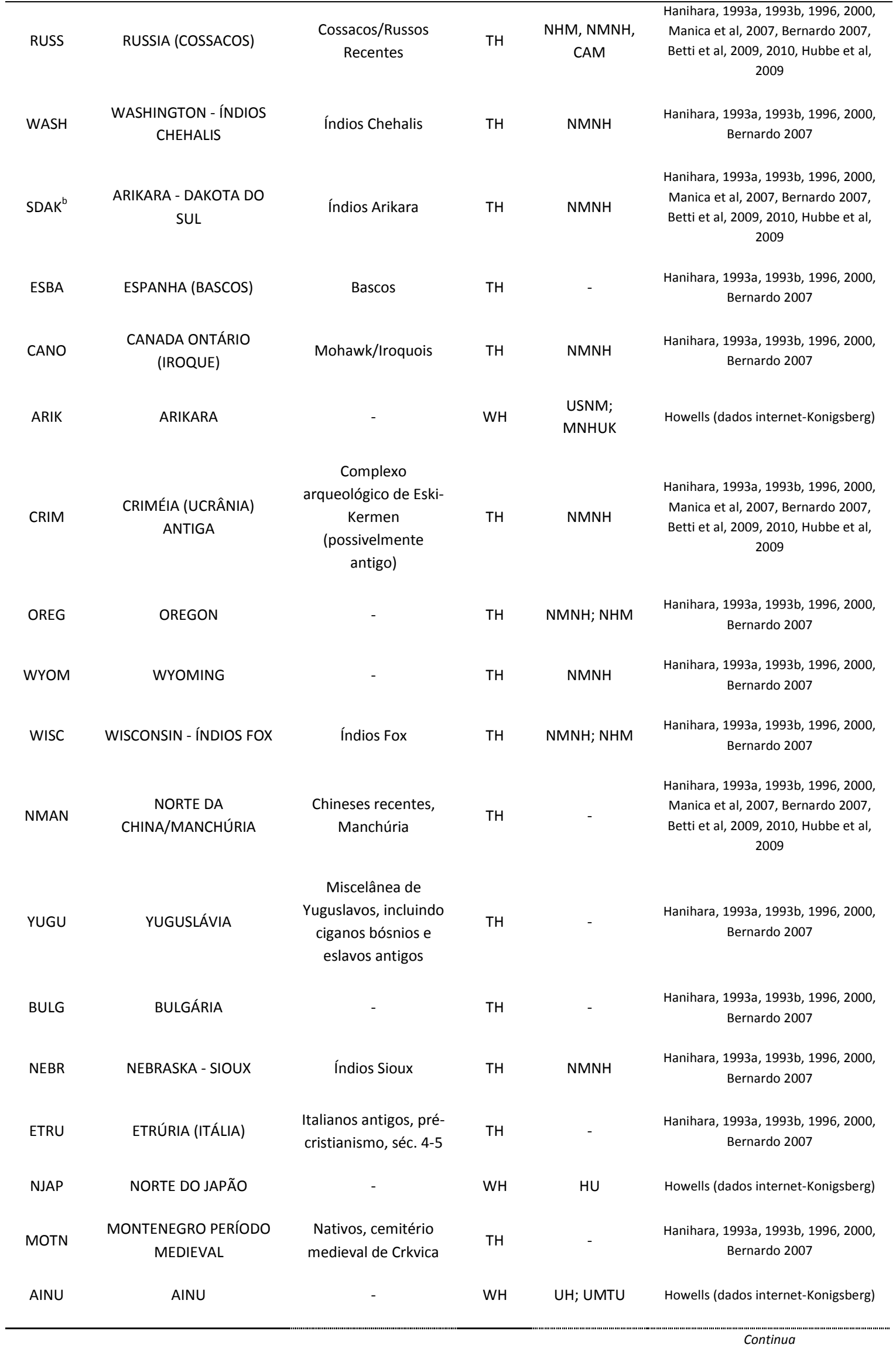




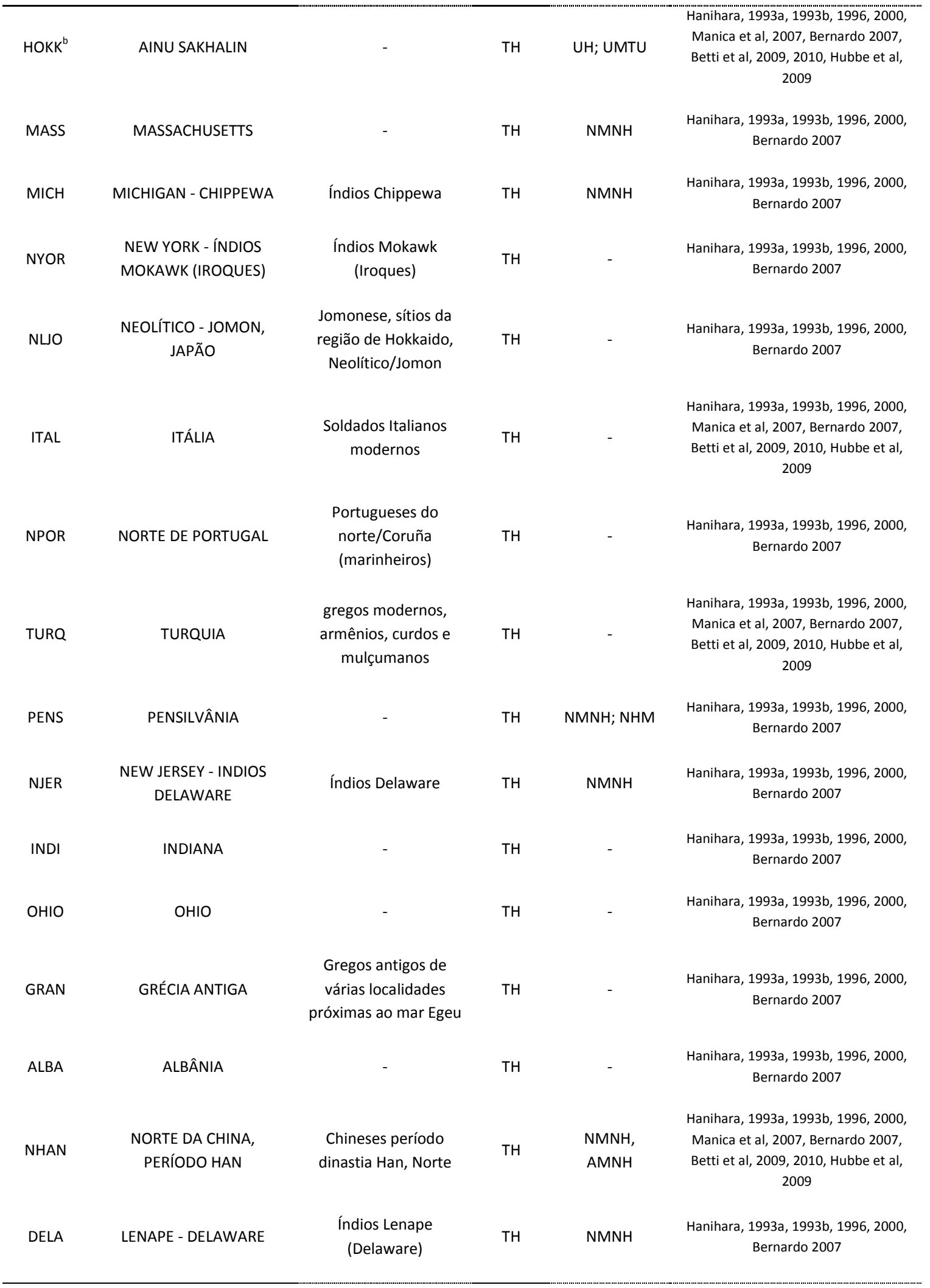




\begin{tabular}{|c|c|c|c|c|c|}
\hline VIRP & $\begin{array}{l}\text { VIRGÍNIA, VALE DO } \\
\text { POTOMAC }\end{array}$ & - & $\mathrm{TH}$ & NMNH & $\begin{array}{l}\text { Hanihara, 1993a, 1993b, 1996, 2000, } \\
\text { Bernardo } 2007\end{array}$ \\
\hline GRRE & GRÉCIA RECENTE & $\begin{array}{l}\text { Gregos recentes de } \\
\text { diversas regiões }\end{array}$ & $\mathrm{TH}$ & - & $\begin{array}{c}\text { Hanihara, 1993a, 1993b, 1996, 2000, } \\
\text { Manica et al, 2007, Bernardo 2007, } \\
\text { Betti et al, 2009, 2010, Hubbe et al, } \\
2009\end{array}$ \\
\hline NEVA & NEVADA & - & $\mathrm{TH}$ & NMNH & $\begin{array}{c}\text { Hanihara, 1993a, 1993b, 1996, 2000, } \\
\text { Bernardo } 2007\end{array}$ \\
\hline JPTH & JAPÃO - TOHOKU & $\begin{array}{l}\text { Japoneses recentes, } \\
\text { distrito de Tohoku }\end{array}$ & $\mathrm{TH}$ & DATU, NMNH & $\begin{array}{c}\text { Hanihara, 1993a, 1993b, 1996, 2000, } \\
\text { Manica et al, 2007, Bernardo 2007, } \\
\text { Betti et al, 2009, 2010, Hubbe et al, } \\
2009\end{array}$ \\
\hline VIRG & VIRGÍNIA & - & TH & NMNH & $\begin{array}{c}\text { Hanihara, 1993a, 1993b, 1996, 2000, } \\
\text { Manica et al, 2007, Bernardo 2007, } \\
\text { Betti et al, 2009, 2010, Hubbe et al, } \\
2009\end{array}$ \\
\hline ILLI & ILLINOIS & $\begin{array}{l}\text { Miscelânea de índios } \\
\text { (confederação Illinois) }\end{array}$ & $\mathrm{TH}$ & NMNH & $\begin{array}{c}\text { Hanihara, 1993a, 1993b, 1996, 2000, } \\
\text { Manica et al, 2007, Bernardo 2007, } \\
\text { Betti et al, 2009, 2010, Hubbe et al, } \\
2009\end{array}$ \\
\hline SACR & $\begin{array}{l}\text { SACRAMENTO, } \\
\text { CALIFÓRNIA }\end{array}$ & - & $\mathrm{TH}$ & - & $\begin{array}{c}\text { Hanihara, 1993a, 1993b, 1996, 2000, } \\
\text { Manica et al, 2007, Bernardo 2007, } \\
\text { Betti et al, 2009, 2010, Hubbe et al, } \\
2009\end{array}$ \\
\hline MARY & MARYLAND & $\begin{array}{l}\text { Miscelânea de nativos } \\
\text { de Maryland }\end{array}$ & $\mathrm{TH}$ & NMNH & $\begin{array}{c}\text { Hanihara, 1993a, 1993b, 1996, 2000, } \\
\text { Manica et al, 2007, Bernardo 2007, } \\
\text { Betti et al, 2009, 2010, Hubbe et al, } \\
2009\end{array}$ \\
\hline UTAH & UTAH & - & $\mathrm{TH}$ & NMNH & $\begin{array}{c}\text { Hanihara, 1993a, 1993b, 1996, 2000, } \\
\text { Bernardo } 2007\end{array}$ \\
\hline COLR & KIOWA - COLORADO & Índios Kiowa & $\mathrm{TH}$ & NMNH & $\begin{array}{c}\text { Hanihara, 1993a, 1993b, 1996, 2000, } \\
\text { Bernardo } 2007\end{array}$ \\
\hline RMNI & ROMÊNIA & Ciganos da Romênia & $\mathrm{TH}$ & - & $\begin{array}{c}\text { Hanihara, 1993a, 1993b, 1996, 2000, } \\
\text { Bernardo } 2007\end{array}$ \\
\hline KANS & WICHITA - KANSAS & Índios Wichita e Kaw & $\mathrm{TH}$ & $\mathrm{NHM}$; NMNH & $\begin{array}{c}\text { Hanihara, 1993a, 1993b, 1996, 2000, } \\
\text { Bernardo } 2007\end{array}$ \\
\hline IRAP & $\begin{array}{l}\text { IRÃ, IMPÉRIO PARTHIA } \\
\text { (PÉRSIA) }\end{array}$ & $\begin{array}{l}\text { Indivíduos do período } \\
\text { do Império da } \\
\text { Parthia, séculos 1-3 } \\
\text { dC }\end{array}$ & $\mathrm{TH}$ & UMT & $\begin{array}{c}\text { Hanihara, 1993a, 1993b, 1996, 2000, } \\
\text { Bernardo } 2007\end{array}$ \\
\hline KNOL & INDIAN KNOLL - KENTUCKY & $\begin{array}{l}\text { Ceramistas pré- } \\
\text { históricos }\end{array}$ & $\mathrm{TH}$ & $\mathrm{NHM}$; NMNH & $\begin{array}{c}\text { Hanihara, 1993a, 1993b, 1996, 2000, } \\
\text { Manica et al, 2007, Bernardo 2007, } \\
\text { Betti et al, 2009, 2010, Hubbe et al, } \\
2009\end{array}$ \\
\hline OKLA & OKLAHOMA OSAGE & $\begin{array}{l}\text { Índios Osage (tronco } \\
\text { Siouan) }\end{array}$ & $\mathrm{TH}$ & - & $\begin{array}{c}\text { Hanihara, 1993a, 1993b, 1996, 2000, } \\
\text { Bernardo } 2007\end{array}$ \\
\hline
\end{tabular}




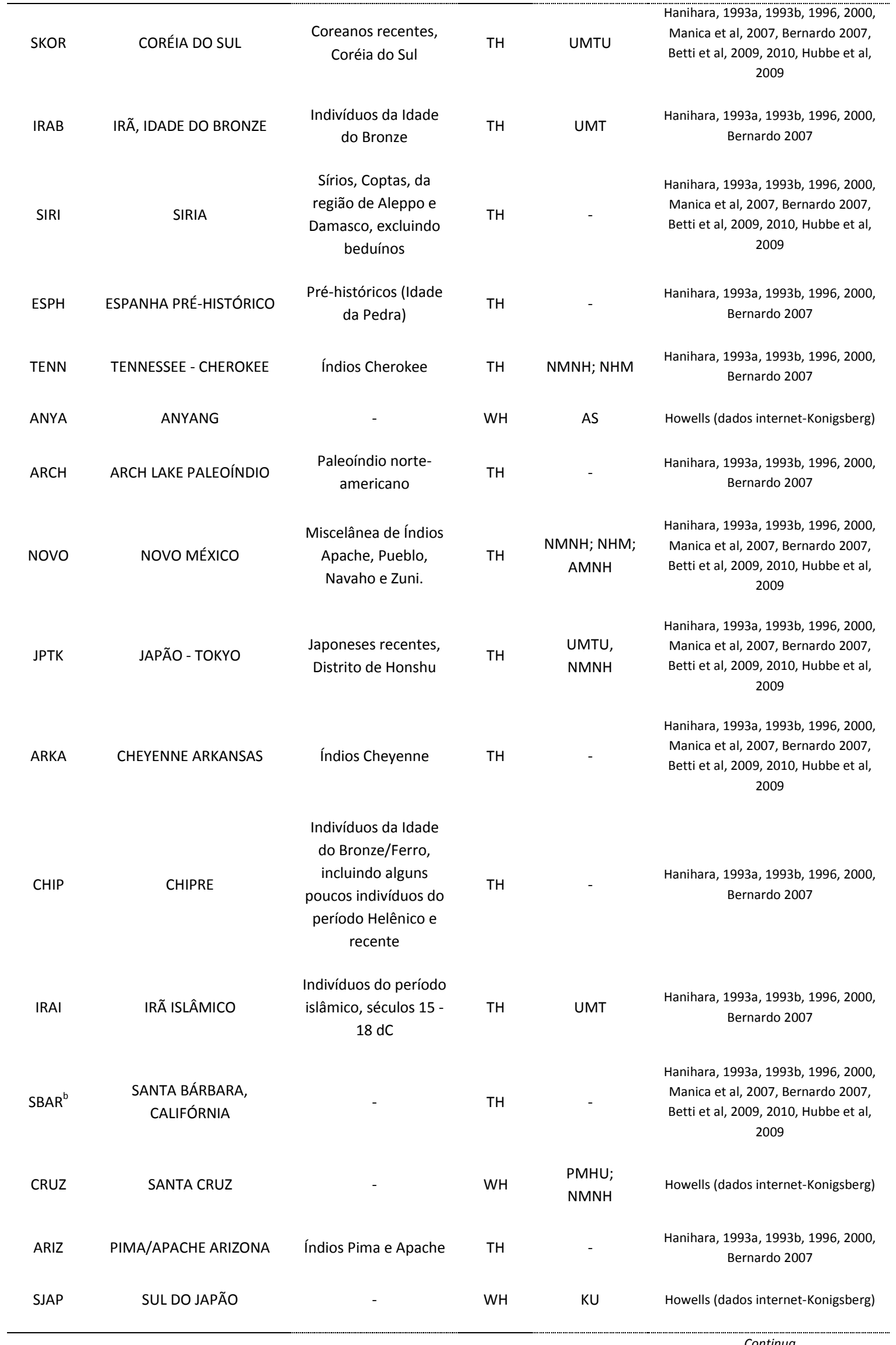




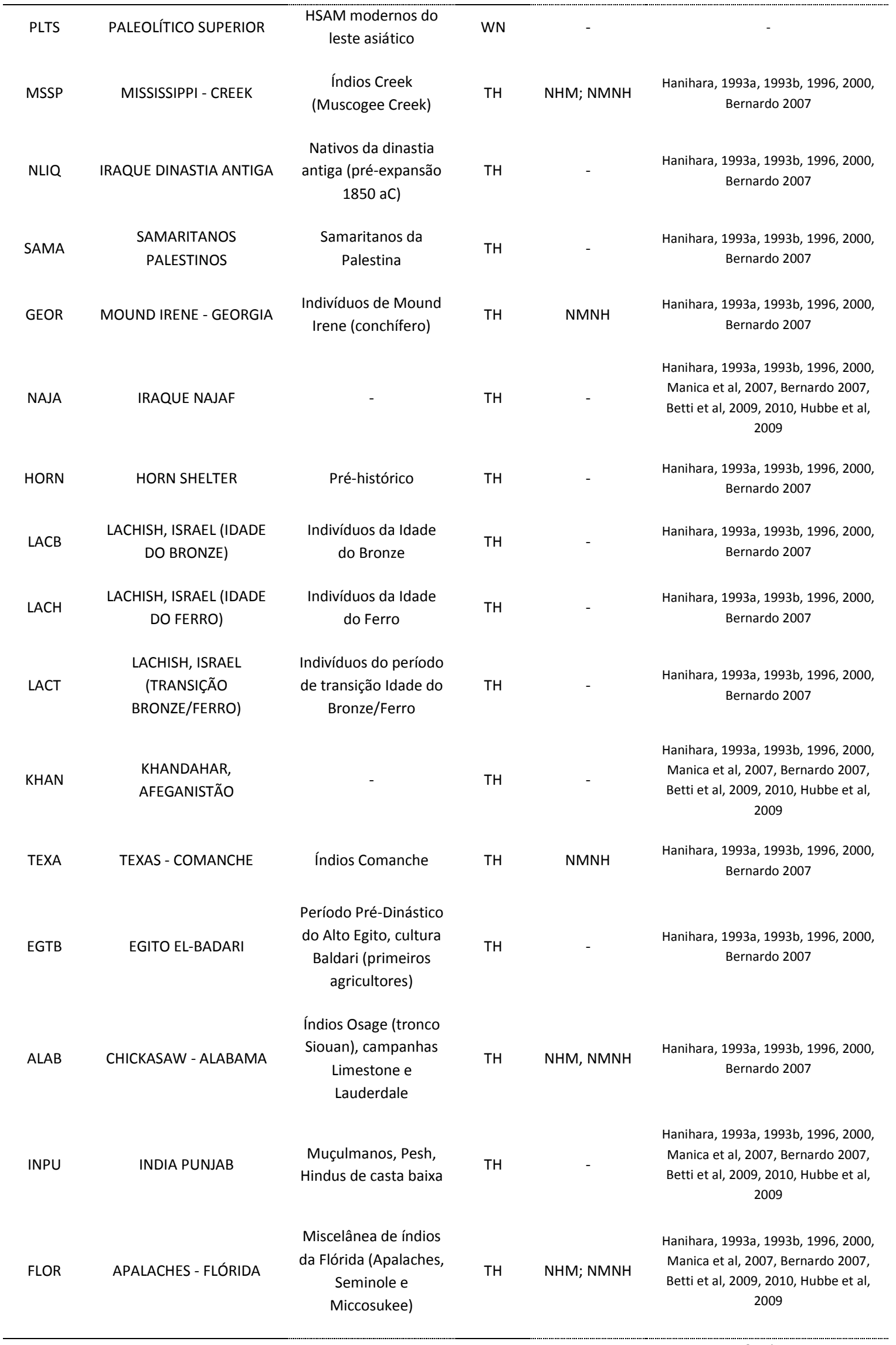




\begin{tabular}{|c|c|c|c|c|c|}
\hline EGTS $^{b}$ & EGITO GIZEH (SUL) & Dinastias XXVI - XXXIX & $\mathrm{TH}$ & - & $\begin{array}{c}\text { Hanihara, } 1993 a, 1993 b, 1996,2000 \\
\text { Bernardo } 2007\end{array}$ \\
\hline EGTG & EGITO GIZEH & - & WH & CAM & Howells (dados internet-Konigsberg) \\
\hline IRAA & IRÃ, AQUEMÊNIDA & $\begin{array}{l}\text { Indivíduos do período } \\
\text { Aquemênida (séculos } \\
66-4 \mathrm{aC} \text { ) }\end{array}$ & TH & UMT & $\begin{array}{c}\text { Hanihara, 1993a, 1993b, 1996, 2000, } \\
\text { Bernardo } 2007\end{array}$ \\
\hline LOUI & ILHA PECAN, LOUISIANA & - & TH & NMNH & $\begin{array}{c}\text { Hanihara, 1993a, 1993b, 1996, 2000, } \\
\text { Bernardo } 2007\end{array}$ \\
\hline EGTL & EGITO EL-LISHT & $\begin{array}{c}\text { Egípcios da XII } \\
\text { Dinastia do Alto Egito }\end{array}$ & TH & - & $\begin{array}{c}\text { Hanihara, 1993a, 1993b, 1996, 2000, } \\
\text { Bernardo } 2007\end{array}$ \\
\hline INDL & INDIA DELHI & - & TH & - & $\begin{array}{c}\text { Hanihara, 1993a, 1993b, 1996, 2000, } \\
\text { Bernardo } 2007\end{array}$ \\
\hline NEPA & NEPAL & Sunuwaris do Nepal & TH & NHM, NMNH & $\begin{array}{c}\text { Hanihara, 1993a, 1993b, 1996, 2000, } \\
\text { Manica et al, 2007, Bernardo 2007, } \\
\text { Betti et al, 2009, 2010, Hubbe et al, } \\
2009\end{array}$ \\
\hline MARR & $\begin{array}{l}\text { ILHAS CANÁRIAS, } \\
\text { MARROCOS }\end{array}$ & Nativos Guanche & TH & $\mathrm{NHM}, \mathrm{NMNH}$ & $\begin{array}{c}\text { Hanihara, 1993a, 1993b, 1996, 2000, } \\
\text { Manica et al, 2007, Bernardo 2007, } \\
\text { Betti et al, 2009, 2010, Hubbe et al, } \\
2009\end{array}$ \\
\hline SHAN & $\begin{array}{c}\text { SUL DA CHINA, PERÍODO } \\
\text { HAN }\end{array}$ & $\begin{array}{l}\text { Chineses nativos, } \\
\text { período dinastia Han, } \\
\text { Sul }\end{array}$ & TH & $\begin{array}{l}\text { NMNH, } \\
\text { AMNH }\end{array}$ & $\begin{array}{c}\text { Hanihara, 1993a, 1993b, 1996, 2000, } \\
\text { Manica et al, 2007, Bernardo 2007, } \\
\text { Betti et al, 2009, 2010, Hubbe et al, } \\
2009\end{array}$ \\
\hline TIBE & TIBET & $\begin{array}{l}\text { Soldados Tibetanos, } \\
\text { mortos durante o } \\
\text { século } 19\end{array}$ & $\mathrm{TH}$ & - & $\begin{array}{c}\text { Hanihara, 1993a, 1993b, 1996, 2000, } \\
\text { Manica et al, 2007, Bernardo 2007, } \\
\text { Betti et al, 2009, 2010, Hubbe et al, } \\
2009\end{array}$ \\
\hline INSI & INDIA SIKKIM & $\begin{array}{l}\text { Lepcha nativos de } \\
\text { Sikkim, India }\end{array}$ & TH & - & $\begin{array}{c}\text { Hanihara, 1993a, 1993b, 1996, 2000, } \\
\text { Manica et al, 2007, Bernardo 2007, } \\
\text { Betti et al, 2009, 2010, Hubbe et al, } \\
2009\end{array}$ \\
\hline INNO & INDIA NOROESTE & $\begin{array}{l}\text { Noroeste da India } \\
\text { (Fronteira Paquistão) }\end{array}$ & $\mathrm{TH}$ & - & $\begin{array}{c}\text { Hanihara, 1993a, 1993b, 1996, 2000, } \\
\text { Bernardo } 2007\end{array}$ \\
\hline INAS & INDIA ASSAM & - & $\mathrm{TH}$ & - & $\begin{array}{c}\text { Hanihara, 1993a, 1993b, 1996, 2000, } \\
\text { Bernardo } 2007\end{array}$ \\
\hline EGTN & EGITO NAQADA & $\begin{array}{l}\text { Remanescentes da } \\
\text { cultura Naqada }\end{array}$ & $\mathrm{TH}$ & - & $\begin{array}{c}\text { Hanihara, 1993a, 1993b, 1996, 2000, } \\
\text { Bernardo } 2007\end{array}$ \\
\hline INBI & INDIA BIHAR & - & TH & - & $\begin{array}{c}\text { Hanihara, 1993a, 1993b, 1996, 2000, } \\
\text { Manica et al, 2007, Bernardo 2007, } \\
\text { Betti et al, 2009, 2010, Hubbe et al, } \\
2009\end{array}$ \\
\hline EGTK & EGITO EL-KHARGA & $\begin{array}{l}\text { Egípcios do período } \\
\text { Luxor/Cóptico }\end{array}$ & TH & - & $\begin{array}{c}\text { Hanihara, 1993a, 1993b, 1996, 2000, } \\
\text { Bernardo } 2007\end{array}$ \\
\hline BEDU & BEDUÍNO, NEGEV & - & TH & - & $\begin{array}{c}\text { Hanihara, } 1993 a, 1993 b, 1996,2000, \\
\text { Bernardo } 2007\end{array}$ \\
\hline
\end{tabular}




\begin{tabular}{|c|c|c|c|c|c|}
\hline ATAY & ATAYAL & - & WH & AS; NTU & Howells (dados internet-Konigsberg) \\
\hline TAIW $^{\mathrm{b}}$ & TAIWAN & - & $\mathrm{TH}$ & - & $\begin{array}{c}\text { Hanihara, 1993a, 1993b, 1996, 2000, } \\
\text { Manica et al, 2007, Bernardo 2007, } \\
\text { Betti et al, 2009, 2010, Hubbe et al, } \\
2009\end{array}$ \\
\hline SUNI & $\begin{array}{c}\text { SUDÃO (CATARATAS DO } \\
\text { NILO) }\end{array}$ & $\begin{array}{l}\text { População do início } \\
\text { da era cristã }\end{array}$ & $\mathrm{TH}$ & - & $\begin{array}{c}\text { Hanihara, 1993a, 1993b, 1996, 2000, } \\
\text { Bernardo } 2007\end{array}$ \\
\hline BANG & DHAKA, BANGLADESH & Mulçumanos e Hindus & $\mathrm{TH}$ & - & $\begin{array}{c}\text { Hanihara, 1993a, 1993b, 1996, 2000, } \\
\text { Manica et al, 2007, Bernardo 2007, } \\
\text { Betti et al, 2009, 2010, Hubbe et al, } \\
2009\end{array}$ \\
\hline INBE & INDIA BENGALA & $\begin{array}{c}\text { Hindus e } \\
\text { Muçulmanos, Distrito } \\
\text { de Bengala, India }\end{array}$ & $\mathrm{TH}$ & - & $\begin{array}{c}\text { Hanihara, 1993a, 1993b, 1996, 2000, } \\
\text { Manica et al, 2007, Bernardo 2007, } \\
\text { Betti et al, 2009, 2010, Hubbe et al, } \\
2009\end{array}$ \\
\hline INCA & India Calcutta & - & $\mathrm{TH}$ & - & $\begin{array}{c}\text { Hanihara, 1993a, 1993b, 1996, 2000, } \\
\text { Manica et al, 2007, Bernardo 2007, } \\
\text { Betti et al, 2009, 2010, Hubbe et al, } \\
2009\end{array}$ \\
\hline INBO & INDIA BOMBAY & - & $\mathrm{TH}$ & - & $\begin{array}{c}\text { Hanihara, 1993a, 1993b, 1996, 2000, } \\
\text { Bernardo } 2007\end{array}$ \\
\hline MOKA & MOKAPU & - & WH & BBM & Howells (dados internet-Konigsberg) \\
\hline MMEX & MISCELÂNEA MÉXICO & - & $\mathrm{TH}$ & - & $\begin{array}{c}\text { Hanihara, 1993a, 1993b, 1996, 2000, } \\
\text { Bernardo } 2007\end{array}$ \\
\hline NLLA & LAOS NEOLÍTICO & Período Neolítico & $\mathrm{TH}$ & - & $\begin{array}{c}\text { Hanihara, } 1993 a, 1993 b, 1996,2000, \\
\text { Bernardo } 2007\end{array}$ \\
\hline INOR & INDIA ORISSA & Tribo Koa & $\mathrm{TH}$ & - & $\begin{array}{c}\text { Hanihara, 1993a, 1993b, 1996, 2000, } \\
\text { Bernardo } 2007\end{array}$ \\
\hline NLVT & NEOLÍTICO DO VIETNAM & $\begin{array}{l}\text { Habitantes do } \\
\text { período Neolítico }\end{array}$ & $\mathrm{TH}$ & - & $\begin{array}{c}\text { Hanihara, 1993a, 1993b, 1996, 2000, } \\
\text { Bernardo } 2007\end{array}$ \\
\hline VIET & VIETNAM RECENTE & $\begin{array}{l}\text { Vietninamitas nativos } \\
\text { recentes }\end{array}$ & $\mathrm{TH}$ & - & $\begin{array}{c}\text { Hanihara, 1993a, 1993b, 1996, 2000, } \\
\text { Manica et al, 2007, Bernardo 2007, } \\
\text { Betti et al, 2009, 2010, Hubbe et al, } \\
2009\end{array}$ \\
\hline HAIN & HAINAN & - & WH & AS; NTU & Howells (dados internet-Konigsberg) \\
\hline KERM & KERMA (NÚBIA/EGITO) & $\begin{array}{l}\text { População nativa } \\
\text { antiga, período da } \\
\text { cultura Kerma }\end{array}$ & $\mathrm{TH}$ & - & $\begin{array}{c}\text { Hanihara, 1993a, 1993b, 1996, 2000, } \\
\text { Manica et al, 2007, Bernardo 2007, } \\
\text { Betti et al, 2009, 2010, Hubbe et al, } \\
2009\end{array}$ \\
\hline HAVP ${ }^{b}$ & HAVAÍ, POLINÉSIA & $\begin{array}{c}\text { Kanaka } \\
\text { (trabalhadores) }\end{array}$ & $\mathrm{TH}$ & - & $\begin{array}{c}\text { Hanihara, 1993a, 1993b, 1996, 2000, } \\
\text { Bernardo } 2007\end{array}$ \\
\hline BIRM & BIRMÂNIA & $\begin{array}{c}\text { Nativos Arakaneses, } \\
\text { Tribo Chin, nativos de } \\
\text { Burma }\end{array}$ & $\mathrm{TH}$ & - & $\begin{array}{c}\text { Hanihara, 1993a, 1993b, 1996, 2000, } \\
\text { Manica et al, 2007, Bernardo 2007, } \\
\text { Betti et al, 2009, 2010, Hubbe et al, } \\
2009\end{array}$ \\
\hline
\end{tabular}


Continuação

\begin{tabular}{|c|c|c|c|c|c|}
\hline PMEX & PIII/MEX & $\begin{array}{l}\text { Paleoamericanos da } \\
\text { Mesoamérica }\end{array}$ & WN & - & González-José et al., 2006 \\
\hline SUDO & SUDÃO (DONGOLA) & $\begin{array}{l}\text { População recente } \\
\text { (200 anos) formada } \\
\text { por anglo-egípcios }\end{array}$ & $\mathrm{TH}$ & - & $\begin{array}{c}\text { Hanihara, 1993a, 1993b, 1996, 2000, } \\
\text { Bernardo } 2007\end{array}$ \\
\hline INSU & INDIA SUL & Recentes & $\mathrm{TH}$ & - & $\begin{array}{c}\text { Hanihara, 1993a, 1993b, 1996, 2000, } \\
\text { Bernardo } 2007\end{array}$ \\
\hline LAOS & LAOS & $\begin{array}{l}\text { Habitantes de } \\
\text { Khammouane }\end{array}$ & $\mathrm{TH}$ & - & $\begin{array}{c}\text { Hanihara, 1993a, 1993b, 1996, 2000, } \\
\text { Manica et al, 2007, Bernardo 2007, } \\
\text { Betti et al, 2009, 2010, Hubbe et al, } \\
2009\end{array}$ \\
\hline INCE & India Central & - & $\mathrm{TH}$ & - & $\begin{array}{c}\text { Hanihara, 1993a, 1993b, 1996, 2000, } \\
\text { Bernardo } 2007\end{array}$ \\
\hline AETA & $\begin{array}{l}\text { TRIBO AETA, NEGRITOS } \\
\text { DAS FILIPINAS }\end{array}$ & $\begin{array}{l}\text { Nativos tribo Agta } \\
\text { (Aeta), Negritos } \\
\text { filipinos }\end{array}$ & $\mathrm{TH}$ & - & $\begin{array}{c}\text { Hanihara, 1993a, 1993b, 1996, 2000, } \\
\text { Bernardo } 2007\end{array}$ \\
\hline EGTO & EGITO OMDURMAN & $\begin{array}{l}\text { Egípcios do período } \\
\text { entre a XV até o final } \\
\text { do período das } \\
\text { Dinastias }\end{array}$ & $\mathrm{TH}$ & - & $\begin{array}{c}\text { Hanihara, 1993a, 1993b, 1996, 2000, } \\
\text { Bernardo } 2007\end{array}$ \\
\hline FLIP & FILIPINAS & - & WH & MSUP & Howells (dados internet-Konigsberg) \\
\hline DOGO & DOGON & - & WH & $\mathrm{MH}$ & Howells (dados internet-Konigsberg) \\
\hline TAIL & TAILÂNDIA & $\begin{array}{c}\text { Tailandeses recentes } \\
\text { de Bangkok }\end{array}$ & $\mathrm{TH}$ & - & $\begin{array}{c}\text { Hanihara, 1993a, 1993b, 1996, 2000, } \\
\text { Manica et al, 2007, Bernardo 2007, } \\
\text { Betti et al, 2009, 2010, Hubbe et al, } \\
2009\end{array}$ \\
\hline GUAM & GUAM & Nativos Chamorros & WH & BBM & Howells (dados internet-Konigsberg) \\
\hline $\mathrm{MARI}^{\mathrm{b}}$ & $\begin{array}{c}\text { ILHAS MARIANA (NATIVOS } \\
\text { GUAM) }\end{array}$ & Nativos Chamorros & $\mathrm{TH}$ & - & $\begin{array}{c}\text { Hanihara, 1993a, 1993b, 1996, 2000, } \\
\text { Bernardo } 2007\end{array}$ \\
\hline CARI & CARIBE & Arawak Carib & $\mathrm{TH}$ & - & $\begin{array}{c}\text { Hanihara, 1993a, 1993b, 1996, 2000, } \\
\text { Bernardo } 2007\end{array}$ \\
\hline INMA & INDIA MADRAS & Nativos (Dravidians) & $\mathrm{TH}$ & - & $\begin{array}{c}\text { Hanihara, 1993a, 1993b, 1996, 2000, } \\
\text { Manica et al, 2007, Bernardo 2007, } \\
\text { Betti et al, 2009, 2010, Hubbe et al, } \\
2009\end{array}$ \\
\hline CAMB & CAMBOJA & - & $\mathrm{TH}$ & - & $\begin{array}{c}\text { Hanihara, 1993a, 1993b, 1996, 2000, } \\
\text { Bernardo } 2007\end{array}$ \\
\hline NEAN ${ }^{b}$ & $\begin{array}{l}\text { NEGRITOS ILHAS } \\
\text { ANDAMÃO }\end{array}$ & $\begin{array}{l}\text { Negritos Illhas } \\
\text { Andamão }\end{array}$ & $\mathrm{TH}$ & - & $\begin{array}{c}\text { Hanihara, 1993a, 1993b, 1996, 2000, } \\
\text { Bernardo } 2007\end{array}$ \\
\hline INMY & INDIA MYSORE & Tribo Vakkaliga & TH & - & $\begin{array}{c}\text { Hanihara, 1993a, 1993b, 1996, 2000, } \\
\text { Bernardo } 2007\end{array}$ \\
\hline
\end{tabular}




\begin{tabular}{|c|c|c|c|c|c|}
\hline ANDA & ANDAMAN & - & WH & $\begin{array}{c}\text { BM; UE; RSM, } \\
\text { CAM; DHAO; } \\
\text { MH; AIC; } \\
\text { AMNH; } \\
\text { PMHU; FM }\end{array}$ & Howells (dados internet-Konigsberg) \\
\hline INHA & INDIA MAHALLS & - & $\mathrm{TH}$ & - & $\begin{array}{c}\text { Hanihara, 1993a, 1993b, 1996, 2000, } \\
\text { Bernardo } 2007\end{array}$ \\
\hline INLB & INDIA MALABAR & $\begin{array}{c}\text { Tribo Tamil (povo } \\
\text { Tamil) }\end{array}$ & $\mathrm{TH}$ & - & $\begin{array}{c}\text { Hanihara, 1993a, 1993b, 1996, 2000, } \\
\text { Bernardo } 2007\end{array}$ \\
\hline NIGM & MISCELÂNEA NIGÉRIA & $\begin{array}{c}\text { Miscelânea de tribos } \\
\text { Hausa, Munshi e } \\
\text { Kagoro }\end{array}$ & $\mathrm{TH}$ & - & $\begin{array}{c}\text { Hanihara, 1993a, 1993b, 1996, 2000, } \\
\text { Manica et al, 2007, Bernardo 2007, } \\
\text { Betti et al, 2009, 2010, Hubbe et al, } \\
2009\end{array}$ \\
\hline INTA & INDIA TAMIL & Tribo Tamil? & $\mathrm{TH}$ & - & $\begin{array}{c}\text { Hanihara, 1993a, 1993b, 1996, 2000, } \\
\text { Bernardo } 2007\end{array}$ \\
\hline ETIO & ETIÓPIA & - & $\mathrm{TH}$ & - & $\begin{array}{c}\text { Hanihara, 1993a, 1993b, 1996, 2000, } \\
\text { Bernardo } 2007\end{array}$ \\
\hline VENE & VENEZUELA & Índios Piaroa & $\mathrm{TH}$ & NHM, NMNH & $\begin{array}{c}\text { Hanihara, 1993a, 1993b, 1996, 2000, } \\
\text { Manica et al, 2007, Bernardo 2007, } \\
\text { Betti et al, 2009, 2010, Hubbe et al, } \\
2009\end{array}$ \\
\hline TERE & ILHA TERESSA, NICOBAR & $\begin{array}{l}\text { Nativos de Ilha } \\
\text { Teressa, Nicobar }\end{array}$ & $\mathrm{TH}$ & - & $\begin{array}{c}\text { Hanihara, 1993a, 1993b, 1996, 2000, } \\
\text { Bernardo } 2007\end{array}$ \\
\hline IGBO & NIGÉRIA, TRIBO IGBO & $\begin{array}{l}\text { Nativos da tribo Igbo } \\
\text { (Ibo) }\end{array}$ & $\mathrm{TH}$ & - & $\begin{array}{c}\text { Hanihara, 1993a, 1993b, 1996, 2000, } \\
\text { Manica et al, 2007, Bernardo 2007, } \\
\text { Betti et al, 2009, 2010, Hubbe et al, } \\
2009\end{array}$ \\
\hline PANA & PANAMA & - & $\mathrm{TH}$ & NMNH & $\begin{array}{c}\text { Hanihara, 1993a, 1993b, 1996, 2000, } \\
\text { Bernardo } 2007\end{array}$ \\
\hline INVE & $\begin{array}{l}\text { INDIA VEDDAH (SRI- } \\
\text { LANKA) ANTIGOS }\end{array}$ & $\begin{array}{c}\text { Nativos do Sri-Lanka } \\
\text { (antigos) }\end{array}$ & $\mathrm{TH}$ & - & $\begin{array}{c}\text { Hanihara, 1993a, 1993b, 1996, 2000, } \\
\text { Bernardo } 2007\end{array}$ \\
\hline COST & COSTA DO MARFIM & $\begin{array}{l}\text { Nativos recentes da } \\
\text { Costa do Marfim }\end{array}$ & $\mathrm{TH}$ & - & $\begin{array}{c}\text { Hanihara, 1993a, 1993b, 1996, 2000, } \\
\text { Manica et al, 2007, Bernardo 2007, } \\
\text { Betti et al, 2009, 2010, Hubbe et al, } \\
2009\end{array}$ \\
\hline AKAN & GANA, ASHANTI (AKAN) & $\begin{array}{l}\text { Nativos Asshanti } \\
\text { (Akan) de Gana }\end{array}$ & $\mathrm{TH}$ & - & $\begin{array}{c}\text { Hanihara, 1993a, 1993b, 1996, 2000, } \\
\text { Manica et al, 2007, Bernardo 2007, } \\
\text { Betti et al, 2009, 2010, Hubbe et al, } \\
2009\end{array}$ \\
\hline
\end{tabular}




\begin{tabular}{|c|c|c|c|c|c|}
\hline NUGA & NUGAL, SOMÁLIA & $\begin{array}{l}\text { Nativos de tribo (clã) } \\
\text { Dhulbahante }\end{array}$ & TH & - & $\begin{array}{c}\text { Hanihara, 1993a, 1993b, 1996, 2000, } \\
\text { Manica et al, 2007, Bernardo 2007, } \\
\text { Betti et al, 2009, 2010, Hubbe et al, } \\
2009\end{array}$ \\
\hline KEDA & MALÁSIA KEDAH & - & TH & - & $\begin{array}{c}\text { Hanihara, 1993a, 1993b, 1996, 2000, } \\
\text { Manica et al, 2007, Bernardo 2007, } \\
\text { Betti et al, 2009, 2010, Hubbe et al, } \\
2009\end{array}$ \\
\hline JOLO & $\begin{array}{l}\text { ILHA JOLO, ARQUIPÉLAGO } \\
\text { SULU }\end{array}$ & - & TH & - & $\begin{array}{c}\text { Hanihara, 1993a, 1993b, 1996, 2000, } \\
\text { Bernardo } 2007\end{array}$ \\
\hline CESS & $\begin{array}{l}\text { LIBÉRIA, RIO CESS, TRIBO } \\
\text { KRU }\end{array}$ & Nativos da tribo Kru & TH & - & $\begin{array}{c}\text { Hanihara, } 1993 a, 1993 b, 1996,2000, \\
\text { Bernardo } 2007\end{array}$ \\
\hline CARO & ILHAS CAROLINA & - & TH & - & $\begin{array}{c}\text { Hanihara, 1993a, 1993b, 1996, 2000, } \\
\text { Bernardo } 2007\end{array}$ \\
\hline $\operatorname{COLB}^{\mathrm{a}}$ & COLOMBIA MUISCA & Muisca/Macusi & TH & - & $\begin{array}{c}\text { Hanihara, 1993a, 1993b, 1996, 2000, } \\
\text { Bernardo } 2007\end{array}$ \\
\hline PCOL & PALEOCOLOMBIANOS & $\begin{array}{l}\text { Paleoamericanos de } \\
\text { Sabana de Bogotá }\end{array}$ & WN & UNC & $\begin{array}{l}\text { Neves et al., 2007b; Bernardo et al., } \\
2011\end{array}$ \\
\hline COLA & COLOMBIANOS ARCAICOS & $\begin{array}{l}\text { Arcaicos da região de } \\
\text { Sabana de Bogotá, } \\
\text { Colômbia }\end{array}$ & WN & UNC & $\begin{array}{l}\text { Neves et al., 2007b; Bernardo et al., } \\
2011\end{array}$ \\
\hline DUAL & DUALA, CAMARÕES & $\begin{array}{l}\text { Nativos de macro- } \\
\text { língua Bantu de } \\
\text { Camarões }\end{array}$ & TH & - & $\begin{array}{c}\text { Hanihara, 1993a, 1993b, 1996, 2000, } \\
\text { Manica et al, 2007, Bernardo 2007, } \\
\text { Betti et al, 2009, 2010, Hubbe et al, } \\
2009\end{array}$ \\
\hline MLNL & $\begin{array}{l}\text { MALÁSIA TRANSIÇÃO } \\
\text { MESOLÍTICO-NEOLÍTICO }\end{array}$ & $\begin{array}{c}\text { Transição Mesolítico- } \\
\text { Neolítico }\end{array}$ & TH & - & $\begin{array}{c}\text { Hanihara, 1993a, 1993b, 1996, 2000, } \\
\text { Bernardo } 2007\end{array}$ \\
\hline GUIA & GUIANA & $\begin{array}{l}\text { Índios Macushi e } \\
\text { Wapishana }\end{array}$ & TH & - & $\begin{array}{c}\text { Hanihara, 1993a, 1993b, 1996, 2000, } \\
\text { Bernardo } 2007\end{array}$ \\
\hline BIBA & $\begin{array}{c}\text { BORNÉU, TRIBO IBAN, } \\
\text { MALÁSIA }\end{array}$ & $\begin{array}{l}\text { Tribo Iban (Dayak), } \\
\text { Imigrantes Novos }\end{array}$ & TH & - & $\begin{array}{c}\text { Hanihara, } 1993 a, 1993 b, 1996,2000, \\
\text { Bernardo } 2007\end{array}$ \\
\hline CING & CINGAPURA & Nativos recentes & TH & - & $\begin{array}{c}\text { Hanihara, 1993a, 1993b, 1996, 2000, } \\
\text { Manica et al, 2007, Bernardo 2007, } \\
\text { Betti et al, 2009, 2010, Hubbe et al, } \\
2009\end{array}$ \\
\hline UGAN & UGANDA & - & TH & - & $\begin{array}{c}\text { Hanihara, 1993a, 1993b, 1996, 2000, } \\
\text { Bernardo } 2007\end{array}$ \\
\hline MOLU & ILHAS MOLUCAS & - & TH & $\begin{array}{l}\mathrm{NMH}, \mathrm{NMNH}, \\
\text { AMNH }\end{array}$ & $\begin{array}{c}\text { Hanihara, 1993a, 1993b, 1996, 2000, } \\
\text { Manica et al, 2007, Bernardo 2007, } \\
\text { Betti et al, 2009, 2010, Hubbe et al, } \\
2009\end{array}$ \\
\hline MAAS $^{b}$ & MAASAI DO QUÊNIA & $\begin{array}{c}\text { Nativos da tribo } \\
\text { Maasai }\end{array}$ & TH & - & $\begin{array}{c}\text { Hanihara, 1993a, 1993b, 1996, 2000, } \\
\text { Manica et al, 2007, Bernardo 2007, } \\
\text { Betti et al, 2009, 2010, Hubbe et al, } \\
2009\end{array}$ \\
\hline
\end{tabular}


Continuação

\begin{tabular}{|c|c|c|c|c|c|}
\hline BPUN & $\begin{array}{c}\text { BORNÉU, TRIBO PUNAN, } \\
\text { MALÁSIA }\end{array}$ & $\begin{array}{c}\text { Tribos Punan e Murut } \\
\text { (Dayak), Imigrantes } \\
\text { antigos }\end{array}$ & $\mathrm{TH}$ & - & $\begin{array}{c}\text { Hanihara, 1993a, 1993b, 1996, 2000, } \\
\text { Bernardo } 2007\end{array}$ \\
\hline MARA & $\begin{array}{l}\text { CERAMISTAS } \\
\text { MARAJOARAS }\end{array}$ & $\begin{array}{l}\text { Ceramistas tardios, } \\
\text { Ilha de Marajó }\end{array}$ & WN & - & $\begin{array}{l}\text { Okumura, 2007; Neves et al., 2011; } \\
\text { Bernardo et al., } 2011\end{array}$ \\
\hline NOIR & $\begin{array}{l}\text { ILHAS MUSSAUS, NOVA } \\
\text { IRLANDA }\end{array}$ & - & TH & - & $\begin{array}{c}\text { Hanihara, } 1993 \mathrm{a}, 1993 \mathrm{~b}, 1996,2000, \\
\text { Bernardo } 2007\end{array}$ \\
\hline JAMB & JAMBI, SUMATRA & $\begin{array}{l}\text { Nativos recentes de } \\
\text { Jambi }\end{array}$ & TH & - & $\begin{array}{c}\text { Hanihara, } 1993 \mathrm{a}, 1993 \mathrm{~b}, 1996,2000, \\
\text { Bernardo } 2007\end{array}$ \\
\hline EQUA & EQUADOR & Quechua & TH & $\mathrm{NHM}, \mathrm{NMNH}$ & $\begin{array}{c}\text { Hanihara, } 1993 a, 1993 b, 1996,2000, \\
\text { Bernardo } 2007\end{array}$ \\
\hline GABA & GABÃO & - & TH & $\mathrm{NHM}, \mathrm{NMNH}$ & $\begin{array}{c}\text { Hanihara, 1993a, 1993b, 1996, 2000, } \\
\text { Manica et al, 2007, Bernardo 2007, } \\
\text { Betti et al, 2009, 2010, Hubbe et al, } \\
2009\end{array}$ \\
\hline CELB & CELEBES, TRIBO BIGI & Tribo Bigi & TH & - & $\begin{array}{c}\text { Hanihara, 1993a, 1993b, 1996, 2000, } \\
\text { Bernardo } 2007\end{array}$ \\
\hline HAYA & TANZÂNIA (HAYA) & $\begin{array}{c}\text { Tribos Haya e } \\
\text { Wagogo (tronco } \\
\text { linguístico Bantu) }\end{array}$ & TH & - & $\begin{array}{c}\text { Hanihara, 1993a, 1993b, 1996, 2000, } \\
\text { Manica et al, 2007, Bernardo 2007, } \\
\text { Betti et al, 2009, 2010, Hubbe et al, } \\
2009\end{array}$ \\
\hline NGLS & $\begin{array}{l}\text { PROVIÍNCIA SEPIK LESTE, } \\
\text { PAPUA NOVA GUINÉ }\end{array}$ & - & TH & - & $\begin{array}{c}\text { Hanihara, 1993a, 1993b, 1996, 2000, } \\
\text { Manica et al, 2007, Bernardo 2007, } \\
\text { Betti et al, 2009, 2010, Hubbe et al, } \\
2009\end{array}$ \\
\hline TNTH & $\begin{array}{c}\text { TENETEHARA DO NORTE } \\
\text { DO BRASIL }\end{array}$ & $\begin{array}{l}\text { Indígenas } \\
\text { atuais/subatuais de } \\
\text { língua Macro-Tupi }\end{array}$ & WN & MNUFRJ & $\begin{array}{l}\text { Atuí, 2005; Neves et al., 2011; } \\
\text { Bernardo et al., } 2011\end{array}$ \\
\hline TEIT & TEITA & - & WH & CAM & Howells (dados internet-Konigsberg) \\
\hline NGOS & $\begin{array}{l}\text { PROVÍNCIA SEPIK OESTE, } \\
\text { PAPUA NOVA GUINÉ }\end{array}$ & $\begin{array}{l}\text { Miscelânia Sepik } \\
\text { Ocidental }\end{array}$ & TH & - & $\begin{array}{c}\text { Hanihara, 1993a, 1993b, 1996, 2000, } \\
\text { Manica et al, 2007, Bernardo 2007, } \\
\text { Betti et al, 2009, 2010, Hubbe et al, } \\
2009\end{array}$ \\
\hline NOBR & NOVA BRETANHA (PAPUA) & - & TH & $\begin{array}{l}\text { SAM; AM; } \\
\text { NMNH }\end{array}$ & $\begin{array}{c}\text { Hanihara, 1993a, 1993b, 1996, 2000, } \\
\text { Bernardo } 2007\end{array}$ \\
\hline BISM & ILHAS BISMARCK & - & $\mathrm{TH}$ & - & $\begin{array}{c}\text { Hanihara, 1993a, 1993b, 1996, 2000, } \\
\text { Bernardo } 2007\end{array}$ \\
\hline TOLA & TOLAI & - & WH & AMNH & Howells (dados internet-Konigsberg) \\
\hline NGMA & $\begin{array}{l}\text { PROVÍNCIA MADANG DE } \\
\text { PAPUA NOVA GUINÉ }\end{array}$ & $\begin{array}{l}\text { Nativos de Vilarejos } \\
\text { da Baía de Astrolabe }\end{array}$ & TH & - & $\begin{array}{c}\text { Hanihara, 1993a, 1993b, 1996, 2000, } \\
\text { Manica et al, 2007, Bernardo 2007, } \\
\text { Betti et al, 2009, 2010, Hubbe et al, } \\
2009\end{array}$ \\
\hline PIGM & $\begin{array}{c}\text { CONGO (PIGMEUS TWA E } \\
\text { KIGERI) }\end{array}$ & $\begin{array}{l}\text { Nativos da tribo Twa } \\
\text { e Kigeri (Pigmeus) }\end{array}$ & TH & - & $\begin{array}{c}\text { Hanihara, 1993a, 1993b, 1996, 2000, } \\
\text { Bernardo } 2007\end{array}$ \\
\hline
\end{tabular}




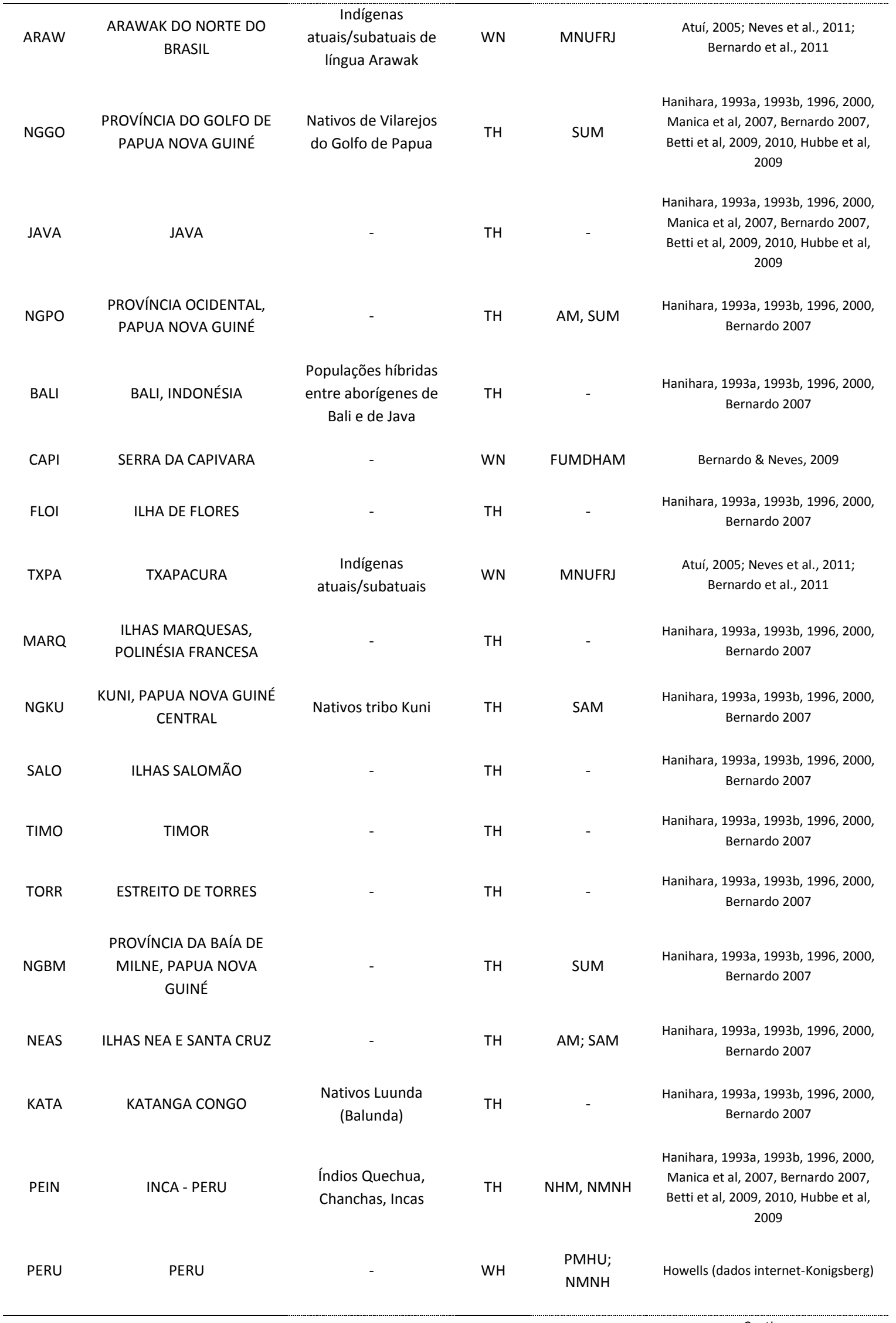


Continuação

\begin{tabular}{|c|c|c|c|c|c|}
\hline AUAR & AUSTRÁLIA ARNHEM & - & TH & - & $\begin{array}{l}\text { Hanihara, 1993a, 1993b, 1996, 2000, } \\
\text { Bernardo } 2007\end{array}$ \\
\hline NYAS & LAGO NYASA, MALAUÍ & $\begin{array}{l}\text { Nativos de língua } \\
\text { Bantu }\end{array}$ & $\mathrm{TH}$ & - & $\begin{array}{c}\text { Hanihara, } 1993 a, 1993 b, 1996,2000, \\
\text { Bernardo } 2007\end{array}$ \\
\hline KAMA & KAMAKÃ & $\begin{array}{l}\text { Indígenas } \\
\text { atuais/subatuais de } \\
\text { língua Macro-Jê } \\
\text { (Aimoré) }\end{array}$ & WN & MNUFRJ & $\begin{array}{l}\text { Atuí, 2005; Neves et al., 2011; } \\
\text { Bernardo et al., } 2011\end{array}$ \\
\hline MOÇA & MOÇAMBIQUE & - & TH & - & $\begin{array}{c}\text { Hanihara, 1993a, 1993b, 1996, 2000, } \\
\text { Bernardo } 2007\end{array}$ \\
\hline NOHE & $\begin{array}{c}\text { ILHA MALAKULA, NOVAS } \\
\text { HÉBRIDAS }\end{array}$ & - & TH & - & $\begin{array}{c}\text { Hanihara, 1993a, 1993b, 1996, 2000, } \\
\text { Bernardo } 2007\end{array}$ \\
\hline BORA & $\begin{array}{l}\text { BORA BORA, POLINÉSIA } \\
\text { FRANCESA }\end{array}$ & - & TH & - & $\begin{array}{c}\text { Hanihara, 1993a, 1993b, 1996, } 2000, \\
\text { Bernardo } 2007\end{array}$ \\
\hline $\mathrm{BBCE}$ & $\begin{array}{l}\text { BOTOCUDO DO BRASIL } \\
\text { CENTRAL }\end{array}$ & $\begin{array}{l}\text { Indígenas } \\
\text { atuais/subatuais de } \\
\text { língua Macro-Jê }\end{array}$ & WN & MNUFRJ & $\begin{array}{l}\text { Atuí, 2005; Neves et al., 2011; } \\
\text { Bernardo et al., } 2011\end{array}$ \\
\hline BOLI & BOLÍVIA & Aymara & TH & - & $\begin{array}{c}\text { Hanihara, 1993a, 1993b, 1996, 2000, } \\
\text { Bernardo } 2007\end{array}$ \\
\hline FIJI & ILHAS FIJI & - & TH & SAM; AM & $\begin{array}{c}\text { Hanihara, 1993a, 1993b, 1996, 2000, } \\
\text { Bernardo } 2007\end{array}$ \\
\hline ZAMB & ZAMBIA & - & TH & - & $\begin{array}{c}\text { Hanihara, 1993a, 1993b, 1996, 2000, } \\
\text { Bernardo } 2007\end{array}$ \\
\hline LSAN & LAGOA SANTA & $\begin{array}{l}\text { Paleoamericanos de } \\
\text { Lagoa Santa }\end{array}$ & DB & LEEH & - \\
\hline NOCA & NOVA CALEDÔNIA & - & TH & - & $\begin{array}{c}\text { Hanihara, 1993a, 1993b, 1996, 2000, } \\
\text { Bernardo } 2007\end{array}$ \\
\hline AUQL & AUSTRÁLIA QUEENSLAND & - & TH & - & $\begin{array}{c}\text { Hanihara, 1993a, 1993b, 1996, 2000, } \\
\text { Manica et al, 2007, Bernardo 2007, } \\
\text { Betti et al, 2009, 2010, Hubbe et al, } \\
2009\end{array}$ \\
\hline MAOR & $\begin{array}{c}\text { MAORI NOVA } \\
\text { ZELÂNDIA/SAMOA }\end{array}$ & Tribo Maori & TH & $\begin{array}{l}\text { SUM, SAM, } \\
\text { NMNH }\end{array}$ & $\begin{array}{c}\text { Hanihara, 1993a, 1993b, 1996, 2000, } \\
\text { Bernardo } 2007\end{array}$ \\
\hline COOK & MANGAIA, ILHAS COOK & $\begin{array}{l}\text { Pré-históricos de } \\
\text { Mangaia }\end{array}$ & TH & - & $\begin{array}{c}\text { Hanihara, 1993a, 1993b, 1996, 2000, } \\
\text { Bernardo } 2007\end{array}$ \\
\hline TUPI & $\begin{array}{c}\text { TUPIGUARANI DO } \\
\text { SUDESTE DO BRASIL (SÃO } \\
\text { PAULO) }\end{array}$ & $\begin{array}{l}\text { Ceramista } \\
\text { Tupiguarani, interior } \\
\text { de São Paulo }\end{array}$ & MO & MAEUSP & $\begin{array}{l}\text { Okumura, 2007; Neves et al., 2011; } \\
\text { Bernardo et al., } 2011\end{array}$ \\
\hline SANP & SAN PEDRO DE ATACAMA & $\begin{array}{l}\text { População de sítios da } \\
\text { região de San Pedro } \\
\text { de Atacama, de } \\
\text { diferentes períodos }\end{array}$ & DB & IIARMPGLP & - \\
\hline AUNO & AUSTRÁLIA NOROESTE & - & TH & - & $\begin{array}{c}\text { Hanihara, } 1993 a, 1993 b, 1996,2000, \\
\text { Bernardo } 2007\end{array}$ \\
\hline
\end{tabular}




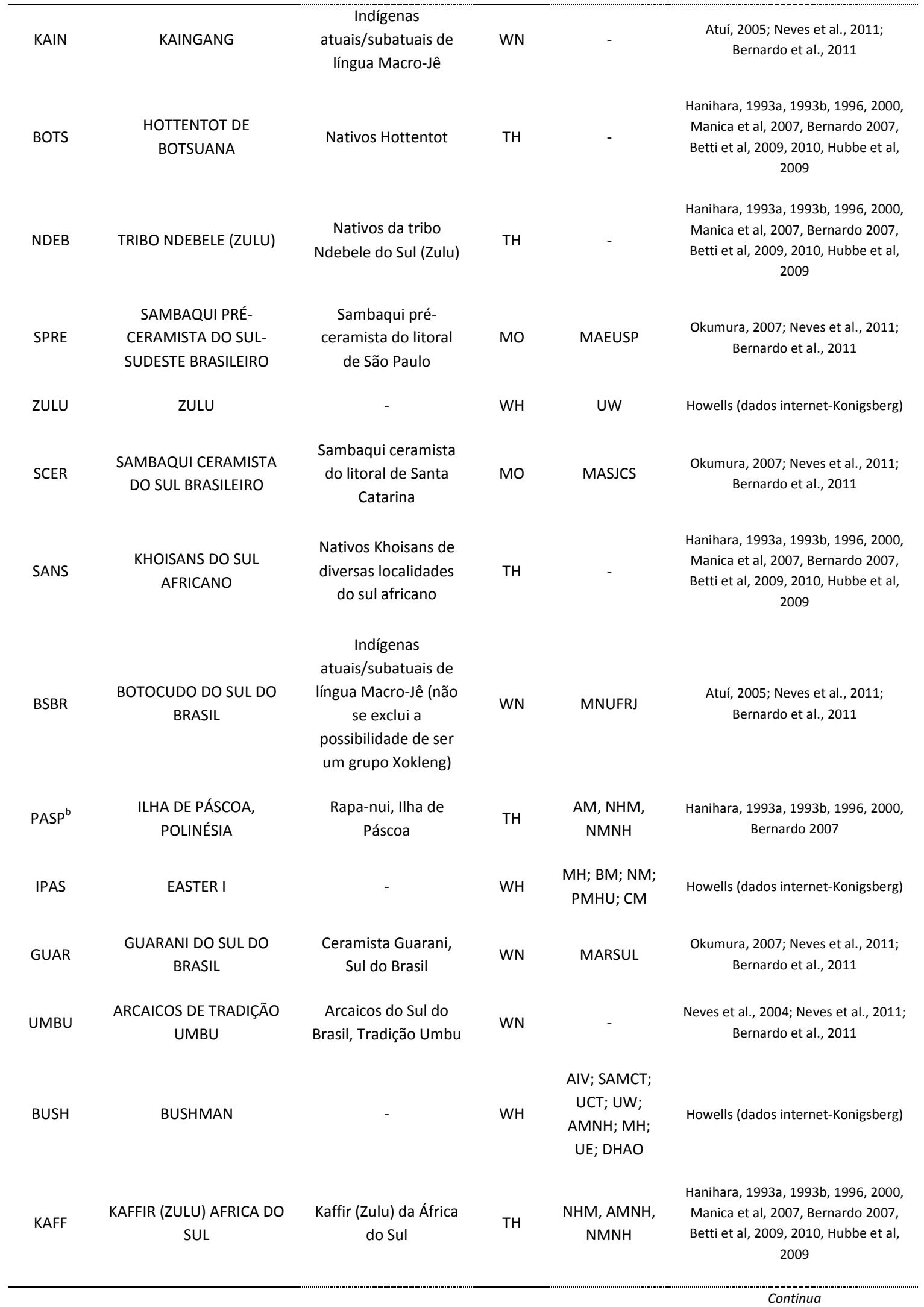




\begin{tabular}{|c|c|c|c|c|c|}
\hline BSHM & $\begin{array}{l}\text { BUSHMAN SUL- } \\
\text { AFRICANOS }\end{array}$ & $\begin{array}{l}\text { Bushman sul- } \\
\text { africanos }\end{array}$ & TH & & $\begin{array}{c}\text { Hanihara, 1993a, 1993b, 1996, 2000, } \\
\text { Manica et al, 2007, Bernardo 2007, } \\
\text { Betti et al, 2009, 2010, Hubbe et al, } \\
2009\end{array}$ \\
\hline AUMR & $\begin{array}{c}\text { AUSTRÁLIA MURRAY } \\
\text { RIVER }\end{array}$ & - & TH & SAM & $\begin{array}{c}\text { Hanihara, } 1993 a, 1993 b, 1996,2000, \\
\text { Bernardo } 2007\end{array}$ \\
\hline AUNS & $\begin{array}{c}\text { AUSTRÁLIA NEW SOUTH } \\
\text { WALES }\end{array}$ & - & TH & AMS & $\begin{array}{c}\text { Hanihara, 1993a, 1993b, 1996, 2000, } \\
\text { Manica et al, 2007, Bernardo 2007, } \\
\text { Betti et al, 2009, 2010, Hubbe et al, } \\
2009\end{array}$ \\
\hline AUST & AUSTRALIA & - & WH & SAM & Howells (dados internet-Konigsberg) \\
\hline AUSS $^{b}$ & AUSTRÁLIA SUL & - & TH & SAM & $\begin{array}{c}\text { Hanihara, 1993a, 1993b, 1996, 2000, } \\
\text { Manica et al, 2007, Bernardo 2007, } \\
\text { Betti et al, 2009, 2010, Hubbe et al, } \\
2009\end{array}$ \\
\hline AUVI & AUSTRÁLIA VICTÓRIA & - & TH & - & $\begin{array}{c}\text { Hanihara, 1993a, 1993b, 1996, 2000, } \\
\text { Bernardo } 2007\end{array}$ \\
\hline CHIL & CHILE & $\begin{array}{l}\text { Mapuche } \\
\text { (Araucanianos) e } \\
\text { Alacaluf }\end{array}$ & TH & - & $\begin{array}{c}\text { Hanihara, 1993a, 1993b, 1996, 2000, } \\
\text { Manica et al, 2007, Bernardo 2007, } \\
\text { Betti et al, 2009, 2010, Hubbe et al, } \\
2009\end{array}$ \\
\hline $\mathrm{MAON}^{\mathrm{c}}$ & MAORI NORTE & - & WH & - & Howells (dados internet-Konigsberg) \\
\hline TAAU $^{\mathrm{b}}$ & TASMÂNIA, AUSTRÁLIA & - & TH & - & $\begin{array}{c}\text { Hanihara, 1993a, 1993b, 1996, 2000, } \\
\text { Bernardo } 2007\end{array}$ \\
\hline TASM & TASMANIA & - & WH & $\begin{array}{c}\text { TM; QVM; } \\
\text { SAM; UM; } \\
\text { NMM; MH; } \\
\text { BM; OU; } \\
\text { CAM; UE; } \\
\text { RSM; AMNH; } \\
\text { FM; NM }\end{array}$ & Howells (dados internet-Konigsberg) \\
\hline MORI & MORIORI & - & WH & $\begin{array}{l}\text { BM; UOMS; } \\
\text { CM; AM }\end{array}$ & Howells (dados internet-Konigsberg) \\
\hline $\mathrm{CHAT}^{\mathrm{b}}$ & $\begin{array}{l}\text { ILHAS CHATHAM, } \\
\text { POLINÉSIA }\end{array}$ & Moriori & TH & $\begin{array}{l}\text { AM, SUM, } \\
\text { SAM }\end{array}$ & $\begin{array}{c}\text { Hanihara, } 1993 a, 1993 b, 1996,2000, \\
\text { Bernardo } 2007\end{array}$ \\
\hline MAOS $^{\mathrm{c}}$ & MAORI SUL & - & WH & - & Howells (dados internet-Konigsberg) \\
\hline FUEG & $\begin{array}{l}\text { FUEGUINOS } \\
\text { PATAGÔNICOS }\end{array}$ & $\begin{array}{l}\text { Indios Yaghan, Ona, } \\
\text { Haush e Alacafuf }\end{array}$ & TH & $\begin{array}{l}\text { NHM, CAM, } \\
\text { AMNH, } \\
\text { NMNH }\end{array}$ & $\begin{array}{c}\text { Hanihara, 1993a, 1993b, 1996, 2000, } \\
\text { Manica et al, 2007, Bernardo 2007, } \\
\text { Betti et al, 2009, 2010, Hubbe et al, } \\
2009\end{array}$ \\
\hline PAIK & $991-773$ & $\begin{array}{l}\text { Paleoamericano do } \\
\text { sul do Chile }\end{array}$ & WN & AMNH & Neves et al., 1999 \\
\hline $\mathrm{AFLE}^{\mathrm{d}}$ & $\begin{array}{l}\text { LESTE AFRICANO, SEM } \\
\text { CONTEXTO }\end{array}$ & - & TH & - & $\begin{array}{c}\text { Hanihara, 1993a, 1993b, 1996, 2000, } \\
\text { Bernardo } 2007\end{array}$ \\
\hline $\mathrm{AFOE}^{\mathrm{d}}$ & $\begin{array}{l}\text { OESTE AFRICANO, SEM } \\
\text { CONTEXTO }\end{array}$ & - & TH & NMNH & $\begin{array}{c}\text { Hanihara, } 1993 a, 1993 b, 1996,2000, \\
\text { Bernardo } 2007\end{array}$ \\
\hline
\end{tabular}


Continuação

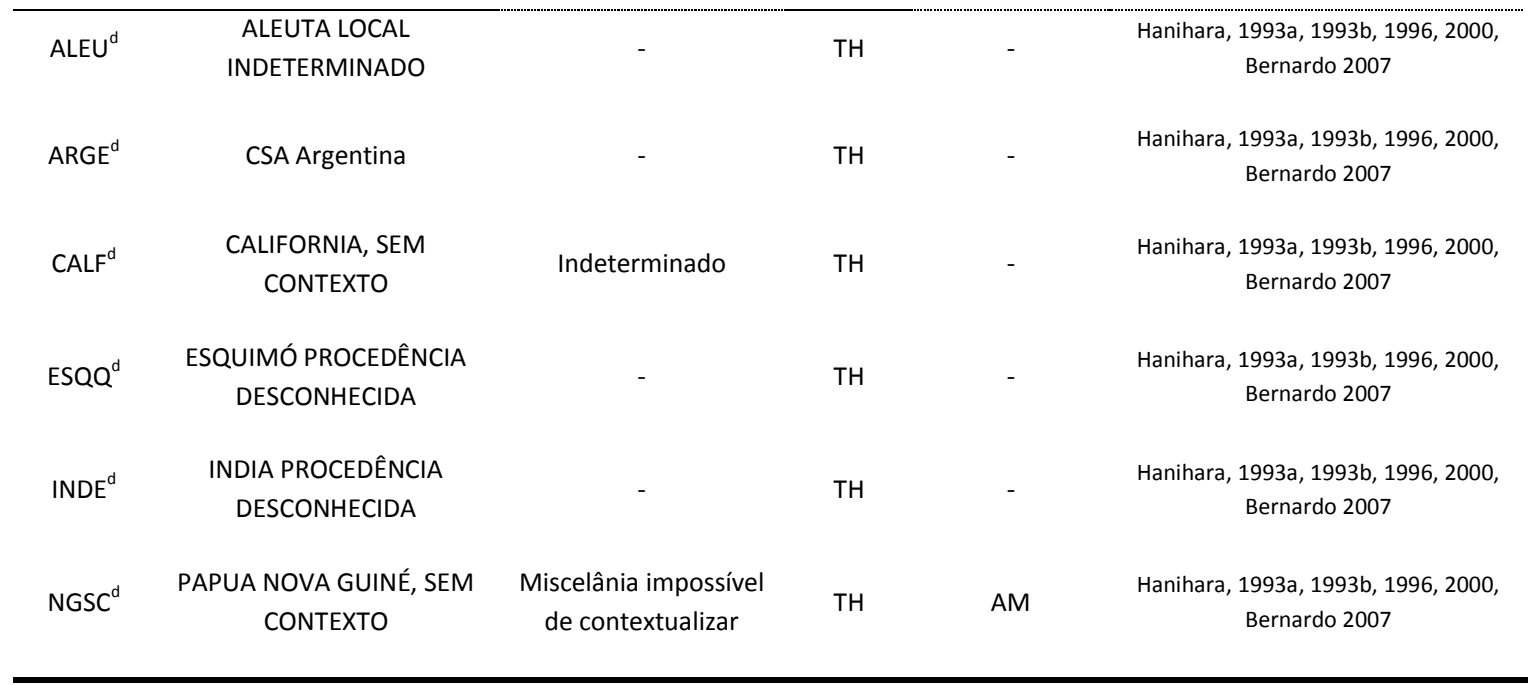

série desclassificada devido a impossibilidade de se diferenciar da similar do banco WN serie desclassficada devido a impossibilade de se derencir da similar do banco WH série desclassificada devido a insuficiência de dados etnográficos

banco de dados consolidado por Tsuneiko Hanihar

banco de dados consolidado por Walter Neves/LEEH

banco de dados consolidado por Mercedes OKUmUra/LEEH

banco de dados agregado por Danilo Bernardo/LEEH

Anthropological Institute, Copenhagen

Instituto Anatômico, Universidade de Oslo

Anthropological Institute, Viena
Anthropological Laboratory, University of Copenhagen

Auckland Museum

American Museum of Natural History

Bernice Bishop Museum, Taiwan

British Museum

Centro de Arqueologia Annete Laming Emperaire, Lagoa Santa

Duckworth Laboratory for Physical Anthropology, Universidade de Cambridge

Canterbury Museum

Department of Human Anatomy, Oxford University

Fundação Museu do Homem Americano, São Raimundo Nonato, Piaul

Faculty of Medicine, Hokkaido University, Sapporo

Institute of Ethnography, Academy of Science, Leningrado

Instituto Histórico Geográfico Brasileiro, Rio de Janeiro
Instituto de Investigaçoes Arqueológicas e Museu Padre Gustavo Le Paige, Universidade Católica do Norte, Chile

Kyushu University, Fukuoka

Humanos, Instituto de Biociências, Universidade de São Paulo, São Paul

Maria

Museu de Arqueogi

Museu Arqueológico do Rio Grande do Sul

Museu Arqueológico de Sambaqui de Joinvil

Musée de l'Homme, Paris

Museu de História Natural e Jardim Botânico da Universidade Federal de Minas Gerais, Belo Horizonte

Museu do Homem do Sambaqui Pe. João Alfredo Roh

Museum of Natural History University of Kansas

Museu Nacional da Universidade Federal do Rio de Janeiro, Rio de Janeiro

Medical School, University of Phillippines, Manil

Museu de Historia Natural, Londres

Museu de História Natural, Busapeste

ationstoris

Nefing

National Taiwan University, Taipei, Taiwan

Oxford University

Peabody Museum, Harvard University

Queen Victoria Museum

Royal Scotish Museum

South Australiam Museum, Adelaide

South African Museum, Cape Town

Tasmanian Museum

University of Cape Town

University of Edinburgh

University Museum University of Tokyo

Universidad Nacional University of Tor

Universidade Estadual de Santa Cata

University of Otago Medical School.

U. S. National Museum, Washington

Universidade de Witwatersrand

Museu de Zoologia da Universidade de Copenhagem

Australian Museum, Sydney 


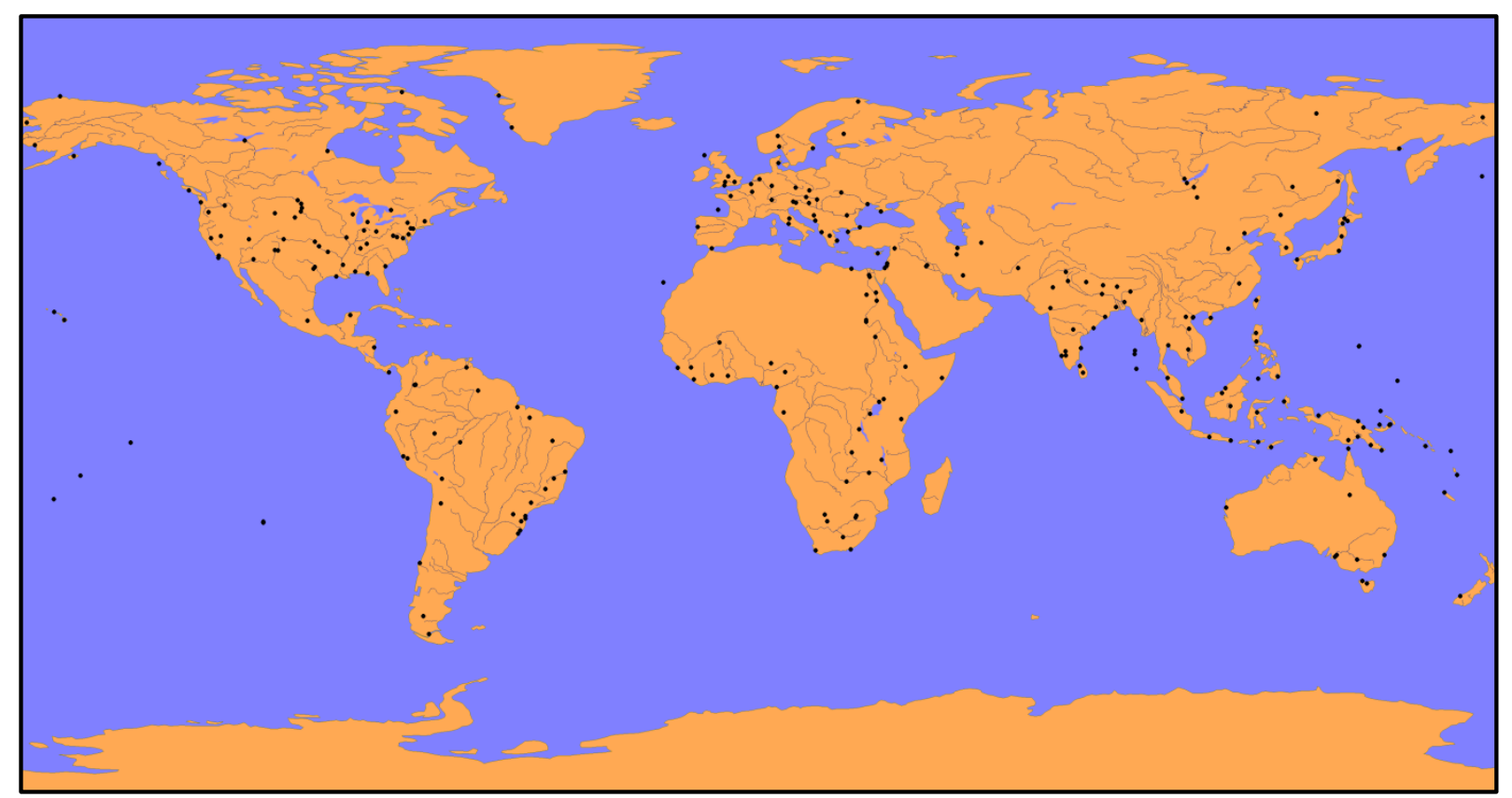

Fig. 3.8 - Distribuição geográfica das 309 séries amostradas.

Conforme antecipado no início da descrição do processo de consolidação do banco de dados, existem incompatibilidades entre parte das variáveis craniométricas que compõe cada uma das bases utilizadas, apesar da fundamentação técnica antropométrica comum aos diferentes "bancos fonte". Dessa forma, somente as variáveis tomadas em acordo com o estabelecido pelo protocolo Howells (1973) permaneceram no banco de dados. Como já pôde ser depreendido a partir da leitura deste capítulo, tal desarranjo atingiu de maneira dramática apenas o banco Hanihara, o qual manteve, das 45 medidas por ele coletadas, apenas 26 variáveis craniométricas. Dessas 26 variáveis, duas não são tomadas por W. Neves e colaboradores, reduzindo, assim, o banco de dados final a 24 medidas.

Tal procedimento promoveu a exposição de um problema comum aos bancos de dados gerados a partir de remanescentes ósseos de origem arqueológica (Bernardo \& Neves, 2009), já citado neste texto: a ocorrência de "missing values". Embora as técnicas estatísticas multivariadas apresentem soluções adequadas e satisfatoriamente eficazes para a eliminação das lacunas de dados, como substituição através de regressão linear múltipla (Little, 1992) ou substituição pela média (Mundfrom \& Whitcomb, 1998), por exemplo, muito ainda se discute 
em relação ao viés imposto aos dados por essas técnicas, afetando, principalmente, sua estrutura de covariação (Donner, 1982; Jones, 1996; Mundfrom \& Whitcomb, 1998; Brokmeier et al., 2003).

Assim, dado o objetivo de não impor nenhum viés aos dados e considerando-se a amplitude numérica efetiva do banco de dados gerado para esta pesquisa, adotou-se a estratégia de eliminar os "missing values" não através de sua substituição mas sim através da exclusão dos indivíduos portadores de valores faltantes.

De maneira semelhante, outra precaução normalmente adotada para otimizar a eficiência das estimativas baseadas nas covariâncias entre as medidas lineares analisadas, é a eliminação de grupos, séries ou populações, que contenham pequeno número de indivíduos. Essa necessidade ocorre uma vez que o cálculo de covariância matricial de um número de casos, ou amostras, menor do que a dimensão, ou o número de variáveis, da matriz, resulta em uma matriz singular, não inversível ${ }^{22}$, o que inviabiliza sua utilização como classificador (Sokhal \& Rohlf, 2012). Assim, séries com menos do que 24 indivíduos foram excluídas do banco de dados, salvo em caso de grupos que apresentem destacada qualificação históricobiológica fundamental para determinada modelagem ou compreensão de eventos da dispersão humana global.

Finalmente, após o levantamento de, ao menos, uma quantidade mínima de informações geográficas e cronológicas de cada população, passou-se ao passo seguinte, que consistiu em procurar através do Google earth ${ }^{\circledR}$ (2011) o melhor (ou mais aproximado) par de coordenadas geográficas para posicioná-la. A mesma lógica operatória foi utilizada para a atribuição da faixa cronológica da amostra, a partir da busca por datações dos espécimes, sítios arqueológicos, períodos culturais e históricos de povoamento que oferecessem bons marcadores da profundidade temporal de cada série do banco de dados. Esse processo de

\footnotetext{
${ }^{32}$ Há, entretanto, a possibilidade de se usar a generalização de Moore-Penrose para a inversão generalizada de matrizes. Embora matematicamente possível, não deixa de ser uma quebra na premissa de singularidade para uso de matrizes como classificadores. Dessa maneira, a generalização será usada neste trabalho apenas em casos de necessidade absoluta em não abrir mão de determinada amostra.
} 
formação do banco de dados resultou, então, em um conjunto final de dados contendo 9287 indivíduos, ou crânios, cuja morfologia é representada por 24 medidas craniométricas lineares, distribuídos em 161 séries. A Tabela 3.2 apresenta a sigla e a denominação de cada série, bem como suas coordenadas geográficas, datação putativa e número de indivíduos que compõe o grupo (números total, masculino e feminino). As séries estão dispostas nesta tabela seguindo a ordem de distância ao ponto de origem africana (DOA), hipoteticamente localizado na Etiópia. Essa região foi escolhida como ponto de partida uma vez que os remanescentes ósseos humanos mais antigos já encontrados, datados de 195 mil anos A. P., o foram na região de Kibish, sul da Etiópia (McDougall et al., 2005) conferindo ao local a condição de "berço da humanidade" (Stringer, 2003). Todas as análises a seguir apresentarão as séries dispostas nesta mesma ordem, mesmo quando a investigação utilizar apenas uma parcela desses dados. As mesmas populações contidas na Tabela 3.2 estão representadas no mapa-múndi da Figura 3.9.

Tabela 3.2 - Informações primárias sobre as populações constituintes do banco de dados consolidado.

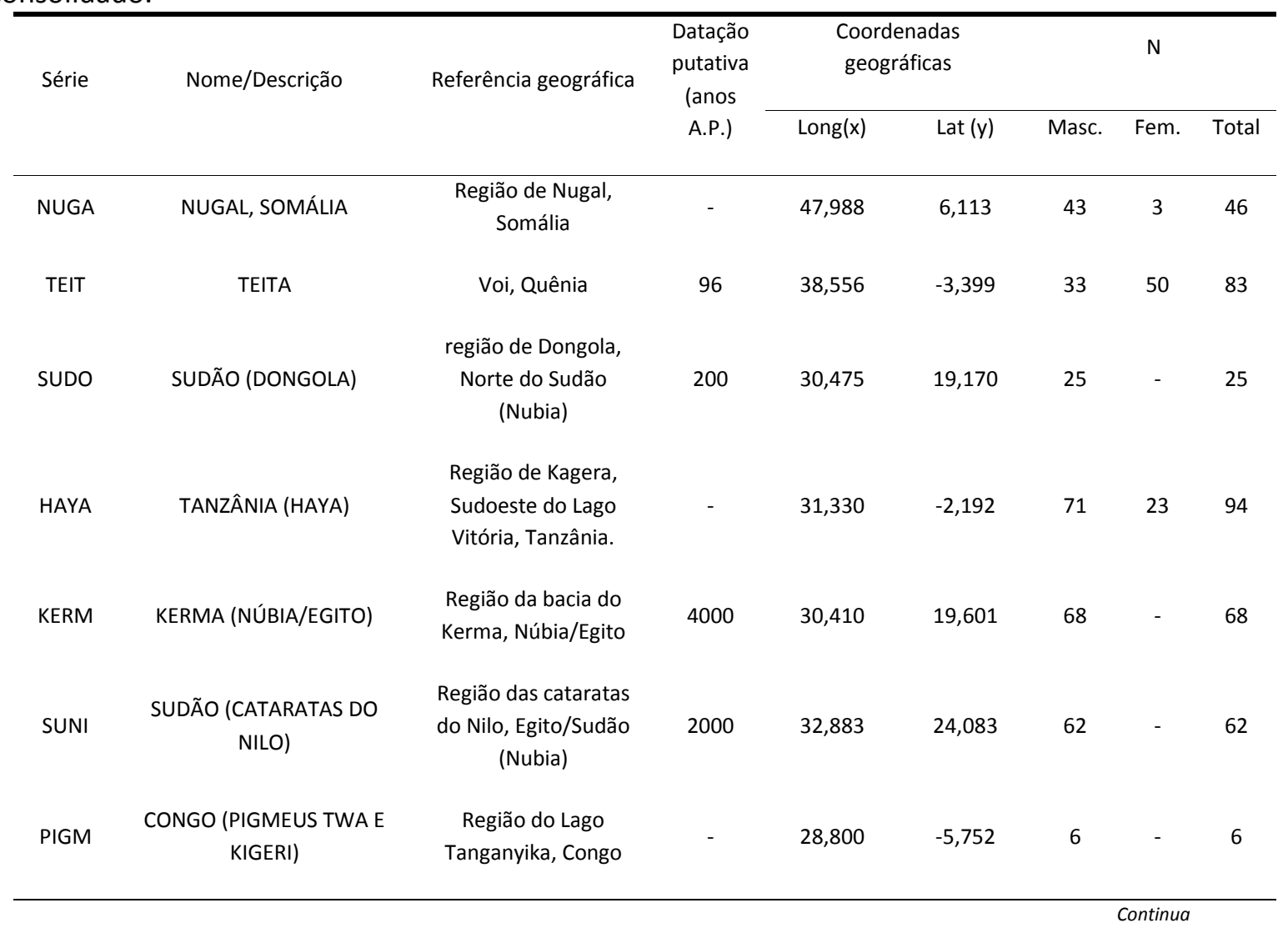




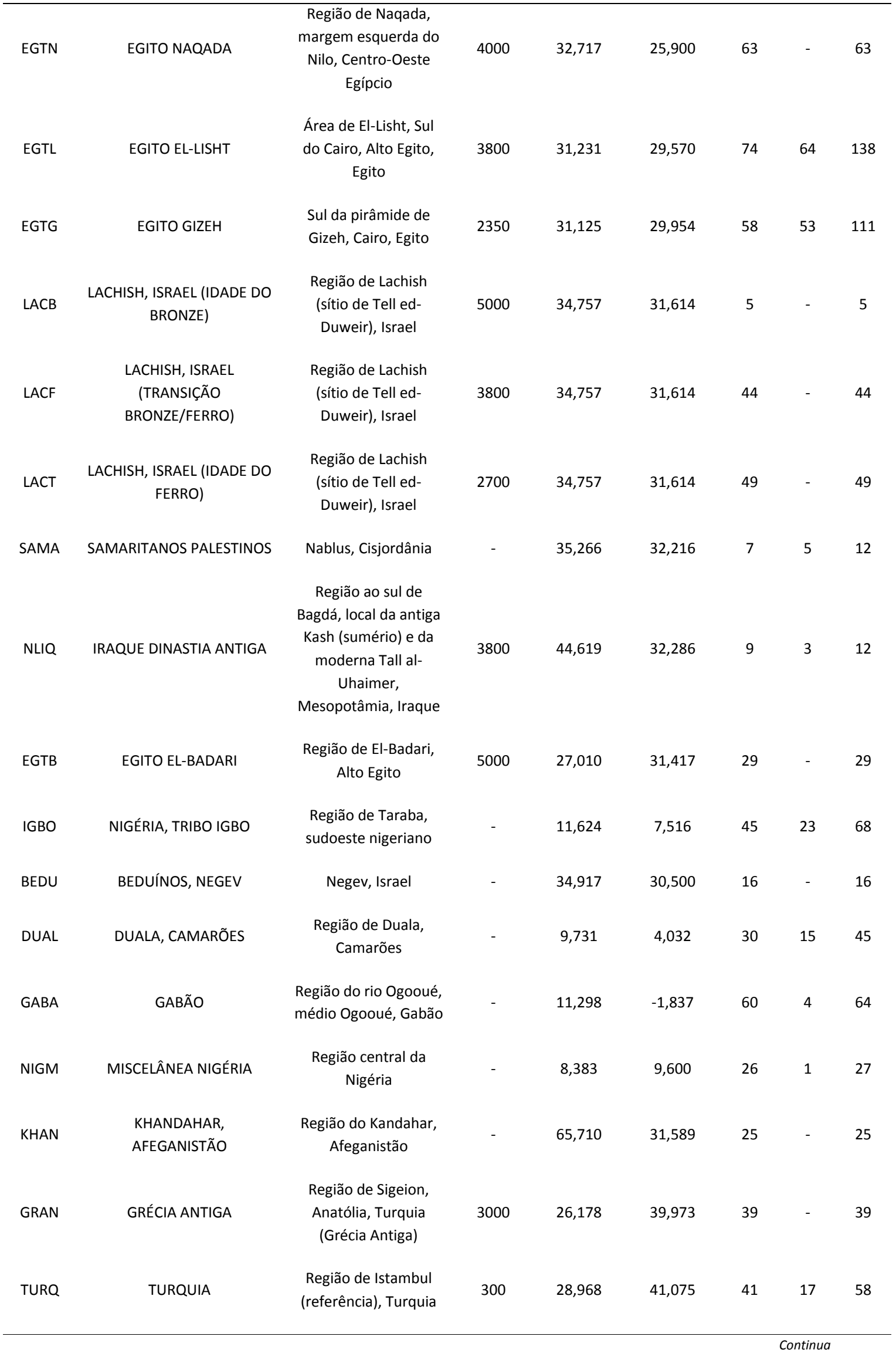




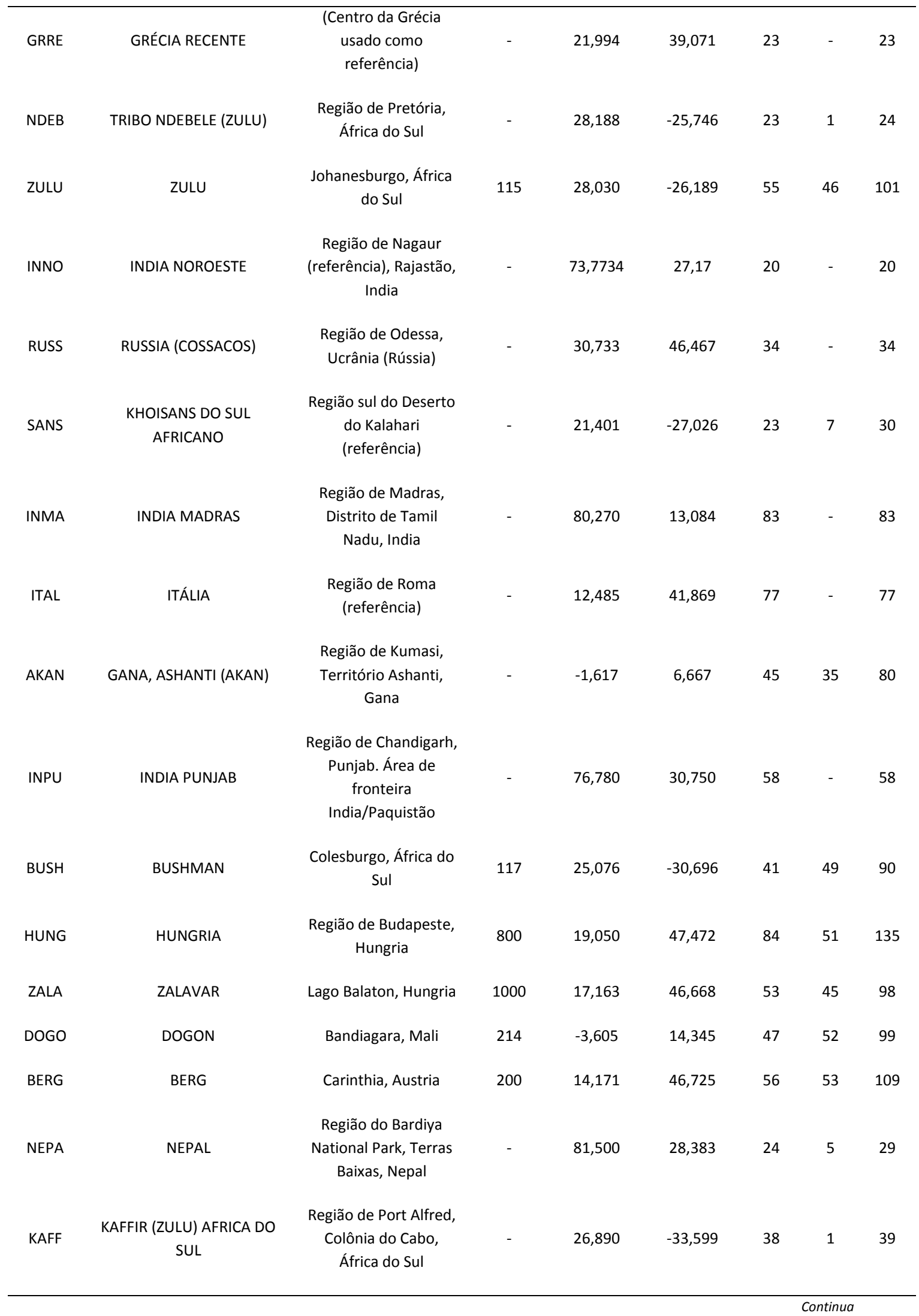




\begin{tabular}{|c|c|c|c|c|c|c|c|c|}
\hline COST & COSTA DO MARFIM & $\begin{array}{c}\text { Região de } \\
\text { Yamoussoukro, Costa } \\
\text { do Marfim }\end{array}$ & - & $-5,283$ & 6,817 & 21 & - & 21 \\
\hline MORA & MORÁVIA & $\begin{array}{l}\text { Região de Olomouc, } \\
\text { Morávia, República } \\
\text { Checa }\end{array}$ & - & 17,251 & 49,594 & 78 & 32 & 110 \\
\hline NLRC & NEOLÍTICO - REGIÃO CHECA & $\begin{array}{c}\text { Stradonice, Distrito de } \\
\text { Kladno, República } \\
\text { Checa }\end{array}$ & 4500 & 14,046 & 50,291 & 4 & - & 4 \\
\hline SUIC & SUIÇA & Região de Zurique & - & 8,533 & 47,378 & 35 & 21 & 56 \\
\hline BSHM & BUSHMAN SUL-AFRICANOS & $\begin{array}{l}\text { Região próxima à } \\
\text { cidade do Cabo } \\
\text { (referência) }\end{array}$ & - & 18,695 & $-33,825$ & 22 & 4 & 26 \\
\hline TIBE & TIBET & $\begin{array}{c}\text { Região de Bhaktapur, } \\
\text { Vale do Khatmandu, } \\
\text { Nepal }\end{array}$ & 150 & 85,417 & 27,667 & 49 & 11 & 60 \\
\hline ALEH & ALEMANHA (HESSIAN) & $\begin{array}{l}\text { Região de Hesse, } \\
\text { Alemanha }\end{array}$ & 200 & 8,591 & 50,666 & 64 & 10 & 74 \\
\hline ESPH & ESPANHA PRÉ-HISTÓRICO & $\begin{array}{l}\text { Caverna Genista 3, } \\
\text { Região de Granada, } \\
\text { Gibraltar, Espanha }\end{array}$ & 10000 & $-5,350$ & 36,193 & 3 & - & 3 \\
\hline INBE & INDIA BENGALA & $\begin{array}{l}\text { Região de Dhaka } \\
\text { (Bangladesh) }\end{array}$ & - & 90,375 & 23,700 & 46 & 23 & 69 \\
\hline HOLA & HOLANDA & $\begin{array}{c}\text { (Centro da Holanda } \\
\text { usado como } \\
\text { referência) }\end{array}$ & - & 5,689 & 52,232 & 30 & 2 & 32 \\
\hline ESBA & ESPANHA (BASCOS) & $\begin{array}{c}\text { Região do Golfo da } \\
\text { Biscaia, País Basco, } \\
\text { Espanha }\end{array}$ & - & $-3,908$ & 45,091 & 10 & - & 10 \\
\hline FRAB & $\begin{array}{l}\text { FRANCESES BAIXA } \\
\text { BRETANHA }\end{array}$ & $\begin{array}{l}\text { Região da Baixa } \\
\text { Bretanha, França }\end{array}$ & 210 & $-0,993$ & 48,269 & 45 & - & 45 \\
\hline ANDA & ANDAMAN & $\begin{array}{c}\text { Port Blair, Ilhas } \\
\text { Andamão e Nicobar }\end{array}$ & 127 & 92,744 & 11,667 & 35 & 35 & 70 \\
\hline SUEM & SUÉCIA & $\begin{array}{l}\text { Cemitério Medieval, } \\
\text { Região de Estocolmo, } \\
\text { Suécia }\end{array}$ & 1000 & 18,067 & 59,350 & 26 & - & 26 \\
\hline SPIM & $\begin{array}{c}\text { SPITALFIELDS GRÃ- } \\
\text { BRETANHA SÉCULOS 16-17 }\end{array}$ & $\begin{array}{l}\text { Spitalfields, Grã- } \\
\text { Bretanha }\end{array}$ & 400 & $-0,075$ & 51,517 & 57 & 12 & 69 \\
\hline SPIV & $\begin{array}{c}\text { SPITALFIELDS GRÃ- } \\
\text { BRETANHA ERA VITORIANA }\end{array}$ & $\begin{array}{l}\text { Spitalfields, Grã- } \\
\text { Bretanha }\end{array}$ & 150 & $-0,075$ & 51,517 & 44 & 49 & 93 \\
\hline BIRM & BIRMÂNIA & $\begin{array}{l}\text { Território Rakhine, } \\
\text { Mianmar (Birmânia) }\end{array}$ & - & 94,320 & 19,534 & 70 & 3 & 73 \\
\hline
\end{tabular}




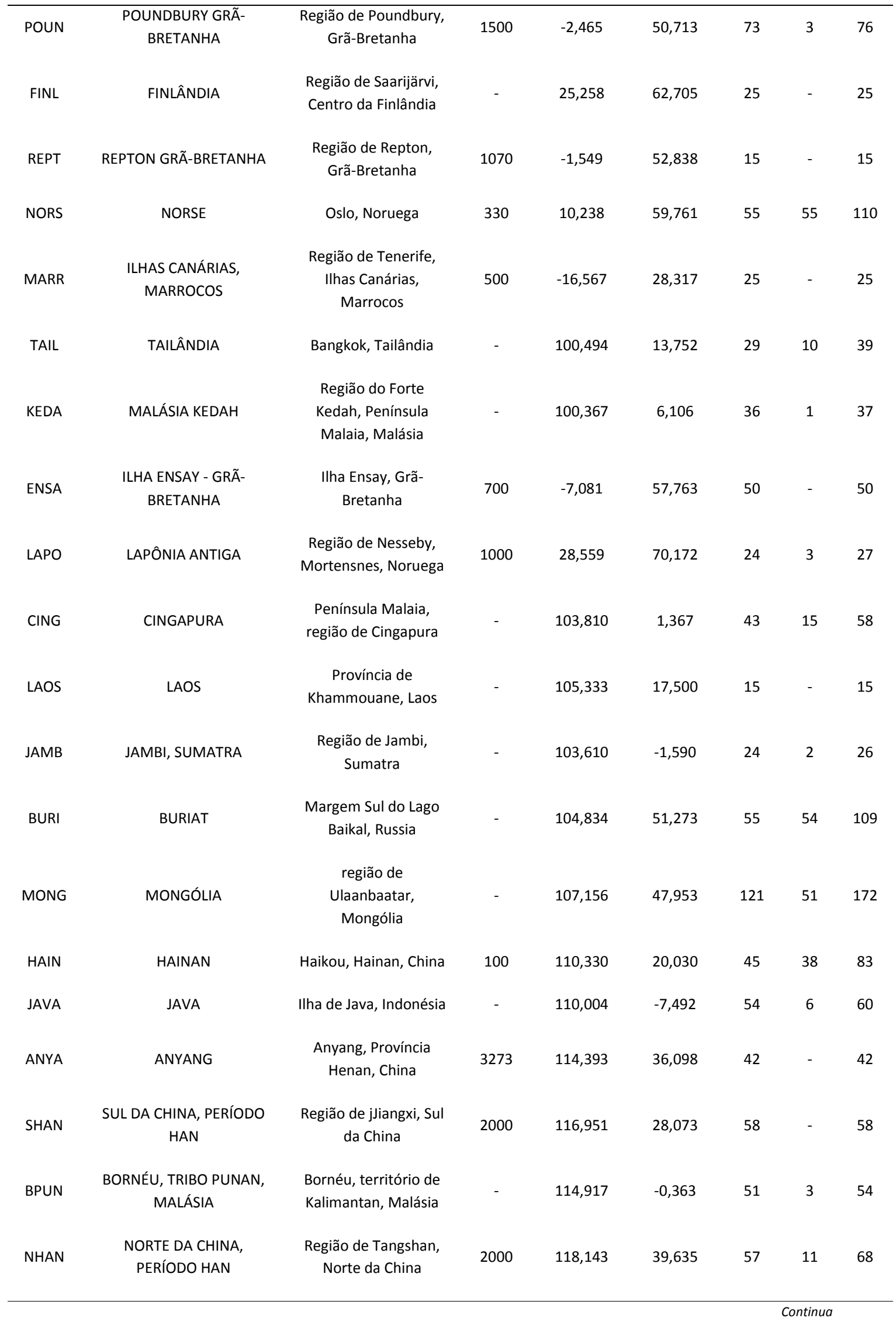


Continuação

\begin{tabular}{|c|c|c|c|c|c|c|c|c|}
\hline ATAY & ATAYAL & Taiwan, China & 20 & 120,941 & 24,095 & 29 & 18 & 47 \\
\hline AETA & $\begin{array}{l}\text { TRIBO AETA, NEGRITOS } \\
\text { DAS FILIPINAS }\end{array}$ & $\begin{array}{c}\text { Região das } \\
\text { Montanhas de Luzon, } \\
\text { Filipinas }\end{array}$ & - & 120,897 & 16,595 & 21 & 7 & 28 \\
\hline FLIP & FILIPINAS & $\begin{array}{l}\text { Baía de Tumon, } \\
\text { Manila, Filipinas }\end{array}$ & 20 & 120,984 & 14,6 & 50 & - & 50 \\
\hline NMAN & $\begin{array}{c}\text { NORTE DA } \\
\text { CHINA/MANCHÚRIA }\end{array}$ & $\begin{array}{l}\text { Região de Jilin, } \\
\text { Manchuria, China }\end{array}$ & 100 & 126,55 & 43,867 & 40 & - & 40 \\
\hline AMUR & AMUR (RUSSIA/CHINA) & $\begin{array}{c}\text { Região da bacia do } \\
\text { baixo/médio Amur, } \\
\text { Russia/China }\end{array}$ & - & 129,329 & 50,438 & 8 & - & 8 \\
\hline ALND & ALASCA NA-DENE & $\begin{array}{c}\text { Região do Forte } \\
\text { McPherson, Território } \\
\text { do Norte/Alaska }\end{array}$ & - & $-134,882$ & 67,435 & 34 & 22 & 56 \\
\hline SJAP & SUL DO JAPÃO & $\begin{array}{l}\text { Norte de Kyushu, } \\
\text { Japão }\end{array}$ & 80 & 130,401 & 33,59 & 50 & 41 & 91 \\
\hline NLO & $\begin{array}{c}\text { NEOLÍTICO - JOMON, } \\
\text { JAPÃO }\end{array}$ & $\begin{array}{l}\text { Região de Usujiricho, } \\
\text { Hokkaido, Japão }\end{array}$ & 6000 & 140,949 & 41,93 & 4 & 1 & 5 \\
\hline NJAP & NORTE DO JAPÃO & $\begin{array}{l}\text { Sapporo, Hokkaido, } \\
\text { Japão }\end{array}$ & 50 & 141,354 & 43,062 & 55 & 32 & 87 \\
\hline JPTH & JAPÃO - TOHOKU & $\begin{array}{l}\text { Distrito de Tohoku, } \\
\text { Japão }\end{array}$ & 100 & 140,683 & 38,9 & 73 & 39 & 112 \\
\hline AINU & AINU & $\begin{array}{l}\text { Província de Hidaka, } \\
\text { Hokkaido, Japão }\end{array}$ & 80 & 142,07 & 42,481 & 48 & 38 & 86 \\
\hline JPTK & JAPÃO - TOKYO & $\begin{array}{c}\text { Região de } \\
\text { Tokyo/Chiba, Distrito } \\
\text { Honshu, Japão }\end{array}$ & 100 & 140,1 & 35,6 & 40 & - & 40 \\
\hline YAKU & YAKUT & $\begin{array}{l}\text { Região do golfo de } \\
\text { Tauisk, Mar de } \\
\text { Okhotsk }\end{array}$ & - & 154,046 & 59,258 & 4 & - & 4 \\
\hline NGLS & $\begin{array}{l}\text { PROVÍNCIA SEPIK LESTE, } \\
\text { PAPUA NOVA GUINÉ }\end{array}$ & $\begin{array}{c}\text { Região da Baía } \\
\text { Cenderawasih (Baía } \\
\text { de Gelvink), Prvíncia } \\
\text { Sepik Oriental, Papua } \\
\text { Nova Guiné }\end{array}$ & - & 135,318 & $-2,53$ & 26 & 22 & 48 \\
\hline CHUK & $\mathrm{CHUKCHI}$ & $\begin{array}{c}\text { Região do Rio Belaya, } \\
\text { Península Chukotka, } \\
\text { Sibéria }\end{array}$ & - & 173,417 & 66,5 & 18 & 2 & 20 \\
\hline GUAM & GUAM & Guam, Ilhas Marianas & 790 & 144,804 & 13,513 & 30 & 27 & 57 \\
\hline ESSB & $\begin{array}{c}\text { ESQUIMÓ YUPIK DA ÁSIA } \\
\text { (SIBÉRIA) }\end{array}$ & $\begin{array}{l}\text { Região da Baía de Port } \\
\text { Providence, Sibéria }\end{array}$ & - & $-173,4$ & 64,417 & 19 & 13 & 32 \\
\hline AUST & AUSTRALIA & Swanport, Austrália & 180 & 139,301 & $-35,16$ & 52 & 49 & 101 \\
\hline
\end{tabular}




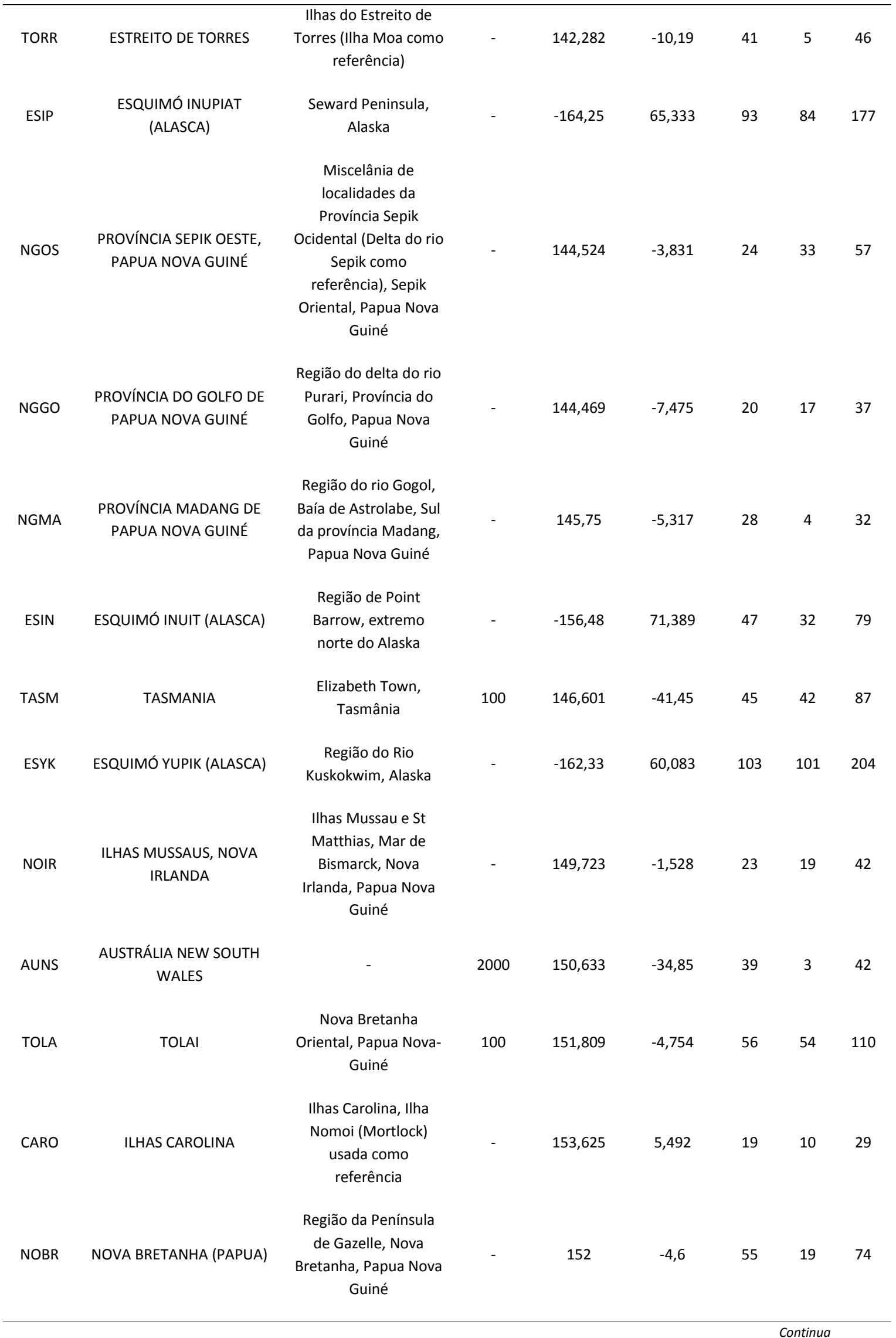


Continuação

\begin{tabular}{|c|c|c|c|c|c|c|c|c|}
\hline ALUN & ALEUTA UNALASKA & - & 550 & $-166,54$ & 53,892 & 62 & 41 & 103 \\
\hline ALFO & ALEUTA FOUR MOUNTAINS & - & 570 & $-169,72$ & 52,981 & 41 & 36 & 77 \\
\hline ALKO & ALASCA KODIAK & Ilha Kodiak & - & $-153,33$ & 57,55 & 13 & 8 & 21 \\
\hline SALO & ILHAS SALOMÃO & $\begin{array}{l}\text { Ilha de Guadalcanal, } \\
\text { Ilhas Salomão }\end{array}$ & - & 160,189 & $-9,617$ & 50 & 21 & 71 \\
\hline ALTL & ALASCA TLINGIT & $\begin{array}{l}\text { Ilhas ao norte da } \\
\text { Entrada Dixon, Ilha } \\
\text { Heceta, Alasca }\end{array}$ & - & $-133,58$ & 55,759 & 25 & 10 & 35 \\
\hline NOCA & NOVA CALEDÔNIA & $\begin{array}{l}\text { Região de } \\
\text { Pouébo/Oubatche, } \\
\text { Nova Caledônia }\end{array}$ & - & 164,569 & $-20,4$ & 29 & 9 & 38 \\
\hline NOHE & $\begin{array}{c}\text { ILHA MALAKULA, NOVAS } \\
\text { HÉBRIDAS }\end{array}$ & $\begin{array}{l}\text { Ilha de Malakula, } \\
\text { Novas Hébridas }\end{array}$ & - & 167,5 & $-16,3$ & 38 & 19 & 57 \\
\hline ESCA & ESQUIMÓ INUIT (CANADÁ) & $\begin{array}{l}\text { Região do Golfo de } \\
\text { Boothia, Nunavut, } \\
\text { Canadá }\end{array}$ & - & $-77,262$ & 72,355 & 24 & 19 & 43 \\
\hline CANY & CANADA YUQUOT & $\begin{array}{l}\text { Yuquot, Columbia } \\
\text { Britânica, Canadá }\end{array}$ & 500 & $-126,62$ & 49,6 & 43 & 21 & 64 \\
\hline FIJI & ILHAS FIJI & $\begin{array}{l}\text { Região de Viti Levu, } \\
\text { Ilhas Fiji }\end{array}$ & - & 178,012 & $-17,85$ & 26 & 3 & 29 \\
\hline SACR & SACRAMENTO, CALIFÓRNIA & $\begin{array}{l}\text { Região de } \\
\text { Sacramento, } \\
\text { Califórnia }\end{array}$ & - & $-121,47$ & 38,556 & 43 & 41 & 84 \\
\hline ESGR & ESQUIMÓ GROELÂNDIA & Nuuk, Groelândia & 360 & $-51,721$ & 64,183 & 53 & 55 & 108 \\
\hline NDAK & SIOUX - DAKOTA DO NORTE & $\begin{array}{l}\text { Região do Forte Rice, } \\
\text { Dakota do Norte }\end{array}$ & 150 & $-100,58$ & 46,51 & 11 & 9 & 20 \\
\hline ARIK & ARIKARA & $\begin{array}{l}\text { Lagoa Ohae, Dakota } \\
\text { do Sul, EUA }\end{array}$ & 275 & $-100,66$ & 44,757 & 42 & 27 & 69 \\
\hline NEBR & NEBRASKA - SIOUX & $\begin{array}{l}\text { Reserva Indígena de } \\
\text { Pine Ridge, Nebraska }\end{array}$ & - & $-102,09$ & 43,353 & 16 & 9 & 25 \\
\hline UTAH & UTAH & $\begin{array}{c}\text { Região de Beaver, } \\
\text { Utah }\end{array}$ & - & $-112,68$ & 38,275 & 58 & 36 & 94 \\
\hline CRUZ & SANTA CRUZ & $\begin{array}{l}\text { Ilha Santa Cruz, } \\
\text { Califórnia, EUA }\end{array}$ & 1015 & $-119,77$ & 34 & 51 & 51 & 102 \\
\hline MOKA & MOKAPU & Heeia, Havaí & 355 & $-157,86$ & 21,421 & 51 & 49 & 100 \\
\hline ARIZ & PIMA/APACHE ARIZONA & $\begin{array}{l}\text { Forte McDowell, } \\
\text { Arizona }\end{array}$ & 100 & $-111,67$ & 33,637 & 37 & 29 & 66 \\
\hline NOVO & NOVO MÉXICO & $\begin{array}{l}\text { Região de Santa Fé, } \\
\text { Novo México }\end{array}$ & - & $-105,96$ & 35,667 & 37 & 39 & 76 \\
\hline
\end{tabular}




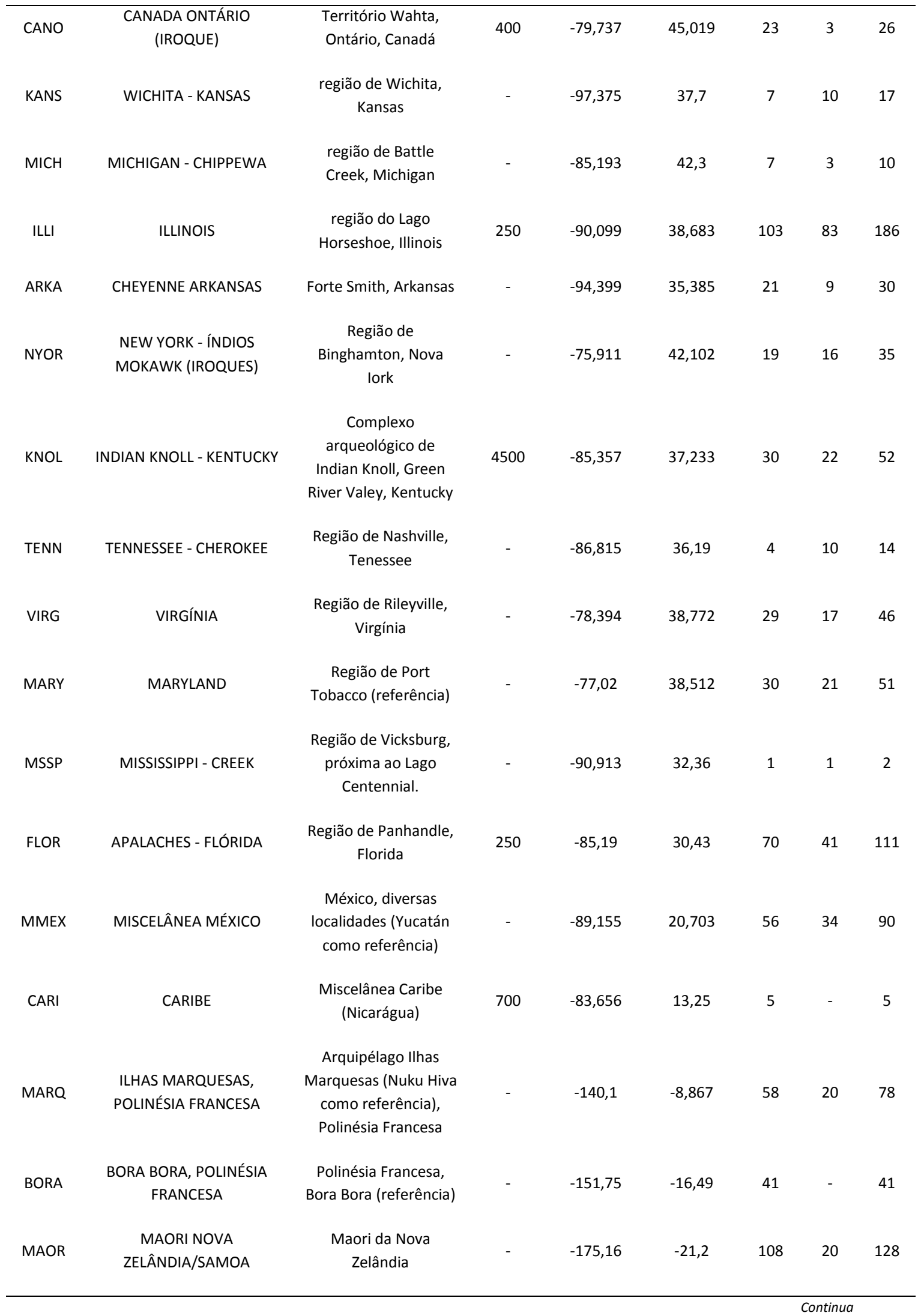


Continuação

\begin{tabular}{|c|c|c|c|c|c|c|c|c|}
\hline & & Parque "La Poma", & & & & & & \\
\hline COLA & COLOMBIANOS ARCAICOS & $\begin{array}{l}\text { Cudinamarca, } \\
\text { Colômbia }\end{array}$ & 4000 & $-74,268$ & 4,543 & 4 & 4 & 8 \\
\hline VENE & VENEZUELA & $\begin{array}{l}\text { Bacia do Orinoco, } \\
\text { Venezuela }\end{array}$ & - & $-62,25$ & 8,617 & 12 & 2 & 14 \\
\hline GUIA & GUIANA & $\begin{array}{c}\text { Região das } \\
\text { Montanhas Kanuku, } \\
\text { Guiana }\end{array}$ & - & $-59,583$ & 3,2 & 4 & - & 4 \\
\hline PEIN & INCA - PERU & Cajamarquilla & 500 & $-76,911$ & $-11,99$ & 210 & 140 & 350 \\
\hline PERU & PERU & Yauyos, Peru & 500 & $-75,923$ & $-12,46$ & 55 & 55 & 110 \\
\hline IPAS & EASTER I & Vaihu, Ilha de Páscoa & 470 & $-109,4$ & $-27,4$ & 49 & 37 & 86 \\
\hline MORI & MORIORI & $\begin{array}{c}\text { Ilhas Chatham, Nova } \\
\text { Zelândia }\end{array}$ & 200 & $-176,41$ & $-43,86$ & 57 & 51 & 108 \\
\hline BOLI & BOLÍVIA & $\begin{array}{l}\text { Região do Altiplano de } \\
\text { Sica Sica, cemitério de } \\
\text { Tama Tam Chullpa }\end{array}$ & 1000 & $-67,918$ & $-17,2$ & 8 & 6 & 14 \\
\hline SANP & SAN PEDRO DE ATACAMA & $\begin{array}{c}\text { San Pedro de } \\
\text { Atacama, Deserto do } \\
\text { Norte, Chile }\end{array}$ & 2400 & $-68,208$ & $-22,92$ & 17 & 15 & 32 \\
\hline BBCE & $\begin{array}{l}\text { BOTOCUDO DO BRASIL } \\
\text { CENTRAL }\end{array}$ & $\begin{array}{c}\text { Região de } \\
\text { Queixadinha, Minas } \\
\text { Gerais }\end{array}$ & 150 & $-42,01$ & $-17,15$ & 9 & 10 & 19 \\
\hline LSAN & LAGOA SANTA & $\begin{array}{l}\text { Região da Gruta do } \\
\text { Sumiduro, Parque } \\
\text { Estadual do } \\
\text { Sumidouro, Pedro } \\
\text { Leopoldo, Minas } \\
\text { Gerais }\end{array}$ & 8500 & $-43,94$ & $-19,54$ & 4 & 1 & 5 \\
\hline SPRE & $\begin{array}{l}\text { SAMBAQUI PRÉ- } \\
\text { CERAMISTA DO SUL- } \\
\text { SUDESTE BRASILEIRO }\end{array}$ & $\begin{array}{l}\text { Região da Baía de } \\
\text { Guaratuba, Paraná }\end{array}$ & 3500 & $-48,566$ & $-25,85$ & 4 & 3 & 7 \\
\hline SCER & $\begin{array}{c}\text { SAMBAQUI CERAMISTA DO } \\
\text { SUL BRASILEIRO }\end{array}$ & $\begin{array}{l}\text { Sul da Ilha de São } \\
\text { Francisco do Sul, } \\
\text { Santa Catarina }\end{array}$ & 950 & $-48,608$ & $-26,43$ & 4 & 2 & 6 \\
\hline CHIL & CHILE & - & 500 & $-73,063$ & $-36,77$ & 16 & 13 & 29 \\
\hline FUEG & FUEGUINOS PATAGÔNICOS & $\begin{array}{l}\text { Miscelânea: Lago San } \\
\text { Martin; Rio Chubut, } \\
\text { Rio Negro, Gueraike }\end{array}$ & - & $-72,284$ & $-49,05$ & 48 & 10 & 58 \\
\hline Total & - & - & - & - & - & 6296 & 2991 & 9287 \\
\hline
\end{tabular}




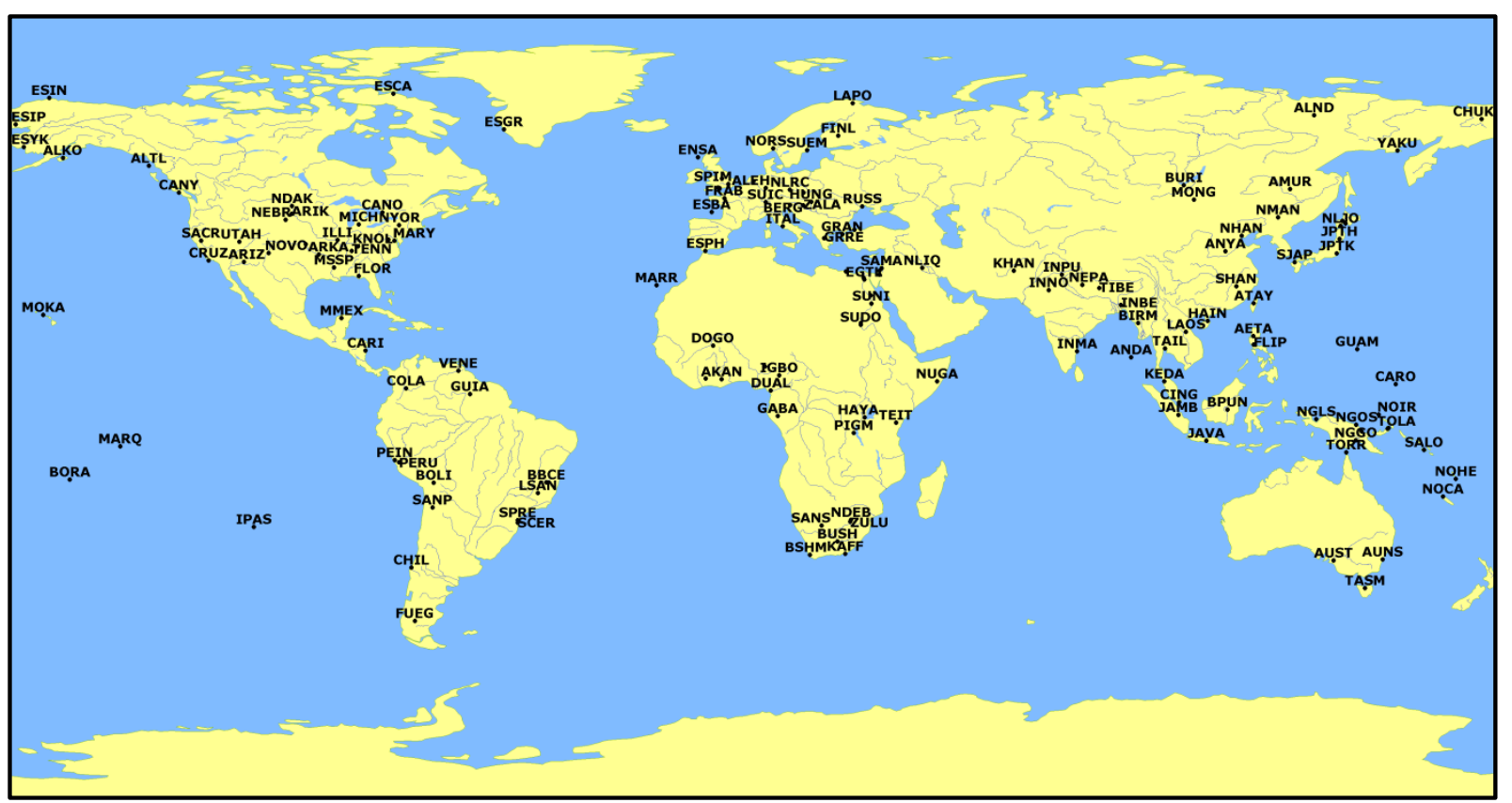

Fig. 3.9 - Distribuição mundial das populações agregadas ao banco de dados consolidado de morfologia craniana.

O mapa da Figura 3.9 foi gerado a partir das coordenadas geográficas de cada uma das populações da Tabela 3.2 com a utilização do programa de GIS (Sistema de Informação Geográfica) Diva ${ }^{\odot}$ 7.3.0 (Hijmans et al., 2005). Essas mesmas coordenadas foram utilizadas em outra plataforma GIS para o cálculo das distâncias geográficas mínimas entre cada par de séries envolvidas na análise. Adotando-se a abordagem de "Cálculo por Grande Círculo CGC" (Prugnolle et al., 2005) e configurando o algoritmo para evitar caminhos de travessia custosa, como oceanos, altitudes superiores a $2000 \mathrm{~m}$ e grandes porções de água, por exemplo, pode-se obtever uma matriz de distâncias geográficas controladas entre todos os pares populacionais. Esse cálculo foi executado através do programa ArcView ${ }^{\circledR} 3.2$ (Esri, 1992), com a extensão PACHMATRIX ${ }^{\odot}$ (Ray, 2005). A matriz de distâncias geográficas (daqui em diante, $\mathrm{D}_{\mathrm{Geo}}$ ) entre todas as 161 populações está apresentada na Tabela $\mathrm{A} 4$ (Apêndice 4).

Ainda em relação à consolidação e quantificação do banco de dados morfológico, um último detalhe merece destaque. Como pode ter sido facilmente notado ao longo deste texto, 
o conjunto de dados é formado por crânios de indivíduos masculinos e femininos, representando uma amostra afetada por dimorfismo sexual.

Embora, quando comparado às espécies hominínias ancestrais, o Homo sapiens apresente baixos níveis de dimorfismo sexual (Frayer \& Wolpoff, 1985; Kimmerle et al., 2008), admite-se que existem diferenças, principalmente relacionadas à estatura e robustez, entre os sexos masculino e feminino na espécie humana (Park, 1996). Tais diferenças, mediadas geneticamente e severamente afetadas por fatores ambientais, como, por exemplo, a nutrição (Corruccini, 1973), são expressas através características sexuais que não se manifestam claramente no esqueleto humano até que ocorra seu total desenvolvimento (Krogman, 1978). Dessa forma, apenas esqueletos de indivíduos que já atingiram a idade adulta podem ser analisados para a correta determinação do sexo (ver Boucher, 1955, 1957 para uma visão crítica).

A classificação de sexo de um esqueleto pode ser efetuada através de diversos métodos, visuais ou morfométricos, a partir de diferentes regiões anatômicas do crânio e do pós-crânio (ver Inglez, 2010 para uma ampla revisão sobre o tema), sendo que o crânio, a mandíbula e a pélvis apresentam os melhores indíces de precisão (classificações corretas quanto ao sexo) do que as outras estruturas anatômicas utilizadas (Tagaya, 1989; Hunnargi, et al., 2008; Cowal \& Pastor, 2008).

Embora alguns autores destaquem a grande precisão dos métodos aplicados à determinação do sexo de esqueletos a partir de análises visuais de características cranianas (Howells, 1973; Walker, 2005; Dayal, et al., 2007), uma parcela considerável destes crânios acabam classificados de maneira errada (sexos invertidos) ou dúbia (sexo indeterminado), devido à subjetividade da inferência e dos erros intra e inter observadores (Bruzek, 2002; Pretorius et al., 2006; Veyre-Goulet et al., 2008). O banco de dados consolidado para esta pesquisa é um bom exemplo deste fenômeno. Durante a qualificação dos dados, não raro, foi 
encontrada classificações de sexo diferentes para um mesmo espécime33, assim como, é muito comum, enfrentar a situação de analisar um esqueleto depositado em um museu e divergir diametralmente da classificação constante em seu inventário (Neves, 1988).

Considerando-se o exposto, isto é, que nem sempre o sexo de um esqueleto é precisamente atribuído, e admitindo que o dimorfismo sexual expresso em esqueletos humanos é majoritariamente relacionado à estatura, ou robustez, não envolvendo grandes derivações na arquitetura genética entre os dois gêneros, a estratégia adotada neste trabalho foi a de apenas minimizar o fator "tamanho", sem distinguir a amostra quanto ao sexo. O Apêndice 5 apresenta os resultados da inferência estatística utilizada para avalizar a decisão de tratar as duas parcelas, masculina e feminina, conjuntamente. Como anteriormente citado, tal correção já se fazia necessária, uma vez que fatores ambientais imediatos podem influenciar no tamanho dos crânios (Corrucini, 1973).

Para tanto, adotou-se a estratégia, amplamente aceita entre os Antropólogos Físicos ${ }^{34}$, de se dividir o valor de cada variável ${ }^{35}$ pelo valor da média geométrica ${ }^{36}$ de todas as variáveis do indivíduo (Darroch \& Mosimann, 1985). Assim, a montagem dos bancos de dados de morfologia craniana resultou em um conjunto de dados relativos apenas à "forma", com indivíduos masculinos e femininos tratados conjuntamente. O Apêndice 6 contém uma discussão mais detalhada do efeito ao que os dados foram submetidos ao se adotar tal estratégia.

\footnotetext{
${ }^{33}$ Nas descrições das populações dos bancos de dados publicados em seus trabalhos seminais Howells $(1973,1989)$ demonstra essa preocupação ao citar, quantitativamente, a frequência de concordância de determinações de sexo feitas entre ele e outros antropólogos (ou curadores).

${ }^{34}$ Diferentes métodos são comumente utilizados para a correção do fator "tamanho" em estudos de antropologia física. Nesta pesquisa, a escolha pela abordagem adotada se deu por sua menor interferência na estruturação dos dados em comparação aos outros métodos disponíveis.

${ }^{35}$ Como cada variável é dividida pelo valor da média geométrica, esse procedimento não permite que nenhuma variável possa ser nula (valor 0) pela propriedade algébrica das operações de multiplicação e divisão com esse valor (nulidade). Nesse caso, indivíduos que apresentaram 0 em alguma de suas variáveis tiveram seus valores alterados para 0,001.

${ }^{36}$ A média geométrica corresponde ao valor da raiz enésima do produto das $n$ variáveis calculadas.
} 


\subsection{2 - Bancos de Dados Moleculares}

Seguindo a estratégia de agregar informações para a investigação da evolução da diversidade craniana humana, foi compilado, também, um pequeno banco de dados de marcadores moleculares com o intuito de avaliar questões pontuais relativas às hipóteses investigadas pelas demais análises propostas nesta pesquisa. Para tanto, duas classes de marcadores moleculares foram exploradas para a formação do banco de dados moleculares: microssatélites autossômicos e DNA mitocondrial (mtDNA).

Microssatélites, também chamados de repetições de sequência simples (SSR, "single sequence repeats"), são sequências curtas formadas por arranjos repetitivos de dois a seis pares de nucleotídeos e figuram entre os locos mais polimórficos dos genomas (Jeffreys et al., 1985). O polimorfismo desses elementos deve-se à variação do número, ou comprimento, de repetições, provavelmente relacionadas a erros da DNA polimerase durante o processo de replicação e reparo da molécula de DNA (Petrukhin et al., 1993). Dessa forma, o marcador é reconhecido por apresentar um padrão evolutivo efetivamente neutro. Seus polimorfismos são identificados através de diferentes técnicas moleculares e sua aplicação é extremamente difundida nas investigações genéticas de identificação genotípica, estimativas de diversidade, construção de mapas genéticos, estruturação de populações, fluxo gênico e frequência de fenômenos migratórios (Snustad \& Simmons, 2008).

O mtDNA, é uma fita dupla de DNA circular, autorreplicadora, encontrada, como fica claro por seu nome, nas mitocôndrias, sendo, assim, esse material genético é transmitido unicamente de maneira matrilinear. Normalmente, o mtDNA é associado à codificação de moléculas de $\mathrm{RNA}^{37}$ ribossômico e transportador e à proteínas atuantes nas funções respiratórias oxidativas mitocondriais (Klug et al., 2009).

Desde os anos 1980 a molécula de mtDNA passou a fazer parte de estudos envolvendo a investigação de relações filogenéticas e de estrutura populacional. A molécula caracteriza-se

\footnotetext{
${ }^{37}$ Ácido ribonucleico.
} 
por ter um genoma pequeno, compacto, de conteúdo bastante conservado, com taxa evolutiva considerada alta quando comparada a do genoma nuclear (Arias et al., 2003), porém essencialmente neutra (Excoffier, 1990)38. Cada grupo de mutações diagnósticas, que representam grupos polimórficos específicos e que caracterizam uma linhagem evolutiva são chamados de haplogrupos (Futuyma, 1998). Os haplogrupos do mtDNA humano são rotulados de A a Z, e suas frequências relativas variam de população para população (Ridley, 2005). É exatamente essa variação na frequência haplotipo-populacional que compõe os dados obtidos para a consolidação do banco de dados deste projeto.

Como já antecipado no início deste capítulo, a investigação da morfologia craniana humana proposta neste trabalho é baseada em uma abordagem comparativa, fundamentada em comparações, de maneira múltipla, intra e inter grupos. A delimitação desses grupos, ou populações, pode ser feita de acordo com diferentes critérios como, por exemplo, distribuição geográfica, filiações linguísticas ou abrangência cronológica (Cavalli-Sforza et al., 1994). Entretanto, é desejável que a atribuição de níveis hierárquicos seja feita a partir da relação filogenética das entidades envolvidas na análise, de maneira a evitar distorções da história evolutiva dos grupos em questão.

Idealmente, então, uma filogenia, refletindo a evolução, história e geografia das populações deveria ser usada para "calibrar" as unidades de análise de padrões morfológicos. No entanto, para muitos grupos, a escassez de amostras inviabiliza tal abordagem. Uma opção para situações como essa é adotar a divisão dos grupos seguindo sua distribuição em grandes áreas geográficas, como continentes. González-José e colaboradores (2004), por exemplo, adotaram tal critério para investigar os padrões de covariação e correlação fenotípica do crânio humano. Entretanto, como discutido anteriormente, o conceito biológico de população é muito complexo, envolvendo outras dimensões, como a temporalidade, por exemplo, para ser reduzido, apenas, à questão geográfica.

\footnotetext{
${ }^{38}$ Ver Ballard \& Kreitman, 1995 e Rand, 2001 para visões críticas e contrárias.
} 
Nesse contexto, admitindo que a utilização de dados moleculares seja, atualmente, a estratégia preferencial para a construção de filogenias (Diniz Filho, 2002) e que a análise de sequências gênicas constitua a forma mais promissora de estudar a evolução de populações humanas (Meyer, 1994), a proposta para este trabalho foi a de utilizar informações sobre a variação genotípica humana, inferida através de fragmentos de microssatélite, para a construção de uma proposta filogenética das populações amostradas. No entanto, como poderá ser notado na Tabela 3.3, apenas uma parcela da populações representadas no banco de dados morfológico apresenta, também, dados referentes à variação em sua constituição genética.

Assim, foi compilado um banco de dados que compreende informações da variação de microsatélites de 683 indivíduos, distribuídos em 36 populações, dispersas nas principais macro-regiões do planeta, correspondentes às mesmas populações (excluindo-se o sentido cronológico) contidas no banco de dados morfológico. Os dados desse conjunto foram obtidos do material suplementar "Dataset S1" de Wang et al. (2007), cuja organização e qualificação de informações foram empreendidas por Tatiana Almeida (Almeida, 2011; comunicação pessoal) e gentilmente cedidos para a elaboração deste trabalho. A Tabela 3.3 apresenta a descrição sumária desse banco de dados.

Tabela 3.3 - Sigla da população correspondente no banco de dados morfológicos, identificação, referências geográficas e tamanho das amostras das populações presentes no banco de dados de microssatélites.

\begin{tabular}{ccccc}
\hline Sigla & População & $\begin{array}{c}\text { Referência } \\
\text { geográfica }\end{array}$ & Região geográfica & $\mathrm{N}$ \\
\hline TEIT & Bantu Quênia & Quênia & África & 12 \\
PIGM & Mbuti Pigmeu & Congo & África & 15 \\
SAMA & Palestinos & Israel-Central & Oriente Médio & 51 \\
BEDU & Beduínos & Israel-Negev & Oriente Médio & 48 \\
NIGM & Yoruba & Nigéria & África & 25 \\
KHAN & Parthian & Khandahar & Centro-sul Ásia & 24 \\
INNO & Burusho & Paquistão & Centro-sul Ásia & 25 \\
\hline
\end{tabular}


Continuação

\begin{tabular}{|c|c|c|c|c|}
\hline RUSS & Russos & Rússia & Europa & 25 \\
\hline SANS & San & Namíbia & África & 7 \\
\hline ITAL & Italianos & Itália-Bergamo & Europa & 13 \\
\hline INPU & Brahui & Índia/Paquistão & Centro-sul Ásia & 25 \\
\hline BERG & Rakhine & China/Birmânia & Leste Ásia & 10 \\
\hline NEPA & Naxi & China & Leste Ásia & 10 \\
\hline KAFF & Bantu (Zulu) África do Sul & África do Sul & África & 8 \\
\hline COST & Mandenka & $\begin{array}{c}\text { Senegal/Costa do } \\
\text { Marfim }\end{array}$ & África & 24 \\
\hline TIBE & Tujia & China & Leste Ásia & 10 \\
\hline ESBA & Bascos & $\begin{array}{c}\text { Fronteira } \\
\text { Espanha/França }\end{array}$ & Europa & 24 \\
\hline FRAB & Franceses & França & Europa & 29 \\
\hline TAIL & Yi & China & Leste Ásia & 10 \\
\hline LAPO & Orcadianos & Ilhas Orkney & Europa & 16 \\
\hline LAOS & Dai & China & Leste Ásia & 10 \\
\hline BURI & Buriat/Daur & Mongólia/Rússia & Leste Ásia & 10 \\
\hline MONG & Mongóis & China & Leste Ásia & 10 \\
\hline HAIN & Miao & China & Leste Ásia & 10 \\
\hline SHAN & Han & China (sul) & Leste Ásia & 34 \\
\hline NHAN & Han-Chineses & China (norte) & Leste Ásia & 10 \\
\hline NMAN & Xibo & China & Leste Ásia & 9 \\
\hline AMUR & Nanai & Rússia/China & Leste Ásia & 9 \\
\hline JPTH & Japoneses & Japão/Tohoku & Leste Ásia & 29 \\
\hline YAKU & Yakut & Sibéria & Leste Ásia & 25 \\
\hline CHUK & Chukchi & Rússia/Sibéria & Leste Ásia & 17 \\
\hline NGOS & Papua & Nova Guiné & Oceania & 17 \\
\hline SALO & Melanésios & Bougainville & Oceania & 19 \\
\hline ARIZ & Pima & Arizona/México & América & 25 \\
\hline MMEX & Maya & México & América & 25 \\
\hline COLA & Colombianos & Colômbia & América & 13 \\
\hline Total & & & & 683 \\
\hline
\end{tabular}

De maneira complementar, informações acerca da frequência de ocorrência de haplogrupos específicos de mtDNA em populações distribuídas mundialmente representam um valioso objeto de estudo para a investigação das relações filogenéticas entre o grupos em questão, possibilitando a inferência de padrões demográficos ao longo de suas histórias evolutivas. Prova disso é a extensa literatura publicada sobre o tema, especificamente no que 
se refere aos eventos de dispersão e diversificação humana (para citar apenas alguns exemplos veja Cann et al., 1987; Merriweather \& Ferrell, 1996; Merriwether et al., 1996; Horai et al., 1996; Hey, 1997; Bonatto \& Salzano, 1997a, 1997b; Starikovskaya et al., 1998; O'Rourke et al., 2000, Mesa et al., 2000, Torroni et al., 2001; Beerli \& Edwards, 2002; Malhi et al., 2002; Lewis et al., 2004; Ruiz-Pesini et al., 2004; Pakendorf \& Stoneking, 2005; Hunley \& Long, 2005; Hunley et al., 2007; Kemp et al., 2007, Pereira et al., 2008; Pereira et al., 2009; Perego et al., 2009; Arnaiz-Villena et al., 2010; Hünemeier et al., 2012; e Cann, 2001 para uma revisão crítica).

No entanto, a geração de uma árvore evolutiva a partir de dados de variação de haplogrupos de mtDNA não foi o intuito da inclusão desta pequena fração desses dados nesta pesquisa. Aproveitando a característica evolutivamente neutra, apesar do atual debate sobre o tema, desse marcador, o objetivo da exploração desse banco é o de se obter uma estimativa de neutralidade para um modelo específico de teste de carateres morfológicos sob influência de seleção. Em outras palavras, da mesma maneira que, como anteriormente exposto, os dados de variação de microssatélites serão usados para a calibração da atribuição de grupos populacionais para a análise comparativa de seus padrões de covariância fenotípica, os dados de variação de mtDNA serão usados para a calibração do modelo de neutralidade.

Dessa forma, foi organizado um banco de dados a partir da compilação feita por Almeida (2011). A parcela relativa aos marcadores moleculares foi consolidada a partir da compilação de dados relativos à classificação quanto aos haplogrupos (A, B, C ou D) de 1481 indivíduos a partir da literatura especializada (Merriwether et al., 1995, Brown et al., 1998, O’Rourke et al., 2000, Malhi, et al., 2001, 2003, 2004, Deberneva et al., 2002, Bolnick \& Smith, 2003, Lewis et al., 2004, Mendes, 2005; Shinoda et al., 2006). A Tabela 3.4 informa as frequências absolutas de ocorrência de cada haplogrupo em cada uma das 22 populações analisadas, bem como as informações pertinentes à correspondência entre essas populações e àquelas do banco morfológico. 
Tabela 3.4 - Sigla da população correspondente no banco de dados morfológicos, identificação e tamanho da amostra das populações presentes no banco de dados de mtDNA, e suas respectivas freqüências absolutas quanto aos haplogrupos A, B, C e D.

\begin{tabular}{|c|c|c|c|c|c|c|}
\hline \multirow{2}{*}{ Sigla } & \multirow{2}{*}{ População } & \multicolumn{4}{|c|}{ Haplogrupos } & \multirow{2}{*}{$\mathrm{N}$} \\
\hline & & A & B & C & $\mathrm{D}$ & \\
\hline ALND & Haida & 35 & 0 & 3 & 0 & 38 \\
\hline ESSB & Esquimó Yupik Sibéria & 101 & 0 & 2 & 26 & 129 \\
\hline ESYK & Esquimó Yupik Alasca & 43 & 0 & 3 & 106 & 152 \\
\hline ALFO & Aleuta & 6 & 0 & 0 & 11 & 17 \\
\hline ALKO & Esquimó Kodiak & 71 & 4 & 0 & 40 & 115 \\
\hline CANY & Nuu-Chah-Nulth & 46 & 7 & 16 & 26 & 95 \\
\hline NDAK & Sioux & 25 & 9 & 8 & 2 & 44 \\
\hline ARIZ & Pima/Apache & 24 & 5 & 7 & 2 & 38 \\
\hline NEBR & Siouan & 18 & 6 & 5 & 2 & 31 \\
\hline CANO & Mohawk & 71 & 21 & 29 & 2 & 123 \\
\hline KANS & Chickasaw & 18 & 6 & 2 & 0 & 26 \\
\hline $\mathrm{MICH}$ & Chippewa & 17 & 3 & 22 & 2 & 44 \\
\hline ARKA & Kickapoo & 30 & 7 & 12 & 0 & 49 \\
\hline TENN & Cherokee & 4 & 17 & 16 & 0 & 37 \\
\hline MSSP & Creek & 40 & 17 & 15 & 38 & 110 \\
\hline CARI & Teribe & 16 & 4 & 0 & 0 & 20 \\
\hline VENE & Piaroa & 5 & 3 & 5 & 5 & 18 \\
\hline GUIA & Cayapa & 35 & 48 & 11 & 0 & 94 \\
\hline PEIN & Quechua (Arequipa) & 2 & 15 & 3 & 2 & 22 \\
\hline BOLI & Aymara & 11 & 116 & 21 & 24 & 172 \\
\hline SANP & Atacamenos & 9 & 45 & 6 & 3 & 63 \\
\hline FUEG & Fueguinos & 0 & 0 & 19 & 25 & 44 \\
\hline Total & - & 627 & 333 & 205 & 316 & 1481 \\
\hline
\end{tabular}

Em posse desse grupo de informações quantitativas e qualitativas, de diferentes naturezas e origens foram delineados os experimentos descritos a seguir, com o intuito de enriquecer a discussão de pontos específicos do atual debate acerca da evolução e diversificação da morfologia craniana humana. 


\section{2 - Metodologias analíticas}

Como antecipado no Capítulo 2, dois pontos de estudo podem ser destacados como questões centrais às investigações propostas nesta tese: 1) a diversidade da morfologia craniana humana, examinada em função de sua composição, padrões de ocorrência e distribuição geográfico-temporal; e, 2) o contexto evolutivo dos padrões de integração, modularidade e estase evolutiva do crânio humano, examinados a partir de seus padrões de variância e covariância.

Depreende-se ainda da Introdução que, apesar de apresentadas aqui separadamente, tais questões compartilham um mesmo substrato analítico comum: o fenômeno da variação biológica. A compreensão dos processos microevolutivos responsáveis pela diversificação e distribuição da morfologia craniana humana atualmente observada passa, indubitavelmente, pela inferência e quantificação desse fenômeno. Pode-se sugerir que o próprio conceito de Seleção Natural, para um exemplo, emergiu da observação e interpretação da variação: "(...) segue-se que todo o ser que varia, ainda que pouco, de maneira a tornar-se-lhe aproveitável tal variação, tem maior probabilidade de sobreviver, este ser é também objeto de uma seleção natural" (Darwin, 1859).

A relação entre variação (ou a quantificação da variação fenotípica) e a interpretação de seu significado evolutivo, como as matrizes genotípicas e fenotípicas, por exemplo, pode ser demonstrada a partir de sua inferência populacional baseada em suas interações genotípicas e ambientais (Hartl \& Clark, 2010). Assim, sob um modelo de genética de populações, o fenótipo de qualquer indivíduo pode ser algebricamente representado por:

$$
P=\mu+G+E
$$

onde $(P)$ é o fenótipo quantitativamente representado, correspondente à soma do valor médio do caráter na população $(\mu)$ com o valor do desvio em relação à média populacional 
devida ao genótipo do indivíduo $(G)$ com o valor do desvio em relação à média da população devida à interação com características ambientais $(E)$.

Tal equação é particularmente apropriada para as relações nas quais o fenótipo é resultado de efeitos aditivos do genótipo e do ambiente, o que significa que, quando a mesma equação pode ser escrita como:

$$
P-\mu=G+E
$$

ou seja, o desvio do valor fenotípico do indivíduo em relação à média da população $(P-\mu)$, que pode ser escrito como $\left(\delta_{P}\right)$, corresponde à soma dos desvios devido ao genótipo $(G)$ e às condições ambientais $(E)$. Elevando ao quadrado os dois termos da equação, temos:

$$
\left(\delta_{P}\right)^{2}=(G+E)^{2}
$$

que pode ser derivada em termos de:

$$
\left(\delta_{P}\right)^{2}=G^{2}+2 G E+E^{2}
$$

admitindo que, como anteriormente demonstrado, $\delta_{P}, G$ e $E$ equivalem, respectivamente, aos desvios em relação às médias populacionais do valor do fenótipo, do genótipo e do ambiente, tem-se que a variância fenotípica $\left(\delta_{P}\right)^{2}$ equivale à soma da variância genotípica $\left(G^{2}\right)$ mais a variância ambiental $\left(E^{2}\right)$ mais duas vezes a covariância entre genótipo e ambiente $(2 G E)$. Essa decomposição constitui a base fundamental da genética quantitativa, ao estabelecer, como indicado na introdução, uma relação operacional entre a genética de populações e a variação de caracteres (Falconer \& Mackay, 1996; Hartl \& Clark, 2010).

De maneira análoga, Cheverud et al. (1985), propuseram que, assim como o componente genotípico $(G)$ contribui para a variação do indivíduo, um componente filogenético $(F)$ contribui para a variação total $(T)$ do grupo (em termos de espécie ou população). Admitindo-se a analogia entre $(G)$ e $(F)$ e que efeitos ambientais e outros eventos 
particulares possam ser concentrados em um único componente específico $(S)$, pode-se, então dizer que a variação total é representada pela equação:

$$
T=F+S
$$

onde $(F)$ corresponde à variação herdada dos ancestrais e $(S)$ à variação devida às diferentes pressões seletivas (Diniz Filho, 2002). Assim como demonstrado nas equações anteriores, a relação acima pode ser descrita em termos de variância, assumindo a seguinte notação:

$$
V_{T}=V_{F}+V_{S}+2 C O V_{F S}
$$

Situações particulares nas quais a covariância entre $F$ e $S$ tendem à zero restringem o potencial de variação de um grupo aos seus componentes $V_{F}$ e $V_{S}$. Tais situações, que podem ser representadas por cenários evolutivamente neutros, por exemplo, com $\left(V_{S}\right)$ desprezível, apresentam constância entre os componentes $\left(V_{F}\right)$ e $\left(V_{T}\right)$, podendo ser compreendidos através de uma relação linear (Lynch, 1991).

Dessa maneira, a proporção estabelecida entre $\left(V_{F}\right)$ e $\left(V_{T}\right)$ representa o componente de variação que é herdada por um grupo ao longo de sua história evolutiva. A esse componente é dada a denominação de inércia filogenética ou herdabilidade entre espécies (Cheverud et al., 1985; Lynch, 1991). Embora sua concepção inicial tenha sido desenvolvida para estabelecer as correlações de diferentes características interespecíficas ao longo de uma filogenia, seu contexto essencialmente fundamentado em genética quantitativa não impede que tal raciocínio possa ser aplicado às relações intraespecíficas.

Basicamente, esse raciocínio é o ponto de partida do qual derivam as diferentes propostas de investigação a seguir. De uma maneira geral, dois grupos de análises foram desenvolvidas, em acordo com os objetivos centrais inicialmente apresentados: 1) Análises sobre os padrões de variação e diversificação humana; e 2) Investigações sobre a estrutura de variância/covariância observadas na morfologia craniana humana. 


\subsection{1 - Padrões de variação e diversificação humana}

Os padrões de distribuição global da diversidade humana vem sendo investigados através do estudo de diferentes marcadores bioantropológicos, com destaque aos marcadores moleculares (Serre \& Päabo, 2004). De maneira geral, tanto os estudos baseados em características genotípicas quanto os feitos sobre características fenotípicas observam uma relação de declínio da diversidade genética intrapopulacional à medida que a localização geográfica da amostra se distancia da África subsaariana (Handley et al., 2007).

Tal padrão em cline sugere que o processo de dispersão do Homo sapiens ocorreu a partir de uma origem única, seguida por uma série de gargalos populacionais de pequena amplitude, num rápido processo de expansão que levou à colonização de todo o planeta (Prugnolle et al, 2005; Ramachandran et al., 2005; Liu et al., 2006; Manica et al., 2007; Hanihara, 2008; von Cramon-Taubadel \& Lycett, 2008; Betti et al., 2010).

O raciocínio por trás dessa sugestão é a assunção de que a distância geográfica inter populacional é uma excelente estimativa da diferenciação genética neutra entre as populações (Handley et al., 2007; Manica et al., 2007; Betti et al., 2009). A concordância entre resultados obtidos a partir de dados de origem morfológica e dados de origem molecular, por sua vez, corrobora a ideia de que processos evolutivos estocásticos, como a deriva genética, tiveram um papel mais importante no processo de diferenciação e diversificação humana do que a seleção natural (Betti et al., 2010).

Diferentes técnicas analíticas vem sendo recorrentemente utilizadas como estimativas quantitativas da diversidade humana. Uma estratégia comumente empregada quando dados morfológicos são analisados é a utilização da variância fenotípica, tanto de maneira direta quanto na forma de coeficientes, como medida de diversidade (Manica et al., 2007; Betti et al., 2009). Nas análises desenvolvidas nesta tese, a medida de variância fenotípica utilizada foi o coeficiente de variação média (CVM), calculados facilmente através de planilhas eletrônicas. 
O coeficiente de variação $(\mathrm{CV})$, usado para o cálculo do CVM, é uma inferência estatística simples, que exprime a variação de uma dispersão qualquer, utilizando como parâmetros a média e o desvio-padrão. Dessa maneira, o CV é uma medida de dispersão que pode ser utilizada para comparações entre diferentes distribuições, independente da unidade de mensuração da variável (Callegari-Jaques, 2003). Seu cálculo se dá pela fórmula39:

$$
C V=\frac{\delta}{\mu}
$$

Onde, $(\mu)$ é o valor intrapopulacional médio para uma determinada variável e $\delta$ é o desvio-padrão desta média. O CVM exprime a média dos CV de uma série qualquer, representando uma medida da variação intrapopulacional.

No entanto, uma abordagem recentemente mais difundida entre os especialistas consiste na utilização do $\mathrm{F}_{\mathrm{ST}}$ como estimativa de diversidade e divergência entre populações. Tal popularidade pode ser atribuída à sua capacidade operacional generalista, adequando-se tanto à análise de dados moleculares quanto de dados morfométricos.

O F $\mathrm{F}_{\mathrm{ST}}$ é um índice utilizado pela genética de populações, derivado do coeficiente $\mathrm{F}$ de endocruzamento, para exprimir o grau de diferenciação genética entre dois subgrupos (Gillespie, 2004). Assim, o $\mathrm{F}_{\mathrm{ST}}$ constitui uma métrica adequada para a estimação da quantidade de variação encontrada entre unidades de análises, que podem ser grupos, populações ou subpopulações, sob a premissa de que as frequências gênicas envolvidas na análise estão sob evolução neutra (Beaumont, 2005). Sua aplicação é comum a dados genético-moleculares, apresentando uma série de maneiras de ser calculado (Beaumont, 2005), sendo que a proposta de Cockerham \& Weir (1984), e suas derivações diretas, são as mais utilizadas. Relethford \& Blangero (1990) e Relethford (1994), apresentaram uma aproximação do cálculo de $\mathrm{F}_{\mathrm{ST}}$ para dados fenotípicos, aplicáveis, assim, às medidas craniométricas. Segundo sua proposta, para aplicá-lo a dados morfológicos, é necessária a

\footnotetext{
${ }^{39}$ Como é adimensional, pode também ser expresso em porcentagem.
} 
inversão da matriz de variância dos dados analisados, a matriz $\mathrm{R}$, a partir da qual o resultado do cálculo das diagonais será proporcional ao valor de $\mathrm{F}_{\mathrm{ST}}$ esperado (Relethford \& Blangero, 1990). Para o cálculo dos $F_{S T}$ sobre dados craniométricos apresentados neste trabalho utilizou-se o programa Rmet 5.0 (Relethford, 2004b), adotando-se um grau de herdabilidade ${ }^{40}\left(h^{2}\right)$ de 0,55 , seguindo o proposto em outros estudos (Devor, 1987; Relethford, 1994; Roseman \& Weaver, 2004; Carson, 2006).

Foram delineados três experimentos exploratórios sobre a variação craniana humana, abordada sob diferentes aspectos: a) sua distribuição intrapopulacional; b) sua distribuição interpopulacional; e, c) sua partição genotípica e fenotípica observada em uma região geográfica específica. Esse grupo de análises foi performado sobre uma parcela do conjunto de dados do banco morfológico final, anteriormente descrito e representado na Tabela 3.2.

\section{a) Distribuição da variação intrapopulacional}

O objetivo desta análise é investigar o comportamento da diversidade craniana humana intrapopulacional em função da distância em relação à África, admitida como uma estimativa de tempo de dispersão ou divergência (Handley et al., 2007; Manica et al., 2007; Betti et al., 2009). Adicionalmente a essas duas dimensões, localizações geográfica (continental) e temporal (cronologia, ou antiguidade) também compuseram a estrutura analítica. Se a diversificação da morfologia craniana humana foi acumulada majoritariamente através de processos evolutivos neutros, como a deriva genética (Manica et al., 2007; von Cramon-Taubadel \& Lycett, 2008; Betti et al., 2010), espera-se, então, que o padrão de declínio de diversidade intrapopulacional observado se mantenha, independentemente dos critérios estabelecidos para se particionar a amostra.

\footnotetext{
${ }^{40}$ Para um caráter complexo, a medida que exprime, num sentido amplo, o valor do efeito agregado de todos os fatores genéticos envolvidos e combinados para a expressão de determinada característica fenotípica é chamada herdabilidade $\left(h^{2}\right)$, definida como a proporção da variância fenotípica e da variância genotípica. Por sua definição depreende-se que para um conjunto hipotético cujo $\mathrm{h}^{2}=1$, entende-se que toda a variância fenotípica desse conjunto pode ser atribuída à sua própria variação genotípica. Por outro lado, para um conjunto qualquer cujo $h^{2}=0$, entende-se que toda a variância fenotípica deve-se às diferenças ambientais (Falconer \& Mackay, 1996; Hartl, 2008).
} 
A amostra utilizada nesta análise é composta pelos 9287 indivíduos distribuídos em 161 séries do banco de dados morfológicos final. Sobre esses dados, chama a atenção as diferenças cronológicas observadas na amostra. Foi possível estabelecer datações putativas a apenas 79 das 161 séries, o que, como comentado anteriormente, não deixa de ser uma cifra notável dada a organização inicial dos dados. Com uma amplitude variando entre 10.000 e 20 anos Antes do Presente ${ }^{41}$ (A.P.), os valores atribuídos podem ser distribuídos conforme é exemplificado através da Tabela 3.5 e da Figura 3.10. Essa informação também foi levada em consideração para a inferência do padrão de variação intrapopulacional observada na morfologia craniana humana.

Tabela 3.5 - Tabela de frequência com a distribuição das antiguidades (anos A. P.) das populações amostradas (Tabela 3.2).

\begin{tabular}{ccccc}
\hline Classes & Frequência & $\begin{array}{c}\text { frequência } \\
\text { cumulativa }\end{array}$ & Porcentagem & $\begin{array}{c}\text { porcentagem } \\
\text { cumulativa }\end{array}$ \\
\hline $0,000000<x<=2000,000$ & 60 & 60 & 75,95 & 75,95 \\
$2000,000<x<=4000,000$ & 12 & 72 & 15,19 & 91,14 \\
$4000,000<x<=6000,000$ & 5 & 77 & 6,33 & 97,47 \\
$6000,000<x<=8000,000$ & 0 & 77 & 0,00 & 97,47 \\
$8000,000<x<=10000,00$ & 2 & 79 & 2,53 & 100,00 \\
\hline Total & 100,00 & 79 & 100,00 & 100,00 \\
\hline
\end{tabular}

O somatório é 79 e não 161 pelo fato de que 82 populações não apresentaram datações putativas.

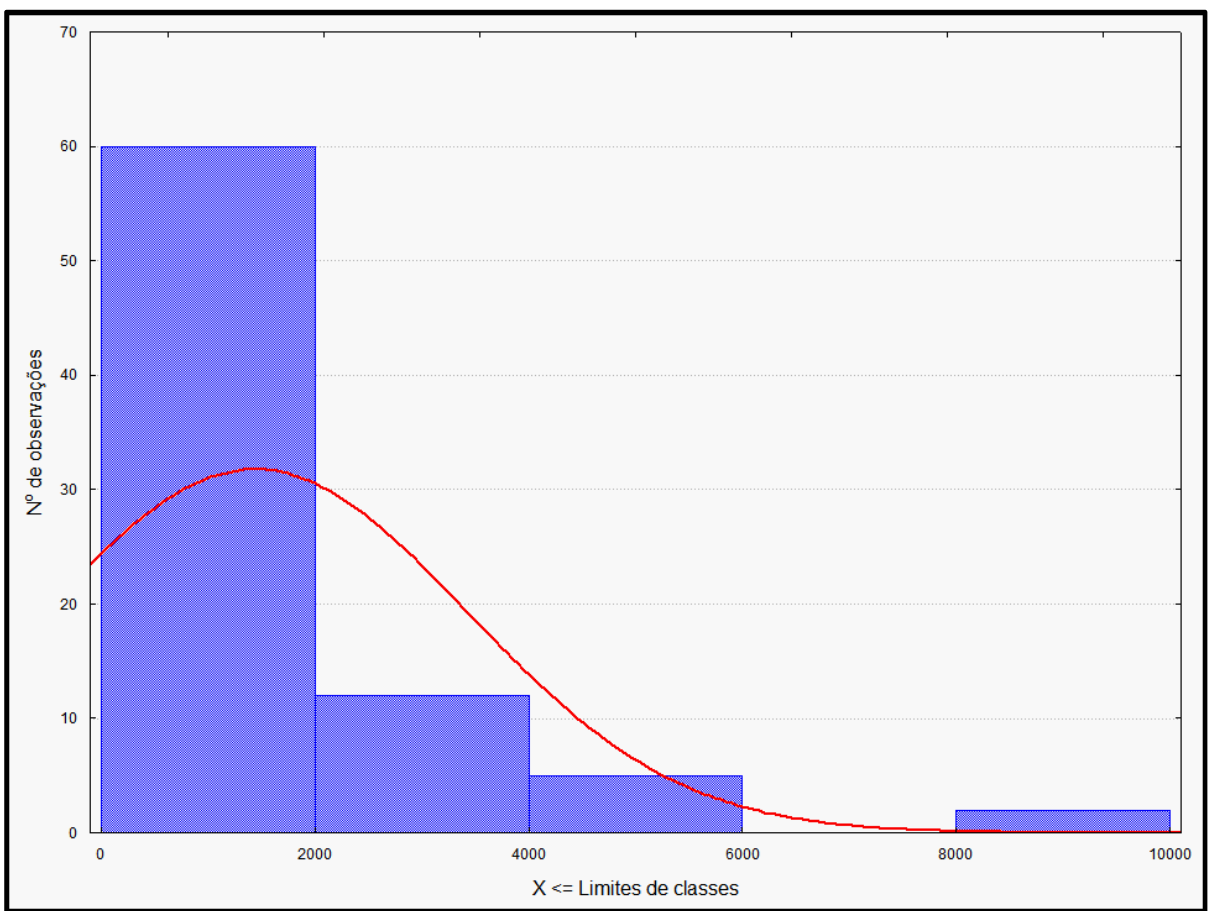

Figura 3.10 - Distribuição das antiguidades atribuídas às populações amostradas.

\footnotetext{
${ }^{41}$ Por convenção, datações radiométricas admitem o presente como 1950 (Stuiver \& Polach, 1977).
} 
Adicionalmente, foi também utilizada, para cada população, a informação de sua distância média em relação à Etiópia (calculadas de acordo com o custo mínimo, conforme já apresentado). Tais distâncias foram extraídas da matriz de distâncias geográficas anteriormente descrita (apresentada no Apêndice 4), e representam as distâncias de cada população amostrada em relação ao ponto de origem africana (DOA) considerado nas análises desenvolvidas nesta tese.

Com esse conjunto de dados, a análise proposta consistiu em correlacionar os valores estimados de variação fenotípica (representados pelos CVM) às cifras de distância para a Etiópia (DOA), para cada uma das populações amostradas. Estatísticas descritivas das retas obtidas forneceram os resultados sobre os quais as interações investigadas serão discutidas. Figuras e equações foram gerados em R x64 2.11.o (R Development Core Team, 2010) e Statistica 8.o (StatSoft Inc., 2007).

\section{b) Distribuição da variação interpopulacional}

De maneira complementar ao teste proposto anteriormente, as mesmas questões se aplicam à questão da diversidade interpopulacional humana, com a particularidade de que, sob um regime evolutivo neutro espera-se que, à medida que aumenta a distância geográfica que as separa, as populações amostradas aumentam o grau de divergência entre elas (Relethford, 2004a). Esse raciocínio baseia-se na ideia de que os subgrupos populacionais acumulam variação intergrupal ao longo do tempo, diferenciando-se uns dos outros e mantendo sua estruturação geográfica como se fossem resultantes de um evento de isolamento por distância (IPD), como definido por Wright (1943), essencialmente relacionado à deriva genética aleatória, de característica neutra. Sob esse raciocínio, espera- 
se que subpopulações oriundas de uma metapopulação inicial apresentam, entre si, divergência genética proporcional ao tempo e à distância que as separam.

Tal padrão de diversificação interpopulacional vem sendo continuamente demonstrado quando marcadores moleculares são utilizados como objeto de estudo (Lewontin, 1972; Nei \& Roychoudhury, 1974; Barbujani et al., 1997; Templeton, 1999; Serre \& Pääbo, 2004; Wang et al., 2007; para uma visão crítica ver Rosenberg et al., 2002) e, apesar dos desajustes atribuídos às diferenças na herdabilidade, resultados semelhantes vem sendo obtidos quando marcadores fenotípicos, notadamente morfologia craniana, são utilizados (Relethford 1994, 2002, 2004a; Roseman, 2004; Roseman \& Weaver, 2004; Manica et al., 2007), sugerindo que "moléculas e ossos" apresentam um perfeito ajuste no que toca aos ditames evolutivos (Roseman \& Weaver, 2007; Betti et al., 2009).

Nesse contexto, o objetivo desta análise é avaliar se a distância geográfica entre populações é, sozinha, um bom preditor da divergência populacional biológica, inferida através de traços craniométricos, como sugerido pelos proponentes da similaridade entre os padrões de diversificação inferidos através de marcadores moleculares e morfológicos. Para tanto, foram construídas matrizes de distâncias geográficas $\left(\mathrm{D}_{\mathrm{Geo}}\right)$, representando, obviamente, as distâncias geográficas, em quilômetros, entre todos os pares possíveis de populações estudadas (como anteriormente descritas), bem como uma matriz de efeito continental $\left(\mathrm{E}_{\mathrm{Con}}\right)^{42}$, apresentando a classificação da relação entre as populações quanto a pertencerem ou não aos mesmos continentes, e uma matriz de distâncias genéticas $\left(\mathrm{D}_{\mathrm{Gen}}\right)$, calculada através do coeficiente de heterozigosidade $\left(F_{\mathrm{ST}}\right)$ entre os pares possíveis de populações estudadas.

Neste trabalho, o $\mathrm{F}_{\mathrm{ST}}$ foi calculado para todas as séries esqueletais que contenham ao menos 25 indivíduos amostrados. Dessa maneira, o cálculo envolveu 8898 indivíduos

\footnotetext{
${ }^{42}$ Consiste em uma matriz binária na qual populações que se localizam dentro de um mesmo continente apresentam valor 0 e populações que localizam-se em continentes diferentes apresentam o valor 1 . Essa nova matriz pode ser correlacionada à matriz de distâncias geográficas, corrigindo-a quanto ao fator continente e também à matriz de distâncias.
} 
distribuídos em 128 populações, analisadas de forma par a par, representando, assim, a variação morfológica interpopulacional, através de uma matriz com a mesma dimensão das de distâncias geográficas e de efeito continental. A interação entre essas matrizes foi avaliada através dos coeficientes de correlação de Pearson [coeficiente de correlação produtomomento "r" (Pearson, 1896)] ao passo que suas significâncias estatísticas foram calculadas através de testes de correlação de Mantel (1967) após 9.999 permutaçõess. Esses cálculos foram efetuados através da utilização do pacote Vegan (Oksanen et al., 2011), na plataforma R (R Development Core Team, 2010).

\section{c) Partição da variação entre fenótipo e genótipo: caso específico de Nativos}

\section{Americanos}

Como introduzido no capítulo 1 e revisitado nos testes anteriormente apresentados, o debate sobre os ditames evolutivos envolvidos no processo de diversificação da morfologia

craniana humana ainda não está completamente solucionado, embora, normalmente, a maior parte dos especialistas tendem a sugerir que a morfologia craniana parece evoluir primariamente através de mecanismos estocásticos (von Cramon-Taubadel \& Weaver, 2009).

De maneira a contribuir para esse debate, a presente análise tem por objetivo investigar o comportamento evolutivo do crânio através da comparação entre marcadores moleculares neutros e marcadores representativos da morfologia craniana humana. Partindo-se da premissa de que marcadores de DNA mitocondrial (mtDNA) evoluem de maneira essencialmente neutra (Excoffier, 1990) espera-se que, caso crânios humanos também tenham evoluído dessa forma, a morfologia craniana apresente um padrão de dispersão geográfica muito semelhante ao observado quando se analisam os marcadores mitocondriais. De maneira complementar, espera-se que se o crânio, ou traços específicos de sua morfologia, apresentar comportamento distinto do esperado a partir dos marcadores neutros, esse sinal possa ser interpretado como assinatura de "não neutralidade". 
Para tanto, foram utilizadas as características craniométricas de 1135 indivíduos de 22 populações nativas do continente americano, contidas no banco de dados morfológicos final consolidado para esta tese. O banco de dados de mtDNA, já apresentado ao longo do texto, é composto pelas frequências haplotípicas de 1481 indivíduos distribuídos pelas mesmas 22 populações. A Figura 3.11 indica a localização geográfica de cada uma das populações amostradas.

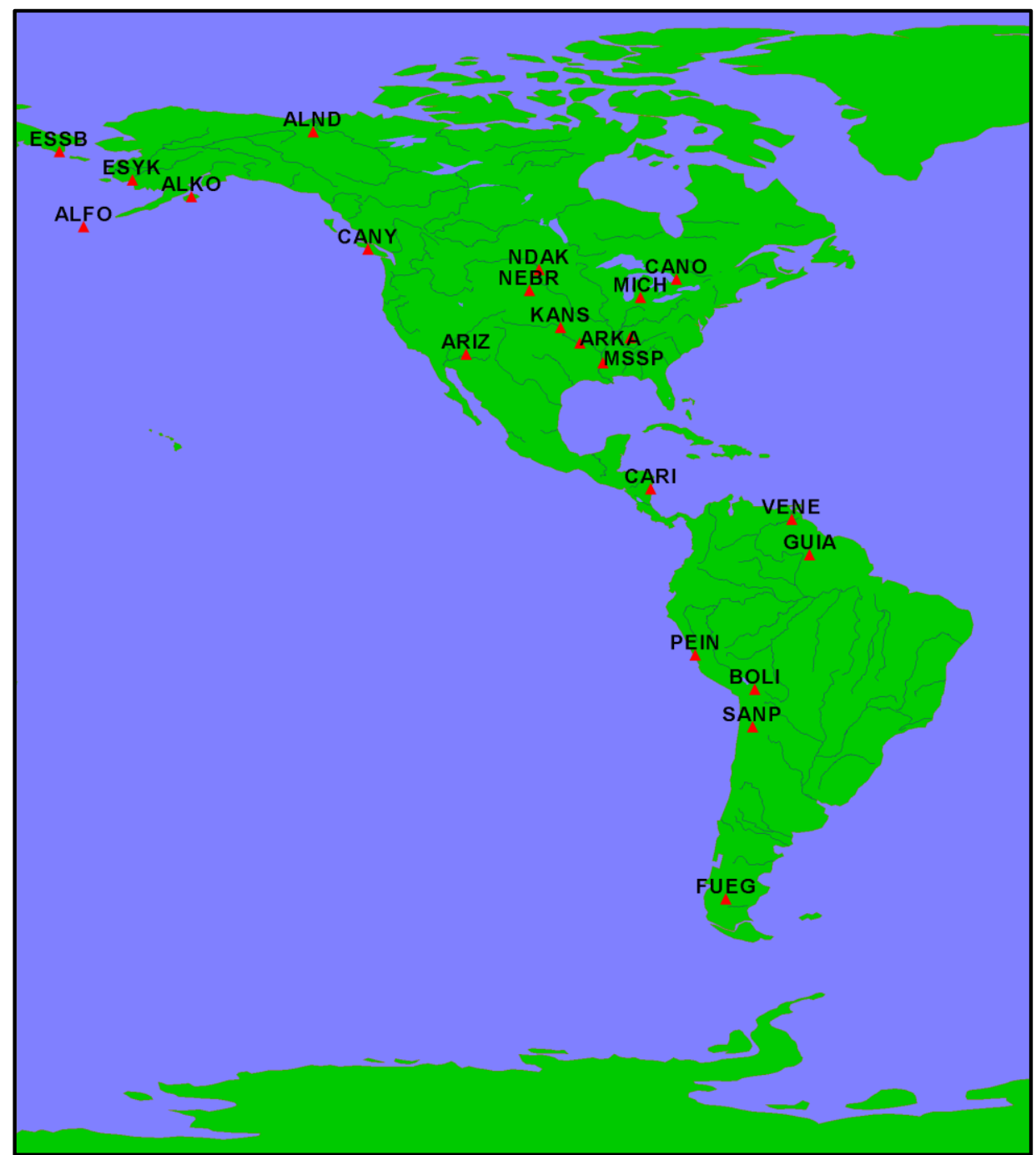

Figura 3.11 - Mapa do continente americano indicando a localização geográfica de cada uma das 22 populações utilizadas neste estudo.

A restrição da análise apenas à populações nativas americanas pode ser explicada por dois motivos: o primeiro deles é relativo à uma questão técnica, uma vez que a amostragem de dados moleculares e sua correspondência com as mesmas populações no banco de dados 
morfológicos foi mais efetiva na América do que aquelas obtidas em outras regiões geográficas. Essa correspondência é crucial para a comparação entre crânios e genes.

O segundo motivo ao qual populações nativas do Novo Mundo foram as escolhidas para a análise reside no fato de que o continente americano apresenta uma grande amplitude de extremos de latitude, i. e., a América ocupa desde extremos próximos ao polo Norte até extremos próximo ao polo Sul. Admitindo que, tratando-se de morfologia craniana, os sinais seletivos descritos na literatura atuam principalmente devido ao clima (Beals et al., 1984; Roseman, 2004; Harvati \& Weaver, 2006; Hubbe et al., 2009), pode-se especular que populações localizadas em pontos de equidistância latitudinal (por exemplo $30^{\circ} \mathrm{N}$ e $30^{\circ} \mathrm{S}$ ), apresentam mais semelhanças morfológicas do que genéticas entre si, revelando, assim, desvios da neutralidade quando se trata de traços cranianos. A Figura 3.12 ilustra esse raciocínio.

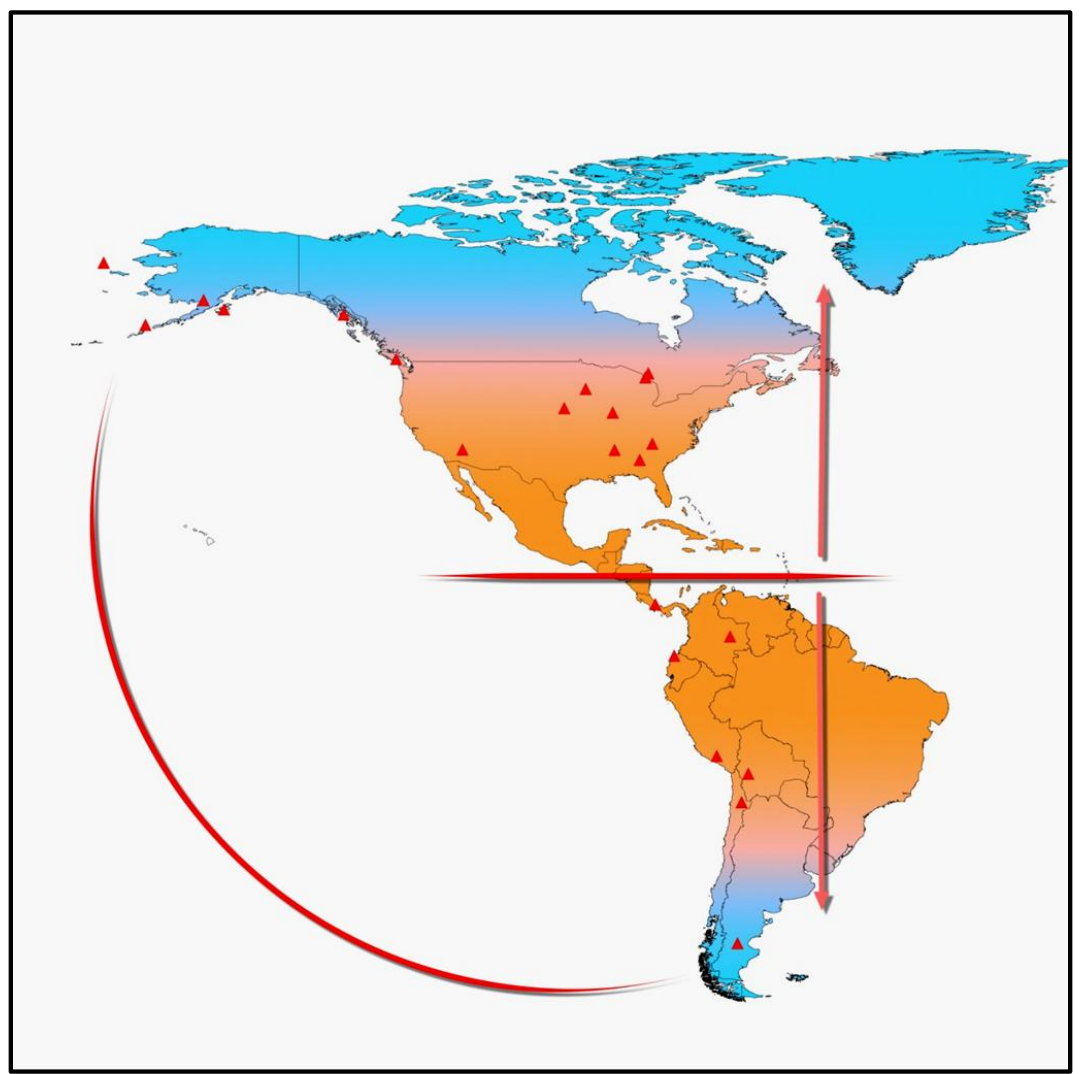

Figura 3.12 - Mapa do continente Americano ilustrando como a equidistância latitudinal poderia, hipoteticamente, representar um escalonamento climático para as populações em estudo. 
Todos os procedimentos quantitativos utilizados para a comparação entre a variação molecular e a morfológica foram realizados a partir da geração de matrizes de distâncias calculadas para todos os pares de populações. Através de correlação de Pearson seguida por teste de significância de Mantel (Mantel, 1967) baseado em 9.999 permutações, pode-se comparar as diferentes matrizes e dimensionar suas interações. Tais cálculos foram realizados através da utilização do pacote Vegan (Oksanen et al., 2011), na plataforma R ( Development Core Team, 2010). Três categorias de matrizes foram calculadas para esta investigação.

Os dados de frequência de haplogrupos de mtDNA, representando os dados moleculares neutros, resultaram em matrizes de distância de dados genéticos $\left(\mathrm{D}_{\mathrm{Gen}}\right)$. Essas matrizes são geradas a partir do cálculo de $\mathrm{F}_{\mathrm{ST}}$. Para o cálculo dos $\mathrm{F}_{\mathrm{ST}}$ foi utilizado o programa Arlequin ${ }^{\circledR} 3.0$ (Excoffier et al., 2005) e as matrizes foram calculadas a partir de 1000 permutações.

Os dados craniométricos, retratando a morfologia, são representados por matrizes de distâncias morfológicas $\left(\mathrm{D}_{\mathrm{Mor}}\right)$, calculada através de Distâncias de Mahalanobis. A Distância de Mahalanobis $\left(\mathrm{D}^{2}\right)$ entre dois grupos é obtida a partir da soma das diferenças ponderada pela matriz de covariância entre os dois grupos para todas as variáveis analisadas (Mahalanobis, 1936). A utilização da Distância de Mahalanobis representa uma poderosa ferramenta para se medir similaridade ou dissimilaridade entre conjuntos de amostras (Clark et al., 1993). Por esse motivo, é classicamente utilizada para medir distâncias biológicas (Reis, 2001; Valentin, 2000). Neste trabalho, as $\mathrm{D}^{2}$ foram calculadas através do programa Statistica ${ }^{\circledR}$ 8.0 (StatSoft Inc., 2007).

A última categoria de matrizes calculadas é a relativa à distância geográfica entre as populações estudadas $\left(D_{G e o}\right)$. Tal matriz foi extraída a partir da matriz anteriormente apresentada (Apêndice 4). 
Com base nas três categorias de matrizes, $\mathrm{D}_{\mathrm{Gen}}$, $\mathrm{D}_{\mathrm{Mor}}$, e $\mathrm{D}_{\mathrm{Geo}}$, três diferentes experimentos foram realizados: 1) Comparação entre as três matrizes e calibração do sinal de neutralidade, através da avaliação da correlação entre elas; 2) Detecção de neutralidade com controle do fator geográfico; 3) Série de comparações para cada uma das variáveis craniométricas estudadas, de maneira a avaliar possíveis desvios pontuais da morfologia craniana.

\subsection{2 - Modularidade, integração e padrões de V/CV da morfologia craniana humana}

Como já antecipado ao longo destes três capítulos, os objetivos centrais da pesquisa desenvolvida nesta tese se concentram, basicamente, na investigação exploratória e crítica exploratória dos padrões de variação da morfologia craniana humana. Enquanto o grupo de análises anteriormente apresentadas foi dedicado à constatação de como varia o formato do crânio de populações globalmente distribuídas, o conjunto de inferências a partir de agora expostas é voltado para a interpretação de como ocorre tal variação.

Para tanto, a estratégia adotada no presente conjunto de análises é, de maneira complementar às investigações anteriormente desenvolvidas, explorar os padrões de covariância, modularidade e integração morfológicas que emergem a partir da morfologia craniana (representada por medidas lineares) de populações humanas autóctones de ampla distribuição mundial. Ao avaliar esses padrões, de maneira intra e inter grupos (ou populações), espera-se detectar dois conjuntos de características (ou estruturações), em termos morfocranianos: a) generalidades comuns a todos os indivíduos, ou grupos; b) particularidades elementares distintivas de grupos específicos, independentemente dos critérios utilizados para o agrupamento (em geral, os critérios utilizados restringem-se à biologia e à localização geográfica dos indivíduos que formam o grupo). O conhecimento desses padrões gerais pode colaborar para a elucidação das interações histórico-estruturais das populações humanas (Gonzaléz-José, et al., 2004). 
Como contextualizado ao longo da Introdução, os conceitos de modularidade e de integração morfológicas passam pela constatação empírica de que, em se tratando de crânios, as medidas craniométricas apresentam maior ou menor associação umas às outras, formando grupos de variáveis mais ou menos coesos, os módulos cranianos. Das relações estabelecidas entre esses módulos ao longo do desenvolvimento do crânio emerge a propriedade denominada integração craniana (Klingenberg, 2005; Porto et al., 2009).

Em humanos são reconhecidas três regiões cranianas que refletem diretamente suas diferentes origens quanto ao desenvolvimento embrionário: a base do crânio, a face e o neurocrânio (Martínez-Abadías et al., 2009). Como modularidade é um conceito hierárquico, essas três regiões cranianas podem ainda ser organizadas de maneiras alternativas, refletindo, além de suas origens quanto ao controle genético de seus traços, as interações ocorridas durante o processo de seu desenvolvimento morfológico (Klingenberg, 2005) ou, ainda, suas necessidades funcionais. Dessa forma, uma maneira de se derivar as diferentes características cranianas representadas por suas medidas craniométricas é aborda-las em dois níveis de associação, um mais inclusivo, o desenvolvimental, e um mais redutivo, o funcional (González-José et al., 2004). Considerando as variáveis craniométricas disponíveis neste estudo, e seguindo parcialmente os modelos desenvolvidos e utilizados por Marroig \& Cheverud (2001) e González-José e colegas (2004), pode-se reconhecer a morfologia craniana humana derivada da seguinte maneira: i) associação desenvolvimental, representada por dois módulos, "Face" e "Neurocrânio"; ii) associação funcional, constituída por seis módulos, "Abóboda craniana", "Nasal", "Basicraniana", "Zigomático-temporal", "Oral" e "Orbital". A Tabela 3.6 apresenta como essa hierarquização se reflete nas 24 medidas cranianas do protocolo Howells (Howells, 1973) utilizada neste estudo. 
Tabela 3.6 - Sigla e nível hierárquico-associativo das medidas craniométricas utilizadas neste trabalho, tomadas de acordo com o protocolo Howells (1973).

\begin{tabular}{|c|c|c|}
\hline Sigla & Associação Desenvolvimental & Associação Funcional \\
\hline GOL & Neurocrânio & Abóboda craniana \\
\hline NOL & Neurocrânio & Abóboda craniana \\
\hline BNL & Face & Nasal \\
\hline BBH & Neurocrânio & Basicraniana \\
\hline XCB & Neurocrânio & Abóboda craniana \\
\hline XFB & Neurocrânio & Abóboda craniana \\
\hline ZYB & Face & Zigomático-temporal \\
\hline AUB & Neurocrânio & Zigomático-temporal \\
\hline ASB & Neurocrânio & Abóboda craniana \\
\hline BPL & Face & Oral \\
\hline NPH & Face & Nasal \\
\hline NLH & Face & Nasal \\
\hline $\mathrm{OBH}$ & Face & Orbital \\
\hline OBB & Face & Orbital \\
\hline NLB & Face & Nasal \\
\hline MAB & Face & Oral \\
\hline MDH & Neurocrânio & Basicraniana \\
\hline MDB & Neurocrânio & Basicraniana \\
\hline ZMB & Face & Oral \\
\hline DKB & Face & Orbital \\
\hline WNB & Face & Nasal \\
\hline FRC & Neurocrânio & Abóboda craniana \\
\hline PAC & Neurocrânio & Abóboda craniana \\
\hline OCC & Neurocrânio & Basicraniana \\
\hline
\end{tabular}

As Figuras 3.13 e 3.14 sintetizam essas informações, apresentando, respectivamente, regiões da anatomia craniana que se agrupam formando módulos específicos. Na Figura 3.13, relativa à representação das associações desenvolvimentais, estruturas preenchidas em cinza correspondem ao módulo neurocraniano, enquanto que as coloridas em laranja correspondem ao módulo facial. A Figura 3.14, representativa das associações modulares funcionais apresenta as estruturas do módulo neurocraniano preenchidas por roxo, as do módulo oral coloridas de marrom, as do módulo zigomático-temporal representadas por 
vermelho, as do módulo nasal em verde, as do módulo orbital em azul e em rosa as do basicraniano.

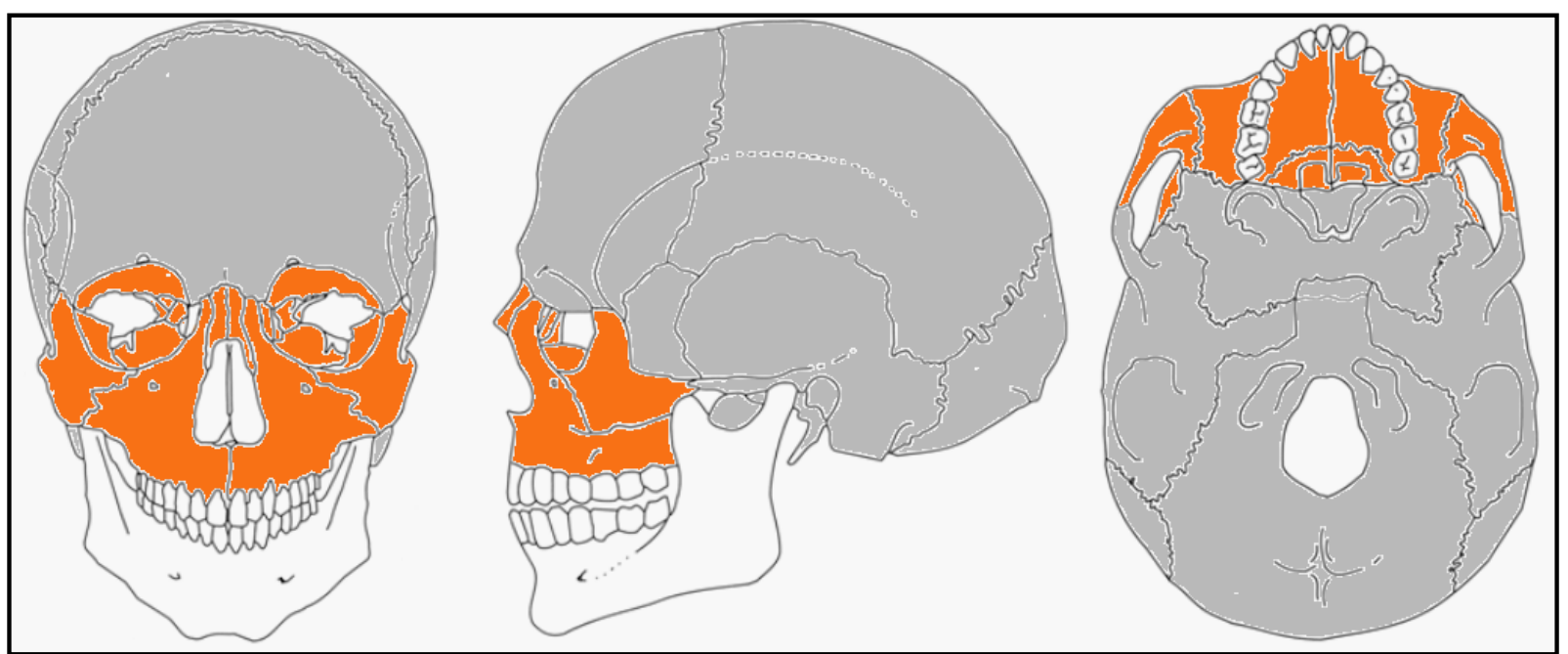

Figura 3.13 - Estruturas dos módulos neurocraniano (cinza) e facial (laranja) da associação modular desenvolvimental do crânio humano.

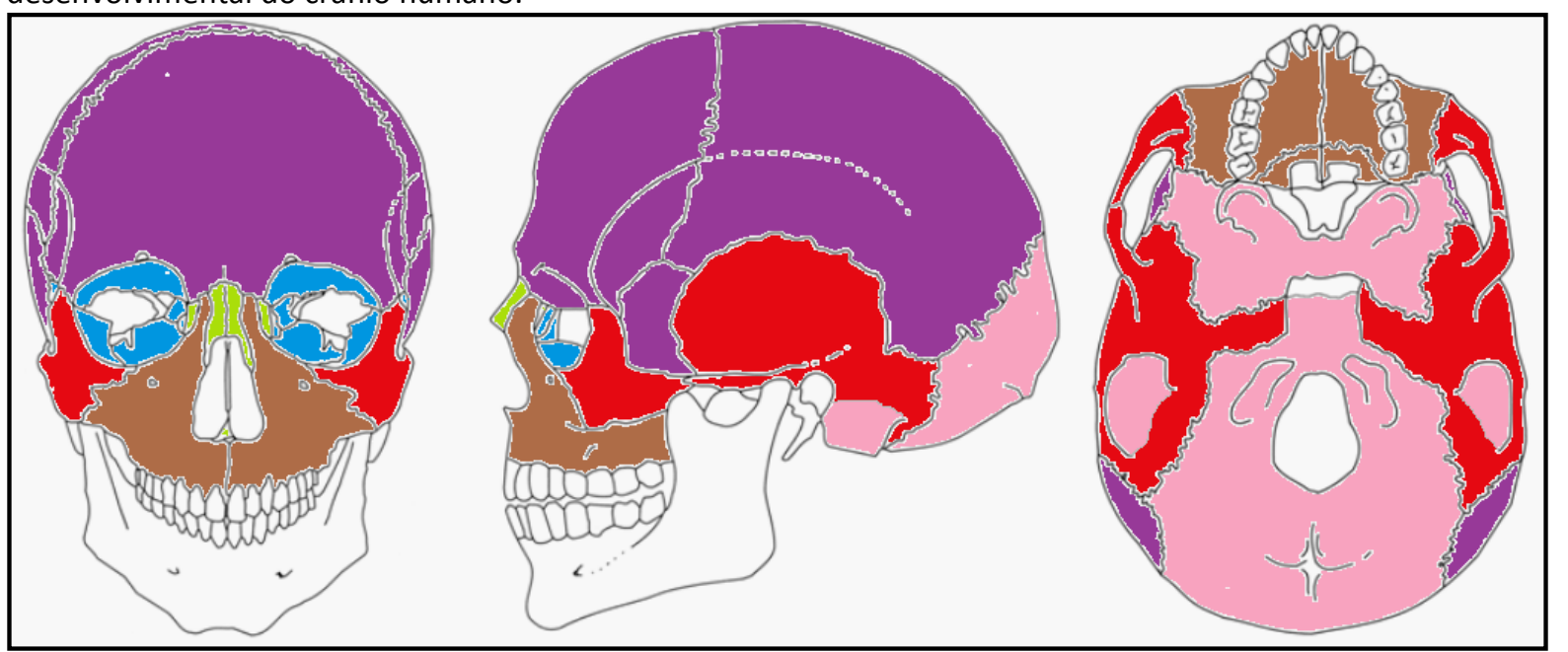

Figura 3.14 - Estruturas dos módulos neurocraniano (roxo), oral (marrom), orbital (azul), nasal (verde), zigomático-temporal (vermelho) e basicraniano (rosa) da associação modular funcional do crânio humano.

A definição dessas categorias permite o cálculo de matrizes hipotéticas de modularidade, as matrizes M. Essas matrizes consistem na representação matemática das relações entre as variáveis compreendidas em um módulo específico. A Figura 3.15 apresenta três variáveis hipotéticas e as relações modulares entre elas. 


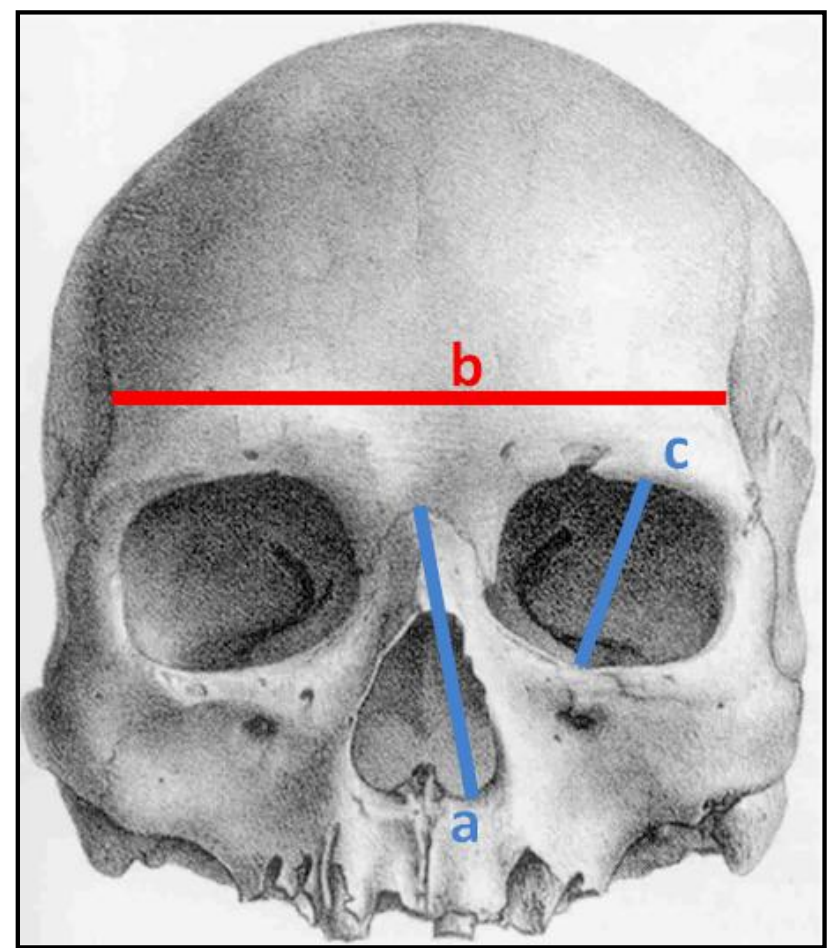

Figura 3.15 - Medidas cranianas e suas relações modulares (representadas pelas cores vermelho e azul) hipotéticas. Norma frontal.

Tomando por base o crânio e as medidas lineares mostrados na Figura 3.15, e admitindo que as cores representam dois módulos cranianos diferentes, vermelho e azul, pode-se construir uma matriz $\mathbf{M}_{\text {modular }}$ que represente algebricamente a relação biológica entre os traços cranianos. Adotando uma notação matricial binária (Duarte Junior, 2008), constituída por valores "1" para medidas pertencentes a um determinado módulo e "o" para as que não pertencem a esse modulo é possível escrever a matriz $M_{\text {Azul }}$ através das relações entre as variáveis conforme mostrado na Tabela 3.7.

Tabela 3.7 - Representação das relações entre as variáveis do módulo hipotético "Azul".

\begin{tabular}{c|ccc}
\hline Variável & A & B & C \\
\hline A & 1 & 0 & 1 \\
B & 0 & 1 & 0 \\
C & 1 & 0 & 1 \\
\hline
\end{tabular}


Em notação matricial, a matriz hipotética $\mathrm{M}_{\text {Azul }}$ é escrita da maneira que se segue.

$$
\mathbf{M}_{\text {Azul }}=\left\|\begin{array}{ccc}
\mathbf{1} & \mathbf{0} & \mathbf{1} \\
\mathbf{0} & \mathbf{1} & \mathbf{0} \\
\mathbf{1} & \mathbf{0} & \mathbf{1}
\end{array}\right\|
$$

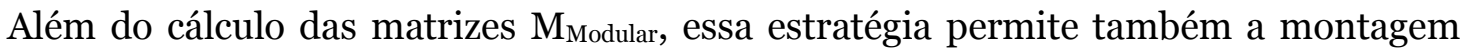
das matrizes $\mathrm{M}_{\text {Integrada, }}$ com as mesmas características das primeiras com a diferença que, no segundo caso, envolve numa mesma matriz quantos módulos forem solicitados. Desta forma, na montagem de uma matriz $\mathrm{M}_{\text {Integrada, a notação binária que representa as medidas lineares }}$ assume valores "1" para características pertencentes a um mesmo módulo e valores "o" para as que pertencem a módulos diferentes. Note que as matrizes M são, obrigatoriamente, simétricas, com todos os elementos de sua diagonal principal assumindo o valor 1. Assim, serão calculadas três matrizes M para o nível associativo desenvolvimental43 e sete para o funcional. Essas matrizes M serão utilizadas como modelo comparativo de integração e modularidade às matrizes representativas das variações fenotípicas (craniométrica) das populações em estudo. Essas matrizes foram montadas com a utilização de planilhas eletrônicas Excel e transformadas em arquivos de texto (formato .txt).

Como já antecipado na Introdução, duas categorias de matrizes fenotípicas, baseadas nos traços craniométricos das populações constantes na Tabela 3.2, foram calculadas neste trabalho. As matrizes $\mathrm{C}$ de correlação e as matrizes V/CV de variância/covariância.

As matrizes $\mathrm{C}$ correspondem às matrizes contendo os coeficientes de correlação de Pearson [coeficiente de correlação produto-momento "r" (Pearson, 1896)] entre todos os pares possíveis de variáveis e considerando todos os indivíduos de cada uma das amostras

\footnotetext{
${ }^{43}$ O termo "desenvolvimental" não apareceu em nenhum dos dicionários da língua portuguesa consultados durante a produção deste texto. Busca em ferramenta especializada no site da Academia Brasileira de Letras na internet também não retornou nenhum resultado. Como a norma da língua admite o substantivo "desenvolvimento", cuja equivalência em inglês é "development", optou-se pela forma "desenvolvimental" como equivalência para "developmental" do inglês.
} 
envolvidas no estudo. É uma medida da intensidade da associação existente entre os elementos de duas variáveis quantitativas e seu valor (r) é dado pela expressão,

$$
r=\frac{S P x y}{\sqrt{S Q x \times S Q y}}
$$

onde $S P_{x y}$ corresponde à soma dos produtos dos elementos de x e y envolvidos, e $S Q_{x}$ e $S Q_{y}$ correspondem, respectivamente, às somas dos desvios quadráticos dos elementos de x e y.

Essas matrizes também são obrigatoriamente simétricas com todos os elementos de sua diagonal principal assumindo o valor 1. O cálculo das matrizes $\mathrm{C}$ foi feito em $\mathrm{R}(\mathrm{R}$ Development Core Team, 2010).

Admitindo o mesmo crânio e variáveis representados na Figura 3.15 seria possível escrever a matriz C resultante para essa população fictícia da maneira como é algebricamente apresentado na Tabela 3.8.

Tabela 3.8 - Representação algébrica da construção de uma matriz de correlação (coeficiente de Pearson) entre três variáveis hipotéticas.

\begin{tabular}{c|cccc}
\hline Variável & A & B & C \\
\hline A & 1 & $r=\frac{S P b a}{\sqrt{S Q b \times S Q a}}$ & $r=\frac{S P c a}{\sqrt{S Q c \times S Q a}}$ \\
B & $r=\frac{S P a b}{\sqrt{S Q a \times S Q b}}$ & 1 & $r=\frac{S P c b}{\sqrt{S Q c \times S Q b}}$ \\
$\mathrm{C}$ & $r=\frac{S P a c}{\sqrt{S Q a \times S Q c}}$ & $r=\frac{S P b c}{\sqrt{S Q b \times S Q c}}$ & 1 \\
\hline
\end{tabular}

O mesmo protocolo foi seguido para a obtenção das matrizes de variância/covariância V/CV. De maneira análoga à correlação entre dois valores, que mede como que o aumento (ou diminuição) do valor de uma variável se relaciona ao crescimento (ou diminuição) do valor de uma outra variável, a covariância exprime como essa mesma relação, de aumento ou diminuição coordenada, se estabelece entre duas variáveis, quantificando, ao invés de seus 
valores absolutos, como na correlação, seus valores relativos, ou mais precisamente, suas variâncias (Sokal \& Rohlf, 2012).

Como o nome sugere, duas entidades matemáticas fazem parte fundamental do conceito de matriz $\mathrm{V} / \mathrm{CV}$ : a variância e a covariância. A variância expressa a variabilidade geral de um conjunto de números, através da média dos desvios desses números em relação à média apresentada pelo conjunto (Callegari-Jacques, 2003). Sua fórmula geral é dada pela expressão,

$$
\delta_{x}^{2}=\frac{\sum\left(x-\mu_{x}\right)^{2}}{n-1}
$$

onde $\mu_{x}$ corresponde à média dos valores do conjunto de $x$ e $n$ é igual ao número de elementos do conjunto. Algebricamente, a variância corresponde ao quadrado do desviopadrão ( $\delta)$.

A covariância é dada pela seguinte expressão,

$$
\operatorname{COV}_{x y}=\frac{1}{n-1} \sum\left(x_{i}-\mu_{x}\right)\left(y_{i}-\mu_{y}\right)
$$

onde $n$ é o número de elementos do conjunto, $\mu_{x}$ é a média dos valores do conjunto $x$, e $\mu_{y}$ é a média dos valores do conjunto $y$.

Das fórmulas acima e retomando o exemplo ilustrado pela situação da Figura 3.15, mais uma vez considerando a situação em termos populacionais, intuitivamente pode-se depreender que o cálculo da variância só se aplica para valores de uma mesma variável, ao passo que o cálculo da covariância, por sua vez, só se aplica a pares de variáveis. Com essa constatação, a Tabela 3.9 apresenta a notação algébrica da matriz V/CV resultante do exemplo tipificado por uma população de crânios como o exemplificado na Figura 3.15. 
Tabela 3.9 - Representação algébrica da construção de uma matriz de variância/covariância entre as três variáveis hipotéticas representadas na Figura 2.14.

\begin{tabular}{c|ccc}
\hline Var. & A & B & C \\
\hline A & $\delta_{a}^{2}=\frac{\sum\left(a-\mu_{a}\right)^{2}}{n-1}$ & $\operatorname{COV}_{b a}=\frac{1}{n-1} \sum\left(b_{i}-\mu_{b}\right)\left(a_{i}-\mu_{a}\right)$ & $\operatorname{COV}_{c a}=\frac{1}{n-1} \sum\left(c_{i}-\mu_{c}\right)\left(a_{i}-\mu_{a}\right)$ \\
B & $\operatorname{COV}_{a b}=\frac{1}{n-1} \sum\left(a_{i}-\mu_{a}\right)\left(b_{i}-\mu_{b}\right)$ & $\delta_{b}^{2}=\frac{\sum\left(b-\mu_{b}\right)^{2}}{n-1}$ & $\operatorname{COV}_{c b}=\frac{1}{n-1} \sum\left(c_{i}-\mu_{c}\right)\left(b_{i}-\mu_{b}\right)$ \\
$\mathrm{C}$ & $\operatorname{COV}_{a c}=\frac{1}{n-1} \sum\left(a_{i}-\mu_{a}\right)\left(c_{i}-\mu_{c}\right)$ & $\operatorname{COV}_{b c}=\frac{1}{n-1} \sum\left(b_{i}-\mu_{b}\right)\left(c_{i}-\mu_{c}\right)$ & \\
& & & \\
\hline
\end{tabular}

Assim como no caso das matrizes $\mathrm{C}$, as matrizes $\mathrm{V} / \mathrm{CV}$ são simétricas, mas, diferentemente daquelas, essas não apresentam sua diagonal principal ocupada por valores 1 . Essas matrizes (V/CV) também foram calculadas em ambiente $\mathrm{R}$ ( $\mathrm{R}$ Development Core Team, 2010).

Dessa forma, o delineamento deste grupo de análises conta, até aqui, com três famílias de matrizes de dados: as matrizes $\mathrm{M}$, as matrizes $\mathrm{C}$ e as matrizes V/CV. Com exceção das M, essas matrizes foram calculadas com base na formação populacional (grupo biológico) em estudo, isto é, foram formadas de acordo com o tipo de interação inter e intra populacional que foi objeto pontual de investigação em determinado momento da análise. Todas os dados craniométricos utilizados para a construção das matrizes $\mathrm{C}$ e V/CV apresentadas neste grupo de análises são referentes às populações contidas no banco de dados morfológicos final, descrito pela Tabela 3.2.

Resta, então, estabelecer quais critérios foram utilizados para a formação de grupos biológicos a partir das populações amostradas na Tabela 3.2. Considerando o grau de 
informação aglutinada através da consolidação dos dados aqui apresentados, foram escolhidas quatro abordagens de hierarquização: I) Morfológica; II) Cronológica; III) Geográfica; IV) Molecular.

\section{I) Hierarquização morfológica}

A hierarquização morfológica obedeceu a formação de grupos biológicos estabelecidos a partir do agrupamento gerado através da análise de agrupamentos ("clusters") sobre uma matriz de distâncias de Mahalanobis $\left(\mathrm{D}^{2}\right)$ calculadas a partir das características craniométricas das populações amostradas conforme indicado na Tabela 3.2. O critério de agregação selecionado para o agrupamento foi o método da ligação simples, ou, como também é conhecido, de vizinhos próximos (Sneath, 1957). Esse critério assume que a similaridade entre dois conglomerados de dados é definida pelos elementos mais similares entre si, fazendo com que os grupos fornados sejam coesos e próximos. Esse algoritmo tende a formar agrupamentos densos e estruturados (Sneath, 1957; Mingoti, 2005). Tanto o cálculo da matriz $\mathrm{D}^{2}$ quanto a análise de agrupamento foram executadas através do programa Statistica 8.0 (Statsoft, 2007).

\section{II) Hierarquização cronológica}

A hierarquização cronológica obedeceu as classes de dados demonstradas na Tabela 3.5 e Figura 3.10. Tal classificação estabelece a formação de quatro grupos cronológicos: 1) de 2000 a o anos A. P. (n=60 séries), de 4000 a 2000 anos A. P. (n=12), de 6000 a 4000 anos A. P. $(n=5)$ e de 10000 a 8000 anos A. P. $(n=2)$. O classe delimitada pelo intervalo que vai de 8000 a 6000 A. P. não apresenta nenhuma série e não será representado na análise. 


\section{III) Hierarquização geográfica}

Dentre os critérios selecionados, este é o de mais difícil operacionalização. O critério geográfico é de difícil aplicação e nem sempre estabelece as melhores relações entre os grupos. Para ilustrar tal dificuldade, pode-se considerar, por exemplo, a população do Marrocos. Não resta dúvidas que o Marrocos localiza-se na África, no entanto, tal população é muito mais próxima da Europa do que de uma outra população sul-africana, por exemplo. Dessa maneira, optou-se por adotar um método que fosse o menos subjetivo possível para o estabelecimento de agrupamentos de acordo com o critério geográfico, resultando na escolha da aplicação de uma análise de agrupamentos ("clusters") utilizando o método de Ward (Ward, 1963). Também conhecido como método da mínima variância, este critério considera, inicialmente, cada elemento da análise como sendo um único grupo. Em cada passo do algoritmo de agrupamento, agrega-se um novo elemento ao grupo previamente estabelecido e calcula-se a soma de quadrados dento de cada grupo formado, mantendo-se os agrupamentos formados quando se obtém as menores somas (Ward, 1963). Tende a combinar agrupamentos dicotômicos ou com pequeno número de observações, além de conglomerados com números próximos de observações, isto é, grupos de tamanhos semelhantes (Mingoti, 2005). Tal análise foi empreendida através do programa Statistica 8.0 (Statsoft, 2007).

\section{IV) Hierarquização molecular}

Para a atribuição de grupos biológicos de acordo com informações moleculares, foi utilizado o banco de dados de microssatélites descrito na Tabela 3.4. Tais dados geraram uma matriz de distâncias genéticas, resultantes do cálculo de $\mathrm{F}_{\mathrm{ST}}$ interpopulacional. A matriz de distâncias foi submetida à aplicação do método de agrupamento "Neighbor Joining Tree" 
$(\mathrm{NJT})^{44}$ (Saitou \& Nei, 1987), resultando em uma árvore filogenética apresentando as relações fenéticas entre as populações amostradas. As populações correspondentes contidas no banco de dados morfológico (Tabela 3.2) foram selecionadas e reagrupadas de acordo com o estabelecido pela árvore evolutiva. $\mathrm{O}$ cálculo de $\mathrm{F}_{\mathrm{ST}}$ foi efetuado a partir do programa Arlequin ${ }^{\circledR} 3.0$ (Excoffier et al., 2005), com a matriz de distâncias calculada a partir de 1000 permutações. O agrupamento de NJT foi executado com a utilização de parte dos códigos do pacote estatístico "APE" (Paradis et al., 2004) na plataforma R (R Development Core Team, 2010).

Com essa estratégia analítica e com a contextualização teórica já apresentada, três tipos de análises exploratórias foram desenvolvidas 45 e aplicadas aos quatro conjuntos de dados estabelecidos pelos critérios de formação de grupos: d) comparações entre matrizes de Correlação (C) e de Variância/Covariância (V/CV) para estimativa dos padrões de similaridade; e) detecção dos padrões de modularidade e integração; f) inferência da magnitude das correlações entre caracteres. Todas as análises foram desenvolvidas sobre os dados contidos no banco morfológico final (Tabela 3.2).

\section{d) Comparações entre matrizes $\mathrm{C}, \mathrm{V} / \mathrm{CV}$, e seus padrões de similaridade}

Seguindo o arcabouço teórico sobre construção de matrizes exposto no início deste tópico, foram calculadas matrizes $\mathrm{C}$ e $\mathrm{V} / \mathrm{CV}$ para todos os arranjos populacionais obtidos através dos critérios de hierarquização anteriormente descritos. Dessa maneira, quatro níveis de organização populacional foram obtidos para cada uma das matrizes inferidas.

O padrão de similaridade entre as matrizes $\mathrm{C}$ foram investigados através do cálculo do coeficiente de correlação (r) de Pearson (1896), seguido de teste de Mantel (1967) para

\footnotetext{
${ }^{44}$ Por ser amplamente difundido nos textos técnicos, mesmo em língua portuguesa, optou-se por manter a grafia do nome do método de agrupamento em inglês.

${ }^{45}$ A fim de tornar a leitura do próximo capítulo mais fluída e agradável, os itens apresentados neste grupo de análise serão ordenados a partir do último posto ocupado no grupo analítico anterior.
} 
detecção de significância após 9.999 permutas entre todos os pares possíveis dentro de cada nível hierárquico de organização populacional. Essa inferência fornecerá uma estimativa direta do comportamento dos caracteres craniométricos no que diz respeito ao padrão de conexões entre diferentes estruturas cranianas e, uma vez que admitimos que a morfologia craniana possa ser informativa da história evolutiva das populações, espera-se que tais padrões revelem informações filogenéticas das séries amostradas. Todos os cálculos realizados nessas análises foram executados em plataforma R ( $\mathrm{R}$ Development Core Team, 2010), apoiado no pacote Vegan (Oksanen et al., 2011).

Já as comparações entre as matrizes $\mathrm{V} / \mathrm{CV}$ foram realizadas através da técnica de "random skewers" (Cheverud, 1996b; Marroig \& Cheverud, 2001; Cheverud \& Marroig, 2007). Tal técnica consiste em estimar a similaridade entre matrizes através da comparação dos vetores-resposta resultantes da multiplicação entre vetores aleatórios e as matrizes que se deseja comparar. Cada vetor aleatório é representado por uma matriz coluna, de dimensão "n" igual a das matrizes objeto de comparação, composto por "n" elementos extraídos aleatoriamente de uma distribuição normal. Como cada vetor aleatório multiplica todas as matrizes alvo de comparação, diferenças entre os vetores-resposta indicam, indiretamente, diferenças entre as matrizes comparadas. As diferenças entre os vetores-respostas é estimada através do cálculo da média dos coeficiente de correlação de Pearson entre todas as matrizes colunas geradas. Assim, essa técnica possibilita a inferência de dissimilaridades entre matrizes dentro de uma amplitude de variação com limites entre -1 e 1.

Neste estudo, foram utilizados 1000 vetores aleatórios para a aplicação da técnica de "random skewers"46. As análises foram realizadas na plataforma R ( R Development Core Team, 2010), com utilização de parte dos códigos contidos no pacote "phytools" o.1-9 (Revell, 2009, 2012).

\footnotetext{
${ }^{46}$ A melhor tradução para "random skewers" seria "vetores aleatórios". No entanto, por ser amplamente difundido entre os especialistas, o termo será utilizado também em inglês.
} 


\section{e) Detecção dos padrões de modularidade e integração morfológica}

Para inferir o padrão de ocorrência de módulos cranianos nas populações envolvidas foi investigada a interação entre as matrizes $\mathrm{C}$ de cada grupo biológico determinado e as matrizes hipotéticas M, referentes a cada módulo de caracteres. Tal interação é quantificada através do cálculo do coeficiente de correlação de Pearson seguido do teste de Mantel para detecção de significância. Nesta análise, as correlações entre matrizes e o teste de Mantel de significância foram efetuados através da utilização do pacote Vegan (Oksanen et al., 2011), na plataforma R (R Development Core Team, 2011), configurados para 9.999 permutações em cada análise.

\section{f) Inferência da magnitude de correlação entre caracteres}

Conforme destacado por Porto e colaboradores (2009), a magnitude das correlações entre caracteres é tão determinante para o resultado evolutivo de um complexo morfológico quanto o é o padrão dessas correlações. Em outras palavras, a intensidade com que as conexões são estabelecidas e tão importante quanto com quais caracteres ocorrem.

Uma maneira de se estimar tal grandeza é através do cálculo do coeficiente de determinação da matriz de correlação $\left(\mathrm{r}^{2}\right)$, que consiste em se calcular a média dos valores $\mathrm{r}$ de uma matriz de correlação de caracteres (matriz C). Tal estimativa independe da escala do organismo analisado, o que a caracteriza como uma medida adequada para a inferência da magnitude de correlação geral (Cheverud et al., 1989).

Foram calculados $\mathrm{r}^{2}$ para todas as matrizes $\mathrm{C}$ estimadas nos diferentes níveis de hierarquia populacional. Assim, foi possível estabelecer uma distribuição de $\mathrm{r}^{2}$ para cada grupo estimado, permitindo a deteç̧ão de desvios dessa amostragem. 


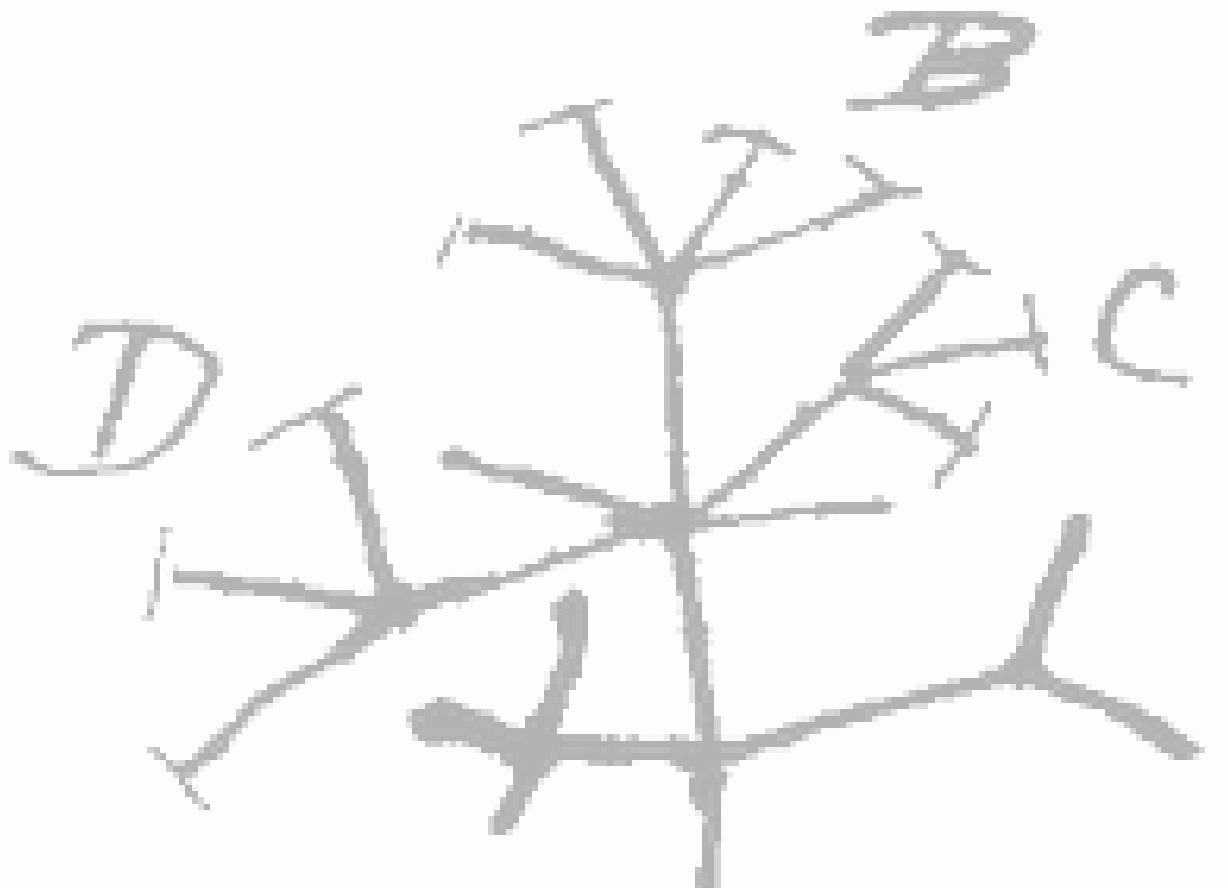

\section{Resultados}

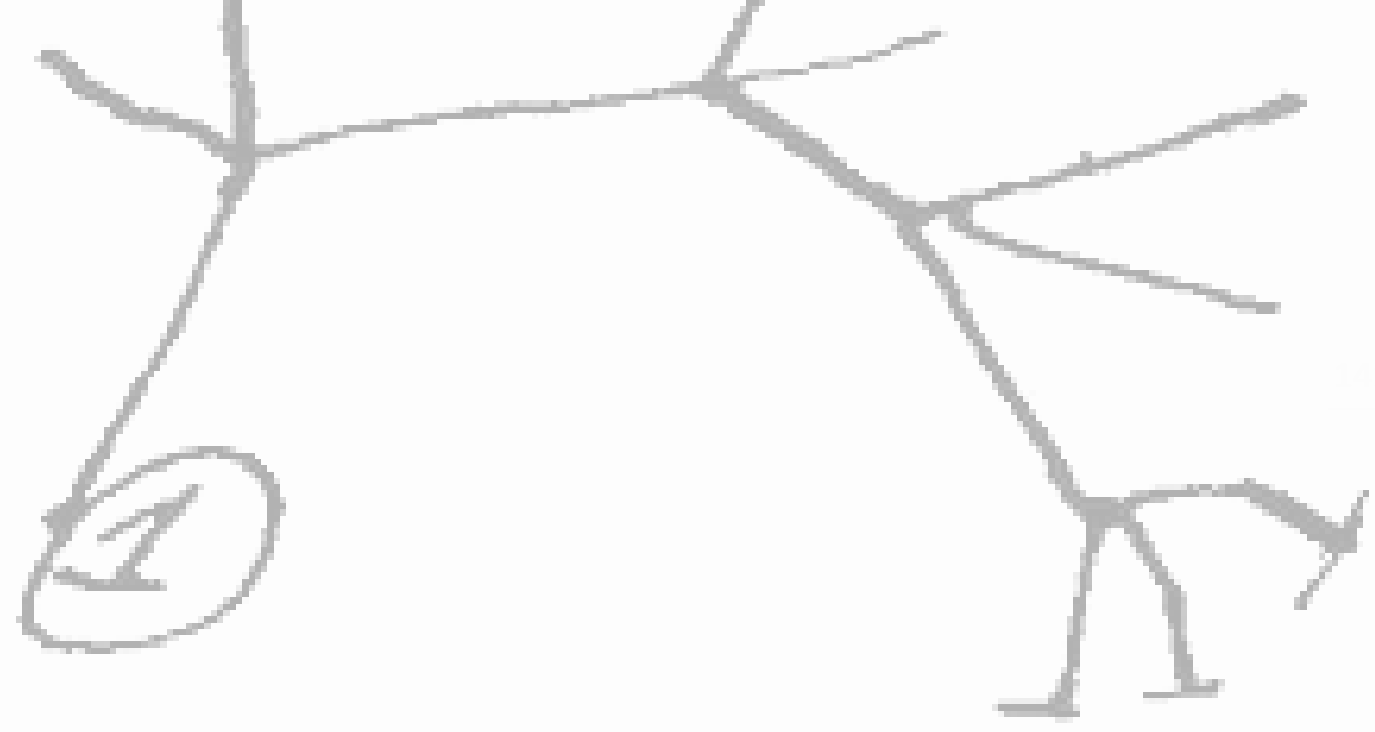

"Desde a tarde, porém, em que chamou os meninos para que o ajudassem a desempacotar as coisas do laboratório, dedicou-lhes as suas melhores horas. No quartinho separado, paredes se foram enchendo pouco a pouco de mapas inverossímeis e gráficos fabulosos, ensinou-os a ler e escrever, fazer contas, $e$ falou das maravilhas do mundo, não só até onde chegavam os seus conhecimentos, mas forçando a extremos incríveis os limites da sua imaginação".

Gabriel García Márquez, "Cem anos de solidão". 



\section{4 - Resultados: Descrição e quantificação da diversidade craniana humana}

Neste capítulo serão apresentados os resultados obtidos através da execução das análises propostas já descritas no capítulo anterior. Uma vez que as principais características das análises já foram minuciosamente apresentadas, detalhes técnicos só serão apresentados neste capítulo quando forem imprescindíveis para a interpretação dos resultados. A apresentação dos mesmos seguirá a mesma ordem de apresentação das descrições do capítulo anterior.

\section{1 - Padrões de variação e diversificação humana}

a) distribuição intrapopulacional

O padrão de variação e diversificação humanas visto a partir da distribuição intrapopulacional foi inferido através do cálculo de coeficientes de variação média (CVM) de 161 populações de ampla distribuição geográfica mundial, contando com um total de 9.287 indivíduos amostrados. A Tabela 4.10 apresenta os CVM de cada população analisada bem como o número de indivíduos amostrados, distância (em quilômetros) em relação ao ponto de origem africana (DOA) e a antiguidade imputada à cada uma das séries analisadas. A Figura 4.16 apresenta o diagrama de dispersão dos CVM em função da DOA para cada população analisada. 
Tabela 4.10 - Valores de CVM, DOA, tamanho amostral e antiguidade de cada uma das populações analisadas. As cores se referem à localização geográfica (continental) de cada uma das séries ${ }^{47}$ (marrom = África; verde = Ásia; laranja = Europa; preto = Oceania; vermelho = Américas). Os símbolos $\bullet$, $\square$, e $\Delta$ após a identificação de cada população representa a classe cronológica a qual cada uma pertence significando, respectivamente, de 0 até 1999 anos A.P., de 2000 até 3999 anos A.P. e, os mais antigos a partir de 4000 anos A.P.

\begin{tabular}{|c|c|c|c|c|}
\hline População & CVM & DOA & $\mathrm{N}$ & Antiguidade (A.P.) \\
\hline NUGA & 0,0537 & 1045,5 & 46 & - \\
\hline TEIT• & 0,0642 & 1601,5 & 83 & 96 \\
\hline SUDO• & 0,0545 & 2570,1 & 25 & 200 \\
\hline HAYA & 0,0572 & 2224,8 & 94 & - \\
\hline KERM $\Delta$ & 0,0515 & 2605,5 & 68 & 4000 \\
\hline SUNI $\square$ & 0,0506 & 2764,1 & 62 & 2000 \\
\hline PIGM & 0,0621 & 2696,1 & 6 & - \\
\hline EGTN $\Delta$ & 0,0493 & 2941,8 & 63 & 4000 \\
\hline EGTL $\square$ & 0,0515 & 3384,8 & 138 & 3800 \\
\hline EGTGロ & 0,0549 & 3427,3 & 111 & 2350 \\
\hline LACB $\triangle$ & 0,0391 & 3391,9 & 5 & 5000 \\
\hline LACF $\square$ & 0,0538 & 3391,9 & 44 & 3800 \\
\hline LACT $\square$ & 0,0527 & 3391,9 & 49 & 2700 \\
\hline SAMA & 0,0480 & 3432,2 & 12 & - \\
\hline NLIQ $\square$ & 0,0537 & 3155,4 & 12 & 3800 \\
\hline EGTB $\Delta$ & 0,0518 & 3833,2 & 29 & 5000 \\
\hline IGBO & 0,0546 & 4323,7 & 68 & - \\
\hline BEDU & 0,0538 & 3628,5 & 16 & - \\
\hline DUAL & 0,0612 & 4566,4 & 45 & - \\
\hline GABA & 0,0570 & 4486,0 & 64 & - \\
\hline NIGM & 0,0532 & 4711,5 & 27 & - \\
\hline KHAN & 0,0553 & 3637,4 & 25 & - \\
\hline GRAN $\square$ & 0,0553 & 4681,1 & 39 & 3000 \\
\hline TURQ• & 0,0546 & 4651,9 & 58 & 300 \\
\hline GRRE & 0,0580 & 4841,1 & 23 & \\
\hline NDEB & 0,0630 & 4453,2 & 24 & - \\
\hline ZULU• & 0,0602 & 4506,5 & 101 & 115 \\
\hline INNO & 0,0569 & 3866,6 & 20 & - \\
\hline RUSS & 0,0557 & 5147,8 & 34 & - \\
\hline SANS & 0,0648 & 5020,8 & 30 & - \\
\hline INMA & 0,0527 & 3895,2 & 83 & - \\
\hline
\end{tabular}

Continua

\footnotetext{
${ }^{47}$ Como discutido no capítulo anterior, em alguns casos a atribuição da localização geográfica torna-se bastante difícil e imprecisa, não refletindo a história demográfica da população representada. Como nenhum critério arbitrário garantiria a minimização de tal problema, adotou-se nesse experimento obedecer a divisão geográfica continental clássica.
} 


\begin{tabular}{|c|c|c|c|c|}
\hline ITAL & 0,0550 & 5700,5 & 77 & - \\
\hline AKAN & 0,0581 & 5897,8 & 80 & - \\
\hline INPU & 0,0528 & 4374,1 & 58 & - \\
\hline BUSH• & 0,0702 & 5127,3 & 90 & 117 \\
\hline HUNG• & 0,0551 & 5767,0 & 135 & 800 \\
\hline ZALA• & 0,0554 & 5797,6 & 98 & 1000 \\
\hline DOGO• & 0,0584 & 6143,4 & 99 & 214 \\
\hline $\mathrm{BERG \bullet}$ & 0,0573 & 5975,1 & 109 & 200 \\
\hline NEPA & 0,0527 & 4635,8 & 29 & - \\
\hline KAFF & 0,0570 & 5320,3 & 39 & - \\
\hline COST & 0,0529 & 6331,6 & 21 & - \\
\hline MORA & 0,0561 & 6052,4 & 110 & - \\
\hline NLRC $\triangle$ & 0,0476 & 6281,2 & 4 & 4500 \\
\hline SUIC & 0,0551 & 6373,9 & 56 & - \\
\hline BSHM & 0,0634 & 5817,4 & 26 & - \\
\hline TIBE• & 0,0618 & 4968,7 & 60 & 150 \\
\hline ALEH• & 0,0551 & 6617,5 & 74 & 200 \\
\hline ESPHA & 0,0337 & 6842,8 & 3 & 10000 \\
\hline INBE & 0,0564 & 5305,9 & 69 & - \\
\hline HOLA & 0,0575 & 6903,0 & 32 & - \\
\hline ESBA & 0,0566 & 7112,4 & 10 & - \\
\hline FRAB• & 0,0564 & 7070,2 & 45 & 210 \\
\hline ANDA• & 0,0594 & 5326,9 & 70 & 127 \\
\hline SUEM• & 0,0567 & 6932,8 & 26 & 1000 \\
\hline SPIM॰ & 0,0549 & 7205,8 & 69 & 400 \\
\hline SPIV• & 0,0527 & 7205,8 & 93 & 150 \\
\hline BIRM & 0,0571 & 5618,2 & 73 & - \\
\hline POUN• & 0,0530 & 7312,2 & 76 & 1500 \\
\hline FINL & 0,0522 & 7060,1 & 25 & - \\
\hline REPT• & 0,0542 & 7379,8 & 15 & 1070 \\
\hline NORS• & 0,0545 & 7275,5 & 110 & 330 \\
\hline MARR• & 0,0532 & 7749,1 & 25 & 500 \\
\hline TAIL & 0,0606 & 6243,7 & 39 & - \\
\hline KEDA & 0,0560 & 6229,9 & 37 & - \\
\hline ENSA• & 0,0484 & 7995,3 & 50 & 700 \\
\hline LAPO• & 0,0534 & 7811,7 & 27 & 1000 \\
\hline CING & 0,0560 & 6686,6 & 58 & - \\
\hline LAOS & 0,0469 & 6828,3 & 15 & - \\
\hline JAMB & 0,0577 & 6708,8 & 26 & - \\
\hline
\end{tabular}


Continuação

\begin{tabular}{|c|c|c|c|c|}
\hline BURI & 0,0601 & 7773,2 & 109 & - \\
\hline MONG & 0,0566 & 7795,7 & 172 & - \\
\hline HAIN• & 0,0584 & 7414,4 & 83 & 100 \\
\hline JAVA & 0,0533 & 7579,0 & 60 & - \\
\hline ANYA $\square$ & 0,0587 & 8065,2 & 42 & 3273 \\
\hline SHAN口 & 0,0598 & 8207,8 & 58 & 2000 \\
\hline BPUN & 0,0585 & 8031,0 & 54 & - \\
\hline $\mathrm{NHAN} \square$ & 0,0549 & 8479,5 & 68 & 2000 \\
\hline ATAY• & 0,0532 & 8612,0 & 47 & 20 \\
\hline AETA & 0,0577 & 8605,9 & 28 & - \\
\hline FLIP• & 0,0548 & 8621,2 & 50 & 20 \\
\hline NMAN• & 0,0545 & 9277,8 & 40 & 100 \\
\hline AMUR & 0,0643 & 9547,3 & 8 & - \\
\hline ALND & 0,0549 & 9952,4 & 56 & - \\
\hline SJAP• & 0,0567 & 9610,8 & 91 & 80 \\
\hline NLJO $\Delta$ & 0,0417 & 10544,4 & 5 & 6000 \\
\hline NJAP• & 0,0586 & 10563,8 & 87 & 50 \\
\hline JPTH• & 0,0576 & 10560,9 & 112 & 100 \\
\hline AINU• & 0,0555 & 10635,0 & 86 & 80 \\
\hline JPTK• & 0,0573 & 10549,4 & 40 & 100 \\
\hline YAKU & 0,0584 & 11107,1 & 4 & - \\
\hline NGLS & 0,0560 & 10485,0 & 48 & - \\
\hline CHUK & 0,0597 & 11679,5 & 20 & - \\
\hline GUAM• & 0,0508 & 11386,5 & 57 & 790 \\
\hline ESSB & 0,0547 & 12331,3 & 32 & - \\
\hline AUST• & 0,0532 & 11318,4 & 101 & 180 \\
\hline TORR & 0,0550 & 11402,1 & 46 & - \\
\hline ESIP & 0,0556 & 12636,1 & 177 & - \\
\hline NGOS & 0,0492 & 11594,5 & 57 & - \\
\hline NGGO & 0,0531 & 11630,2 & 37 & - \\
\hline NGMA & 0,0515 & 11757,8 & 32 & - \\
\hline ESIN & 0,0582 & 12923,7 & 79 & - \\
\hline TASM• & 0,0581 & 12025,3 & 87 & 100 \\
\hline ESYK & 0,0587 & 13122,2 & 204 & - \\
\hline NOIR & 0,0610 & 12185,2 & 42 & - \\
\hline AUNS & 0,0559 & 12427,6 & 42 & 2000 \\
\hline TOLA• & 0,0546 & 12470,9 & 110 & 100 \\
\hline CARO & 0,0588 & 12549,8 & 29 & - \\
\hline NOBR & 0,0566 & 12491,9 & 74 & - \\
\hline
\end{tabular}




\begin{tabular}{|c|c|c|c|c|}
\hline & & & & Continuação \\
\hline ALUN• & 0,0581 & 13643,5 & 103 & 550 \\
\hline ALFO• & 0,0554 & 13679,6 & 77 & 570 \\
\hline ALKO & 0,0624 & 13709,7 & 21 & - \\
\hline SALO & 0,0593 & 13503,7 & 71 & - \\
\hline ALTL & 0,0581 & 14735,7 & 35 & - \\
\hline NOCA & 0,0572 & 14002,1 & 38 & - \\
\hline NOHE & 0,0568 & 14359,9 & 57 & - \\
\hline ESCA & 0,0575 & 15582,1 & 43 & - \\
\hline CANY• & 0,0565 & 15625,2 & 64 & 500 \\
\hline FIJI & 0,0599 & 15543,1 & 29 & - \\
\hline SACR & 0,0525 & 16979,3 & 84 & - \\
\hline ESGR・ & 0,0632 & 17016,6 & 108 & 360 \\
\hline NDAK• & 0,0542 & 17113,1 & 20 & 150 \\
\hline ARIK• & 0,0539 & 17286,6 & 69 & 275 \\
\hline NEBR & 0,0516 & 17366,1 & 25 & - \\
\hline UTAH & 0,0501 & 17408,2 & 92 & - \\
\hline CRUZ• & 0,0526 & 17538,8 & 102 & 1015 \\
\hline MOKA• & 0,0555 & 17603,5 & 100 & 355 \\
\hline ARIZ• & 0,0521 & 17942,9 & 66 & 100 \\
\hline NOVO & 0,0519 & 17988,8 & 76 & - \\
\hline CANO• & 0,0538 & 18152,8 & 26 & 400 \\
\hline KANS & 0,0557 & 18165,4 & 17 & - \\
\hline $\mathrm{MICH}$ & 0,0489 & 18215,3 & 10 & - \\
\hline ILLI• & 0,0513 & 18385,9 & 186 & 250 \\
\hline ARKA & 0,0524 & 18544,8 & 30 & - \\
\hline NYOR & 0,0534 & 18615,6 & 35 & - \\
\hline KNOLA & 0,0504 & 18745,8 & 52 & 4500 \\
\hline TENN & 0,0484 & 18793,7 & 14 & - \\
\hline VIRG & 0,0551 & 18873,4 & 45 & - \\
\hline MARY & 0,0533 & 18957,2 & 51 & - \\
\hline MSSP & 0,0430 & 19023,7 & 2 & - \\
\hline FLOR• & 0,0500 & 19484,9 & 111 & 250 \\
\hline MMEX & 0,0517 & 20367,9 & 90 & - \\
\hline CARI• & 0,0494 & 21435,2 & 5 & 700 \\
\hline MARQ & 0,0514 & 21597,1 & 78 & - \\
\hline BORA & 0,0515 & 22195,1 & 41 & - \\
\hline MAOR & 0,0549 & 22467,9 & 128 & - \\
\hline COLA $\triangle$ & 0,0507 & 22818,5 & 8 & 4000 \\
\hline VENE & 0,0511 & 22869,3 & 14 & - \\
\hline
\end{tabular}


Continuação

\begin{tabular}{|c|c|c|c|c|}
\hline GUIA & 0,0417 & 23586,9 & 4 & - \\
\hline PEIN• & 0,0523 & 24533,2 & 350 & 500 \\
\hline PERU• & 0,0527 & 24629,9 & 110 & 500 \\
\hline IPAS• & 0,0535 & 24789,0 & 86 & 470 \\
\hline MORI• & 0,0520 & 25174,9 & 108 & 200 \\
\hline BOLI• & 0,0586 & 25515,3 & 14 & 1000 \\
\hline SANP $\square$ & 0,0571 & 26127,0 & 32 & 2400 \\
\hline BBCE• & 0,0565 & 26555,8 & 19 & 150 \\
\hline LSAN $\Delta$ & 0,0577 & 26758,4 & 5 & 8500 \\
\hline SPRE口 & 0,0527 & 27290,1 & 7 & 3500 \\
\hline SCER• & 0,0529 & 27353,0 & 6 & 950 \\
\hline CHIL• & 0,0551 & 27393,9 & 29 & 500 \\
\hline FUEG & 0,0525 & 28681,5 & 58 & - \\
\hline Total & - & - & 9287 & - \\
\hline
\end{tabular}

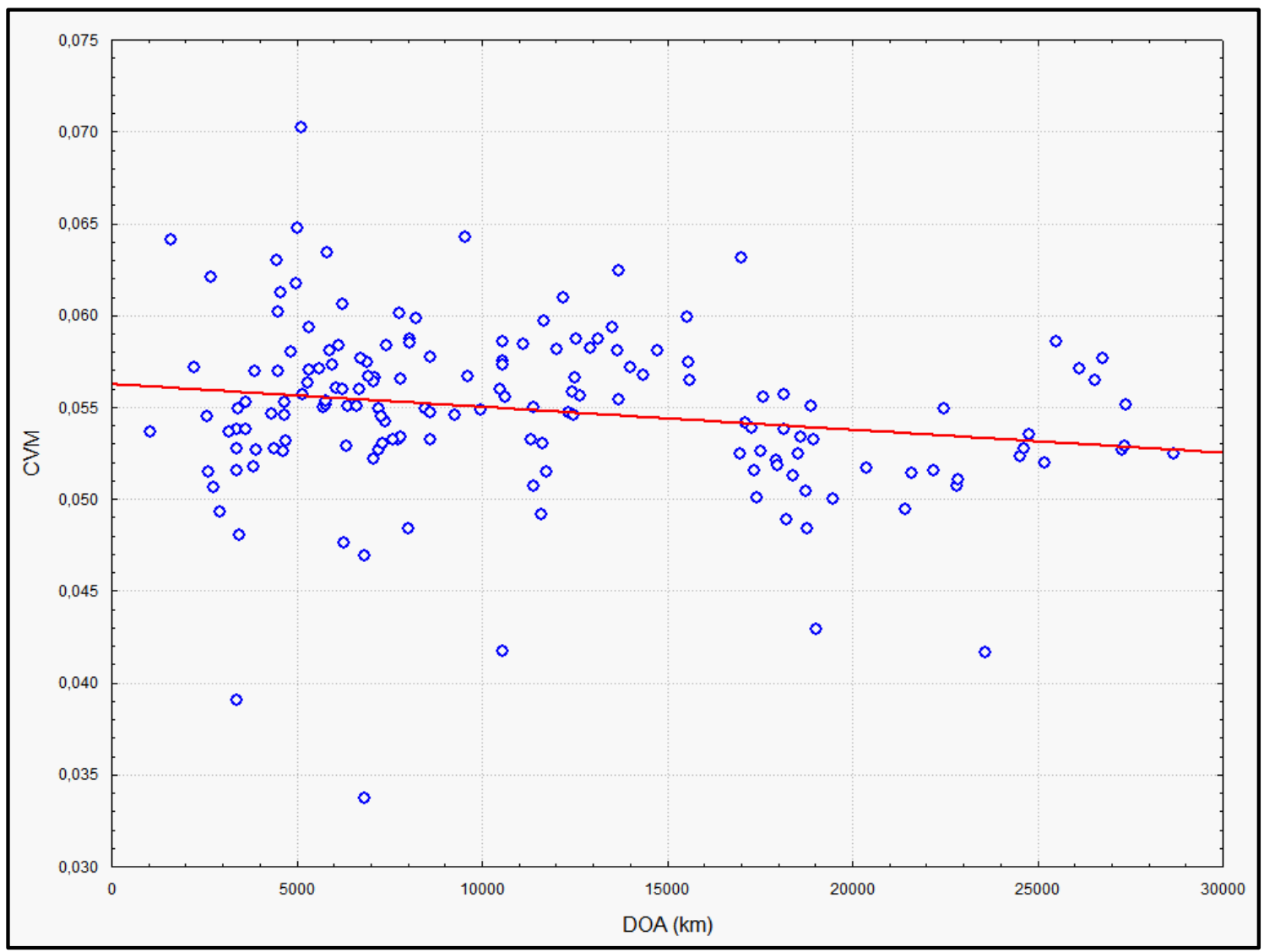

Fig. 4.17 - Diagrama de dispersão de CVM em função de DOA para as populações amostradas. 
No diagrama de dispersão apresentado na Figura 4.17, a linha vermelha representa a curva de regressão obtida entre os valores de CVM em função de DOA. O coeficiente de correlação obtido para a dispersão é $\mathbf{r}=\mathbf{- 0 , 1 8 8 3}(\mathbf{p}=\mathbf{0 , 0 1 6 8})$. Tais parâmetros permitem afirmar que é observada uma fraca correlação negativa entre CVM e DOA, estatisticamente significativa.

De maneira complementar, como exposto na proposta apresentada no capítulo anterior, o mesmos dados foram novamente analisados, efetuando-se, porém, um recorte balizado por suas cronologias (Tabela 4.10). As Figuras 4.18, à 4.21 exibem, respectivamente, as dispersões obtidas para os valores de CVM em função de DOA para todas as populações com datação imputada e para as frações com populações com antiguidade entre o e 1999 anos A.P., 2000 e 3999 anos A.P. e mais antigas que 4000 anos A.P. A Tabela 4.11 apresenta os respectivos valores para $r, r^{2}$ e $p$ descritivos da correlação de tais dados.

Tabela 4.11 - Características descritivas (observações, $r, p$ e $r^{2}$ ) das populações amostradas de acordo com sua faixa cronológica.

\begin{tabular}{ccccc}
\hline Faixa cronológica & Observações & $\mathrm{R}$ & $\mathrm{p}$ & $\mathrm{r}^{2}$ \\
\hline 0 a 10000 A. P. & 79 & $-0,0234$ & 0,8377 & 0,0005 \\
0 a 1999 A. P. & 56 & $\mathbf{- 0 , 3 4 9 8}$ & $\mathbf{0 , 0 0 8 2}$ & $\mathbf{0 , 1 2 2 4}$ \\
2000 a 3999 A. P. & 13 & 0,2308 & 0,4480 & 0,0533 \\
Acima de 4.000 A. P. & 10 & 0,4603 & 0,1807 & 0,2119 \\
\hline
\end{tabular}

Em negrito valores estatisticamente significativos $(p<0,05)$ 


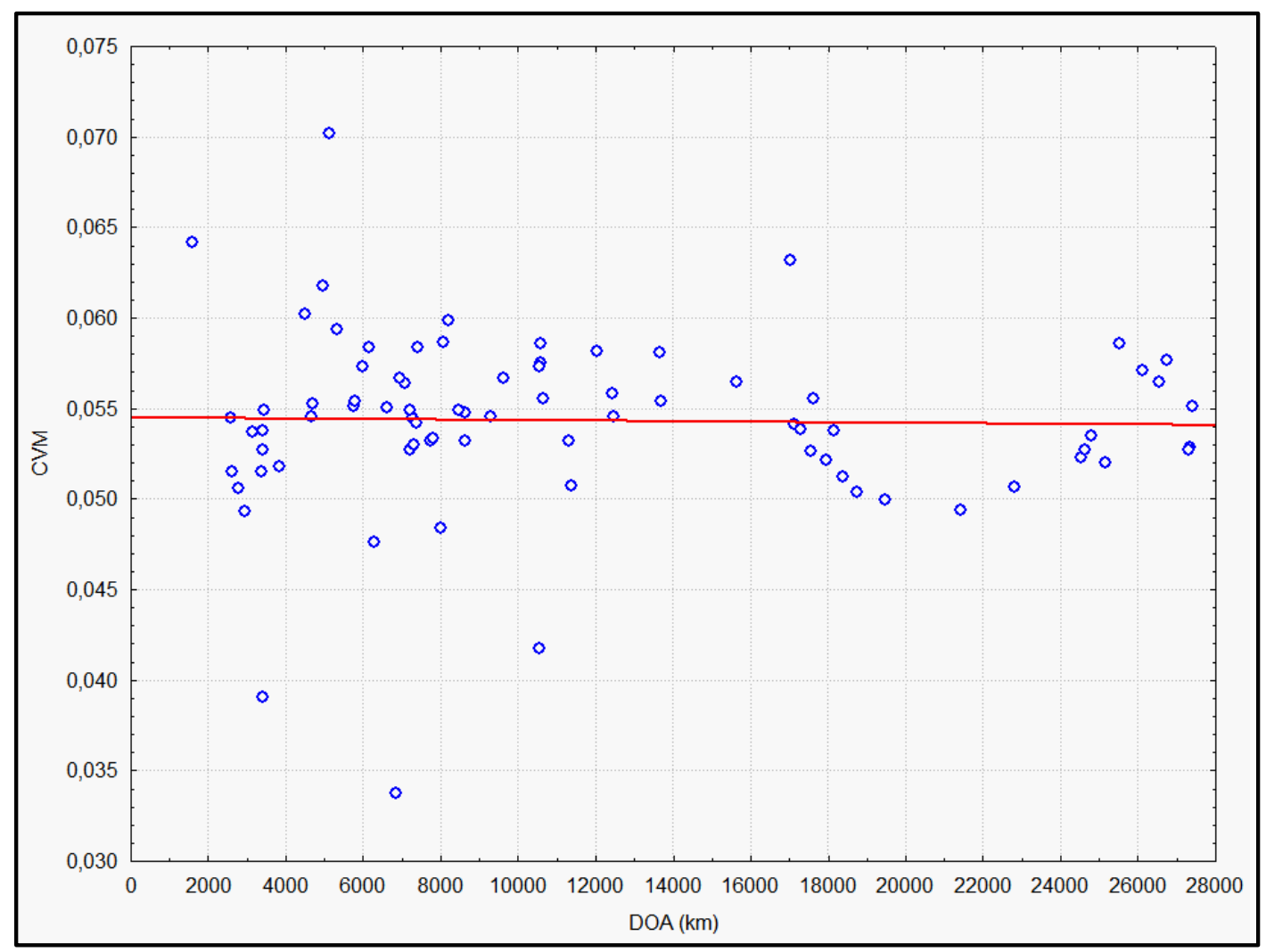

Fig. 4.18 - Diagrama de dispersão de CVM em função de DOA para as populações com cronologia entre 0 e 10000 anos A.P. amostradas.

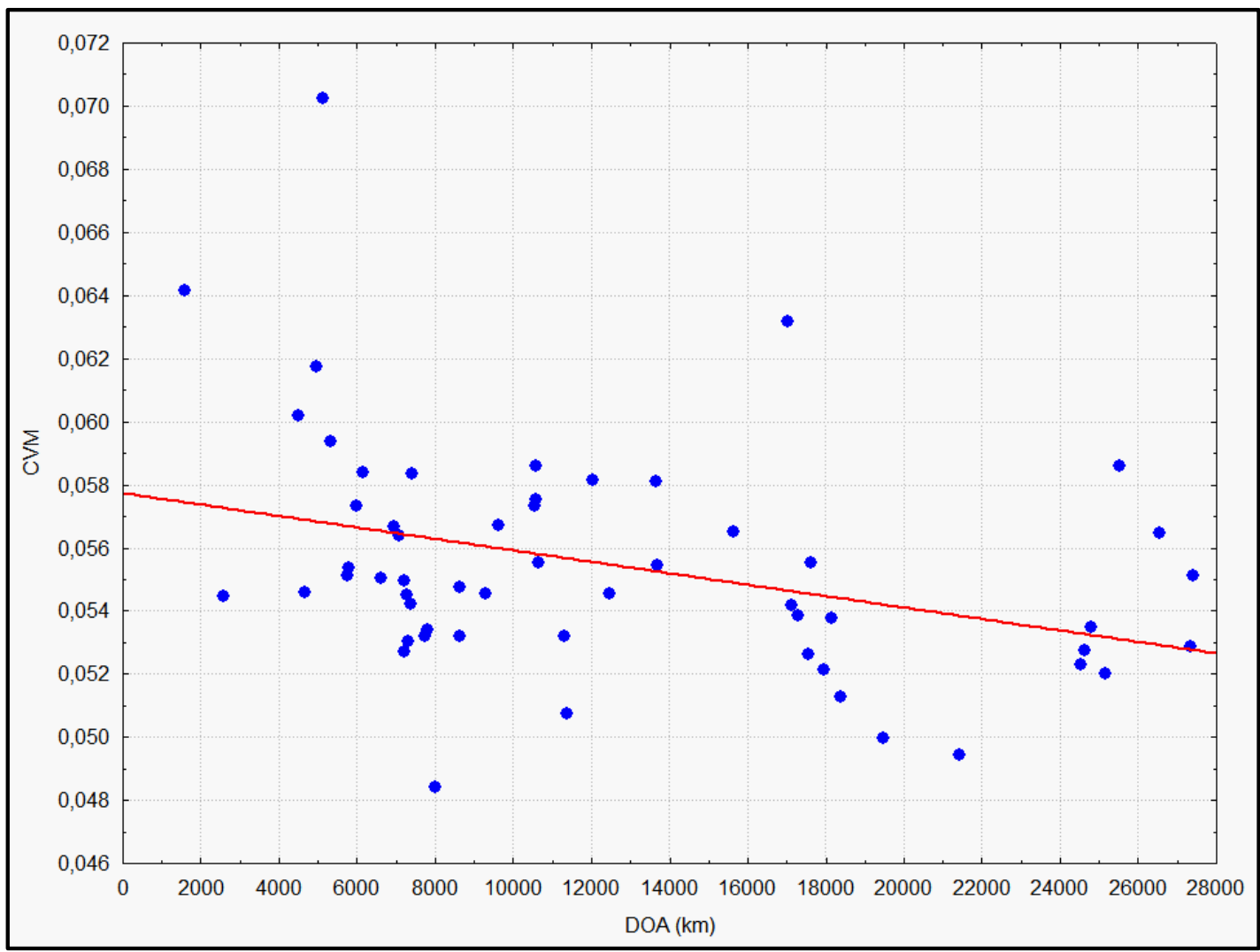

Fig. 4.19 - Diagrama de dispersão de CVM em função de DOA para as populações com cronologia entre 0 e 1999 anos A.P. amostradas. 


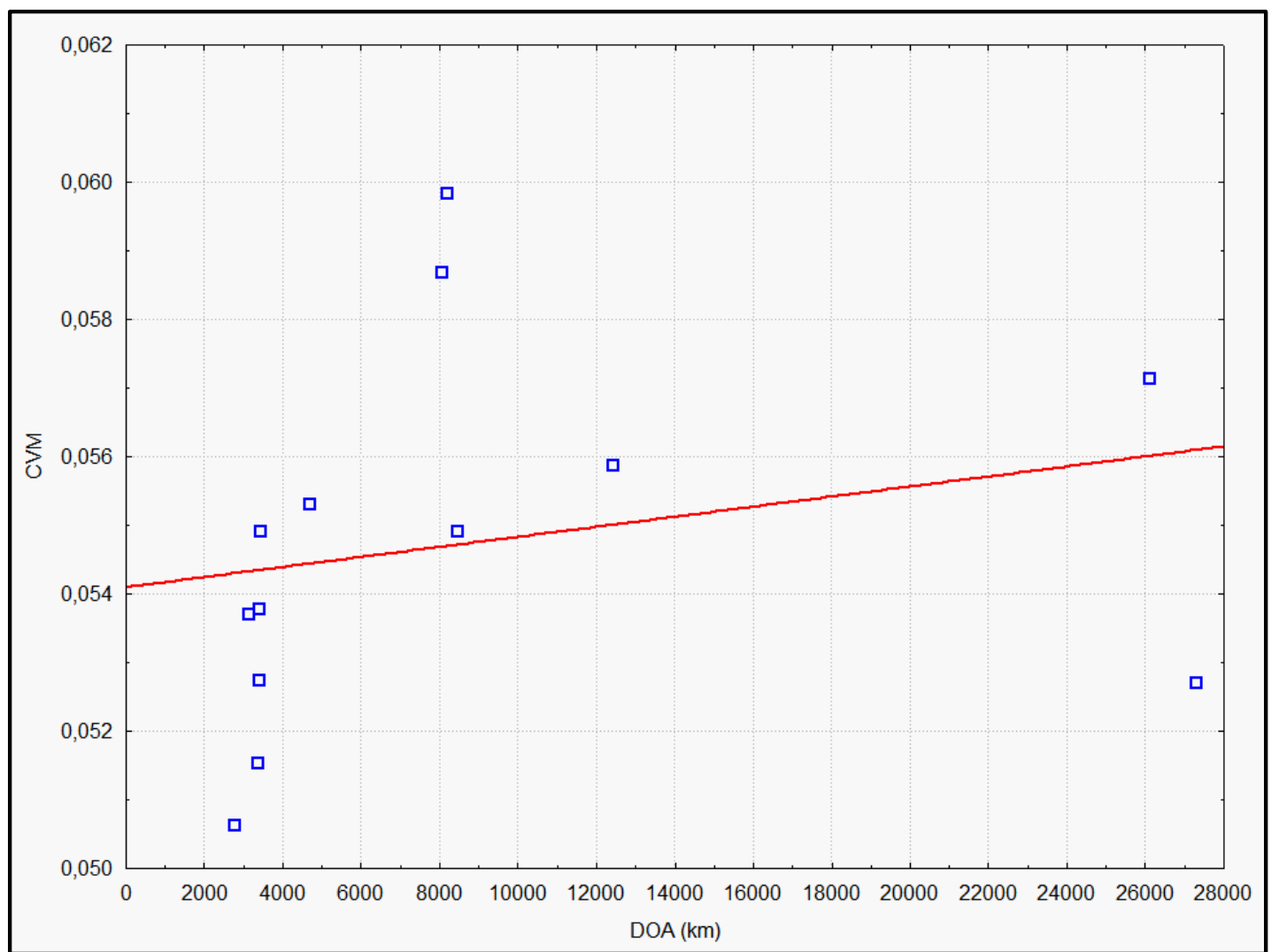

Fig. 4.20 - Diagrama de dispersão de CVM em função de DOA para as populações com cronologia entre 2000 e 3999 anos A.P. amostradas.

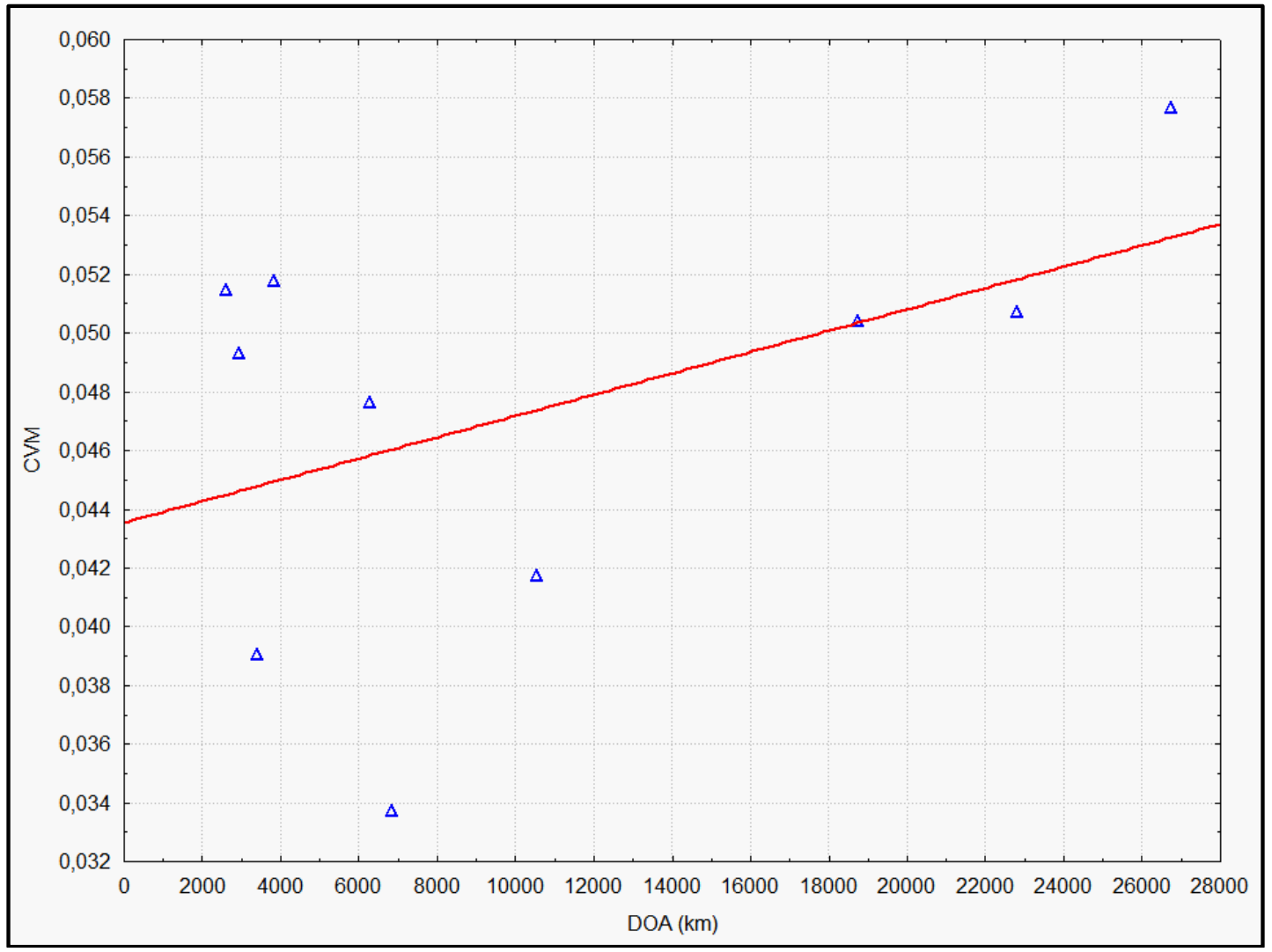

Fig. 4.21 - Diagrama de dispersão de CVM em função de DOA para as populações com antiguidade de 4000 ou mais anos A.P. amostradas. 
Apenas os dados relativos às populações mais recentes, datadas entre o e 1999 anos A.P., apresentam correlação significativa entre CVM e DOA. Tal correlação pode ser interpretada em função de seu coeficiente $(\mathbf{r}=-\mathbf{0 , 3 4 9 8} ; \mathbf{p}=\mathbf{0 , 0 0 8 2})$ como sugestiva de que a variação intrapopulacional diminui à medida que os grupos se distanciam do ponto de origem na África.

No entanto, embora não tenham alcançado significância estatística, as coeficientes obtidos para as correlações entre CVM e DOA das outras duas parcelas de dados, populações com antiguidades entre 2000 e 3999 anos A. P. e com mais de 4000 anos A. P. também merecem destaque. Ambas dispersões apresentaram características inversas às apresentadas quando as populações mais recentes foram analisadas, isto é, ao invés dos valores de CVM decrescerem à medida que os de DOA aumentaram, indicando diminuição da variação intrapopulacional inferida nessas populações. A absoluta não-significância, do ponto de vista estatístico, desses coeficientes de correlação dificulta qualquer explicação que fuja às motivadas pelo acaso, como erros e insuficiências amostrais, por exemplo. De maneira a municiar a discussão sobre as causas desse fenômeno, foi realizada também a análise da dispersão dos CVM em função de suas antiguidades, mostrada na Figura 4.22.

Tal fenômeno, a aparente discordância entre correlações em diferentes estratos das dispersões, também pode ser observada em alguns casos específicos quando as populações foram analisadas obedecendo-se uma lógica geográfica, dividindo-se as populações de acordo com os "grandes" blocos continentais ${ }^{4}$. Os resultados obtidos pelas análises segundo essa estratégia são mostrados na Tabela 4.12 e nas Figuras 4.23 à 4.27 .

\footnotetext{
${ }^{48}$ Como discutido anteriormente (capítulo 3), a divisão das séries quanto suas localizações geográficas continentais não é tão trivial quanto pode parecer. Assim, a estratégia adotada foi a de se considerar uma classificação que fosse relativante correspondente às grandes extensões de terra, delimitadas por mares e oceanos. Ainda assim, algumas classificações discutíveis não puderam ser totalmente evitadas. Exemplos dessa condição são os grupos "Ásia", congregando populações localizadas na Ásia e no Oriente Médio, e "Oceania", agregando populações da Australomelanésia, Polinésia e Micronésia.
} 


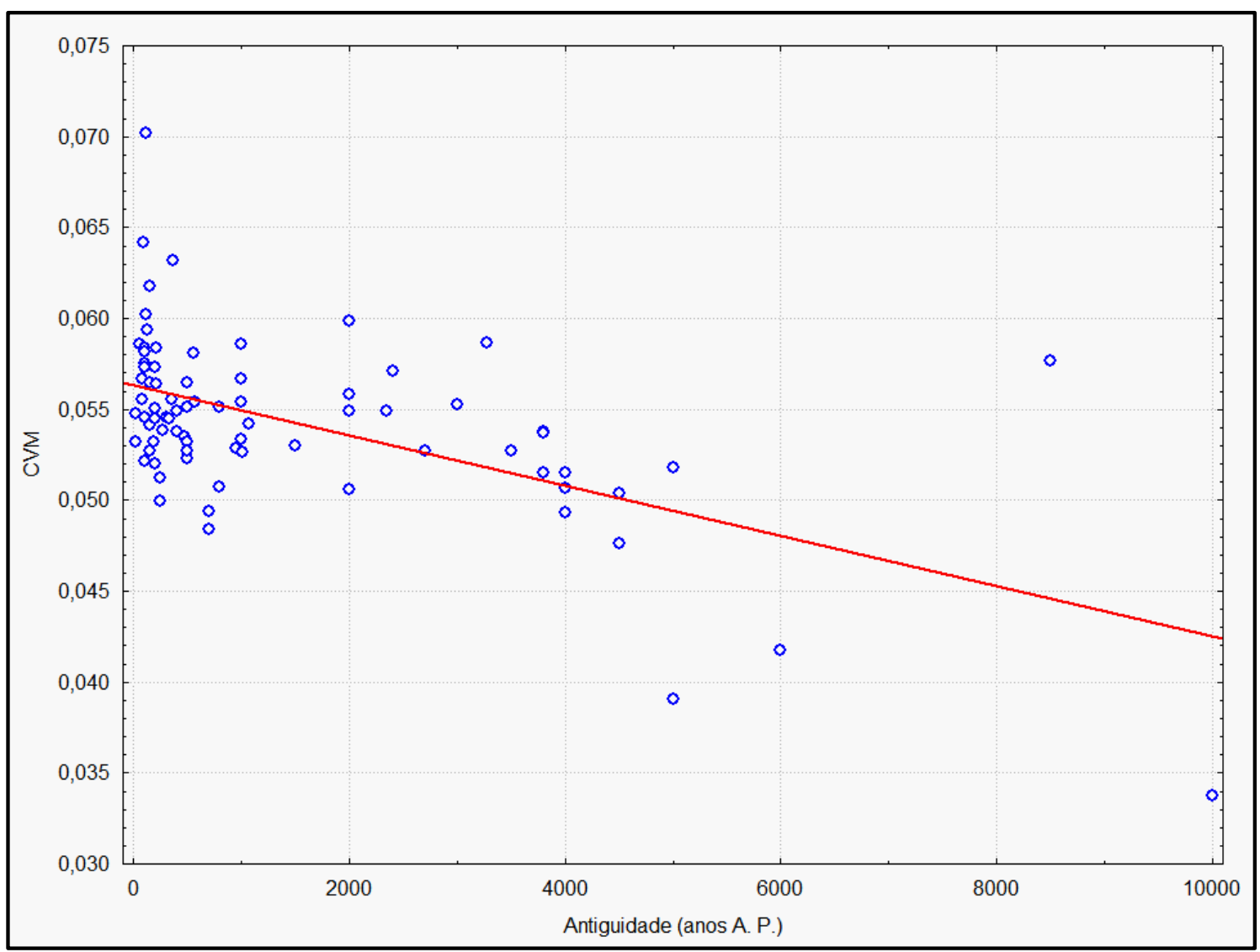

Fig. 4.22 - Diagrama de dispersão de CVM em função da Antiguidade (em anos A. P.) das populações amostradas.

Na Figura 4.22 é mostrado o diagrama de dispersão de CVM em função da antiguidade (em anos A. P.) obtido através da análise sobre todas as populações amostradas cujas cronologias puderam ser inferidas (79 observações). O coeficiente produto-momento obtido para o conjunto de dados indica uma correlação regular e estatisticamente significativa $(\mathbf{r}=-\mathbf{0 , 5 6 0 6} ; \mathbf{p}<\mathbf{0 , 0 0 0 0})$, ocupando destacada posição no universo dos resultados gerados nesta bateria de análises. A interpretação deste resultado sugere a ocorrência de maior variação morfológica entre as amostras mais recentes do que entre as mais antigas.

Tabela 4.12 - Características descritivas ( $n, r, p$ e $r^{2}$ ) das populações amostradas de acordo com sua localização geográfica.

\begin{tabular}{ccccc}
\hline Localização geográfica & Observações & $r$ & $p$ & $r^{2}$ \\
\hline África & 25 & 0,1790 & 0,3919 & 0,0320 \\
Ásia & 43 & 0,2828 & 0,0661 & 0,0800 \\
Europa & 24 & $-0,2648$ & 0,2112 & 0,0701 \\
América & 46 & $-0,2406$ & 0,1072 & 0,0579 \\
Oceania & 23 & $-0,2574$ & 0,2358 & 0,0662 \\
\hline
\end{tabular}




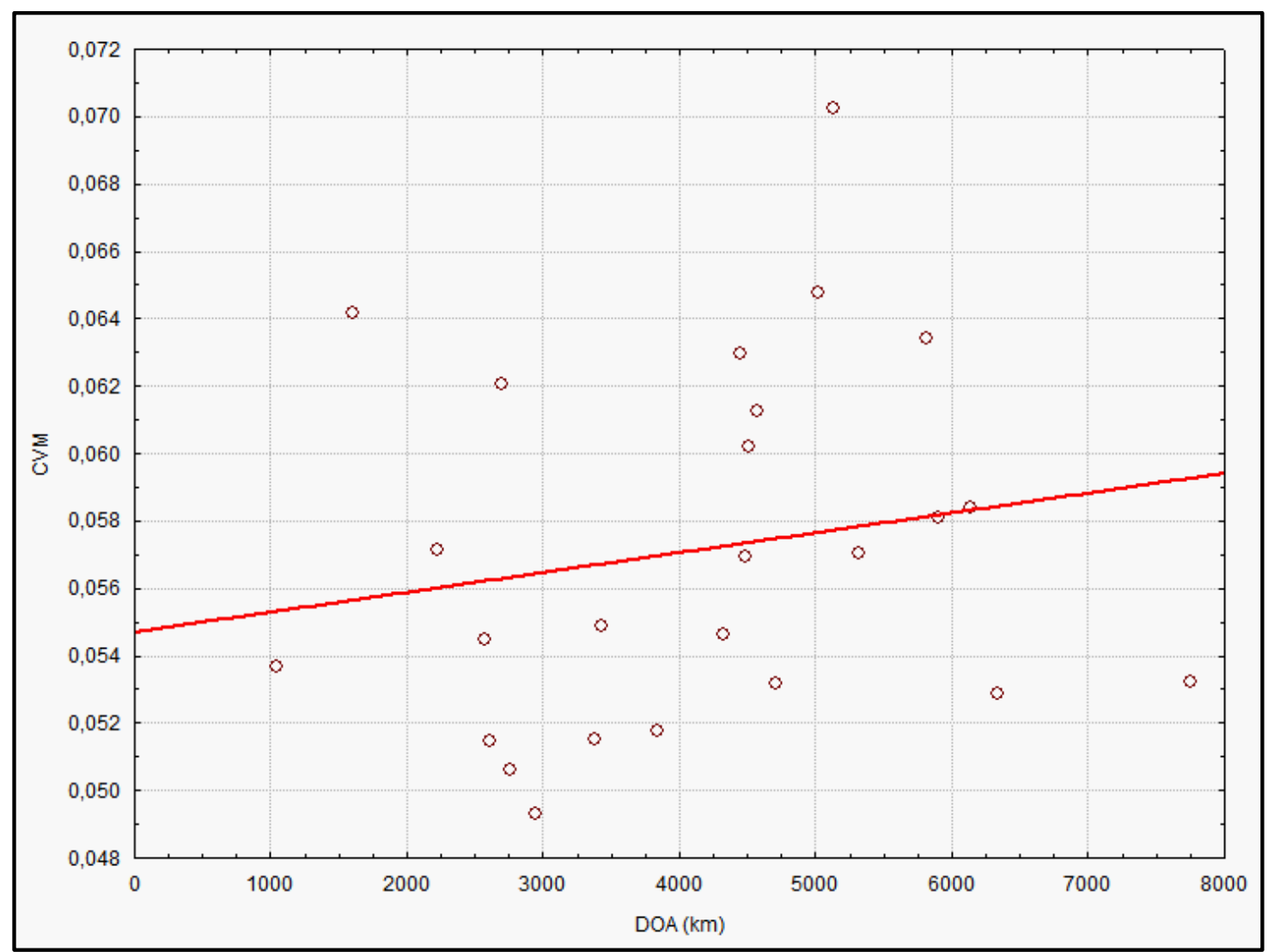

Fig. 4.23 - Diagrama de dispersão de CVM em função de DOA para as populações localizadas no continente africano (25 observações).

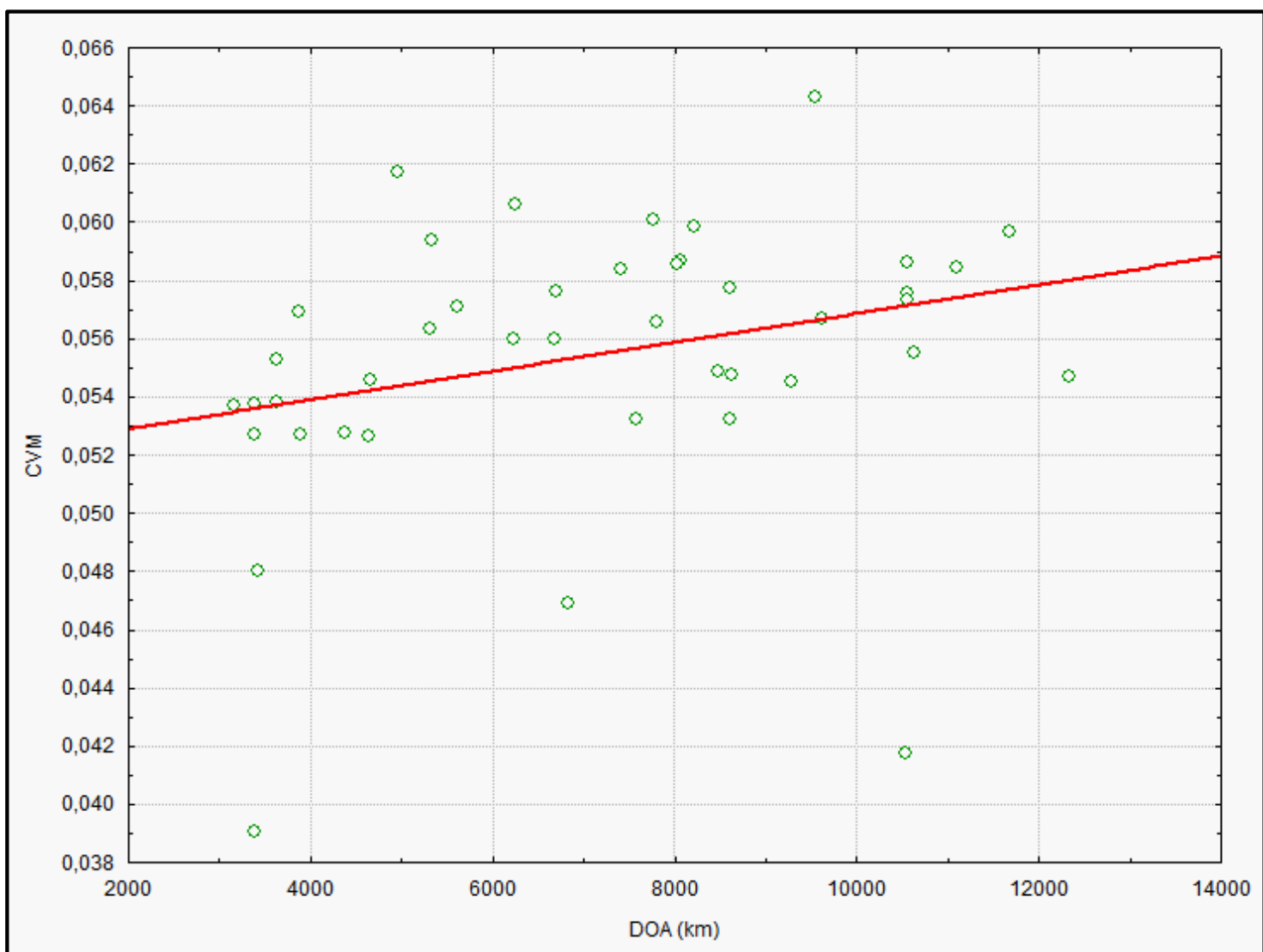

Fig. 4.24 - Diagrama de dispersão de CVM em função de DOA para as populações localizadas no continente asiático (43 observações). 


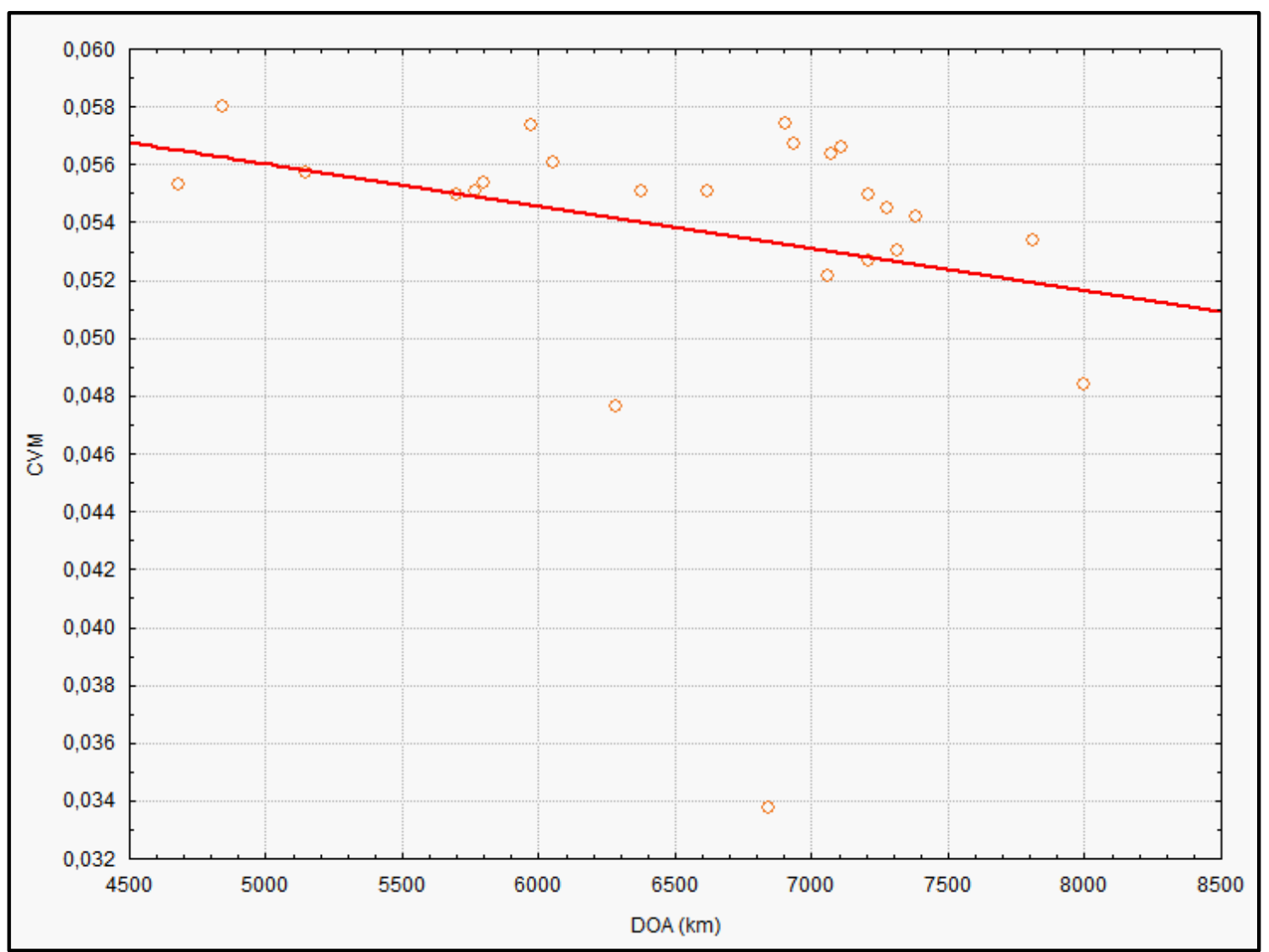

Fig. 4.25 - Diagrama de dispersão de CVM em função de DOA para as populações localizadas no continente europeu (24 observações).

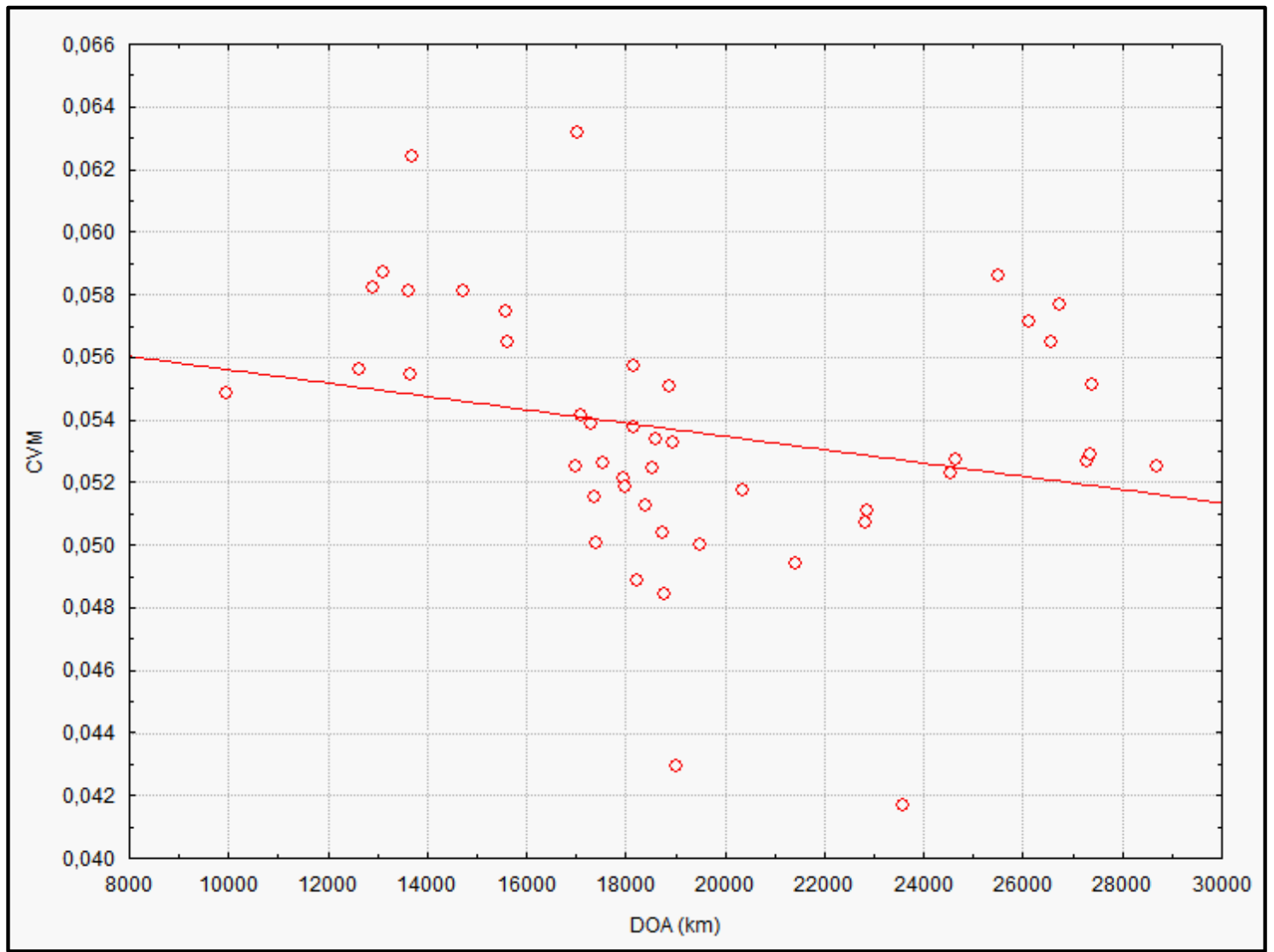

Fig. 4.26 - Diagrama de dispersão de CVM em função de DOA para as populações localizadas no continente americano (46 observações). 


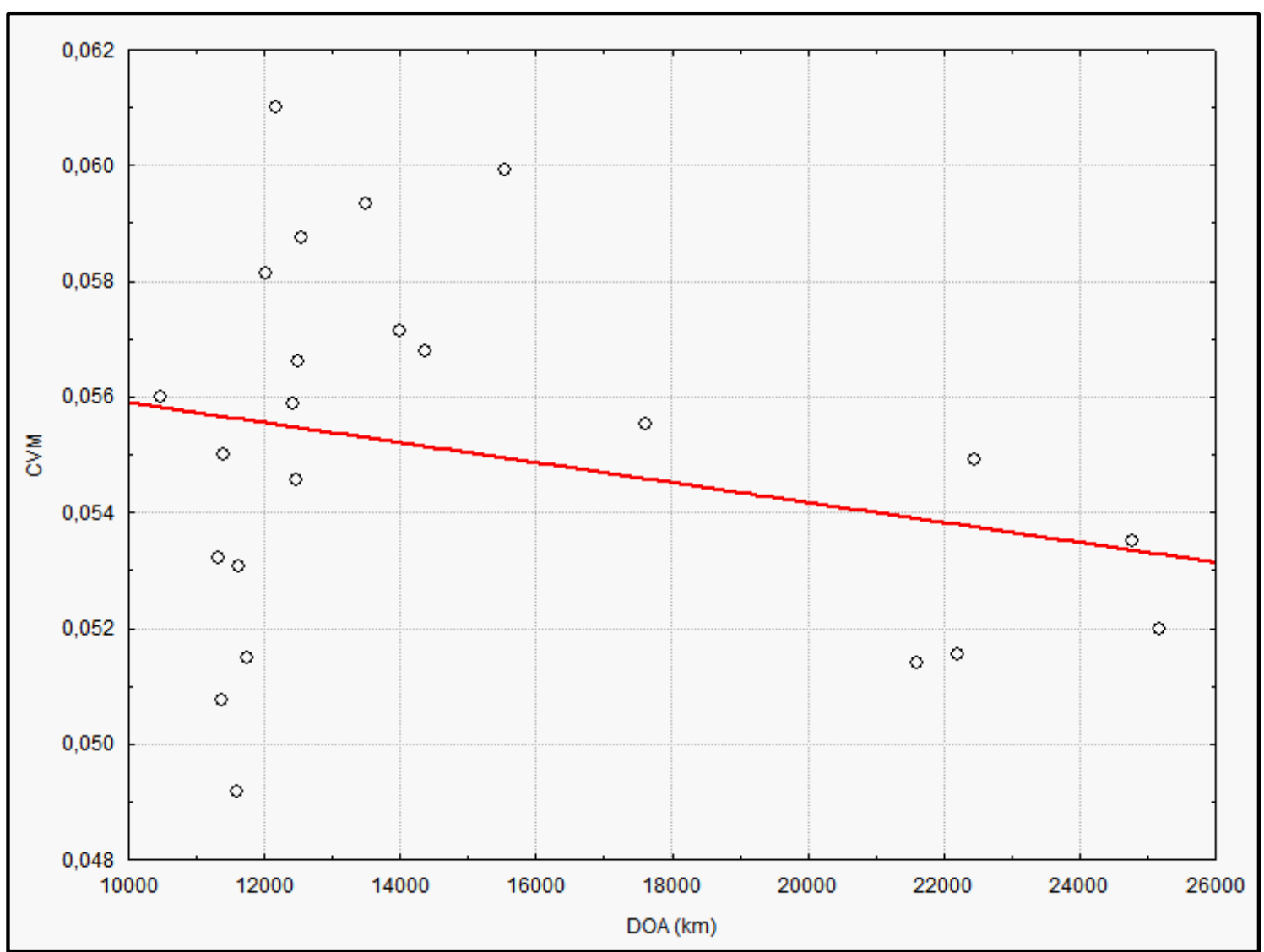

Fig. 4.27 - Diagrama de dispersão de CVM em função de DOA para as populações localizadas na Oceania (23 observações).

A análise dessa parcela de dados apresenta resultados similares aos obtidos na da parcela cujo critério de estratificação da amostra foi a cronologia das populações, um quadro no qual a relação entre CVM e DOA não se apresenta de maneira constante para os diferentes grupos de dados.

Dois dos cinco grupos analisados, África (Fig. 4.23) e Ásia (Fig. 4.24), apresentaram correlação positiva para a dispersão de CVM em função de DOA (r = $\mathbf{0 , 1 7 9 0}$ e $\mathbf{r}=\mathbf{0 , 2 8 2 8}$, respectivamente), sugerindo que à medida que suas populações se afastam do ponto de origem na África maior é a quantidade de variação apresentada entre os indivíduos que a formam. Esse cenário é diametralmente oposto ao demonstrado quando todas as populações foram analisadas conjuntamente (Fig. 4.17), livres de critérios ad hoc para subdivisões da amostra, de que a variação 
intrapopulacional decai à medida que sua localização afasta-se do ponto de origem na Etiópia. Em contrapartida, os outros três conjuntos analisados, europeus (Fig. 4.25), americanos (Fig. 4.26) e australo-melanésios 49 (Fig. 4.27), apresentaram, de maneira oposta à africanos e asiáticos, a tendência de diminuição da variação intrapopulacional em função do incremento da distância em relação à um ponto de origem da humanidade. Tal constatação emerge da análise dos coeficientes de correlação obtidos para cada conjunto (Europa, $r=-0,2648$; América, $r=-0,2406$; Oceania, $r=-0,2574$ ), além da observação das dispersões e das curvas de regressão mostradas nas figuras.

Tal cenário não deixa de apresentar-se moderamente surpreendente, uma vez que, ao menos no que pode ser depreendido da literatura já publicada sobre o tema (Handley et al., 2007; Manica et al., 2007; Betti et al., 2009, para alguns exemplos) não parece existir nenhum efeito adicional à distância em relação à África (como uma estimativa de tempo de dispersão) para a predição do nível de variação craniana intrapopulacional. No entanto, é necessário destacar que todos os coeficientes produtomomento obtidos para as análises em questão, a correlação estimada da dispersão de CVM em função de DOA dentro dos grandes blocos continentais, não apresentaram significância estatística, o que impossibilita interpretações definitivas baseadas nesses dados.

Já quando o conjunto total de análises da variação morfológica intrapopulacional desempenhadas é considerado, isto é, a verificação da dispersão de CVM em função de DAO ou antiguidade, independentemente do critério utilizado para seleção da amostra utilizada, três dispersões se destacam entre as demais devido suas significâncias estatísticas.

Duas destas três dispersões, (Fig. 4.17, $\mathbf{r}=\mathbf{- 0 , 1 8 8 3 ,}, \mathbf{p}=\mathbf{0}, \mathbf{0 1 6 8})$ e (Fig. 4.19, $\mathbf{r}=$ $-\mathbf{0 , 3 4 9 8}, \mathbf{p}=\mathbf{0 , 0 0 8 2})$ correspondem à variações morfológicas $(\mathrm{CVM})$ em função da

\footnotetext{
${ }^{49}$ Incluindo, além de australianos e melanésios, populações da Polinésia e da Micronésia.
} 
distância em relação ao ponto de origem na África (DOA) e a única diferença entre elas é o critério utilizado para a seleção das amostras utilizadas. Em ambas análises, a DOA é uma inferência indireta do tempo de divergência entre as populações (Manica et al., 2007), e seus resultados indicam o decréscimo da variação intrapopulacional à medida que as populações se distanciam da África, ou, apresentem maior tempo de separação entre elas. Assim, ambas refletem os mesmos eventos demográficos, com significados biológicos semelhantes e, provelmente, são explicadas pelos mesmos fenômenos evolutivos.

No entanto, o terceiro destes exemplos (Fig. 4.22, $\mathbf{r}=\mathbf{- 0 , 5 6 0 6 , p}<\mathbf{0 , 0 0 0 0}$ ), a correlação mais expressiva obtida nestes experimentos, não pode ser diretamente associada às outras duas observações. Embora, numa primeira análise, tal observação pareça estar em perfeita consonância às outras duas, a informação que se depreende de sua análise é a de que ao longo dos últimos 10000 anos pode se observar um aumento na magnitude da variação da morfologia craniana humana, quando inferida de maneira intrapopulacional e sem nenhuma distinção quanto à localização geográfica dessas amostras, um cenário, ao menos parcialmente, contrário ao sugerido quando as correlações significativas foram observadas através das dispersões de CVM e DOA.

\section{b) distribuição interpopulacional}

O padrão de variação e diversificação da morfologia craniana humana visto a partir da distribuição interpopulacional foi inferido através da quantificação das interações, medidas através dos coeficientes de correlação de Pearson ${ }^{50}$, entre três matrizes de dados. A divergência entre as populações, estimada pela distância geográfica entre elas, é representada pela matriz de distâncias geográficas $\left(\mathrm{D}_{\mathrm{Geo}}\right)$,

\footnotetext{
${ }^{50}$ As significâncias estatísticas dos coeficientes de correlação foram estimadas por teste de Mantel nos casos em que duas matrizes foram avaliadas e teste parcial de Mantel para as situações na qual o efeito de uma terceira matriz também foi considerado (Mantel, 1967; Legendre, 2000).
} 
construída a partir da matriz de distâncias calculadas com controle de custos, conforme descrito no capítulo anterior. Já a variação entre as populações, estimada com base no valor do $\mathrm{F}_{\mathrm{ST}}$ (calculado sobre medidas cranianas) extraído entre todos os pares populacionais, é representada pela matriz de distâncias genéticas $\left(\mathrm{D}_{\mathrm{Gen}}\right)$.

De maneira complementar, as populações foram, também, analisadas de acordo com o tipo de interação apresentada entre elas em relação a pertencerem aos mesmos continentes ou continentes diferentes. Tal informação está sintetizada na matriz de efeito continental $\left(\mathrm{E}_{\mathrm{Con}}\right)$, construída seguindo a mesma lógica utilizada para a construção das matrizes $\mathrm{M}$, também explicada no capítulo anterior.

Foram utilizadas 128 populações, envolvendo 8.898 indivíduos. Dessa maneira, as matrizes $\mathrm{D}_{\mathrm{Geo}}, \mathrm{D}_{\mathrm{Gen}}$ e $\mathrm{E}_{\mathrm{Con}}$ apresentam dimensão $128 \times 128$, motivo pelo qual são mostradas apenas nos apêndices (respectivamente, Tabelas 4A, 7A e 8A dos Apêndices 4, 7 e 8). As populações utilizadas nesta análise são as mesmas que foram estudas na análise anterior (apresentadas na Tabela 4.10), com exceção daquelas que apresentam $\mathrm{N}<25$. Suas classificações quanto à localização geográfica continental também são as mesmas daquelas apresentadas na Tabela 4.10.

As principais informações resultantes das análises das interações entre as três categorias de matrizes construídas estão sintetizadas na Tabela 4.13.

Tabela 4.13 - Valores de correlação observados entre as matrizes DGen, DGeo e ECon.

\begin{tabular}{ccc}
\hline Interações & Correlação $(r)$ & p-valor \\
\hline$D_{G e n} \times D_{G e o}$ & $\mathbf{0 , 2 0 3 9 8}$ & $\mathbf{0 , 0 0 0 1 *}$ \\
$D_{G e n} \times E_{C o n}$ & $\mathbf{0 , 3 3 3 2 6}$ & $\mathbf{0 , 0 0 0 1 *}$ \\
$D_{G e n} \times D_{G e o}$ & $\mathbf{0 , 0 8 9 4 0}$ & $\mathbf{0 , 0 1 1 7 * *}$ \\
$\begin{array}{c}\left.\text { [corrigida para "continente" }\left(E_{\text {Con }}\right)\right] \\
D_{G e n} \times E_{\text {Con }}\end{array}$ & $\mathbf{0 , 2 8 2 7 3}$ & $\mathbf{0 , 0 0 0 1 * *}$ \\
\hline corrigida para "geografia" $\left.\left(D_{G e o}\right)\right]$ &
\end{tabular}

Em negrito valores estatisticamente significativos $(p<0,05)$

* significância estatística determinada por teste de Mantel

*** significância estatística determinada por teste parcial de Mantel 
Quando $D_{\text {Gen }}$ e $D_{\text {Geo }}$ são avaliadas de maneira direta, envolvendo todas as populações, observa-se uma correlação positiva $(\mathbf{r}=\mathbf{0 , 2 0})$ e estatisticamente significativa $(\mathbf{p}<\mathbf{o , o o o})$ para a medida de diversidade fenotípica interpopulacional em relação às distâncias geográficas as separam. Embora fracamente correlacionadas, a associação observada entre as duas matrizes indica que a amplitude de variação da morfologia craniana entre populações tende a aumentar à medida que as distâncias geográficas que as separam também se tornem maiores. Correlação semelhante, apresentando-se, porém, com intensidade relativamente maior $(\mathbf{r}=\mathbf{0}, \mathbf{3 3} ; \mathbf{p}<\mathbf{0 , 0 0 0})$, foi observada quando $\mathrm{D}_{\mathrm{Gen}} \mathrm{e} \mathrm{E}_{\mathrm{Con}}$ foram comparadas, indicando as maiores diversificações interpopulacionais da morfologia craniana são observadas quando as comparações envolvem populações de continentes diferentes do que quando envolve populações pertencentes à mesma região geográfica continental.

Esses resultados indicam que tanto o fato de localizarem-se mais ou menos distantes uma das outras quanto o fato de terem ou não grandes barreiras geográficas (oceanos ou cadeias montanhosas) entre elas pouco alteram a forma de como as populações analisadas tem estruturados seus índices de divergência genética. Esse cenário, entretanto, é um pouco alterado quando $\mathrm{D}_{\mathrm{Gen}}$ e $\mathrm{D}_{\mathrm{Geo}}$ e $\mathrm{D}_{\mathrm{Gen}}$ e $\mathrm{E}_{\mathrm{Con}}$ são testadas corrigindo-se, respectivamente, os efeitos da localização geográfica das populações (continentes iguais ou diferentes, representados em $\mathrm{E}_{\mathrm{con}}$ ) e a amplitude da distância que as separam (distâncias geográficas, representadas em $\mathrm{D}_{\mathrm{Geo}}$ ).

Quando as matrizes $\mathrm{D}_{\mathrm{Gen}}$ e $\mathrm{D}_{\mathrm{Geo}}$ são analisadas considerando-se o efeito do fator continental sobre elas, é observada uma fraca correlação $(\mathbf{r}=\mathbf{0 , 0 9})$, positiva e significativa $(\mathbf{p}=\mathbf{0}, \mathbf{0 1 1 7})$. Já quando a associação testada é a entre $D_{G e n}$ e $E_{\text {Con }}$ considerando-se o efeito das distâncias geográficas interpopulacionais, o coeficiente de correlação obtido $(\mathbf{r}=\mathbf{o}, \mathbf{2 8})$, positivo e estatisticamente significativo $(\mathbf{p}<\mathbf{0 , 0 0 0})$, é relativamente mais expressivo do que o obtido na análise da interação anterior. Isto quer dizer que, quando se agrega à interação o efeito devido à informação "continentes 
iguais ou continentes diferentes", o poder explicativo da distância geográfica como preditora do grau de diferenciação entre as populações diminui. De maneira geral, esses resultados indicam que para se estimar o grau de divergência observado entre duas populações $\left(D_{G e n}\right)$, a informação relativa ao efeito continental, i. e., se essas duas populações estão em continentes iguais ou diferentes, $\left(\mathrm{E}_{\mathrm{Con}}\right)$ é uma melhor preditora do que a informação referente à distância geográfica que separa essas duas populações $\left(\mathrm{D}_{\mathrm{Geo}}\right)$.

Utilizando o mesmo conjunto de dados composto por $\mathrm{D}_{\mathrm{Geo}}$, $\mathrm{D}_{\mathrm{Gen}} \mathrm{e} \mathrm{E}_{\mathrm{Con}}$, as diferenças entre as associações entre diversidade da morfologia craniana e distância e localização geográfica, e as consequências evolutivas de tais diferenças, podem, ainda, ser avaliadas através de uma abordagem alternativa à comparação entre suas matrizes interpopulacionais.

Para o valor de $\mathrm{F}_{\mathrm{ST}}$ calculado para cada par de populações da matriz $\mathrm{D}_{\mathrm{Gen}}$ podese associar uma distância geográfica, calculada entre as mesmas duas populações, presente na matriz $\mathrm{D}_{\mathrm{Geo}}$. Já a matriz $\mathrm{E}_{\mathrm{Con}}$ indica, para esse dado par de populações, se elas se encontram em continentes iguais ou diferentes. Tal conjunto de informações permite a divisão dos dados ( $\mathrm{F}_{\mathrm{ST}}$ associado à distância geográfica para cada par de populações) em dois grupos, intra e inter, de acordo com sua condição geográfica continental.

A Figura 4.28 apresenta a dispersão desses pares, em termos de $\mathrm{D}_{\mathrm{Gen}}\left(\mathrm{ou} \mathrm{F}_{\mathrm{ST}}\right)$ em função de $\mathrm{D}_{\mathrm{Geo}}$ (ou distância geográfica). Na figura, pontos azuis indicam pares de populações de continentes diferentes enquanto que pontos vermelhos indicam os pares de continentes iguais. As curvas de regressão para cada um dos grupos estão representadas por linhas cheias, nas mesmas cores dos pontos correspondentes ao seu grupo. Adicionalmente, também está plotada a curva de regressão (linha cheia, em preto) considerando apenas $\mathrm{D}_{\mathrm{Gen}}$ e $\mathrm{D}_{\mathrm{Geo}}$, independentemente de sua localização 
geográfica continental. A Tabela 4.14 apresenta a descrição sumária dos parâmetros obtidos para a regressão dos dados da dispersão.

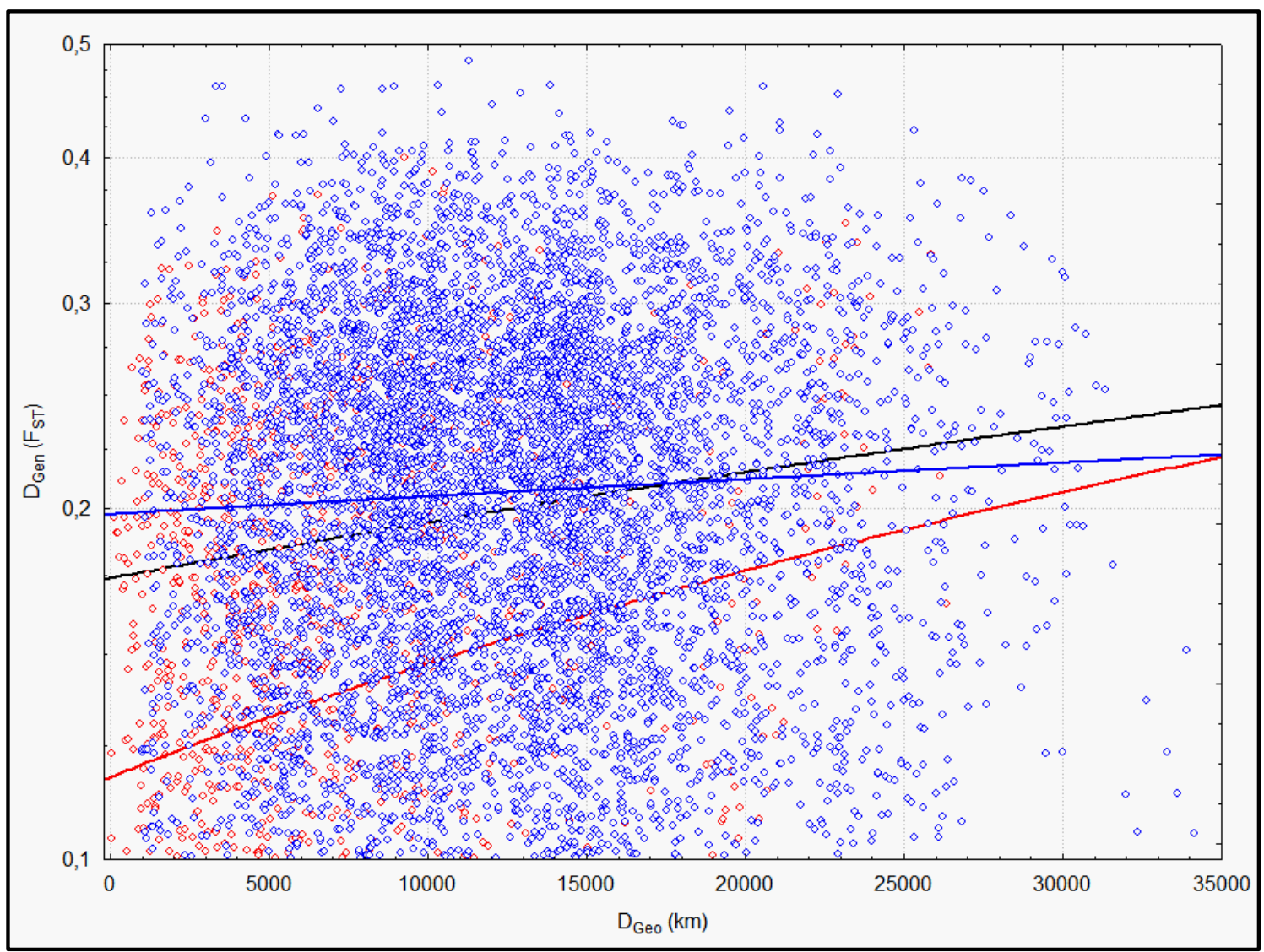

Fig. 4.28 - Diagrama de dispersão de $\mathrm{F}_{\mathrm{ST}}$ em função de distância geográfica, calculados para pares de populações. O eixo y está em escala logarítimica para facilitar a visualização. Pontos vermelhos representam pares de populações localizados no mesmo continente e azuis em continentes diferentes. Linha cheia vermelha representa a curva de regressão para os pares intracontinentais, azul para os intercontinentais e preta para todos os pares independentemente do continente.

Tabela 4.13 - Valores de correlação observados entre as matrizes DGen, DGeo e ECon.

\begin{tabular}{ccc}
\hline Pares populacionais & Correlação $(r)$ & p-valor \\
\hline Pares intracontinentais & $\mathbf{0 , 1 9 3 3 1}$ & $\mathbf{0 , 0 0 0 0}$ \\
Pares intercontinentais & $\mathbf{0 , 0 5 8 8 0}$ & $\mathbf{0 , 0 0 0 0}$ \\
Todos os pares & $\mathbf{0 , 1 5 2 3 6}$ & $\mathbf{0 , 0 2 3 2}$ \\
\hline
\end{tabular}

Em negrito valores estatisticamente significativos $(p<0,05)$

Os coeficientes obtidos para as correlações entre $\mathrm{F}_{\mathrm{ST}}$ e distância geográfica são positivos e significativos para as três diferentes configurações dos dados (intracontinentais, intercontinentais e independentes dos continentes). Chama a atenção o fato de um desses conjuntos apresentar om valor de correlação sensivelmente 
diferente do apresentado para os outros dois casos. Como pode ser visto na Tabela 4.13, os coeficientes produto-momento resultantes da interação entre dados intracontinentais e independente do continente $(\mathbf{r}=\mathbf{0 1 9}$ e $\mathbf{r}=\mathbf{0 , 1 5}$, respectivamente) são bastante parecidos, indicando que, para esta situação, a relação entre diversificação interpopulacional em função da distância entre as populações comporta-se de maneira semelhante tanto para as populações confinadas numa mesma extensão de terra quanto para as que se encontram separadas por grandes barreiras geográficas.

Tal observação, num primeiro instante, pode parecer contrária às feitas anteriormente nesta seção, quando a informação sobre a localização geográfica continental das populações pareceu ser melhor preditora do grau de diversificação interpopulacional do que as distâncias geográficas que as separam.

No entanto, uma informação adicional deve ser agregada a este quadro, a intensidade da correlação obtida quando apenas as populações localizadas em continentes diferentes são consideradas. Como pode ser observado na Tabela 4.13, quando é esta a condição analisada, o coeficiente obtido é menor do que o observado nas outras situações $(\mathbf{r}=\mathbf{0}, \mathbf{0 6} ; \mathbf{p}<\mathbf{0 , 0 0 0 0})$, indicando uma correlação mais fraca para F $_{\mathrm{ST}}$ em função da distância geográfica interpopulacional quando as populações em questão encontram-se em continentes diferentes do que quando estão localizadas nos mesmos continentes. Isto significa que, independentemente da correlação observada entre diversificação e distância considerando-se tanto populações intracontinentais quanto intercontinentais, parte das diferenças observadas na morfologia craniana humana quando analisadas em nível populacional são devidas à sua localização geográfica, que deve representar particularidades da história evolutiva de tais populações, e não exclusivamente à distância geográfica, ou, em perspectiva estimativa, tempo de divergência, que as separa. 


\section{c) Partição da variação entre fenótipo e genótipo}

A partição entre fenótipo e genótipo da variação craniana de populações nativas americanas foi investigada a partir de três diferentes análises baseadas em três categorias de matrizes, inferidas a partir dos dados anteriomente apresentados: uma matriz de distâncias morfológicas ( $\mathrm{D}_{\mathrm{Mor}}$ ), ou fenotípicas, representadas pelas distâncias de Mahalanobis $\left(\mathrm{D}^{2}\right)$; uma matriz de distâncias genéticas $\left(\mathrm{D}_{\mathrm{Gen}}\right)$, representando genótipos e construída a partir de uma matriz de distâncias de $\mathrm{F}_{\mathrm{ST}}$; e, uma matriz de distâncias geográficas $\left(\mathrm{D}_{\mathrm{Geo}}\right)$, representando a distância geográfica entre as populações estudadas. $\mathrm{A}_{\mathrm{Geo}}$ serve, neste trabalho, como uma estimativa indicativa de qual seria $\mathrm{o}$ comportamento intergrupal de populações sob regimes seletivos neutros.

Como dito, três diferentes análises foram desenvolvidas para explorar as características intrínsecas à essas matrizes: c.1) comparação direta entre matrizes; c.2) detecção de seleção natural; c.3) assinaturas evolutivas das variáveis craniométricas. As matrizes $D_{\text {Gen e }} D_{\text {Mor }}$ são apresentas, respectivamente, nas Tabelas 9A e 9B do Apêndice 9. Já a matriz $D_{\mathrm{Geo}}$ não será apresentada, uma vez que foi construída a partir da matriz de distâncias geográficas já apresentada na Tabela 4A do Apêndice 4.

\section{c.1 - Comparação direta entre as matrizes}

O primeiro experimento executado sobre $D_{G e n}$, $D_{M o r}$ e $D_{G e o}$ consistiu na comparação direta entre elas, através de correlação de Pearson seguida por teste de significância de Mantel. Seguindo o raciocínio anteriormente apresentado, as comparações entre $\mathrm{D}_{\mathrm{Gen}}$ e $\mathrm{D}_{\mathrm{Mor}}$ com $\mathrm{D}_{\mathrm{Geo}}$ explicitam como cada um dos dois marcadores se comporta quando comparados sob uma escala comparativa neutra, representando a situação idealizada no modelo de isolamento por distância - IPD (Wrigth, 1943). A Tabela 4.14 apresenta os resultados obtidos para as correlação entre essas matrizes. 
Tabela 4.14 - Coeficiente de correlação e valor de p obtidos para as comparações entres as matrizes $D_{G e n}, D_{\text {Mor, }}$ e $D_{G e o}$.

\begin{tabular}{ccc}
\hline Matrizes & $R$ & $P$ \\
\hline$D_{G e n} \mid D_{G e o}$ & $\mathbf{0 , 5 6 2 9}$ & $\mathbf{0 , 0 0 0 1}$ \\
$D_{\text {Mor }} \mid D_{G e o}$ & $\mathbf{0 , 3 5 8 2}$ & $\mathbf{0 , 0 0 1 6}$ \\
$D_{G e n} \mid D_{\text {Mor }}$ & $\mathbf{0 , 2 3 4 2}$ & $\mathbf{0 , 0 1 9 7}$
\end{tabular}

Valores significativos $(p<0,05)$ em negrito.

Como pode ser observado na Tabela 3.14, todos os valores de correlação encontrados para as interações entre as matrizes geradas são estatisticamente significativos. Dentre esses valores, pode-se destacar, em especial, a correlção $D_{\text {Gen }}$ | $\mathrm{D}_{\mathrm{Geo}}(\mathbf{r}=\mathbf{o}, \mathbf{5 6})$, a mais intensa entre as três obtidas. Tal correlação entre as medidas de distâncias genética e geográfica sugere que a diversificação genética observada entre as populações estudadas obedece de maneira regular o distanciamento geográfico entre elas, comportamento conforme o esperado para fenômenos ditados pelo modelo de IPD.

De maneira similar, a morfologia craniana entre as populações em questão comparativamente com a distância geográfica que as separa também indica a ação dos mesmos ditames evolutivos envolvidos no seu processo de diversificação. Tal constatação é embasada pela correlação observada entre as duas matrizes medidas $(\mathbf{r}=\mathbf{0}, \mathbf{3 5})$.

Embora semelhantes em efeito, uma observação importante deve ainda ser feita em relação as comparações entre $D_{G e n} \mid D_{G e o}$ e entre $D_{M o r} \mid D_{G e o}$. A menor intensidade de correlação observada da segunda ( $\left.\mathrm{D}_{\text {Mor }}\right)$ em comparação à primeira $\left(\mathrm{D}_{\mathrm{Gen}}\right)$ sugere que, seguindo o raciocínio empregado, marcadores moleculares apresentam-se melhor ajustados ao modelo evolutivo neutro do que o são os marcadores morfológicos. Tal observação pode ser fortalecida quando se considera a correlação obtida para a comparação entre $\mathrm{D}_{\mathrm{Gen}} \mid \mathrm{D}_{\mathrm{Mor}}$. 
Conforme pode ser observado na Tabela 4.14, quando a matriz construída com o valor do $\mathrm{F}_{\mathrm{ST}}$ calculado sobre as frequências de haplótipos de mtDNA é comparada com a matriz de distâncias de $\mathrm{D}^{2}$ calculadas sobre os traços craniométricos das populações em questão, é obtida uma pequena correlação, que pode sugerir que, ao menos em partes, morfologia craniana e marcadores moleculares não seguem processos evolutivos absolutamente iguais. Testar formalmente tal observação não é uma tarefa simples, uma vez que as estimativa dos parâmetros envolvidos, genes e morfologia, dificilmente é realizada sobre os mesmos indivíduos. No entanto, uma alternativa para tal questão é abordar, em termos populacionais, estratégias que detectem diferentes padrões evolutivos sobre esse mesmo tipo de dados aqui utilizados. Em outras palavras, uma alternativa à detecção das diferenças da magnitude de ação do IPD, ou de um processo estocástico evolutivamente neutro, para diferentes marcadores é a inferência de como um outro ditame evolutivo, como a seleção natural, por exemplo, poderia explicar o padrão de divergência observado entre as populações em questão.

\section{c.2 - Inferência de seleção natural}

O segundo experimento foi desenhado com o intuito de verificar o efeito do clima sobre a morfologia das populações, inferindo, indiretamente, possíveis efeitos da seleção natural no padrão de diversificação observado entre as populações amostradas. O continente Americano apresenta uma grande amplitude de extremos de latitude, i. e., a América ocupa desde extremos próximos ao pólo Norte até extremos próximo ao pólo Sul. Admitindo que, tratando-se de morfologia craniana, os sinais seletivos descritos na literatura atuam principalmente devido ao clima (Roseman, 2004, Hubbe et al., 2009), pode-se especular que populações localizadas em pontos de equidistância latitudinal (por exemplo $30^{\circ} \mathrm{N}$ e $30^{\circ} \mathrm{S}$ ), apresentem mais semelhanças morfológicas do que genéticas entre si, revelando, assim, desvios da neutralidade quando se trata de traços cranianos. A Figura 3.12, no capítulo anterior, ilustra tal raciocínio. 
Assim, o continente americano foi dividido em duas regiões sujeitas a características climáticas semelhantes, variando do extremo glacial ao equatorial. Essa configuração foi utilizada para executar essa rodada de análises. As matrizes $\mathrm{D}_{\mathrm{Gen}}, \mathrm{D}_{\mathrm{Mor}}$, e $\mathrm{D}_{\mathrm{Geo}}$ foram divididas em duas frações: América do Norte e América Central-Sul, resultando em um novo conjunto de matrizes, novamente submetidas a análise de correlação de Pearson seguido por teste de Mantel. A Tabela 4.15 apresenta os resultados obtidos para esses testes.

Tabela 4.15 - Coeficiente de correlação e valor de $p$ obtidos para as comparações entres as matrizes $D_{G e n}, D_{M o r}$, e $D_{G e o}$ divididas em frações América do Norte e América Central-Sul.

\begin{tabular}{ccccc}
\hline \multirow{2}{*}{ Matrizes } & \multicolumn{2}{c}{ América do Norte } & \multicolumn{2}{c}{ América Central-Sul } \\
& Correlação & $P$ & Correlação & $P$ \\
\hline$D_{G e n} \mid D_{G e o}$ & $\mathbf{0 , 4 3 0 3}$ & $\mathbf{0 , 0 0 1}$ & $\mathbf{0 , 6 3 4 7}$ & $\mathbf{0 , 0 0 7}$ \\
$D_{\text {Mor }} \mid D_{G e o}$ & $\mathbf{0 , 5 1 7 7}$ & $\mathbf{0 , 0 0 0 2}$ & $-0,0410$ & 0,505 \\
$D_{G e n} \mid D_{\text {Mor }}$ & $\mathbf{0 , 3 4 1 9}$ & $\mathbf{0 , 0 0 4}$ & $-0,0993$ & 0,545 \\
\hline
\end{tabular}

Valores significativos $(p<0,05)$ em negrito.

Os resultados obtidos neste experimento indicam que, para a América do Norte, os dois marcadores se ajustam ao esperado, considerando-se uma situação evolutiva conforme prevista pelo modelo de IPD. Tal afirmação é embasada pelos coeficientes obtidos entre $D_{G e n} \mid D_{G e o}$ e entre $D_{\text {Mor }} \mid D_{G e o}$, ambos positivos e estatisticamente significativos ( $r=\mathbf{0 , 4 3}$ e $\mathbf{r}=\mathbf{0 , 5 1}$, respectivamente). Em outras palavras, considerando apenas as populações da região norte do continente americano, crânios e mtDNA se comportam de maneira neutra, com, inclusive, um melhor ajuste obtido entre a divergência da morfologia craniana entre populações e as distâncias geográficas que as separam do que o observado entre a divergência de mtDNA interpopulacional comparado com a localização geográfica (medidas em km) entre elas. Finalmente, essa observação pode ainda ser corroborada pela relação obtida quando $D_{G e n}$ e $D_{\text {Mor }}$ são comparadas, indicando, também, a existência de correlação positiva e significativa 
entre elas $(r=0,34)$, favorecendo a ideia de que ambos os marcadores apresentam assinaturas evolutivas semelhantes.

O mesmo, entretanto, não pode ser dito quando as Américas Central e do Sul são consideradas. Nessa fração, a comparação entre as matrizes $D_{G e n} \mid D_{G e o}$ indica que os marcadores moleculares apresentam-se fortemente correlacionados à geografia $(\mathbf{r}=\mathbf{0 , 6 3})$, demonstrando uma estruturação espacial indicativa de que as populações apresentam entre si uma maior diversificação genotípica à medida que aumentam as distâncias geográficas que as separam. Tal comportamento é plenamente factível num cenário cujo processo evolutivo determinante seja neutro, como preconizado no modelo de IPD, por exemplo.

No entanto, quando $D_{\text {Mor }} \mid D_{G e o}$ foram comparadas, diversificação morfológica e distanciamento geográfico não se correlacionam, apresentando comportamento diferente daquele observado entre mtDNA e distâncias interpopulacionais e como seria esperado sob um regime evolutivo majoritariamente neutro. Tal cenário torna-se ainda mais evidente quando a comparação realizada envolve as matrizes calculadas a partir dos marcadores moleculares e morfológicos. Nesse caso, a a ausência de correlação significativa entre as matrizes reforça a ideia de que ambos apresentam-se regidos por contingências específicas, medidas diretamente através da diversificação interpopulacional das frequências de haplótipos de mtDNA e da morfologia do crânio nas populações das Américas Central e do Sul.

A razão de tal diferença de comportamento entre os dois marcadores quando a região geográfica do continente americano na qual se localizam é considerada é de difícil explicação. No entanto, se, conforme explorado ao longo da Introdução, a complexidade inerente aos mecanismos de regulação gênica da expressão de características fenotípicas métricas (Parichy, 2005), com ênfase à complexidade 
biológico-evolutiva do crânio (Zelditch, 2005), é admitida, pequenas diferenças na história demográfica das populações em questão podem levar a produtos genotípicos extremos, como diferentes respostas ao ambiente, por exemplo. Nesse sentido, diferentes respostas seletivas entre as populações da América do Norte em relação as da América do Sul, e vice-versa, poderiam responder, ao menos parcialmente, o motivo de a diversificação morfológica de ambas comportarem-se de maneira oposta quando a diversificação medida por mtDNA é usado como base comparativa.

\section{c.3 - assinaturas evolutivas das variáveis craniométricas}

Este terceiro grupo de experimentos realizado foi delineado com o intuito de quantificar quais características cranianas específicas podem ser consideradas como tendo assinaturas evolutivas neutras e não-neutras. Para tanto, uma série de matrizes de $\mathrm{D}^{2}$ foram calculadas considerando-se cada uma das 24 variáveis craniométricas por vez ${ }^{51}$. As novas matrizes morfológicas resultantes foram então comparadas, através de correlação de Pearson e teste de Mantel, com as matrizes $\mathrm{D}_{\mathrm{Gen}}$ e $\mathrm{D}_{\mathrm{Geo}}$. Com essa estratégia espera-se diagnosticar de maneira diferencial o comportamento de cada traço craniométrico, inferindo o quanto cada um aproxima-se ou afasta-se do esperado sob uma perspectiva evolutiva neutra. Os testes de correlação foram feitos para três grupos distintos de análises: América, América do Norte e América Central-Sul. Dessa forma, foram geradas 72 matrizes (24 para cada grupo) morfológicas e obtidos 144 coeficientes de correlação (e seus respectivos valores de p). As Tabelas 4.16 a 3.18 mostram os valores de correlação gerados pela comparação entre as matrizes considerando-se, respectivamente, as frações América, América do Norte, América Central-Sul. As Figuras 4.29 a 4.4.31 indicam os traços craniométricos que apresentam assinatura evolutiva neutra, respectivamente para as mesmas frações geográficas.

\footnotetext{
${ }^{51}$ Nesse caso, devido à singularidade das matrizes a medida de divergência deixa de ser, formalmente, a $D^{2}$ e passa a ser a diferença entre as médias populacionais padronizadas através das variâncias médias intra-populacionais. No entanto, o raciocínio empregado para sua utilização não se invalida.
} 
Tabela 4.16 - Coeficiente de correlação e valor de $p$ obtidos para as comparações entres as matrizes $\mathrm{D}_{\text {Mor }}$ (obtida variável-a-variável), $\mathrm{D}_{\mathrm{Gen}}$, e $\mathrm{D}_{\mathrm{Geo}}$, representando a América toda.

\begin{tabular}{|c|c|c|c|c|}
\hline \multirow{2}{*}{ Variávies } & \multicolumn{2}{|c|}{$\overline{D_{G e n}}$} & \multicolumn{2}{|c|}{$\mathrm{D}_{\mathrm{Geo}}$} \\
\hline & Correlação & $P$ & Correlação & $P$ \\
\hline GOL & 0,0184 & 0,424 & $-0,006$ & 0,507 \\
\hline NOL & $-0,0071$ & 0,726 & $-0,0561$ & 0,066 \\
\hline $\mathrm{BNL}$ & 0,0066 & 0,465 & 0,1115 & 0,162 \\
\hline $\mathrm{BBH}$ & $-0,0761$ & 0,718 & $-0,0835$ & 0,735 \\
\hline XCB & 0,0445 & 0,336 & 0,0896 & 0,218 \\
\hline XFB & $-0,1186$ & 0,829 & $-0,1585$ & 0,938 \\
\hline ZYB & 0,2505 & 0,011 & 0,165 & 0,085 \\
\hline$A \cup B$ & 0,1979 & 0,036 & 0,1335 & 0,114 \\
\hline ASB & 0,0414 & 0,374 & 0,2211 & 0,059 \\
\hline BPL & 0,1167 & 0,233 & 0,2406 & 0,076 \\
\hline $\mathrm{NPH}$ & 0,2323 & 0,026 & 0,3098 & 0,009 \\
\hline NLH & 0,2647 & 0,007 & 0,356 & 0,002 \\
\hline $\mathrm{OBH}$ & 0,0326 & 0,371 & 0,0972 & 0,189 \\
\hline OBB & 0,0572 & 0,514 & 0,1746 & 0,602 \\
\hline NLB & 0,2732 & 0,006 & 0,1142 & 0,149 \\
\hline MAB & $-0,0459$ & 0,563 & $-0,0441$ & 0,547 \\
\hline $\mathrm{MDH}$ & $-0,0337$ & 0,410 & $-0,089$ & 0,684 \\
\hline MDB & $-0,451$ & 0,613 & 0,1481 & 0,152 \\
\hline ZMB & $-0,1529$ & 0,922 & $-0,2019$ & 0,981 \\
\hline DKB & 0,1323 & 0,147 & 0,3354 & 0,008 \\
\hline WNB & 0,4012 & 0,0005 & 0,409 & 0,001 \\
\hline FRC & $-0,0315$ & 0,598 & 0,0511 & 0,314 \\
\hline PAC & 0,0447 & 0,372 & 0,0988 & 0,218 \\
\hline OCC & 0,0121 & 0,447 & $-0,1054$ & 0,791 \\
\hline
\end{tabular}

Valores significativos $(p<0,05)$ em negrito.

A observação direta da Tabela 4.16 indica que, quando todas as populações estudadas são consideradas, apenas seis das 24 variáveis craniométricas avaliadas se mostram significativamente correlacionadas com a matriz de divergência genética entre 
populações. Quando as mesmas variáveis representativas da morfologia craniana dessas populações são comparadas com a matriz de distâncias geográficas que as separam, esse número, de correlações estatisticamente significativas, cai pela metade, representando apenas três variáves. Essas mesmas três variáveis, por outro lado, apresentam correlações significativas tanto com a matriz $\mathrm{D}_{\text {Gen }}$ quanto com a matriz $\mathrm{D}_{\mathrm{Geo}}$, o que poderia sugerir que $\mathrm{NPH}, \mathrm{NLH}$ e WNB (as variáveis em questão) apresentam-se diferenciadas, em termos interpopulacionais, de maneira semelhante a observada quando marcadores evolutivamente são analisados.

No entanto, tal destaque para NPH, NLH e WNB não pode eclipsar totalmente as outras três variáveis (ZYB, AUB, NLB) que mostraram-se significativamente correlacionadas no experimento, afinal, a associação observada para essas variáveis foi obtida justamente quando a matriz comparativa utilizada foi, provavelmente o melhor marcador de comportamento evolutivo neutro utilizado no experimento. Assim, a Figura 4.29 apresenta a representação das seis medidas craniométricas que apresentam assinatura evolutiva neutra neste conjunto de análises.

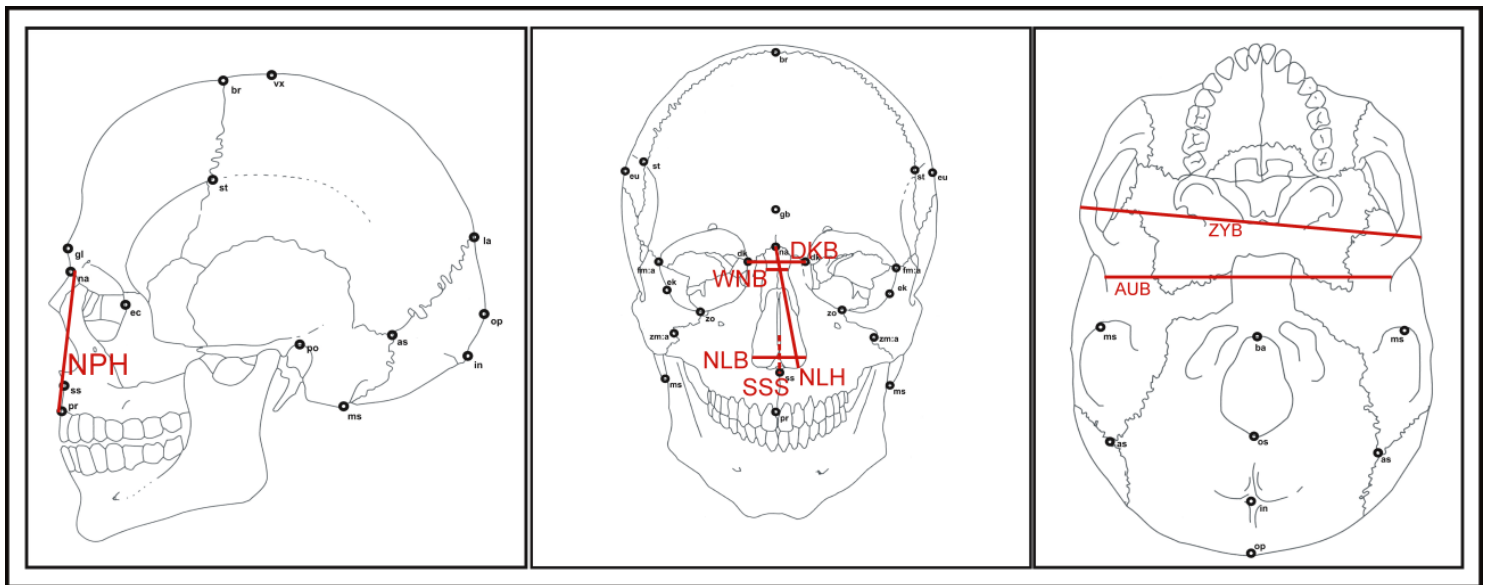

Figura 4.29 - Representação das variáveis craniométricas que apresentaram sinal de neutralidade, quando foram analisadas populações de todo o continente americano. 
Cenário semelhante é observado quando apenas as populações localizadas na América do Norte foram testadas. Os resultados expostos pela Tabela 4.17, representando os coeficientes de correlação obtidos das comparações entre morfologia craniana e variação de mtDNA e entre morfologia craniana e distâncias geográficas mostram que nove das 24 variáveis craniométricas analisadas mostraram algum tipo de correlação significativa com o padrão observado nos genes ou nas localizações geográficas.

Três dos noves coeficientes observados (BPL, NPH e NLB) aparecem correlacionados tanto com os dados moleculares quanto com os de distanciamento geográfico sugerindo, como nomcaso anterior, um forte ajuste dessas variáveis ao comportamento esperado de uma característica sob um ditame evolutivo neutro. Surpreendentemente, um número maior de traços cranianos aparece exclusivamente correlacionado à matriz de distâncias geográficas do que à matriz de divergência genética. No primeiro caso, cinco variáveis (BNL, ASB, NLH, DKB e WNB) mostram-se significativamente correlacionados ao padrão de separação geográfica observado entre as populações, ao passo que no segundo, apenas uma das variáveis (ZYB) aparece em correlação exclusiva com o padrão estabelecido pela análise da frequência de polimorfismos do mtDNA das populações localizadas na América do Norte incluídas neste estudo. Todas as variáveis que apresentaram alguma correlação com o padrão esperado sob um regime evolutivo neutro estão representadas na Figura 4.30.

Tabela 4.17 - Coeficiente de correlação e valor de $p$ obtidos para as comparações entres as matrizes $D_{M o r}$ (obtida variável-a-variável), $D_{G e n}$, e $D_{G e o,}$ representando apenas a fração América do Norte.

\begin{tabular}{ccccc}
\hline \multirow{2}{*}{ Variávies } & \multicolumn{3}{c}{$\mathrm{D}_{\text {Gen }}$} & \multicolumn{2}{c}{$\mathrm{D}_{\text {Geo }}$} \\
\cline { 2 - 5 } & Correlação & $\mathrm{P}$ & Correlação & $\mathrm{p}$ \\
\hline GOL & $-0,0735$ & 0,658 & $-0,0763$ & 0,646 \\
NOL & $-0,1073$ & 0,741 & $-0,0603$ & 0,611 \\
BNL & 0,0048 & 0,456 & $\mathbf{0 , 2 8 4 8}$ & $\mathbf{0 , 0 2 1}$ \\
BBH & 0,1545 & 0,175 & 0,0478 & 0,033 \\
\hline
\end{tabular}


Continuação

\begin{tabular}{ccccc}
\hline XCB & 0,1014 & 0,242 & 0,2035 & 0,093 \\
XFB & $-0,0676$ & 0,684 & $-0,1389$ & 0,855 \\
ZYB & $\mathbf{0 , 3 1 0 3}$ & $\mathbf{0 , 0 4 2}$ & 0,1841 & 0,014 \\
AUB & 0,1931 & 0,102 & 0,0824 & 0,253 \\
ASB & 0,1896 & 0,169 & $\mathbf{0 , 4 3 5 2}$ & $\mathbf{0 , 0 1 1}$ \\
BPL & $\mathbf{0 , 3 9 7 3}$ & $\mathbf{0 , 0 1 2}$ & $\mathbf{0 , 5 7 1 1}$ & $\mathbf{0 , 0 0 0 4}$ \\
NPH & $\mathbf{0 , 2 7 3 5}$ & $\mathbf{0 , 0 5 4}$ & $\mathbf{0 , 3 8 3 4}$ & $\mathbf{0 , 0 1 1}$ \\
NLH & 0,1967 & 0,074 & $\mathbf{0 , 3 9 5 9}$ & $\mathbf{0 , 0 0 4}$ \\
OBH & 0,1408 & 0,194 & 0,1657 & 0,145 \\
OBB & 0,0940 & 0,1894 & 0,0738 & 0,4930 \\
NLB & $\mathbf{0 , 4 3 8 2}$ & $\mathbf{0 , 0 0 3}$ & $\mathbf{0 , 2 4 1 7}$ & $\mathbf{0 , 0 5 2}$ \\
MAB & $-0,0135$ & 0,799 & $-0,0628$ & 0,621 \\
MDH & 0,2784 & 0,2732 & 0,1096 & 0,3501 \\
MDB & 0,0012 & 0,397 & 0,2578 & 0,132 \\
ZMB & $-0,1766$ & 0,874 & $-0,1156$ & 0,752 \\
DKB & 0,0152 & 0,428 & $\mathbf{0 , 4 9 5 7}$ & $\mathbf{0 , 0 0 0 4}$ \\
WNB & 0,1841 & 0,145 & $\mathbf{0 , 3 5 7 4}$ & $\mathbf{0 , 0 1 8}$ \\
FRC & 0,1285 & 0,206 & 0,1976 & 0,105 \\
PAC & 0,0915 & 0,274 & 0,2322 & 0,085 \\
OCC & $-0,1392$ & 0,788 & $-0,2585$ & 0,997 \\
\hline$V a r$ & & & \\
\hline
\end{tabular}

Valores significativos $(p<0,05)$ em negrito.

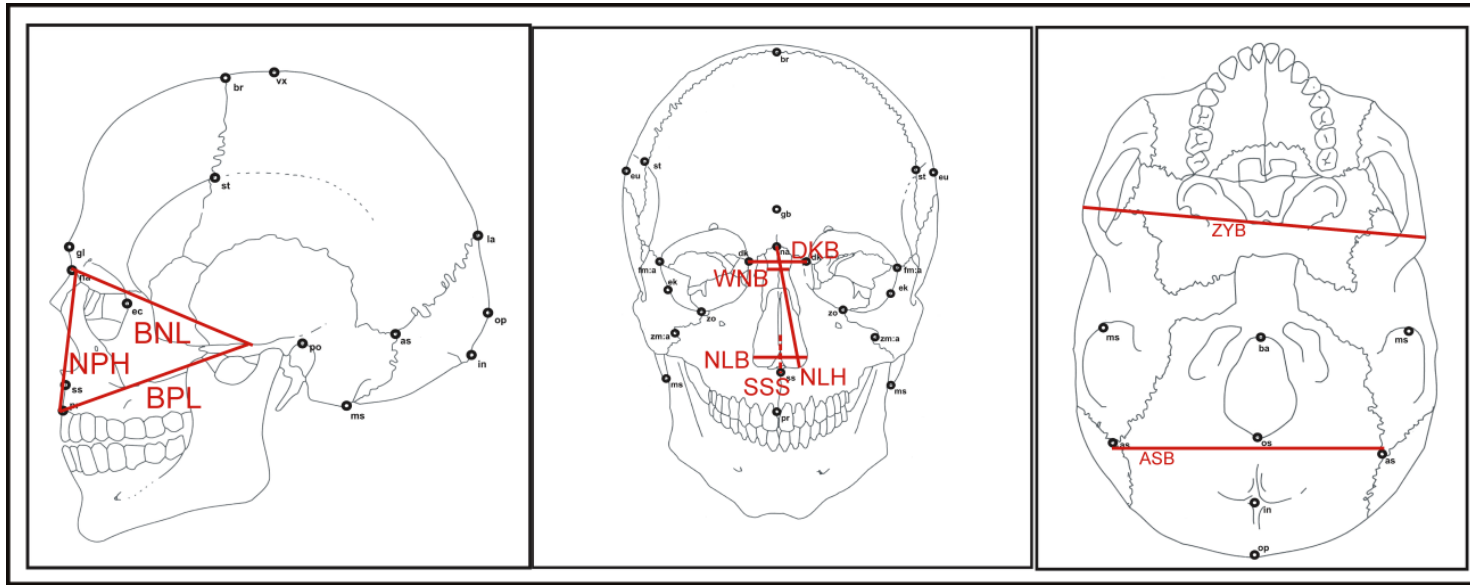

Figura 4.30 - Representação das variáveis craniométricas que apresentaram sinal de neutralidade, quando foram analisadas apenas as populações localizadas na América do Norte. 
Este cenário relativamente estável quando se considera a América como um todo e a porção Norte em particular não se confirma quando apenas as populações da fração Centro-Sul são analisadas. Quando apenas essas últimas são testadas, apenas duas das 24 variáveis analisadas (NLB e WNB) apresentam qualquer sinal que possa ser interpretado como neutro, das quais apenas uma (NLB) apresenta correlações significativas tanto com $\mathrm{D}_{\mathrm{Gen}}$ quanto com $\mathrm{D}_{\mathrm{Geo}}$. Essa queda drástica da quantidade de traços craniométricos que se apresentam significativamente correlacionados com $\mathrm{D}_{\mathrm{Gen}}$ ou $\mathrm{D}_{\mathrm{Geo}}$ ajuda a explicar a diferença observada na Tabela 4.15, quando foi constatado a diferença entre os padrões de associação obtidos para America do Norte e para América Central e do Sul. No entanto, a natureza de tal diferença é de difícil explicação, ainda mais quando considera-se que justamente entre as populações Centro-sul americanas é que se observou a maior correlação entre $\mathrm{D}_{\mathrm{Gen}}$ e $\mathrm{D}_{\mathrm{Geo}}$.

Nesse cenário, não restam muitas explicações alternativas à de que, entre as populações das Américas Central e do Sul, crânio e moléculas não caminham, majoritariamente, sob os mesmos ditames evolutivos. A Tabela 4.18 mostra os coeficientes de correlação obtidos das comparações entre os traços craniométricos com $\mathrm{D}_{\mathrm{Gen}}$ e $\mathrm{D}_{\mathrm{Geo}}$ para as populações centro-sul americanas ao passo que a Figura 4.31 ilustra as variáveis cuja assinatura inferida foi interpretada como evolutivamente neutra.

Tabela 4.18 - Coeficiente de correlação e valores de $p$ obtidos para as comparações entres as matrizes $D_{M o r}$ (obtida variável-a-variável), $D_{G e n}$ e $D_{G e o}$, representando apenas a fração América Central-Sul..

\begin{tabular}{ccccc}
\hline \multirow{2}{*}{ Variávies } & \multicolumn{3}{c}{$\mathrm{D}_{\text {Gen }}$} & \multicolumn{2}{c}{$\mathrm{D}_{\text {Geo }}$} \\
\cline { 2 - 5 } & Correlação & $\mathrm{P}$ & Correlação & $\mathrm{p}$ \\
\hline GOL & 0,3075 & 0,203 & 0,4786 & 0,057 \\
NOL & 0,3111 & 0,171 & 0,3774 & 0,107 \\
BNL & $-0,0502$ & 0,528 & 0,2183 & 0,161 \\
BBH & $-0,2244$ & 0,776 & $-0,0273$ & 0,513 \\
XCB & $-0,2246$ & 0,653 & $-0,0548$ & 0,494 \\
XFB & $-0,1031$ & 0,534 & $-0,2397$ & 0,823 \\
ZYB & 0,4658 & 0,073 & 0,3593 & 0,102 \\
AUB & 0,0808 & 0,349 & 0,2188 & 0,218 \\
\hline
\end{tabular}


Continuação

\begin{tabular}{ccccc}
\hline ASB & $-0,3646$ & 0,953 & $-0,3708$ & 0,968 \\
BPL & $-0,2695$ & 0,822 & $-0,1847$ & 0,698 \\
NPH & 0,5157 & 0,058 & 0,3738 & 0,122 \\
NLH & $-0,1455$ & 0,704 & 0,0962 & 0,331 \\
OBH & $-0,0315$ & 0,371 & 0,1587 & 0,229 \\
OBB & $-0,0872$ & 0,448 & $-0,1353$ & 0,625 \\
NLB & $\mathbf{0 , 6 0 1 6}$ & $\mathbf{0 , 0 1 8}$ & $\mathbf{0 , 7 9 5 9}$ & $\mathbf{0 , 0 0 2}$ \\
MAB & $-0,3041$ & 0,944 & $-0,1898$ & 0,729 \\
MDH & $-0,0288$ & 0,609 & $-0,0318$ & 0,553 \\
MDB & $-0,0856$ & 0,601 & $-0,1696$ & 0,743 \\
ZMB & 0,3266 & 0,122 & 0,2944 & 0,151 \\
DKB & $-0,1044$ & 0,538 & $-0,0105$ & 0,464 \\
WNB & $\mathbf{0 , 5 3 2 2}$ & $\mathbf{0 , 0 3 3}$ & 0,3682 & 0,083 \\
FRC & 0,1288 & 0,296 & 0,1594 & 0,214 \\
PAC & 0,0618 & 0,431 & $-0,2143$ & 0,791 \\
OCC & $-0,0366$ & 0,524 & 0,0951 & 0,324 \\
\hline
\end{tabular}

Valores significativos $(p<0,05)$ em negrito.

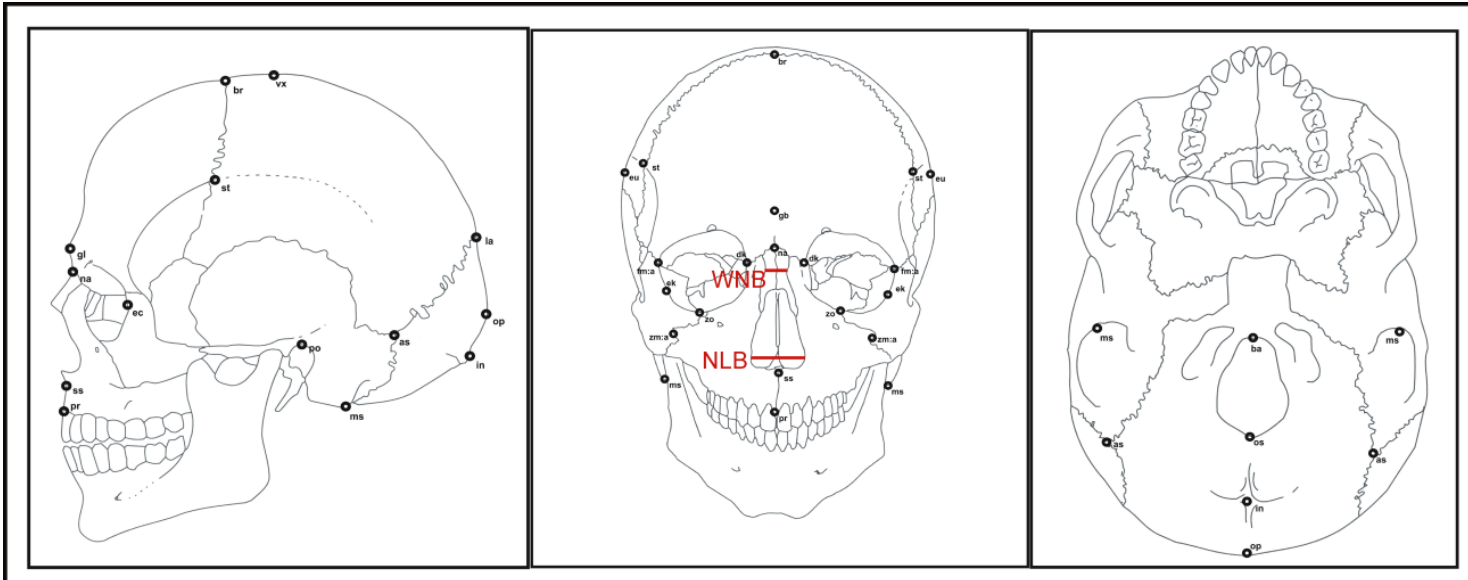

Figura 4.31 - Representação das variáveis craniométricas que apresentaram sinal de neutralidade, quando foram analisadas apenas as populações localizadas nas Américas Central e do Norte. 


\section{2 - Modularidade, integração e padrões de (V/CV) da morfologia craniana humana}

Nesta seção serão apresentados os resultados gerados a partir das análises realizadas sobre a estrutura de variação e covariação de caracteres descritivos da morfologia craniana humana, visando a investigação dos padrões de modularidade, integração e proporcionalidade. Como antecipado anteriormente, no entanto, uma condição que precede tal investigação é a adoção de uma estrutura de organização hierárquica para as populações amostradas. Assim, os primeiros resultados aqui apresentados se referem às análises dessas estruturas a partir dos quatro critérios adotados neste trabalho.

\subsection{1 - Critérios de agrupamento}

Como descrito no capítulo 3, foram adotados quatro critérios para a compartimentalização dos dados craniométricos a serem analisados. Os resultados a seguir apresentam as decisões tomadas a partir dos quatro experimentos executados.

\section{I) Hierarquização morfológica}

Como antecipado, a hierarquização morfológica foi estabelecida através de um dendrograma gerado através de uma análise de "cluster" aplicada sobre uma matriz D². Tal matriz foi calculada a partir das características craniométricas de 9.127 indivíduos de 149 populações amostradas (Tabela 3.2). Esses mesmos dados serão submetidos à análise dos padrões de modularidade, integração e V/CV.

Conforme apresentado no capítulo Material e Métodos, a escolha das séries envolvidas nesta análise seguiu três critérios previamente estabelecidos. O primeiro desses critérios relaciona-se ao tamanho das amostras. Inicialmente, apenas séries contando com um mínimo de 25 indivíduos foram selecionadas para a análise, 
resultando em 8.898 indivíduos distribuídos em 128 séries. Já o segundo critério utilizado, a correspondência com populações amostradas no banco de dados de microssatélites, foi responsável pela agregação de outras 11 populações (140 indivíduos). Finalmente, outros 89 indivíduos, pertencentes a 10 populações, tambérm foram incluídos devido à sua importância em termos históricos (como a reconstituição de uma sequência populacional, por exemplo) ou particularidades morfológicas específicas, o que representa o terceiro critério adotado.

A matriz de $\mathrm{D}^{2}$ resultante foi submetida à uma análise de "cluster" baseada no método de ligação simples ("single linkage"), ou, como também é conhecida, método dos vizinhos próximos (Sneath, 1957; Mingoti, 2005). Tal escolha foi baseada na característica operacional do algoritmo, que favorece a formação de grupos densos, coesos e que privilegia a similaridade morfológica em todos os níveis de agrupamento (Sneath, 1957). A topologia obtida está representada na Figura 4.32. Nela, a distância de ligação entre os ramos do dendrograma estão escalonados em função das distâncias máximas obtidas. Assim, as distâncias de ligação apresentadas na topologia são representadas por $\mathrm{i}$ = distância de ligação/distância máxima.

Ainda em relação ao formato utilizado para representar as relações do dendrograma gerado, cabe destacar que as populações aparecem nomeadas com as siglas definidas na Tabela 3.2 e identificadas quanto ao continente no qual se localizam seguindo o critério e esquema de cores utilizados a partir da Tabela 4.10.

Para a formação dos grupos de análise, utilizou-se a topologia em três níveis de associação. O primeiro nível, o mais inclusivo de todos, corresponde à primeira clivagem do agrupamento, ocorrida em $\mathrm{i}=100$. Tal ramificação divide a amostra total (149 séries) em dois grupos (um de 71 e outro de 78 populações). Observando a Figura 4.32 de cima para baixo, um grupo é formado pelo "cluster" que reúne de SCER até EGTG, enquanto que o outro é formado pelo agrupamento de vai desde LSAN até 
NUGA. Nota-se no primeiro grupo citado um claro predomínio de populações nativas americanas (vermelhas) e asiáticas (verdes). Raras exceções, como algumas séries da Polinésia (pretas) e da Europa52 (laranjas) também aparecem neste "cluster", que pode ser interpretado, grosso modo, como um agrupamento composto por populações caracterizadas por morfologia especializada ${ }^{53}$. Já o segundo grande conglomerado formado é caracterizado pela presença das populações da África subsaariana, das populações australo-melanésias e européias. A esses grupo estão associadas também algumas populações asiáticas e das outras regiões da Oceania que ainda não foram citadas. Em oposição ao grupo anteriormente descrito, as afinidades apresentadas por este "cluster" permitem a sugestão de que, embora não de maneira exclusiva e intensa, sua associação representa o padrão morfológico generalizado. Dois detalhes sobre as afinidades observadas neste agrupamento corroboram tal posição.

A primeira delas refere-se ao fato de que as populações de maior profundidade cronológica na amostra (NLIQ, NLRC e NLJO, por exemplo) aparecem agregadas a esse "cluster", cuja característica inicialmente descrita, a presença maciça dos representantes da África subsaariana, o colocam automaticamente em associação com um padrão morfológico primitivo54. Em segundo lugar, as únicas populações nativas americanas localizadas neste agrupamento são, justamente, as mesmas populações (LSAN, COLA, BBCE) cujas afinidades morfológicas já foram observados em especial harmonia com o padrão observado entre africanos e australo-melanésios modernos em detrimento aos outros nativos americanos (Neves \& Hubbe, 2005; Neves et al., 2007a; Bernardo, 2007; Bernardo et al., 2011; Neves et al., 2011).

\footnotetext{
${ }^{52}$ Neste agrupamento ocorre a associação de EGTG (Egito, sul da pirâmide de Gizeh) com um "cluster" formado por BERG, AINU, NORS e ZALA. Essas cinco séries são pertencentes ao banco Howells, sendo que BERG, NORS e ZALA são as representantes européias do referido banco de dados. Embora EGTG seja, tecnicamente, localizado na África, o próprio autor chama a atenção para a natureza "européia" da série egípcia (Howells, 1973), motivo pelo qual a presença dessa população africana pode ser ignorada na interpretação da topologia.

${ }_{53}$ Morfologia generalizada é o padrão morfológico similar àquele que caracterizou os primeiros Homo sapiens, que da África se dispersaram por todo o planeta antes que o processo de raciação tivesse ocorrido. Tal padrão pode ser associado em tempos modernos à morfologia apresentada pelos africanos subsaarianos e australo-melanésios nativos. Em oposição à morfologia generalizada pode-se reconhecer a morfologia especializada, correspondente às populações racializadas no nordeste asiático a partir de 40 mil anos atrás. Nativos americanos (ameríndios) em geral e asiáticos (leste da Ásia) modernos são os retentores desse padrão morfológico (Lahr, 1995, 1996).

${ }^{54}$ No sentido cladístico, em oposição a derivado (Hennig, 1965).
} 
O segundo nível hierárquico corresponde à divisão dos grupos anteriormente formados, resultando em quatro novos subconjuntos. Seguindo a mesma lógica utilizada no caso anterior, analisando a topologia de cima para baixo, os quatro grupos fornados são assim delimitados: o primeiro pelo conglomerado que se inicia em SCER e termina em TIBE, o segundo iniciando em YAKU e finalizando em EGTG, o terceiro composto pelo "cluster" começado em LSAN e interrompido em TEIT e o quarto, e último, formado pelo agrupamento que se inicia em BSHM e termina em NUGA. Do ponto de vista de afinidades morfológicas, esta segunda clivagem pouco acrescentou ao cenário desenhado quando da primeira divisão populacional.

O terceiro nível hierárquico divide por dois cada um dos grupos anteriormente formados, resultando em oito parcelas populacionais. Observando a topologia da Figura 4.32 a partir de seu extremo superior em sentido ao limite inferior, os grupos formados são assim referenciados: de SCER até ALND, de SANP até TIBE, de YAKU até BURI, de PERU até EGTG, de LSAN até COLA, de TASM até TEIT, de BSHM até HAYA e de MARR até NUGA.

No que se refere às características morfológicas dos grupos formados, poucas informações merecem destaque neste terceiro nível de hierarquização. Chama a atenção o fato de duas populações arcaicas do litoral sul brasileiro aparecerem em estreita associação com populações esquimós do extremo norte do continente americano. Tal associação, improvável, pode ser explicada pela recente posição tomada por Reich e colaboradores (2012) que sugerem que o estoque biológico responsável pela gênese dos Esquimós e Aleutas seja marcado por intensa mistura ao patrimônio genético responsável pela colonização da vasta maioria do continente americano. Ademais, os agrupamentos ocorridos neste terceiro nível hierárquico promoveram circunscrições mais precisas do ponto de vista geográfico, biológico e cronológico, garantindo confiabilidade à amostra utilizada. 


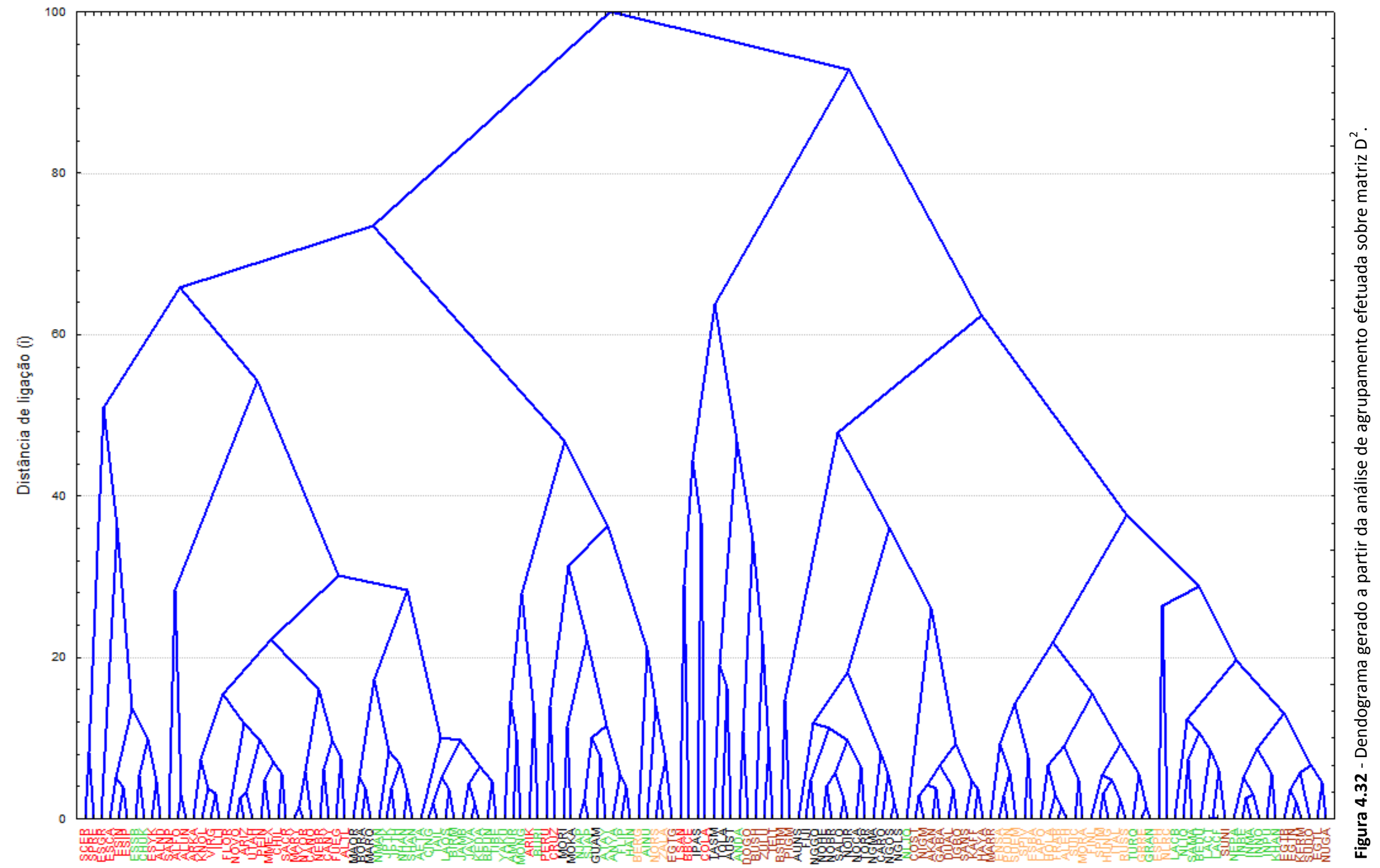


Todos os níveis hierárquicos formados sob o critério morfológico foram analisados seguindo duas abordagens: análise intragrupo e intergrupos.

\section{II) Hierarquização cronológica}

Como já descrito, a hierarquização cronológica será baseada na distribuição de frequências das datações inputadas às populações conforme apresentadas na Tabela 3.5 (Capítulo 3). Como pode ser depreendido de tal tabela, as antiguidades conhecidas no banco de dados distribuem-se em quatros classes, cujos limites são estabelecidos de o a 2000 anos A. P., de 2000 a 4000 anos A. P., de 4000 a 6000 anos A. P., e de 8000 a 10000 anos A. P., cujas frequências de observações são, respectivamente, 6o, 12, cinco e duas. A classe delimitada pelas datações de 6000 a 8000 anos A.P. não conta com nenhuma observação. Devido ao baixo número de observações relativas às duas últimas categorias, foi adotada uma classe composta delimitada pelas antiguidades de 4000 a 10000 anos A. P. Das 79 populações cujas antiguidades estão representadas na Tabela 4.10, 75 foram mantidas para as análises que serão desenvolvidas neste bloco da pesquisa. Assim, a Tabela 4.19 apresenta a configuração final da distribuição de datações e classes adotadas para a hierarquização cronológica das 75 populações amostradas. A Figura 4.33 apresenta a dispersão dessas observações (datações) em função de DOA.

Tabela 4.19 - Tabela de frequência com a distribuição das antiguidades (anos A. P.) das populações amostradas (Tabela 4.10).

\begin{tabular}{ccccc}
\hline Classes & Frequência & $\begin{array}{c}\text { frequência } \\
\text { cumulativa }\end{array}$ & Porcentagem & $\begin{array}{c}\text { porcentagem } \\
\text { cumulativa }\end{array}$ \\
\hline $0,000000<x<=2000,000$ & 56 & 56 & 74,67 & 74,67 \\
$2000,000<x<=4000,000$ & 12 & 68 & 16,00 & 90,67 \\
$4000,000<x<=10000,000$ & 7 & 75 & 9,33 & 100,00 \\
\hline Total & 75 & 75 & 100,00 & 100,00 \\
\hline
\end{tabular}




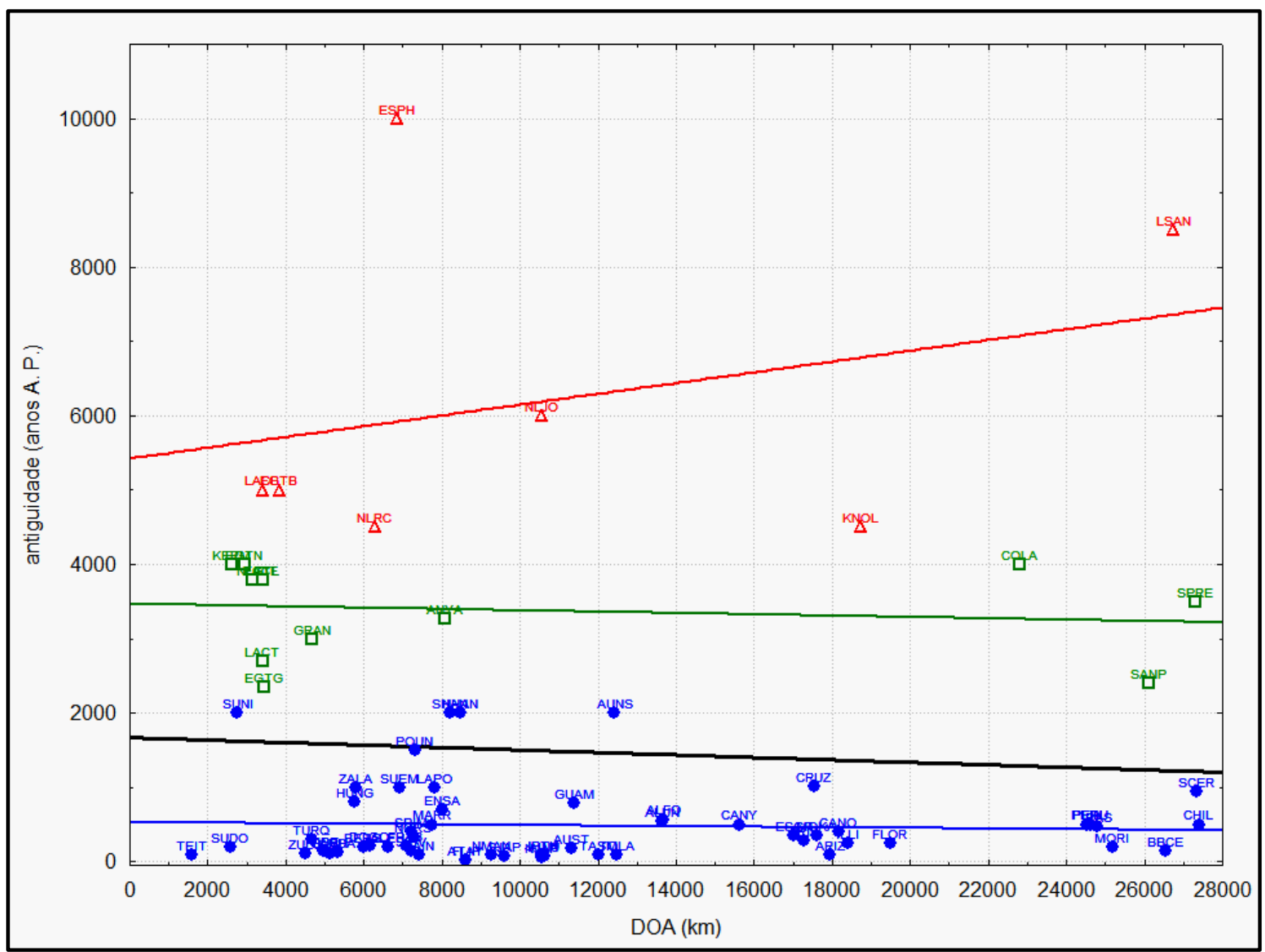

Fig. 4.33 - Diagrama de dispersão de antiguidade (em anos A.P.) em função de DOA (em km) para as populações amostradas para a análise por hierarquização cronológica. Círculos cheios (azuis) correspondem às datações da primeira classe de observações, quadrados verdes às da segunda classe e triângulos vermelhos às da terceira classe. Linhas cheias representam as curvas de regressão para cada classe de dados, de acordo com suas respectivas cores. Linha preta cheia representa a curva de regressão para todas as populações consideradas conjuntamente.

A dispersão representada na Figura 4.33 mostra os grupos populacionais formados em função de suas antiguidades. Nota-se na figura, a inexistência de qualquer associação específica entre os grupos quando testadas suas antiguidades em função de suas localizações geográficas em relação ao ponto de origem africano (DOA). Tal afirmação é reforçada pelo fato de que nenhuma das correlações obtidas nesta análise apresentou-se estatisticamente significativa.

Dessa maneira, a hierarquização cronológica funcionará simplesmente como uma escala de divisão global da amostra, sem considerar informações geográficas. Assim, as populações serão divididas nos três grupos apresentados, e seus padrões morfológicos serão testados de maneira intra e intergrupos. 


\section{III) Hierarquização geográfica}

Diferentemente da estratégia adotada para o desenvolvimento das análises $3.1 \mathrm{a}$ e $3.1 \mathrm{~b}$, nas quais a classificação das populações amostradas em relação à localização geográfica continental ocorreu de maneira mais ou menos subjetiva, para a hierarquização dos grupos populacionais adotou-se o critério de se eleger uma característica classificatória para a função. Assim, foi adotada a distância geográfica entre as populações (uma matriz de dissimilaridades) para ser examinada através de uma análise de agrupamentos ("cluster"). As características dessa análise são as mesmas que da hirarquização morfológica, inclusive com a mesma amostra populacional, exceto pela regra de agrupamento escolhida para cada um dos casos. Quando o objeto de estudo foi a morfologia craniana, optou-se por utilizar o critério dos vizinhos próximos como método de agrupamento, por se desejar um algoritmo que privilegiasse as menores distâncias entre os elementos, formando grupos mais homogêneos do ponto de vista morfológico (Sneath, 1957). Para os dados geográficos, a intenção é agrupar as populações que se encontram o mais próximas umas das outras, sem que a variância da medida de distância entre eles decaia entre cada nível de agrupamento55. O critério adotado para a análise, o método de Ward (também chamado de método da mínima variância) atende, exatamente, essas necessidades (Ward, 1963).

A Figura 3.34 apresenta o dendrograma obtido a partir da matriz de distâncias geográficas interpopulacionais controladas quanto ao "custo". Os braços do dendrograma estão ponderados pela maior distância verificada. Na figura, as populações estão identificadas quanto ao continente de origem, de acordo com as cores já utilizadas anteriormente para tal fim (Tabela 4.10).

\footnotetext{
${ }^{55}$ Essa preocupação em não interferir na variância da medida de dissimilaridade se justifica pelo fato de que a grandeza distância geométrica não é o objeto de estudo das análises posteriores. Dessa maneira, não faria sentido usar exatamente este critério para a hierarquização dos grupos.
} 


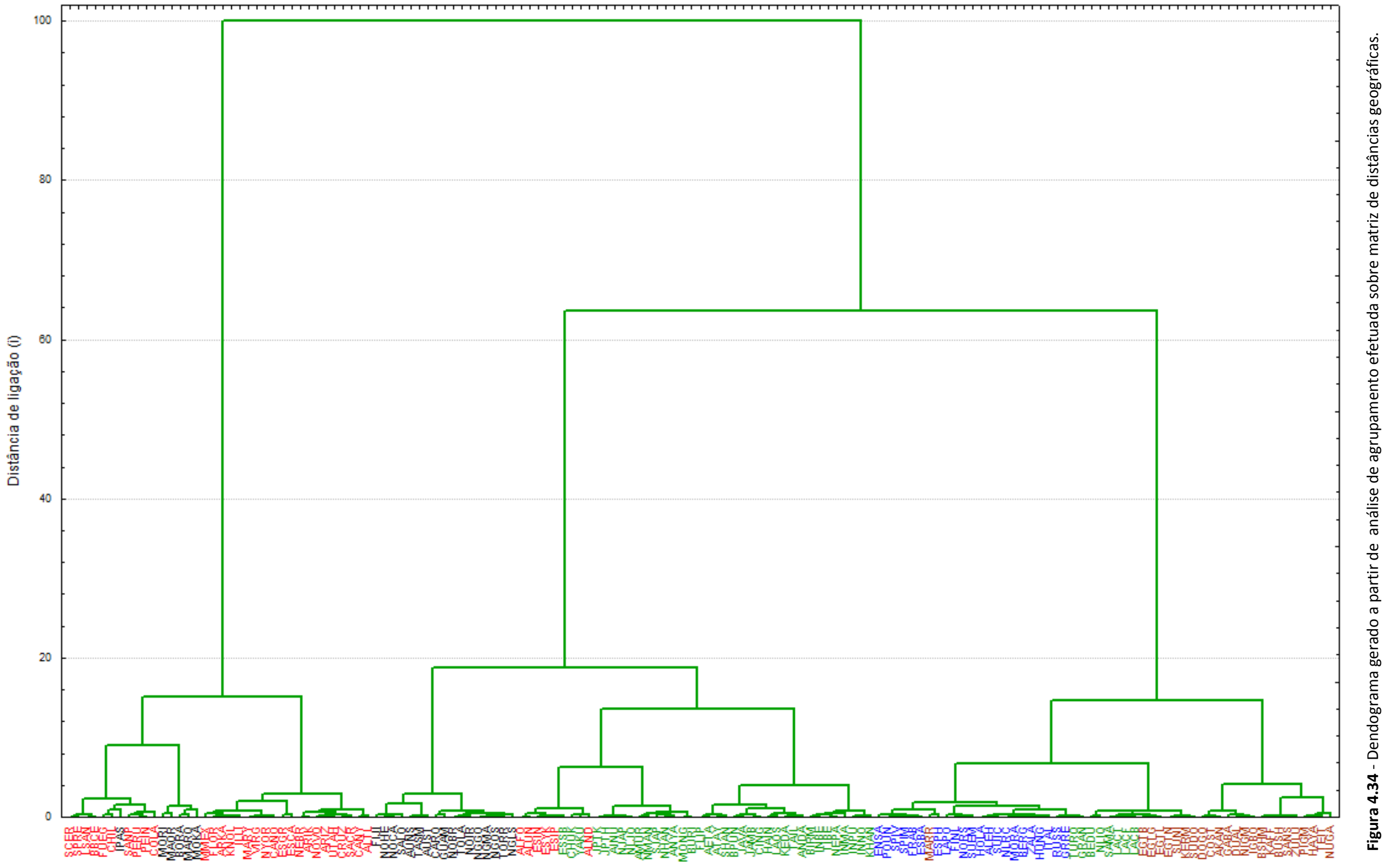


Como pode ser observado na topologia apresentada na Figura 3.34, a clássica divisão geográfica do planeta em Velho e Novo Mundo pode ser perfeitamente apoiada com base nas distâncias geográficas calculadas neste trabalho. Com raras exceções, perfeitamente justificáveis devido a suas posições extremas, todas as populações nativas americanas foram agregagadas em um "cluster" em oposição à todas as outras séries amostradas que foram reunidas em um segundo agrupamento. As exceções localizadas no ramo ocupado pelas populações americanas são referentes à populações da Polinésia, cujas particulariedades geográficas (como localização insular entre a Oceania e a América, por exemplo) podem facilmente serem empregadas para explicar tal associação. Não obstante, duas dessas populações, IPAS e MOKA são localizadas em territórios reconhecidos, atualmente, como pertencente a países do continente americano (Chile e Estados Unidos, respectivamente). Explicação semelhante se aplica às populações americanas que se associaram ao "cluster" dominados pelas populações do Velho Mundo. As séries nativo-americanas localizadas nesse agrupamento referem-se às populações Esquimó e Aleuta, localizadas na região do Estreito de Bering, no extremo norte americano.

No entanto, apesar da topologia obtida se apresentar de maneira coerente ao perfil geográfico da amostra analisada, a divisão entre Velho e Novo Mundo não constitui a configuração mais precisa obtida para a associação geográfica das populações em questão. Observando a topologia, de cima para baixo, o primeiro agrupamento (o dos nativos americanos) pode ser dividido em dois novos grupos, definindo, de maneira grosseira, um "cluster" da América do Sul e um da América do Norte. Em posição intermediária a esses dois grupos encontra-se o "cluster" formado pelas populações polinésias, com exceção de IPAS que se associou aos sulamericanos. Assim, esse ramo da topologia é definido por três agrupamentos (lendo-se de cima para baixo): "América do Sul", indo de SCER até COLA; "Polinésia", reunindo de MORI até MOKA e "América do Norte", de MMEX até ALTL.

Continuando a interpretação de cima para baixo, encontra-se um grupo densamente ocupado, congregando séries da Ásia e da Oceania (além das populações americanas 
intrusivas já comentadas). Tal agrupamento resolve-se em três novos conjuntos populacionais: "Australo-micro-melanésios", delimitado por FIJI e NGLS; "Leste asiático", incluindo séries do nordeste asiático e extremo noroeste americano, começando por ALFO e indo até BURI; e, "Sul-Sudoeste asiático", indo de FLIP até KHAN.

Finalmente, um terceiro ramo do dendrograma pode ser definido, congregando tres grupos bem delimitados. O primeiro desses, "Europa", reúne as populações localizadas a partir de ENSA até GRAN. O grupo seguinte, iniciado por BEDU e finalizado por SUDO, pode ser definido como "Oriente Médio". Por útlimo, o grupo que reúne as populações da "África subsaariana", delimitadas por KERM e NUGA.

Em suma, o método empregado para a hierarquização geográfica das populações amostradas neste trabalho permitiu a formação de 9 grupos geográficos. Assim como nos casos anteriores, esses grupos terão seus padrões de variância e covariância morfológica explorados de maneira intra e intergrupos.

Uma última informação foi depreendida da análise em questão. Aproveitando a similaridade (dimensões iguais e mesmas populações) entre as matrizes calculadas para as divisões hierárquicas morfológica (matriz $\mathrm{D}^{2}$ ) e geográfica, foi calculada a correlação entre elas, uma vez que ambas as grandezas são de grande importância para os estudos de dispersão, variação e reconstituição demográfica das populações humanas. O valor obtido para o coeficiente de Pearson foi de $\mathbf{r}=\mathbf{0 , 3 7 8 9}$, considerado significativo ( $\mathbf{p}<\mathbf{0 , 0 0 0}$ ) após 9.999 permutações (teste de Mantel).

\section{IV) Hierarquização molecular}

O último grupo de procedimentos para inferência de agrupamentos entre as populações é baseado na estrutura observada em uma parcela populacional a partir da diversidade de polimorfismos de microssatélites de DNA. Tal análise é a que conta com o 
menor número de séries e indivíduos envolvidos entre as aqui executadas, devido a depedência de se encontrar correspondência entre as populações amostradas no banco de dados morfológico consolidado (Tabela 3.2) e do banco de dados de microssatélites (Tabela 3.3). Assim, tal análise foi realizada sobre 36 populações, contendo fragmentos de microssatélites de 683 indivíduos).

Os dados de diversidade de microssatélite das 36 séries amostradas foram submetidos ao cálculo de $\mathrm{F}_{\mathrm{ST}}$ entre todos os pares populacionais. Os valores obtidos a partir dessa análise resultaram na construção de uma matriz de distâncias genéticas, que foi submetida à uma análise de agrupamento por "Neighbor Joining Tree" (Saitou \& Nei, 1987), originando a árvore filogenética apresentada na Figura 4.35. Neste exercício, o cálculo de $\mathrm{F}_{\mathrm{ST}}$ bem como a construção da matriz de distâncias foram realizadas através do programa computacional ARLEQUIN 3.0 (Excoffier et al., 2005). Já a análise de NJT foi baseada no código do pacote "APE" (Paradis, et al., 2004) na plataforma R (R Development Core Team, 2010).

Depreende-se da Figura 4.35 a existência de cinco agrupamentos bem estruturados envolvendo as populações amostradas. Observando a árvore a partir de seu ponto extremo, no alto e à esquerda, nota-se um grupo composto por 14 populações, todas localizadas na Ásia, especialmente nas suas porções central e oriental. O ramo que apresenta maior afinidade a esse "cluster" asiático é o composto por apenas três amostras de nativos americanas.

Seguindo a leitura da topologia em sentido da esquerda para a direita e de cima para baixo, encontra-se localizado em posição aproximadamente da árvore um agrupamento que reúne populações localizadas na Europa e no Oriente Médio, formando um "cluster" de amostra da Eurásia. A estruturação observada entre as amostras desse agrupamento segue essa divisão regional de maneira mais ou menos estável, posicionando os representantes do Oriente Médio mais acima no "cluster" em oposição aos europeus localizados em sua região 
inferior. Apenas as populações da Rússia (Europa) e Beduínos e Samaritanos (Oriente Médio) encontram-se localizadas em ramos diferentes dos de sua região geográfica.

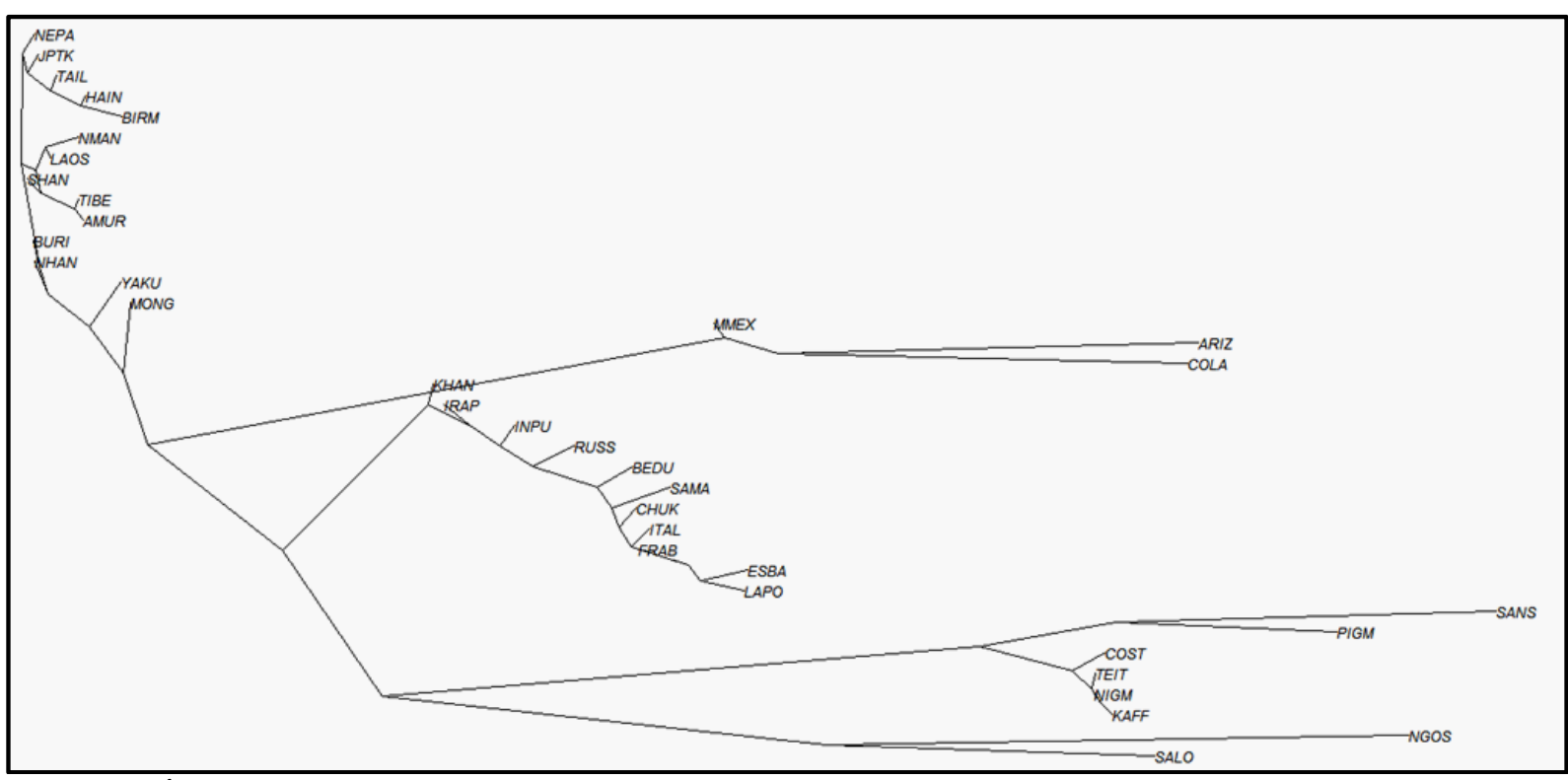

Fig. 4.35 - Árvore filogenética construída a partir das informações de microssatélites de 36 populações.

A região localizada nos limites abaixo e à direita da árvore é ocupada pelos dois útlimos agrupamentos gerados. O maior deles, contendo seis populações, é composto por amostras do continente africano, com destaque para a formação de dois subgrupos dentro deste "cluster". Embora coloque SANS e PIGM em relativa oposição à COST, TEIT, NIGM e KAFF, para efeitos comparativos, o grupo será considerado, conjuntamente, como África subsaariana.

Finalmente, o útlimo grupo formado nesta análise congrega as duas única populações localizadas na Oceania entre as amostradas. Chama a atenção nessa observação, sua proximidade genética com o "cluster" da África subsaarina.

Os cinco grupos definidos por essa análise baseada em diversidade de microssatélites, serão utilizados para hierarquizar a parcela de 1712 crânios do banco de dados morfológico, para comparação de seus padrões de variância e covariância fenotípica, de maneira intra e intergrupal. 
No entanto, as características dos dados coletados e dos resultados gerados durante essa hierarquização permitiram, ainda, uma última análise, que consistiu na comparação entre as matrizes de distâncias genéticas $\left(\mathrm{F}_{\mathrm{ST}}\right)$ calculadas sobre dados dos microssatélites e de distância geográfica interpopulacional (parcela correspondente às populações amostradas). Uma vez que tais matrizes possuem mesma ordem (e mesma populações), foi possível compará-las através do cálculo do coeficiente produto-momento de Pearson, seguido de teste de Mantel, após 9.999 permutações, para determinação de significância estatística. Adicionalmente, uma matriz de $\mathrm{D}^{2}$ e uma de $\mathrm{Q}_{\mathrm{ST}^{56}}$, foram calculadas sobre as mesmas populações usadas para a análise com microssatélites. Assim como as anteriores, estas também serão comparadas através de correlação de Pearson. Todos os cálculos foram executados com o programa R ( $\mathrm{R}$ Development Core Team, 2010). A Tabela 4.20 apresenta os resultados dessas comparações.

Tabela 4.20 - Coeficientes de correlação obtidos na comparação entre as matrizes FST, DGeo, D2 e QST.

\begin{tabular}{c|cccc}
\hline Matrizes & $F_{S T}$ & $D_{G \text { Ge }}$ & $D^{2}$ & $Q_{S T}$ \\
\hline$F_{S T}$ & $\mathbf{1}$ & $\mathbf{0 , 7 3 0 8}$ & $\mathbf{0 , 3 5 5 2}$ & 0,1393 \\
$D_{G e o}$ & $\mathbf{0 , 0 0 0 1}$ & $\mathbf{1}$ & $\mathbf{0 , 4 1 7 3}$ & $\mathbf{0 , 1 7 2 4}$ \\
$D^{2}$ & $\mathbf{0 , 0 0 3 6}$ & $\mathbf{0 , 0 0 1 7}$ & $\mathbf{1}$ & $\mathbf{0 , 4 1 3 0}$ \\
$Q_{S T}$ & 0,0808 & $\mathbf{0 , 0 0 2 6}$ & $\mathbf{0 , 0 0 0 1}$ & $\mathbf{1}$ \\
\hline
\end{tabular}

Em negrito valores estatisticamente significativos $(p<0,05)$

Na matriz, a diagonal superior é ocupada pelos coeficientes de correlação, enquanto que a inferior apresenta os respectivos valores de p. Como pode ser observado, todas as comparações, exceto a realizada entre $\mathrm{F}_{\mathrm{ST}}$ e $\mathrm{QST}^{57}$ apresentam correlações positivas e estatisticamente significativas. Isso significa que é possível encontrar estruturação a partir da inferência estatística desses estimadores, argumentando favoravelmente à abordagem utilizada neste trabalho.

\footnotetext{
${ }^{56}$ Corresponde à matriz (e ao cálculo) de $F_{\text {ST }}$ para dados métricos quantitativos. Embora não tenha sido usada em outros momentos ao longo deste texto, tal notação foi aqui aplicada para evitar equívocos com o $\mathrm{F}_{\mathrm{ST}}$ calculado para dados moleculares.

${ }^{57}$ Tal efeito pode ser explicado devido a alguns valores extremos de $Q_{S T}\left(Q_{S T}=1\right)$, resultantes de populações com tamanho amostral profundamente comprometido.
} 


\subsection{2 - Inferência dos padrões de Variância/Covariância (V/CV) e Correlação (C)}

Os resultados a seguir estão agrupados de acordo com as análises descritas anteriormente, no capítulo 3. Para facilitar a organização dos assuntos, como já foi observado, os tópicos desta seção estão identificados seguindo a mesma sequência da seção anterior, assim como foi feito em Material e Métodos. As especificidades devidas aos agrupamentos sugeridos serão comentadas dentro de cada seção.

\section{d) Comparações entre matrizes e padrões de similaridade}

Do apresentado no capítulo 3, depreende-se que as análises empreendidas neste bloco de análises foram baseadas em dois tipos fundamentais de dados: os gerados a partir de matrizes de $\mathrm{V} / \mathrm{CV}$ e os a partir de matrizes de C. A apresentação dos resultados dessas análises será feita separamente para cada tipo de matriz analisado.

\section{d.1 - Similaridades das matrizes de V/CV}

As similaridades entre as matrizes de $\mathrm{V} / \mathrm{CV}$ foram investigadas através da técnica de "random skewers" (Cheverud, 1996b; Marroig \& Cheverud, 2001; Cheverud \& Marroig, 2007; Revell, 2012), utilizando-se 1.000 vetores para cada comparação entre duas matrizes V/CV. A média das diferenças entre os "vetores-resposta" obtidos em cada uma das comparações foi considerada como o valor de similaridade entre as matrizes $\mathrm{V} / \mathrm{CV}$ comparadas. $\mathrm{O}$ valor de $\mathrm{p}$, com valor crítico estabelecido em $\alpha=0,05$, para a determinação de significância do valor médio obtido, foi calculado a partir do teste de hipóteses baseado na distribuição dos valores de correlação dos vetores aleatórios calculados (Callegari-Jacques, 2003). Só foram considerados significativos os valores médios cujo valor p calculado foi menor ou igual a 0,05 . 
Os valores médios resultantes da interação entre os vetores aleatórios e cada par de matrizes de V/CV comparadas foram utilizados para a construção de matrizes de similaridades das matrizes de V/CV. Seguindo a proposta apresentada ao longo do capítulo 3, foram realizadas quatro séries comparativas, de acordo com os critérios hierárquicos sugeridos.

\section{Hierarquização morfológica}

Como pôde ser depreendido da Figura 4.32, considerando-se o dendrograma obtido pela análise de "cluster" realizada a partir da matriz de $\mathrm{D}^{2}$ das 149 populações selecionadas para a análise, uma primeira partição das séries divide a amostra em dois grandes grupos (A e B). Um segundo nível de divisão permite o reconhecimento de quatro grupos $(\mathrm{C}$ e $\mathrm{D}$, resultantes da clivagem de A, e E e F, resultantes da clivagem de B). Uma terceira partição das populações, seguindo o grau de similaridade sugerido pela topologia, resulta na formação de oito novos grupos (G, H, I e J a partir de C e D, e , K, L, M e N a partir de E e F). A Figura 4.36 ilustra o raciocínio aplicado para a determinação desses grupos. Note-se que, para essas análises, o termo "grupo" sempre será usado para a denominação de um agrupamento de populações.

Seguindo o raciocínio apresentado, as 149 populações foram arranjadas, então, de três maneiras diferentes: em dois grupos (A e B), quatro grupos (C, D, E e F) e oito grupos (G, H, I, J, K, L, M e N). As similaridades das matrizes de V/CV foram inferidas de duas maneiras: intragrupos e intergrupos. 


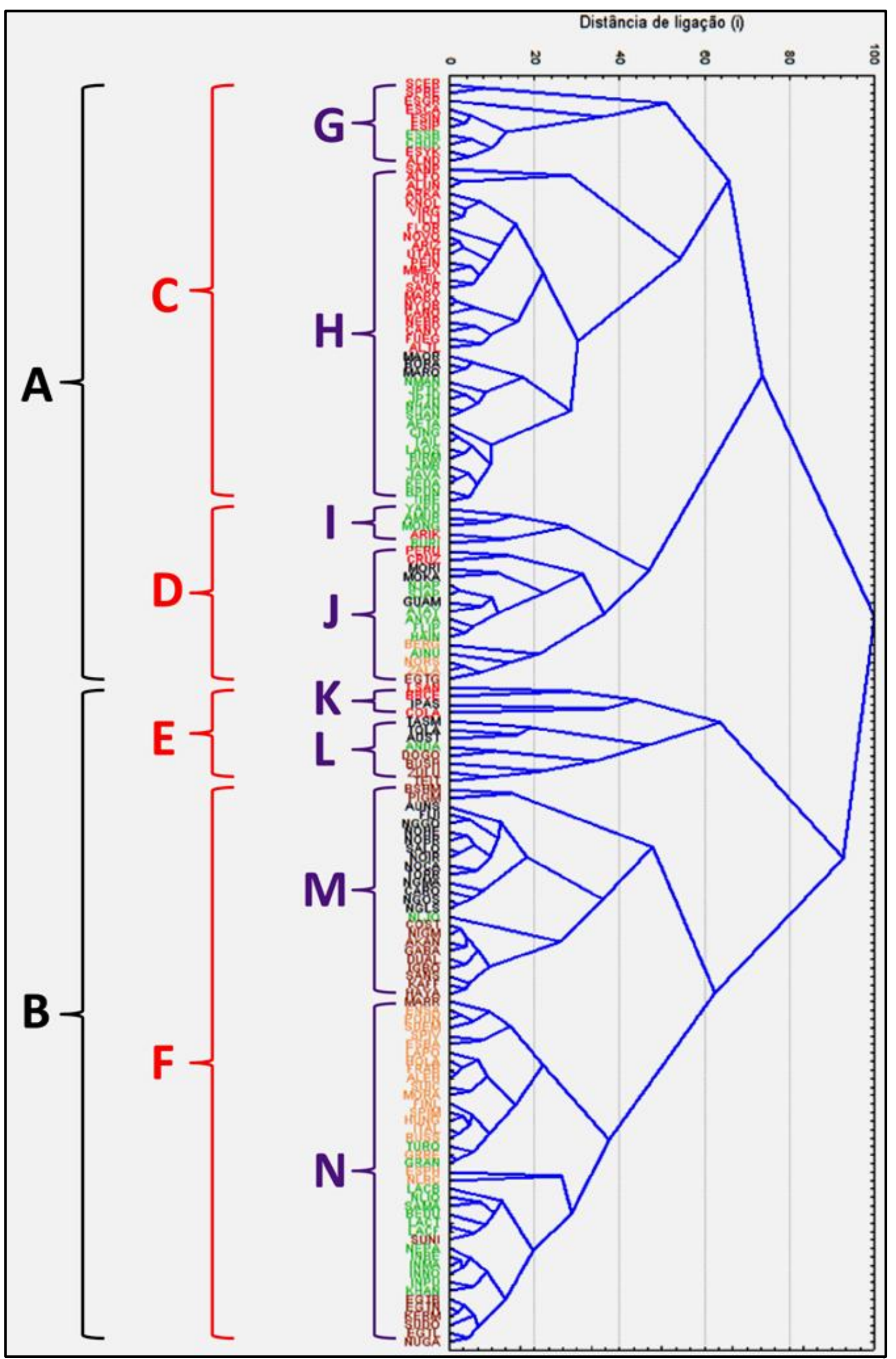

Fig. 4.36 - Topologia apresentada na Figura 4.32 (análise de agrupamento efetuado sobre a matriz $\mathrm{D}^{2}$ das 149 populações amostradas), ilustrando a formação dos grupos de análise. 
A análise em nível intragrupal consistiu na comparação das matrizes de V/CV de cada população dentro do grupo (de A até N). Adicionalmente, foi executada também a comparação entre todas as 149 populações, sem nenhum tipo de subdivisão. Dessa forma, a comparação intragrupal resultou na construção de 15 matrizes de similaridades, de dimensões variadas (desde $V / C V_{4 \times 4}$ até $V / C V_{149 \times 149}$ ). Dada a dificuldade de se analisar comparativamente dados dessa magnitude (como era de se esperar pela expressividade numérica da amostra, somada à estratégia estabelecida de adotar-se diferentes estratos de dados, o número de interações entre matrizes tornou-se absolutamente alto), ao invés de se apresentar matriz por matriz, decidiu-se fazê-lo a partir das tendências centrais de cada comparação. Tais indicadores estão apresentados na Tabela 4.21.

Tabela 4.21 - Agrupamentos populacionais, número de observações estatisticamente significativas (s.), valor mínimo (min), valor médio $(\bar{x})$ e valor máximo (max.), obtidos para a comparação intragrupo das matrizes de $\mathrm{V} / \mathrm{CV}$.

\begin{tabular}{ccccc}
\hline Grupo & s. & min. & $\bar{x}$ & max. \\
\hline Todas & $10824(98,17 \%)$ & 0,3528 & 0,7585 & 1 \\
A & $2474(99,56 \%)$ & 0,3394 & 0,7904 & 0,9442 \\
B & $5898(96,94 \%)$ & 0,3583 & 0,7380 & 1 \\
C & $2449(99,96 \%)$ & 0,4130 & 0,4909 & 0,5505 \\
D & $208(99,05 \%)$ & 0,3677 & 0,4112 & 0,4432 \\
E & $66(100,0 \%)$ & 0,4199 & 0,7610 & 0,9202 \\
F & $2107(98,23 \%)$ & 0,3307 & 0,7269 & 0,9909 \\
G & $44(97,78 \%)$ & 0,4553 & 0,7176 & 0,9447 \\
H & $780(100,0 \%)$ & 0,5871 & 0,8086 & 0,9280 \\
I & $9(90,0 \%)$ & 0,4298 & 0,6276 & 0,9092 \\
J & $120(100,0 \%)$ & 0,7810 & 0,8658 & 0,9256 \\
K & $6(100,0 \%)$ & 0,4280 & 0,5695 & 0,7708 \\
L & $28(100,0 \%)$ & 0,8150 & 0,8762 & 0,9192 \\
M & $300(100,0 \%)$ & 0,3618 & 0,7387 & 0,8815 \\
N & $779(95,0 \%)$ & 0,3194 & 0,7203 & 0,9908 \\
\hline
\end{tabular}

Depreende-se da Tabela 4.21 que, como esperado, a maioria esmagadora das comparações apresentou-se positiva e estatisticamente significativa. Tal fenômeno deve-se ao fato de que as amostras utilizadas são representativas de uma única espécie, com origem recente em termos evolutivos. Nesse contexto, a única explicação plausível para a ocorrência 
de valores sem significância estatística (raríssimos nesta análise) reside em deficiências da amostragem, como pequenos tamanhos, por exemplo. De fato, uma rápida inspeção nos dados que originaram tais resultados permite, facilmente, a associação direta entre a ocorrência de valores estatisticamente não significativas com pequenos tamanhos amostrais.

Apesar da aparente monotonia dos resultados apresentados, outras características apresentadas na Tabela 4.21 merecem destaque. Com raras exceções, os valores máximos obtidos nas comparações entre matrizes V/CV apresentaram-se entre 0,9 e 1 (ou muito próximo a esse intervalo), indicando uma similaridade muito efetiva entre elas. As exceções mais expressivas, representadas pelos grupos C e D (valores máximos de 0,55 e 0,44, respectivamente) podem estar relacionadas à heterogeneidade morfológica e populacional do agrupamento, uma vez que tal fenômeno (valores máximos obtidos de menor amplitude em comparação com os outros agrupamentos) deixa de ser observado quando os grupos C e D são subdivididos em G, H, I e J.

Os valores médios apresentados na Tabela 4.21 apresentam a mesma tendência geral da observada em relação aos valores máximos. A maioria das observações apresentam valores próximos ao intervalo definido por 0,7 e 0,9, também considerados altos. As exceções, mais uma vez, estão relacionadas aos resultados obtidos nos grupos C e D. No entanto, diferentemente do que foi observado entre os valores máximos, neste caso, os valores médios resultantes das análises relativas aos grupos I e K também apresentaram-se abaixo dos observados para os outros grupos. Para essa observação, o número de populações no grupo (consequentemente, o número de observações) e o tamanho amostral das populações parece ser a melhor explicação para sua ocorrência.

Quando o foco de atenção passa a ser o valor mínimo observado em cada agrupamento, a, já citada, monotonia observada permanece ditando a tônica de suas interpretações. A grande maioria dos agrupamentos analisados apresenta valores definidos pelo intervalo 0,32 e 0,58 , que indica uma similaridade regular entre as matrizes. No 
entanto, os valores calculados para os grupos $\mathrm{J}$ e L (0,78 e 0,81, respectivamente) destacamse absolutamente entre os demais.

Embora tentador, nenhum significado biológico pode, porém, ser atribuído a esse fenômeno. Tanto o grupo $\mathrm{J}$ quanto o grupo L são compostos única e exclusivamente por amostras oriundas do banco Howells (vide capítulo 3), o que sugere que a ocorrência de tal similaridade esteja relacionada à alguma característica intrínseca à coleta dos dados. Se, no entanto, por um lado tal observação possa ser, num primeiro momento, amplamente desanimadora em relação à concepção do banco de dados utilizado nesta análise, por outro pode ser bastante animadora em outras perspectivas.

O fato que de tal influencia da amostragem (restringindo-se, aqui, à coleta de dados e erros inerentes a esse processo) fica evidenciada apenas quando os menores agrupamentos adotados foram analisados, sugere que tal influencia fica "diluída" à medida que agrupamentos mais inclusivos são considerados. De fato, novos agrupamentos exclusivos à populações oriundas do banco Howells não acontecem nos níveis hierárquicos mais inclusivos. Animadora, também, é a constatação de que a estratégia adotada na execução deste trabalho possa reter informação biológica mesmo quando a análise executada é confrontada com alguma contingência externa, ou adicional, ao experimento executado. Tal afirmação é feita sob o raciocínio de que se nenhuma outra informação estivesse retida na estrutura dos dados analisados, associações outras, com interpretações válidas sob diferentes escopos analíticos, como o biológico, por exemplo, a imputada à origem e coleta dos dados não seriam observadas.

Em suma, os padrões de similaridade entre as matrizes de $\mathrm{V} / \mathrm{CV}$, inferidas de maneira intragrupal, cujos grupos foram definidos por suas afinidades morfológicas (investigadas a partir de uma matriz de distância de Mahalanobis) apresentaram-se, de maneira geral, altas e significativas entre todos os agrupamentos investigados. Tal observação indica a existência de 
um padrão de covariação semelhante a todas as populações amostradas, refletindo uma história evolutiva recente e comum por elas compartilhada.

De maneira semelhante à executada de maneira intragrupal, foi também realizada uma análise em nível intergrupos. As características principais da análise, como método, número de vetores e agrupamentos adotados, por exemplo, foram as mesmas da análise dentro dos grupos. A única diferença entre elas deveu-se à configuração da construção das matrizes de V/CV analisadas. Enquanto que na primeira abordagem, intragrupos, cada população amostrada deu origem a uma matriz de V/CV, nesta, a intergrupos, todas as populações presentes em cada um dos grupos deu origem a uma única matriz de V/CV. Como era de se esperar, os efeitos observados na análise intragrupal, como alguns valores sem significância estatística e desvios devido a peculiaridades amostrais, por exemplo, desapareceram neste nível hierárquico. A Tabela 4.22 apresenta a síntese dos resultados obtidos nesta análise.

Tabela 4.22 - Grupos comparados, número de observações estatisticamente significativas (s.), valor mínimo (min), valor médio $(\bar{x})$ e valor máximo (max.), obtidos para a comparação intergrupos das matrizes de V/CV.

\begin{tabular}{|c|c|c|c|c|}
\hline Grupos & S. & $\min$. & $\bar{x}$ & $\max$. \\
\hline$A \times B$ & $1(100,0 \%)$ & - & - & 0,9251 \\
\hline$C \times D \times E \times F$ & $6(100,0 \%)$ & 0,8711 & 0,9036 & 0,9351 \\
\hline$G \times H \times I \times J \times K \times L \times M \times N$ & $28(100,0 \%)$ & 0,8524 & 0,9162 & 0,9576 \\
\hline
\end{tabular}

Os dados apresentados na Tabela 4.22 reforçam a ideia anteriormente apresentada de que os padrões de $\mathrm{V} / \mathrm{CV}$ observados entre as populações amostradas é marcado por uma alta similaridade. Quando as amostras foram organizadas em grandes agrupamentos populacionais, como os delineados neste experimento, todas as matrizes de $\mathrm{V} / \mathrm{CV}$ resultantes desses grupos populacionais mostraram-se altamente similares, variando de 0,85 a 0,96 . Tal informação significa que as populações humanas amostradas neste trabalho encontram-se sob um estado de estase evolutiva no que se refere ao padrão de $\mathrm{V} / \mathrm{CV}$ inferida a partir da morfologia de seus crânios. 


\section{Hierarquização cronológica}

Com o objetivo de aproveitar ao máximo o corpo de informações levantadas durante o processo de consolidação do banco de dados apresentado no capítulo 3 (Tabela 3.2) estabeleceu-se, também, a estratégia de adotar as cronologias apresentadas pelas populações amostradas como um critério de agrupamento hierárquico.

Como pode ser depreendido da Tabela 4.19 e da Figura 4.33, cronologicamente, as populações amostradas $5^{8}$ podem ser divididas em três grandes grupos: i) composto por $5^{6}$ populações, cujas antiguidades variam entre o e 2.000 anos A. P.; ii) 12 populações datadas entre 2.000 anos A. P. e 4.00o anos A. P.; e, iii) populações, 7 no total, cujas antiguidades variam entre 4.000 anos A. P. e 10.000 anos A. P. A Tabela 4.23 apresenta a síntese dos resultados obtidos da análise do padrão de similaridade intragrupos sobre as populações alocadas nesses três grupos cronológicos. Na mesma tabela, adicionalmente, encontram-se os resultados obtidos para a análise realizada entre todas as populações, independentemente de suas classificações quanto à antiguidade inferida.

Tabela 4.23 - Agrupamentos populacionais segundo o critério cronológico, número de observações estatisticamente significativas (s.), valor mínimo ( $\mathrm{min}$ ), valor médio $(\bar{x})$ e valor máximo (max.), obtidos para a comparação intragrupo das matrizes de V/CV.

\begin{tabular}{ccccc}
\hline Grupo & s. & $\min$. & $\bar{x}$ & $\max$. \\
\hline Todas & $2705(97,48 \%)$ & 0,3470 & 0,7509 & 0,99 \\
I & $1540(100,0 \%)$ & 0,3628 & 0,8088 & 0,9277 \\
li & $66(100,0 \%)$ & 0,3931 & 0,7032 & 0,9903 \\
lii & $12(57,14 \%)$ & 0,3728 & 0,4571 & 0,7672 \\
\hline
\end{tabular}

Depreende-se da Tabela 4.23 que apenas a parcela relativa às populações de maior antiguidade (mais antigas que 4.000 anos A. P.) apresentam uma grande quantidade (aproximadamente 42,8\%) de valores médios de similaridade sem significância estatística dentro dos limites estabelecidos nesta pesquisa. Tal fenômeno pode ser facilmente explicado considerando-se os pequenos tamanhos amostrais envolvidos no grupo em questão. Não obstante, o padrão de similaridade inferido pelos valores obtidos nos quatro grupos

\footnotetext{
${ }^{58}$ Aqui, consideradas apenas aquelas cujas antiguidades prováveis puderam ser estimadas.
} 
analisados apresentam-se em relativa concordância. Seus valores mínimos concentram-se entre 0,3 e 0,4, incluindo aí a categoria (ou grupo) iii. Uma pequena alteração nesse cenário se dá quando os valores médios e máximos são considerados. Uma vez mais, devido à deficiência amostral, as populações do grupo iii, mais antigas, se comportam diferentemente das demais, cujos valores médios transitam entre 0,7 e o,8 e máximos entre 0,93 e 0,99.

Outra informação que emerge da Tabela 4.23 faz sentido quando analisada comparativamente à Tabela 4.21 (valores médios de similaridade obtidos através da comparação intragrupos de acordo com o critério morfológico). Os valores mínimos, médios e máximos de ambas as análises tornam-se qualitativamente semelhantes quando é adotado um padrão "mínimo $\approx 0,4$-médio $\approx 0,7-$ máximo $\approx 0,9 "$, evidenciando, ainda mais, as discrepâncias relacionadas à amostragem anteriormente observadas.

Os grupos formados pelas populações amostradas sob o critério cronológico também foram analisados segundo a abordagem intergrupos. A estratégia adotada seguiu os mesmos procedimentos descritos para o caso dos agrupamentos morfologicamente guiados. A análise de "random skewers" para essa parcela resultou na construção de uma matriz de similaridades composta pelos três grupos de dados, representada na Tabela 4.24.

Tabela 4.24 - Matriz de similaridadades entre os grupos cronológicos i, ii e iii.

\begin{tabular}{c|ccc}
\hline Grupos & i & ii & lii \\
\hline i & 1 & 0,9478 & 0,9118 \\
ii & 0,9478 & 1 & 0,9152 \\
iii & 0,9118 & 0,9152 & 1 \\
\hline
\end{tabular}

Da Tabela 4.24 depreende-se que um grupo mais inclusivo, cujas deficiências amostrais tornam-se desprezíveis, apresenta valores de similaridade mais expressivos a partir da comparação de suas matrizes de V/CV. Tal observação remonta à feita sobre a análise anterior, sobre os dados morfologicamente hierarquizados (Tabela 4.22), sugerindo um modelo de estase evolutiva para a morfologia craniana humana a partir da inferência de seus padrões de V/CV. 


\section{Hierarquização geográfica}

Baseado na topologia apresentada na Figura 4.34, cuja hierarquização das populações foi gerada a partir da matriz de distâncias geográficas entre elas, foram organizados nove grupos populacionais de acordo com suas localizações geográficas aproximadas. O primeiro desses grupos, representativo da América do Sul (ADS), é composto por onze populações, sendo nove sulamericanas e uma da Polinésia. O agrupamento mais fortemente a ele associado é o grupo representante da Polinésia (PNS), composto por cinco populações. Somado a esses dois agrupamentos encontra-se um terceiro, relativo às polução nativas americanas do norte (20 séries amostradas), representando a América do Norte (ADN). Juntos, esses três agrupamentos congregam a maior parte das populações do Novo Mundo amostradas neste estudo, representando um dos dois grandes "clusters" obtidos na análise efetuada.

O outro grande "cluster" obtido na análise associa seis agrupamentos populacionais. Desses, três grupos, Australo-micro-melanésios (AMM), Leste asiático (LAS) e Sul-Sudoeste asiático (SSA), composto, respectivamente por 17, 21 e 21 populações. Com exceção de LAS, os dois outros subconjuntos estabelecidos neste "cluster" apresentam exclusivamente populações de suas próprias regiões geográficas. Tal característica também é atribuível, com algum ajuste adicional, aos outros três grupos estruturados dentro desse "cluster". O primeiro desses grupos arranja 25 populações européias, formando, assim, o agrupamento identificado como Europa (EUR). Neste agrupamento está presente as populações do Marrocos e da Turquia. Como as populações externas à Europa propriamente dita encontranse em áreas de transição entre, respectivamente, a Europa e a África e a Europa e o Oriente Médio, a interpretação de que este agrupamento é representativo das populações européias não é prejudicado. Ao agrupamento EUR outros dois conjuntos menores de dados aparecem associados, Oriente Médio (ORM), com 13 populações e África subsaariana (ASA) com 16.

Devido à notória divisão geográfica mundial entre Novo e Velho Mundo (correspondentes aos dois grandes "clusters" observáveis na Figura 4.34), as similaridades 
entre as matrizes de $\mathrm{V} / \mathrm{CV}$ intra e intergrupos foram investigadas em dois níveis hierárquicos: o correspondente aos nove agrupamentos descritos e ao representativos das duas grandes regiões geográficas mundiais. A Tabela 4.25 apresenta a síntese dos resultados obtidos da comparação de similaridade intragrupo (definidos pelo critério geográfico) das matrizes de $\mathrm{V} / \mathrm{CV}$.

Tabela 4.25 - Agrupamentos populacionais, número de observações estatisticamente significativas (s.), valor mínimo (min), valor médio $(\bar{x})$ e valor máximo (max.), obtidos para a comparação intragrupo das matrizes de V/CV (critério geográfico).

\begin{tabular}{ccccc}
\hline Grupo & s. & min. & $\bar{x}$ & max. \\
\hline ADS & $50(90,9 \%)$ & 0,3695 & 0,6268 & 0,8951 \\
PLN & $10(100,0 \%)$ & 0,8126 & 0,8729 & 0,9213 \\
ADN & $190(100,0 \%)$ & 0,6609 & 0,8193 & 0,9138 \\
AMM & $136(100,0 \%)$ & 0,7142 & 0,8214 & 0,8935 \\
LAS & $205(97,62 \%)$ & 0,3624 & 0,7518 & 0,9409 \\
SSA & $210(100,0 \%)$ & 0,6155 & 0,7907 & 0,9026 \\
EUR & $290(96,67 \%)$ & 0,3421 & 0,7447 & 0,9294 \\
ORM & $76(97,44 \%)$ & 0,3957 & 0,7056 & 0,9905 \\
ASA & $120(100,0 \%)$ & 0,3874 & 0,7630 & 0,9196 \\
\hline
\end{tabular}

Uma inspeção direta da Tabela 4.25 revela a ocorrência um padrão mais ou menos uniforme na distribuição dos valores centrais apresentados por cada um dos grupos analisados. Tal constatação é particularmente verdadeira quando os valores máximos observados em cada análise são considerados, delimitados todos dentro do intervalo variando de 0,89 e 0,99. Tal cenário é ligeiramente modificado quando os valores médios observados em cada grupo analisado tornam-se foco das atenções. Neste caso, oito dos nove valores contabilizados encontram-se dentro do intervalo definido entre 0,71 e 0,87. A exceção encontrada neste conjunto de dados é relativa à análise da parcela ADS, cujo composição conta, entre outras, com algumas populações de tamanho amostral reduzido. Uma vez que a técnica de "random skewers" apresenta baixa sensibilidade à comparações de pequeno tamanho amostral (Cheverud \& Marroig, 2007), a explicação de tal exceção (como feita também nos casos anteriores) é facilmente atribuível à inexpressividade da amostra. 
Em relação aos valores mínimos observados o cenário inferido é um pouco mais difícil de ser interpretado. A maior parte dos agrupamentos analisados apresenta valores mínimos de similaridade média entre o,36 e 0,40, incluindo aí o agrupamento ADS, cuja deficiência amostral foi anteriormente citada. No entanto, destacam-se quatro outros agrupamentos, todos com 100,0\% dos valores de similaridade média obtidos com significância estatística, cujos valores mínimos variam entre 0,62 e o,81. Dado que tal relação, a associação entre maior quantidade de valores significativos com maiores valores de similaridade média, não havia emergido nas análises anteriores, uma explicação alternativa à essa observação é a de que, nesses casos, trata-se de agrupamentos cujas populações apresentam alto grau de similaridade em seus padrões de variância e covariância.

Dois níveis de comparação intergrupos foram conduzidos nesta parcela da análise. Um deles, cujos resultados estão sumarizados na Tabela 4.26, consistiu na comparação entre os nove grupos anteriormente estabelecidos, com a diferença que, nesta análise, novas matrizes de $\mathrm{V} / \mathrm{CV}$ foram calculadas sem a discriminação populacional dentro de cada grupo. O segundo nível de comparação intergrupal foi efetuado a partir do reagrupamento das populações originando dois grupos únicos, comparados diretamente: Novo e Velho Mundo. A similaridade média obtida neste caso foi de 0,9376 , estatisticamente significativa $(\mathrm{p}<0,000)$.

Tabela 4.26 - Número de observações estatisticamente significativas (s.), valor mínimo (min), valor médio $(\bar{x})$ e valor máximo (max.), obtidos para a comparação intergrupos das matrizes de V/CV (critério geográfico).

\begin{tabular}{ccccc}
\hline Grupo & s. & min. & $\bar{x}$ & max. \\
\hline Intergrupos & $36(100,0 \%)$ & 0,8623 & 0,9176 & 0,9497 \\
\hline
\end{tabular}

Tanto os valores obtidos para a comparação entre Velho e Novo Mundo quanto as cujos valores estão sumarizados na Tabela 4.26 dispensam maiores comentários para suas interpretações. Assim como ocorrido nas outras categorias analíticas, os grupos mais inclusivos, geralmente formados nas análises intergrupais, apresentam os maiores valores mínimos e médios de similaridade média entre as matrizes de $\mathrm{V} / \mathrm{CV}$, associados, sempre, à significância estatística da totalidade das observações. 


\section{Hierarquização molecular}

A análise dos dados de diversidade de microssatélites das 36 populações amostradas no banco de dados representado na Tabela 3.3 resultou na árvore filogenética apresentada na Figura 4.35. Como descrito anteriormente, a inspeção direta das relações estabelecidas entre as populações representadas na filogenia em questão permite a estratificação desta amostra em cinco grupos (Ásia, América, Eurásia, África e Oceania), correspondentes às suas localizações geográficas continentais. A análise dos padrões de similaridade entre as matrizes de V/CV foi conduzida a partir de duas abordagens comparativas: uma intragrupo, baseadas nas populações dentro de cada continente e outra intergrupos, na qual todas as populações de um continente foram consideradas conjuntamente e comparadas entre as diferentes regiões geográficas. A Tabela 4.27 apresenta a síntese das informações obtidas para a comparação intragrupal. Já a Tabela 4.28 apresenta os dados oriundos da análise intergrupal.

Tabela 4.27 - Agrupamentos populacionais, número de observações estatisticamente significativas (s.), valor mínimo ( $\min )$, valor médio $(\bar{x})$ e valor máximo (max.), obtidos para a comparação intragrupo das matrizes de V/CV (critério geográfico).

\begin{tabular}{ccccc}
\hline Grupo & s. & $\min$. & $\bar{x}$ & max. \\
\hline Todas & $621(98,57 \%)$ & 0,3375 & 0,7016 & 0,9125 \\
Ásia & $88(96,7 \%)$ & 0,3374 & 0,7253 & 0,9136 \\
América & $3(100,0 \%)$ & 0,6296 & 0,6332 & 0,8245 \\
Eurásia & $55(100,0 \%)$ & 0,5322 & 0,6940 & 0,8493 \\
África & $15(100,0 \%)$ & 0,3709 & 0,6258 & 0,8126 \\
Oceania & $1(100,0 \%)$ & - & 0,8741 & 0,8741 \\
\hline
\end{tabular}

Tabela 4.28 - Número de observações estatisticamente significativas (s.), valor mínimo (min), valor médio $(\bar{x})$ e valor máximo (max.), obtidos para a comparação intergrupos das matrizes de V/CV (critério geográfico).

\begin{tabular}{ccccc}
\hline Grupo & s. & $\min$. & $\bar{x}$ & $\max$. \\
\hline Intergrupos & $10(100,0 \%)$ & 0,8402 & 0,8849 & 0,9287 \\
\hline
\end{tabular}


Assim como observado nas outras três categorias de análises, o padrão de similaridade média das matrizes de V/CV apresenta-se variando sempre dentro dos mesmo limites, aproximadente 0,3 e 0,9. Tal estabilidade reflete-se na observação adicional, também comum em todas as análises executadas, de que grupos mais inclusivos, normalmente associados aos continentes, estão relacionados, quase que constantemente, aos maiores valores médios de similaridade entre matrizes. Embora tal fenômeno possa estar relacionado ao incremento numérico do tamanho amostral, favorecendo, assim, a aplicação da técnica de "random skewers" (Cheverud \& Marroig, 2007), suas possíveis consequências evolutivas não podem ser completamente negligenciadas.

\section{e) Detecção de módulos cranianos}

A investigação de módulos cranianos foi executada analisando-se todas as populações amostradas na Tabela 3.2, explorando-se, separadamente, matrizes de correlação C e de variância/covariância $\mathrm{V} / \mathrm{CV}$.

\section{Correlações entre matrizes $M$ e C}

As matrizes C, contendo os coeficientes de correlação de Pearson entre as 24 variáveis craniométricas para cada população em estudo (além de uma contendo todas as populações) foram correlacionadas com as matrizes $\mathrm{M}$, modeladas para explorar as características desenvolvimentais e funcionais da morfologia craniana humana, produzindo um total de 1500 coeficientes $\mathrm{r}$ e seus respectivos valores p (após teste de Mantel para detecção de significância). Destes 1500 coeficientes r, 645 correspondem a valores significativos $(\mathrm{p} \leq \mathrm{0}, 025)$. As características descritivas destes coeficientes estão expressas na Tabela 4.29. A Figura 4.28 apresenta suas frequências observadas ajustadas para uma distribuição normal. Ambas foram produzidas através do Statistica 8.o (Statsoft, 2007). 
Tabela 4.29 - Descrição sumária dos coeficientes de correlação de Pearson entre matrizes C e M. Apenas coeficientes com valores $\mathrm{p} \leq$ 0,025 (Mantel) foram considerados significativos e contabilizados. Em negrito, valores iguais ao máximo de interações possíveis.

\begin{tabular}{cccccc}
\hline Módulo & $\begin{array}{c}\mathrm{N}^{0} \text { de } \\
\text { Observações }\end{array}$ & Média & Mínimo & Máximo & $\begin{array}{c}\text { Desvio- } \\
\text { padrão }\end{array}$ \\
\hline Desenvolvimental & $\mathbf{1 5 0}$ & 0,269155 & 0,140600 & 0,373700 & 0,057814 \\
Face & $\mathbf{1 5 0}$ & 0,305521 & 0,126800 & 0,484700 & 0,091283 \\
Neurocrânio & 19 & 0,124433 & 0,086710 & 0,162100 & 0,024792 \\
$\begin{array}{c}\text { Funcional } \\
\text { Abóbada } \\
\text { craniana }\end{array}$ & $\mathbf{1 5 0}$ & 0,205207 & 0,111700 & 0,305800 & 0,045369 \\
$\begin{array}{c}\text { Basicraniana } \\
\text { Nasal }\end{array}$ & $\mathbf{3 4}$ & 0,136402 & 0,044520 & 0,235600 & 0,045719 \\
$\begin{array}{c}\text { Zigomático- } \\
\text { temporal }\end{array}$ & 12 & 0,111460 & 0,092460 & 0,129800 & 0,012525 \\
Oral & 1 & 0,112600 & 0,112600 & 0,112600 & - \\
Orbital & 129 & 0,172166 & 0,107600 & 0,239700 & 0,031780 \\
\hline Total & 0 & - & - & - & - \\
\hline
\end{tabular}

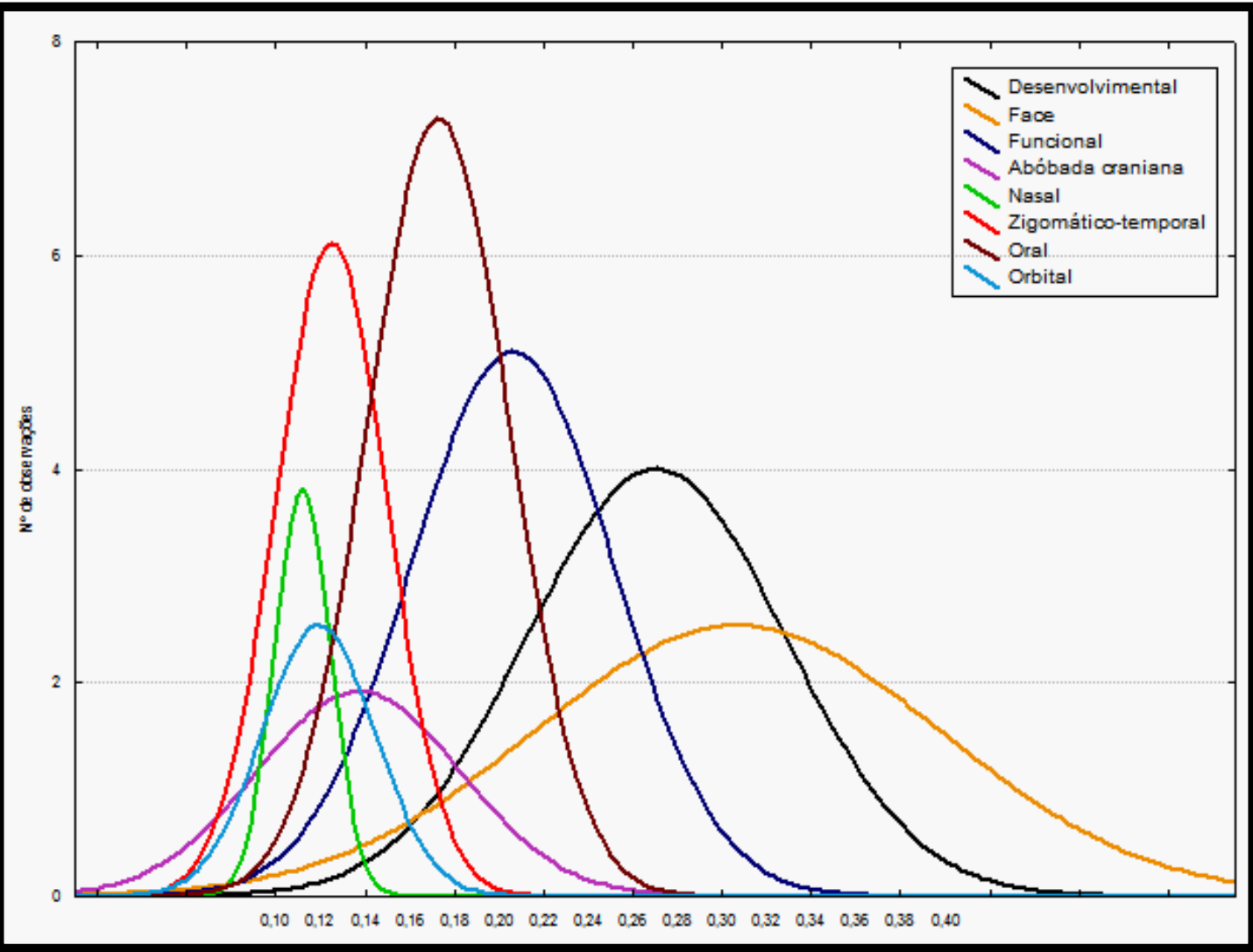

Figura 4.27 - Distribuições normais ajustadas baseadas em histograma múltiplo para cada módulo morfológico craniano. Note que Neurocrânio e Basicraniana não aparecem distribuídas uma vez que não tiveram observações suficientes para constituírem o histograma. 
A observação da Tabela e da Figura anteriores sugere que, independentemente das magnitudes das interações, a região facial e a região oral são as responsáveis diretas pela integração morfológica do crânio humano para as dimensões desenvolvimentais e funcionais, respectivamente. Isso quer dizer que a diversificação observada na morfologia craniana mundial, em suas diferentes características e variáveis, está, invariavelmente, associada a mudanças localizadas na região da face (de maneira global, uma vez que o módulo oral está completamente contido no módulo facial). Uma importante decorrência dessa observação é a constatação de que diferentes alterações da morfologia do crânio, em diferentes áreas da estrutura, possam ser resultado de processos microevolutivos que atuem diretamente na face. As Figuras 4.35 e 4.36 ilustram a ocorrência desses módulos no crânio.

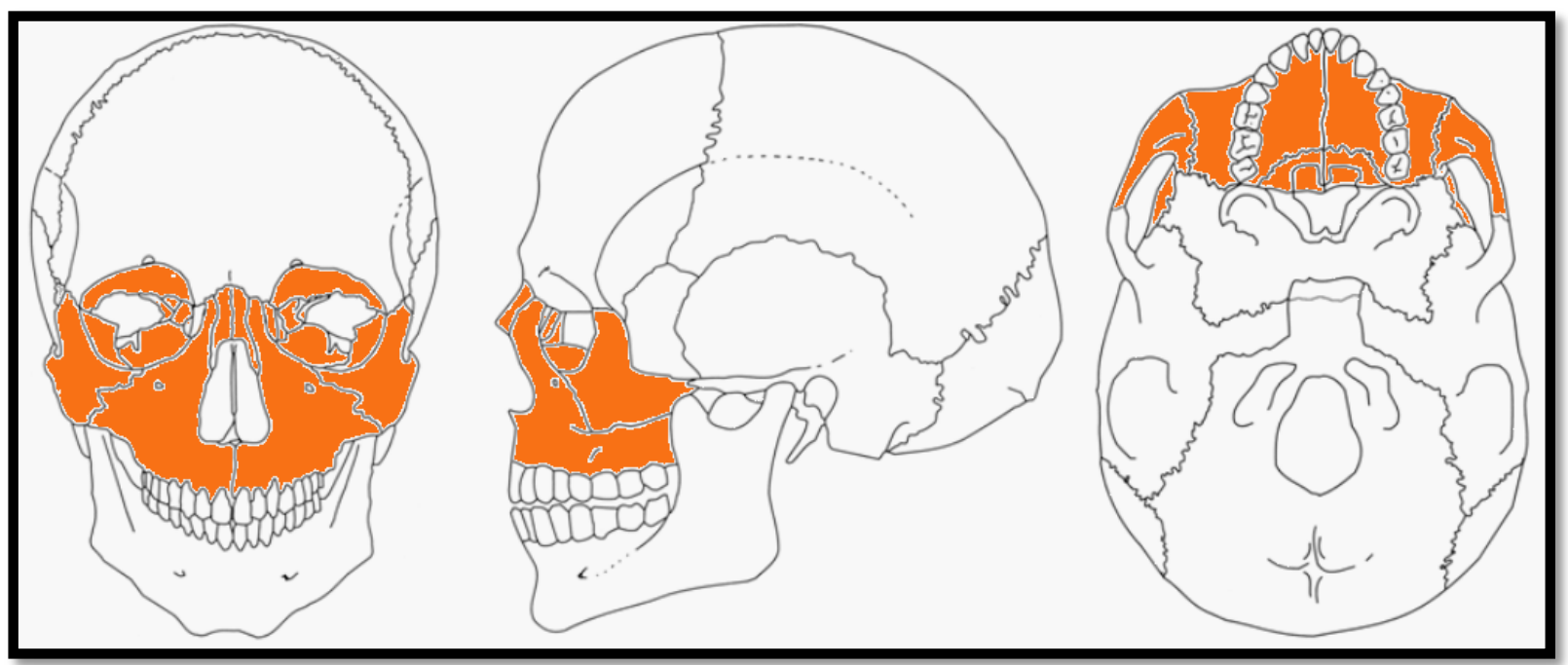

Figura 3.35 - Área e estruturas envolvidas no módulo desenvolvimental facial.

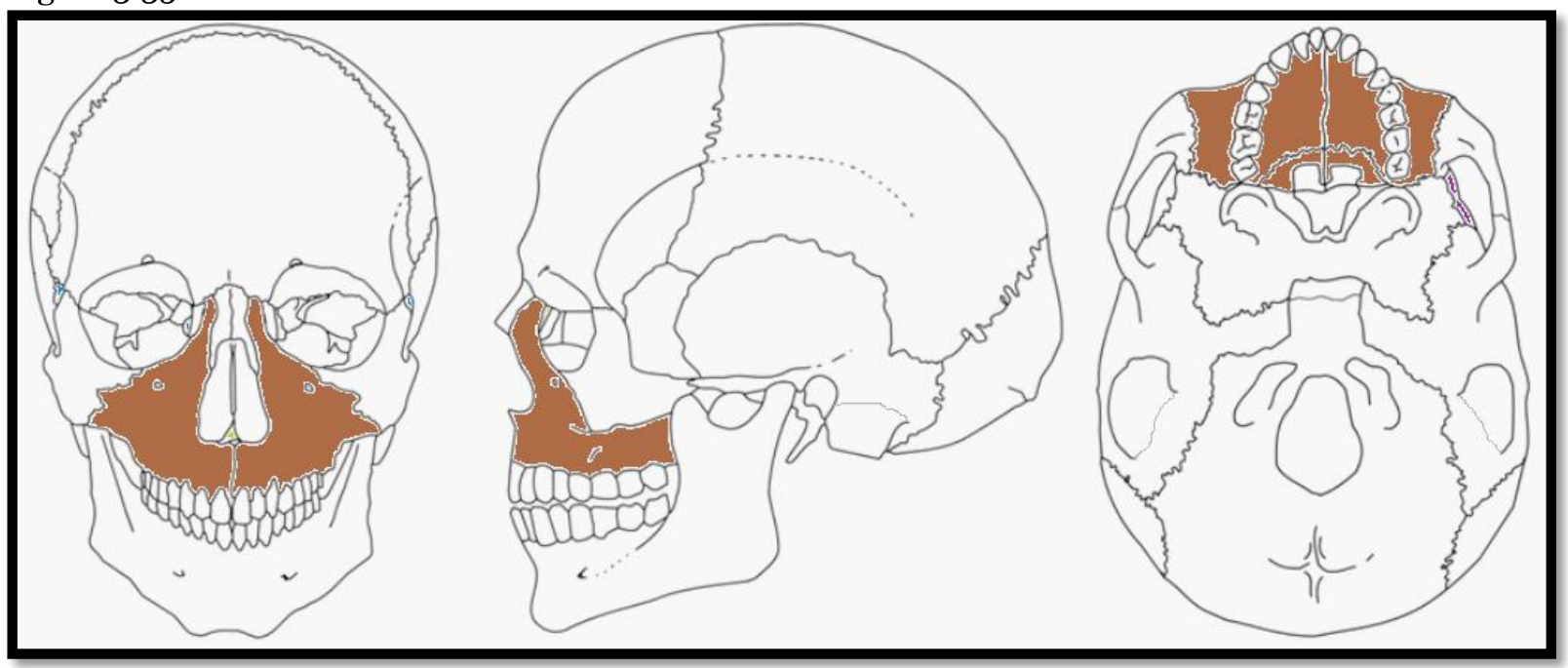

Figura 3.36 - Área e estruturas envolvidas no módulo funcional oral. 


\section{Correlações entre matrizes $M$ e $V / C V$}

Seguindo a mesma estratégia adotada para a comparação entre as matrizes $\mathrm{M}_{\text {modulares }} \mathrm{e}$

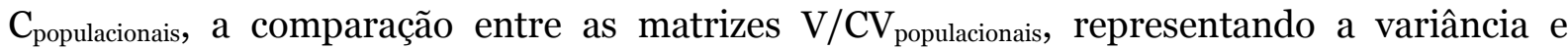
covariância entre os 57 caracteres cranianos para cada uma das se deu através da performance do cálculo do coeficiente de Pearson entre cada par de matrizes, seguido do teste de Mantel para detecção de significância (após 9.999 permutações). O valor de p estabelecido como limite para a determinação de significância continuou em o,025. Esse limite pode ser considerado bastante rigoroso, uma vez que foi considerado um valor $a=$ 0,05, dividido entre as duas terminações da distribuição ( $p_{\text {limite }}=\alpha / 2=0,025$ ), valor classicamente aceito como determinante de significância em ensaios biológicos (CallegariJacques, 2003). Novamente, um total de 1500 valores de coeficientes de correlação $\mathrm{r}$ foram gerados, dos quais 416 obtiveram significância estatística e são apresentados na Tabela 3.15.

Tabela 4.30 - Descrição sumária dos coeficientes de correlação de Pearson entre matrizes V/CV e M. Apenas coeficientes com valores $\mathrm{p} \leq \mathrm{0,025}$ (Mantel) foram considerados significativos e contabilizados. Em negrito, valores iguais ao máximo de interações possíveis.

\begin{tabular}{cccccc}
\hline Módulo & $\begin{array}{c}\text { No de }^{0} \\
\text { Observações }\end{array}$ & Média & Mínimo & Máximo & $\begin{array}{c}\text { Desvio- } \\
\text { padrão }\end{array}$ \\
\hline Desenvolvimental & $\mathbf{1 5 0}$ & 0,196279 & 0,079200 & 0,337400 & 0,061226 \\
Face & 19 & 0,220350 & 0,165100 & 0,325600 & 0,047907 \\
Neurocrânio & 16 & 0,198460 & 0,130800 & 0,267000 & 0,046553 \\
$\begin{array}{c}\text { Funcional } \\
\text { Abóbada } \\
\text { craniana }\end{array}$ & $\mathbf{1 5 0}$ & 0,227697 & 0,100800 & 0,360600 & 0,061262 \\
$\begin{array}{c}\text { Basicraniana } \\
\text { Nasal }\end{array}$ & 44 & 0,227905 & 0,138000 & 0,471300 & 0,075996 \\
$\begin{array}{c}\text { Zigomático- } \\
\text { temporal } \\
\text { Oral }\end{array}$ & 0 & - & - & - & - \\
Orbital & 0 & - & - & - & - \\
Total & 37 & 0,195138 & 0,010930 & 0,297700 & 0,059755 \\
\hline
\end{tabular}


Saltam aos olhos diferenças qualitativas entre os resultados expressos na Tabela 4.30 (correlações M e C) e os da Tabela 4.29 (correlações entre M e V/CV). Enquanto que para as comparações entre M e C 645 valores de $\mathrm{r}$ foram considerados estatisticamente significativos (43\% dos coeficientes obtidos) e que em apenas dois dos módulos (basicrânio e neurocrânio) não foram observados valores com significância, quando se comparou $M$ e V/CV essa quantidade baixou para 416 valores de r (28\% dos casos) sendo que, além do basicrânio, os módulos nasal e orbital também não contaram com nenhuma ocorrência de correlação com significância estatística. A Figura 3.37 mostra as distribuições normais esperadas dessas correlações, separadas por módulos, ajustadas para os valores observados.

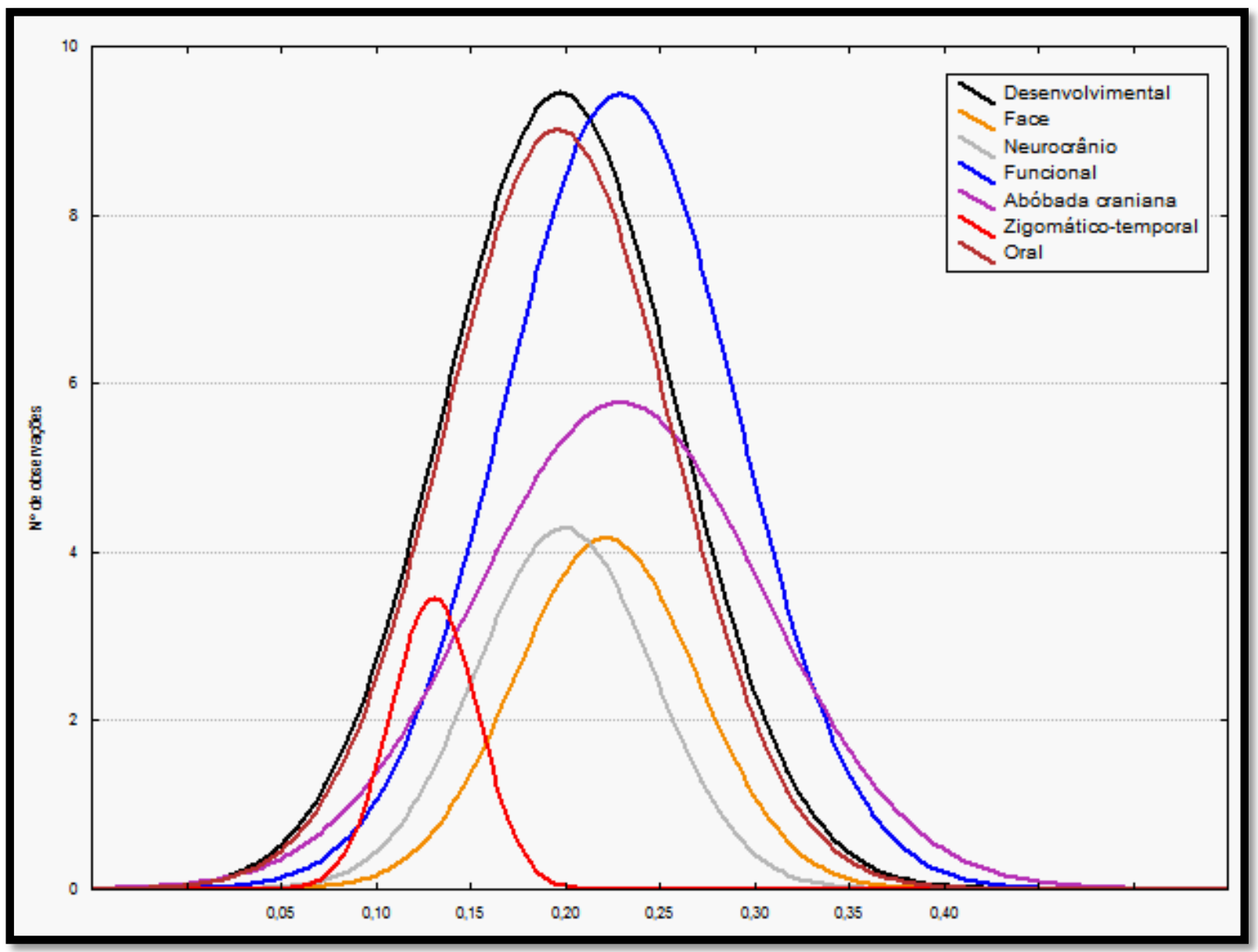

Figura 4.37 - Distribuições normais ajustadas baseadas em histograma múltiplo para cada módulo morfológico craniano. Note que basicrânio, nasal e orbital não aparecem distribuídas uma vez que não tiveram observações suficientes para constituírem o histograma. 
Uma observação mais detida da distribuição apresentada na Figura 19 sugere que, em comparação ao mostrado na Figura 3.37 (curvas de distribuição para as comparações entre M e C, as correlações obtidas entre $\mathrm{M}$ e $\mathrm{V} / \mathrm{CV}$ apresentam, em especial para os módulos desenvolvimental, funcional e oral, uma maior concordância entre si. A Figura 3.38 apresenta todas essas curvas em um mesmo gráfico, de maneira a facilitar sua análise comparativa.

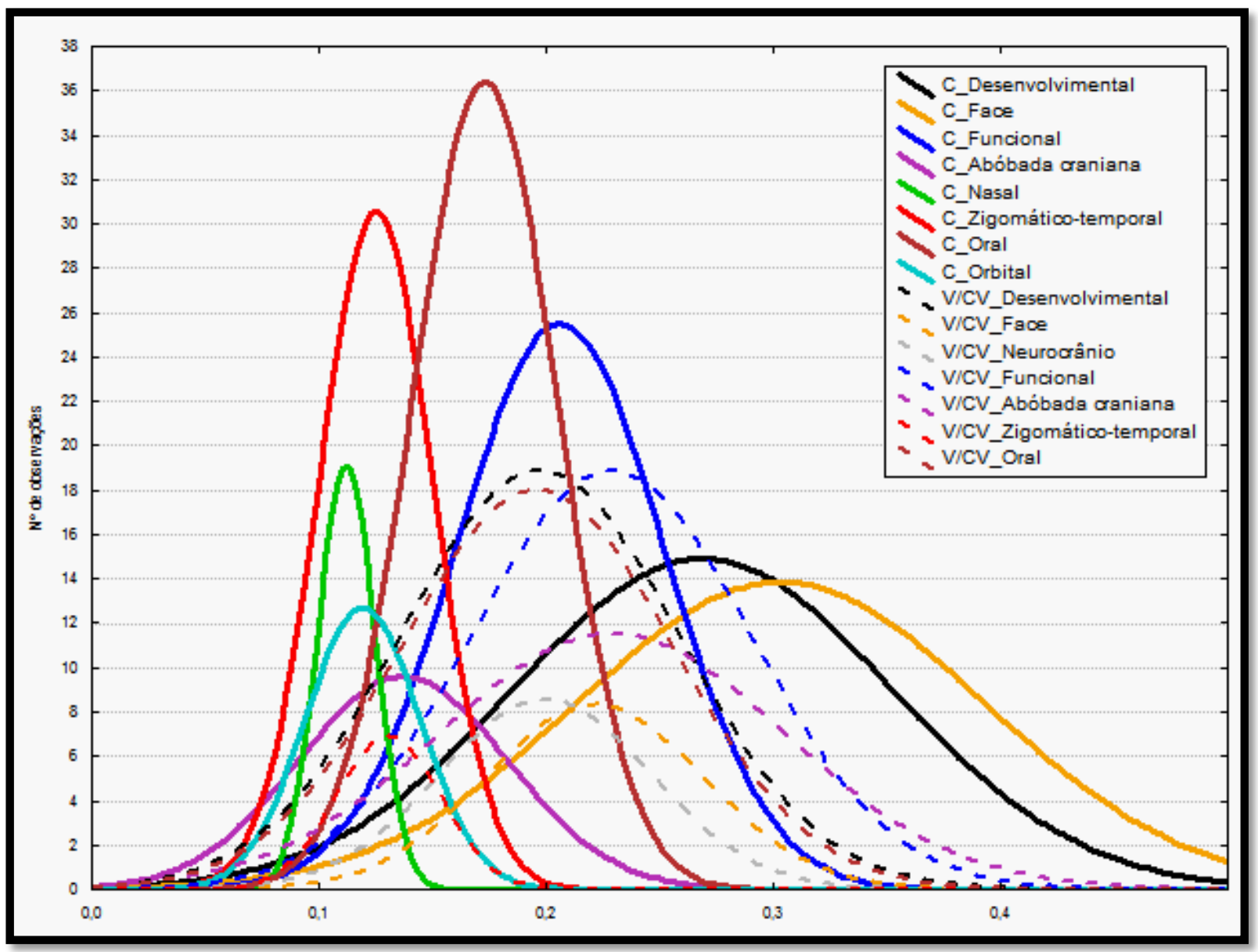

Figura 3.38 - Distribuições normais ajustadas baseadas em histograma múltiplo para cada módulo morfológico craniano, entre duas classes de comparações: matrizes M e C (linhas cheias) e matrizes M e V/CV (linhas tracejadas).

A análise da Figura 3.38 sugere uma particularidade entre as interações investigadas: de maneira discreta, e com algumas (duas) exceções à esta regra, observa-se a tendência de as 
correlações entre $\mathrm{M}$ e $\mathrm{C}$ predominarem em número de observações, ao passo que as correlações entre $\mathrm{M}$ e V/CV sugerem predomínio em relação à intensidade, ou valor, dos coeficientes. Em outras palavras, a tendência sugerida é que enquanto as interações significativas entre $\mathrm{M}$ e $\mathrm{C}$ ocorre mais vezes (maior quantidade), as entre $\mathrm{M}$ e V/CV ocorrem em maiores valores (maior intensidade). No entanto, é necessário destacar que o verdadeiro significado biológico dessas relações esteja eclipsado por viés da amostra utilizada. Como pode ser depreendido da Tabela 2.6, que apresenta a composição relativa das matrizes M, existe uma forte discrepância na quantidade de variáveis craniométricas envolvidas em cada um dos módulos desenhados. Não por acaso, os módulos que apresentam essa ausência de correlação são exatamente os mesmo que apresentam o menor número de variáveis representadas nas matrizes $\mathrm{M}$.

Ainda assim, a aparente concordância existente para a covariação entre os diferentes módulos cranianos mostrada na Figura 3.37 sugere a ocorrência de um padrão intenso de integração craniana no que toca a variação conjunta entre caracteres de módulos diferentes. A Figura 3.39 e 3.40 ilustram os módulos que se destacam em termos de concordância e amplitude das correlações obtidas para os níveis associativos desenvolvimental e funcional, respectivamente.

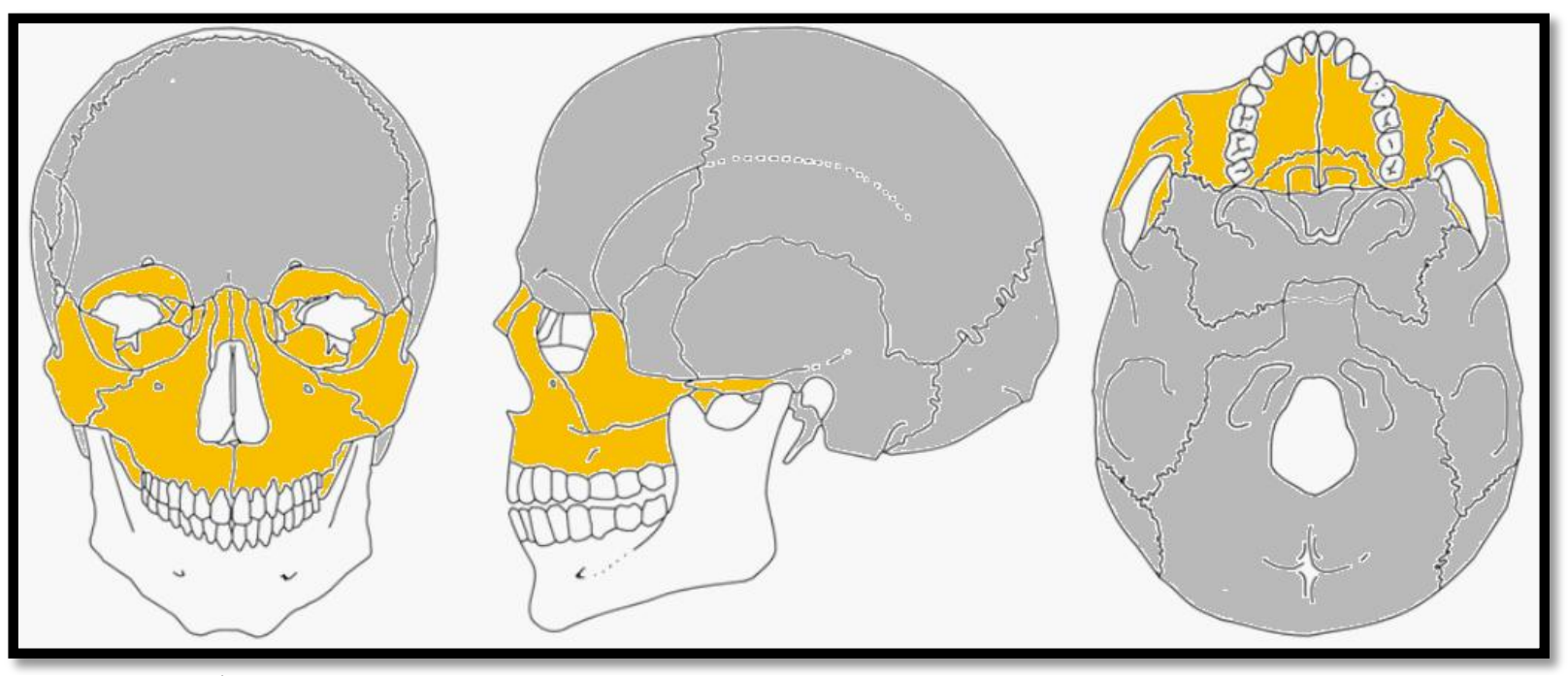

Figura 3.39 - Área e estruturas envolvidas nos módulos desenvolvimentais facial e neurocrâniano. 


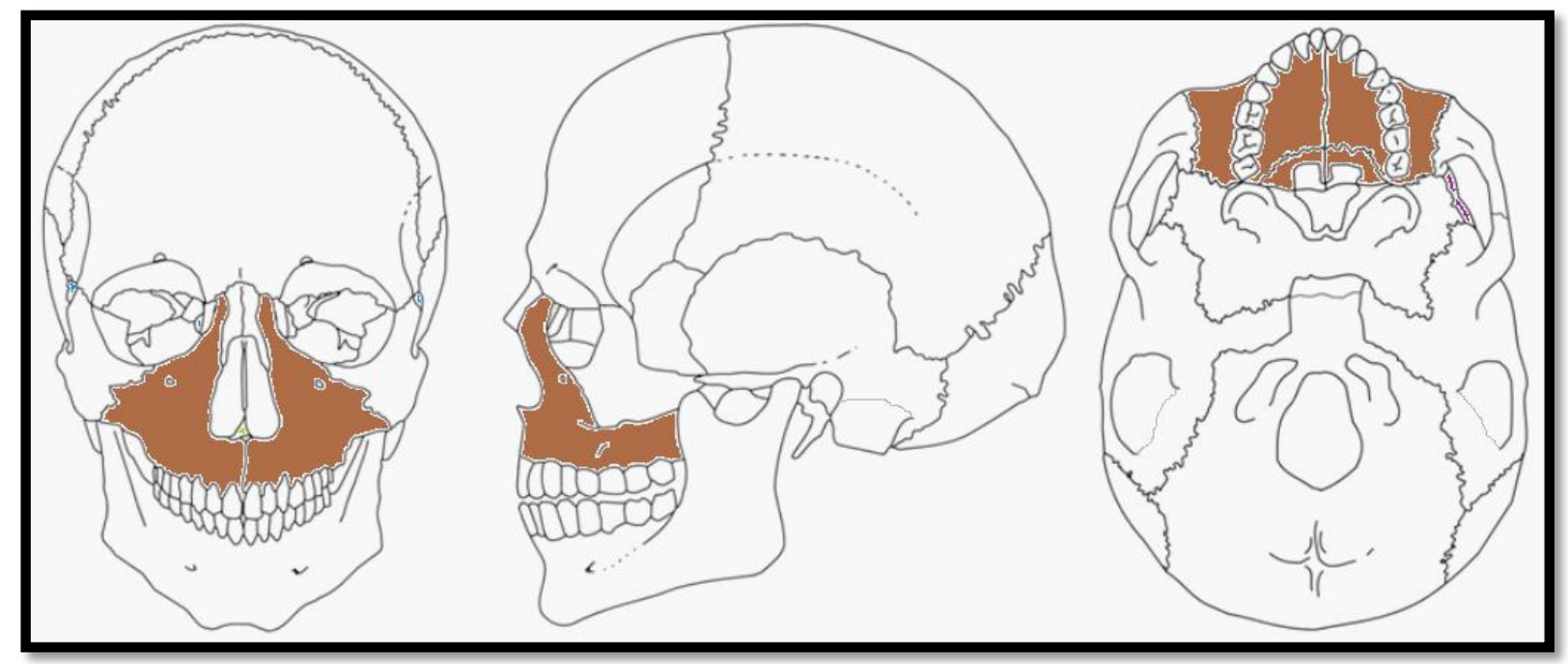

Figura 3.40 - Destaque do nível associativo funcional. Área e estruturas envolvidas no módulo oral. 

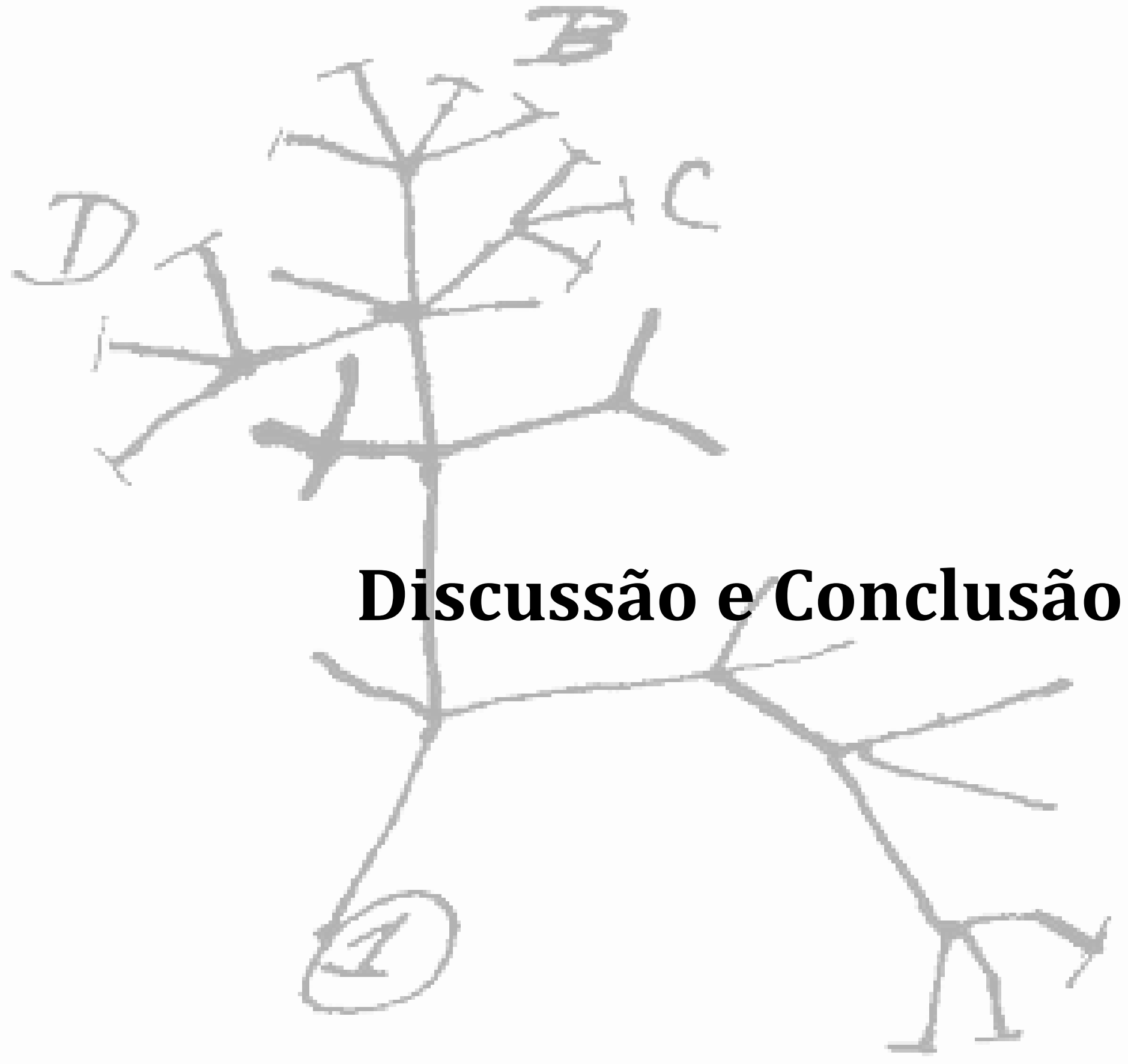

"Primeira regra, os conceitos se ligam por analogia. Não há regras para se decidir de início se uma analogia é boa ou má, porque qualquer coisa é semelhante a qualquer outra sob certo grau de relacionamento. Exemplo. Batata se cruza com maça, porque ambas são vegetais e arredondadas. De maça vai-se a serpente, por conexão bíblica. De serpente a rosca, por similitude formal, de rosca a salva-vidas e daí a roupa de banho, de banho a carta náutica, de carta náutica a papel higiênico, de higiene ao álcool, do álcool à droga, da droga à seringa, da seringa ao buraco, do buraco ao terreno, do terreno à batata".

Umberto Eco, "O Pêndulo de Foucault". 



\section{5 - Discussão e conclusão: Interpretação e hipóteses}

Conforme exposto nos dois capítulos iniciais, o objetivo geral deste trabalho é caracterizar o comportamento evolutivo da morfologia craniana humana. Desse ponto de vista, pode-se destacar que, de maneira geral, os resultados gerados através das diferentes estratégias empregadas para essa investigação demonstraram que, conforme já exposto na literatura, crânios se comportam como um mosaico de traços, com alguns traços neutros e outros sujeitos a forças seletivas (Guglielmo-Matessi et al., 1979, Roseman, 2004, Lieberman, 2008, Hubbe et al., 2009). Ainda assim, o caráter neutro da morfologia craniana humana, em detrimento da interpretação seletiva (vide Lieberman, 2008 para uma visão contrária), segue ditando a tônica dos estudos microevolutivos sobre o tema, apoiado, principalmente, na comprovada estruturação geográfica observada quando crânios humanos são analisados (Relethford, 1994, 2002, Roseman, 2004, Roseman \& Weaver, 2004, Manica et al., 2007, Weaver et al., 2007, Hubbe et al., 2009, von Cramon-Taubadel \& Weaver, 2009). Essa estruturação geográfica também foi demonstrada nos resultados aqui obtidos, com a ressalva de situações particulares, envolvendo diferentes escalas cronológicas, ambientais e populacionais, que se apresentaram contrários à tal interpretação.

Nesse contexto, os resultados obtidos podem apresentar implicações diretas para as discussões comumente centrais aos estudos que utilizam a diversidade da morfologia craniana humana como marcador bioantropológico. A primeira observação que merece destaque nos resultados gerados é a demonstração formal da correlação estatisticamente significativa entre três importantes características geralmente atribuídas, ou depreendidas, das populações que são objeto de estudo nessas investigações: as matrizes de distância geográfica $\left(\mathrm{D}_{\mathrm{Geo}}\right)$, de distância generalizada de Mahalanobis $\left(\mathrm{D}^{2}\right)$ e de distâncias de $\mathrm{F}_{\mathrm{ST}}\left(\mathrm{F}_{\mathrm{st}}\right)$.

As correlações obtidas, todas significativas de acordo com o teste de Mantel, indicam uma maior correspondência entre $\mathrm{D}^{2}$ e $\mathrm{D}_{\mathrm{Geo}}$ do que entre $\mathrm{F}_{\mathrm{ST}}$ e $\mathrm{D}_{\mathrm{Geo}}$. Uma vez que ambas as métricas utilizadas, Mahalanobis e $\mathrm{F}_{\mathrm{ST}}$, nesta análise exprimem características, ou, mais 
precisamente, diversidade morfocraniana, a diferença entre a magnitude de correspondência apresentada entre as duas medidas em relação a distâncias geográficas pode ter um significado biológico supranumerário em relação às significâncias estatísticas obtidas. Os resultados apresentados pelas interações entre $\mathrm{D}^{2}$ e $\mathrm{D}_{\text {Geo }}$ sugerem que a inconveniência do uso da morfologia craniana como marcador de diversidade possa estar relacionada ao $\mathrm{F}_{\mathrm{ST}}$, embora o valor da correlação entre $\mathrm{D}^{2}$ e $\mathrm{F}_{\mathrm{ST}}$ desencoraje essa interpretação. Novos estudos, utilizando técnicas estatísticas de reamostragem, com diferentes níveis de herdabilidade seriam elucidativos para a investigação do real significado biológico dessas observações. Embora avaliar a adequação dessas métricas não fosse, em momento algum, o objetivo deste trabalho, a constatação dessas diferentes associações não poderia passar despercebida uma vez que pode trazer implicações diretas à sua utilização, que é amplamente aceita como marcador de diversidade craniana (Relethford \& Blangero, 1990, Relethford, 1994, 2002).

Um exemplo das implicações resultantes de inconsistência entre marcadores bioantropológicos pode ser observado a partir da análise dos diagramas de correlação contendo as dispersões de CVM em função de distância em relação à África.

A análise das dispersões dos dados de coeficiente médio de variação CMV em função da distância em relação à África, reforçadas pelas retas de regressão linear, faz saltar aos olhos a divisão das distribuições seguindo dois padrões diferentes. Enquanto a premissa de que os valores de CMV decaem à medida que as populações se afastam da África vale perfeitamente ao se analisar os dados em conjunto (todas as populações), das médias (valores médios representativos de cada continente) e das populações africanas e americanas, o mesmo não ocorre quando as populações européias, asiáticas e da Oceania são analisadas separadamente. Embora os valores dos coeficientes de correlação tenham se apresentado estatisticamente significativos em apenas dois dos casos, quando todas as populações são consideradas e quando apenas as asiáticas são utilizadas, os resultados sugerem que a premissa amplamente vigente nas pesquisas biomoleculares não parece ser completamente aplicável aos dados de origem fenotípica, ou, neste caso, craniométrica. 
Os resultados mostram que propor que a diversidade presente nas populações humanas obedece a um declínio gradual a partir da África, como é bastante observada em estudos moleculares (Serre \& Paäbo, 2005), por exemplo, não parece ser a melhor, ou a única, explicação para quando se tratam dados fenótipicos, mais especificamente dados craniométricos, ao contrário do que é afirmado por Betti et al. (2009), entre outros. Os resultados obtidos sugerem, no entanto, que, se não totalmente explicados por clusters como sugere Rosenberg et al. (2005), a estruturação populacional humana, inferida através dos dados oriundos de medidas cranianas, é marcada por um regime de descontinuidades, o que pode indicar que, além da distância geográfica em relação ao ponto de origem (o que, consequentemente, indica distância cronológica em relação aos ancestrais comuns), outros fatores, como as barreiras geográficas, por exemplo, podem conferir uma parcela de identidade genética às populações autóctones de cada grande região mundial. A maior correlação entre a matriz de $\mathrm{F}_{\mathrm{ST}}$, a $\mathrm{D}_{\mathrm{Gen}}$, e a $\mathrm{E}_{\mathrm{Con}}$ do que entre a DGen e a DGeo constitui um bom exemplo para ilustrar essa observação.

As decorrências imediatas dessa observação implicam na constatação de que a divergência entre as populações, medida pelo $\mathrm{F}_{\mathrm{ST}}$, não pode ser somente atribuída a eventos neutros, como a deriva genética, necessitando, assim, da investigação e da modelagem de outros mecanismos evolutivos envolvidos no processo de diferenciação das populações humanas.

Os resultados gerados pela investigação baseada na correlação entre CMV e as distâncias geográficas a partir de um ponto de origem hipotético, na África, também suscitam mais questionamentos aos resultados amplamente difundidos pelos autores que defendem o modelo neutro, ou o isolamento por distância somado aos sucessivos gargalos populacionais, como o principal fator responsável pela diversidade fenotípica observada nos humanos atuais (Manica et al., 2007; Betti et al. 2009; 2010). Os resultados aqui expostos sugerem que o padrão gradual, de cline, observado a partir da África pode ser decorrente de artifícios estatísticos, como ficou demonstrado pelo gráfico de dispersão CMV x DOA que, envolvendo 
todas as populações, apresenta uma reta de correlação negativa mesmo quando vemos, no mesmo gráfico, retas de correlação positiva quando tratando de populações isoladas continentalmente. Essa problemática, inicialmente abordada por Felsenstein (1985), pode refletir a incapacidade de reconstituírem-se determinadas estruturações filogenéticas através de relações matemáticas. Em outras palavras, o que se depreende dos resultados aqui obtidos, é que, em se tratando dos dados craniométricos estudados, a estruturação populacional humana deve se comportar, quando estimados a variação em função da origem geográfica comum, como um cline escalonado, i. e., um contínuo de variação que apresenta estruturações preferenciais em certos intervalos observados (Felsenstein, 1976, Barton, 1983), aproximando esses resultados aos obtidos por Rosenberg e colaboradores (2002).

De maneira sintética, esses resultados possibilitam a inferência de que o modelo que melhor explica a estrutura populacional observada na diversidade morfocraniana humana não pode ser explicada apenas pela ideia de um declínio gradual de variação a partir da África, mas sim por um padrão discreto para cada área, marcado por descontinuidades que revelam uma identidade dentro de cada grande região geográfica.

Uma possível explicação para tal fenômeno poderia estar associada à ocorrência de eventos evolutivos distintos. A diversidade craniana humana observada poderia ser produto, majoritariamente, de um evento não-estocástico. Tal sugestão reside no fato de que, em termos histórico-evolutivos, a última grande alteração estrutural observada no crânio humano foi o surgimento da morfologia especializada, na Ásia (Lahr, 2004; Hubbe et al, 2011). O comportamento diferencial das populações asiáticas favorece essa especulação.

Para tanto, porém, seria necessário que as assinaturas evolutivas de crânios e moléculas fossem absolutamente diferentes, ou, que os mecanismos de controle e desenvolvimento morfológico, os módulos cranianos, guardassem relações históricopopulacionais específicas. 
A primeira proposta foi investigada a partir do estudo específico do caso dos nativos americanos. Nessa investigação, a comparação direta entre os três marcadores de variabilidade (um deles, a distância geográfica, ad hoc) mostrou, de maneira incontestável, correlações significativas entre todos os pares comparativos. Seguindo o raciocínio inicialmente proposto no experimento, este é um argumento favorável à interpretação de que os dois marcadores, tanto o morfológico quanto o molecular, apresentam afinidade com o modelo de isolamento por distância (IPD), evidência da neutralidade do marcador. Ainda assim, quando os coeficientes de correlação obtidos são organizados em ordem decrescente, a intensidade das interações é ranqueada em $\mathrm{D}_{\mathrm{Gen}}\left|\mathrm{D}_{\mathrm{Geo}}>\mathrm{D}_{\mathrm{Mor}}\right| \mathrm{D}_{\mathrm{Geo}}>\mathrm{D}_{\mathrm{Gen}} \mid \mathrm{D}_{\mathrm{Mor}}$. Isolando-se a “variável” $\mathrm{D}_{\mathrm{Geo}}$, chama a atenção, nesse ranqueamento, o maior valor obtido quando $\mathrm{D}_{\mathrm{Gen}}$ é a matriz comparativa do que quando $\mathrm{D}_{\text {Mor }}$ é a utilizada. Essa observação, a partir de um ponto de vista matematicamente pouco rigoroso, indica que genes comportam-se "mais geograficamente estruturados” do que crânios, o que, em última análise, pode ser interpretado como genes sendo mais neutros do que crânios. O resultado obtido quando

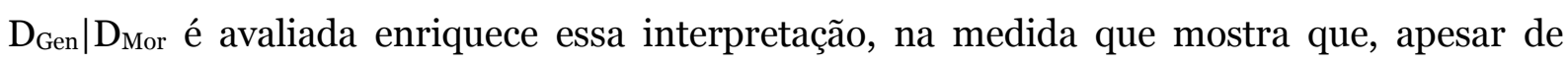
existir correlação significativa entre elas, o valor é o mais baixo encontrado no experimento.

Sob a luz dessa interpretação é que os resultados obtidos no segundo experimento vêm à tona. Com o intuito de investigar as causas para a ocorrência da menor correlação entre $D_{\text {Mor }} \mid D_{\text {Geo }}$ do que entre $D_{\text {Gen }} \mid D_{\text {Geo }}$ adotou-se a estratégia de fracionar o banco de dados com o objetivo de detectar pontos específicos de maiores ou menores correlações que poderiam afetar as comparações globais. O critério para o fracionamento foi promover a divisão entre América do Norte e América Central-Sul, de maneira a relativizar os efeitos climáticos sobre as populações. O raciocínio empregado para tal estratégia é relativamente simples: conforme mostrado na Figura 3.12, o continente Americano ocupa uma posição geográfica que apresenta a peculiaridade de apresentar pontos, que, mesmo separados por grandes distâncias geográficas, apresentam características climáticas semelhantes. Um bom exemplo desse caso é a similaridade climática encontrada entre os extremos Norte e Sul do 
continente. Sob essa perspectiva, essa oscilação harmônica na distribuição do clima em função da geografia poderia "embaralhar" o sinal de neutralidade. Por exemplo, tomando duas populações, uma do extremo Norte e outra do extremo Sul, ambas sob regimes climáticos semelhantes, elas podem apresentar semelhanças morfológicas entre si, devido a adaptações ao ambiente, diferentemente do que seria esperado de acordo com sua estruturação genética.

Chama a atenção, de imediato, entre os resultados mostrados na Tabela 4.14, o fato de todos os coeficientes obtidos para o conjunto de dados "América do Norte" apresentarem valores estatisticamente significativos ao passo que entre os coeficientes calculados para o conjunto de dados "América Central-Sul" apenas um tenha se comportado dessa maneira. Em si, esse resultado já indica diferença estrutural entre essas duas regiões. Outra novidade obtida a partir do fracionamento da análise foi o aumento nos valores dos coeficientes de correlação, indicando, que, talvez, esses resultados possam ter um significado biológico mais pronunciado do que aqueles obtidos no primeiro experimento. No entanto, os resultados mais intrigantes desta análise foram os obtidos para a parcela "América Central-Sul”. Para esse conjunto de dados apenas a correlação entre $D_{G e n}$ e $D_{G e o}$ mostrou-se estatisticamente significativa. Além disso, apresenta o maior valor de correlação obtido entre todas as combinações do experimento, inclusive quando "América do Norte" é considerada. Seguindo o raciocínio utilizado para a interpretação de todos os outros resultados, não restam dúvidas que na amostra "América Central-Sul” os marcadores moleculares empregados (mtDNA) apresentam um padrão evolutivo neutro. O mesmo pode ser dito quando se testa a amostra da "América do Norte". Entretanto, quando analisamos morfologia craniana a interpretação não é tão simples. Se, por um lado, para a fração “América do Norte" a correlação entre $\mathrm{D}_{\text {Mor }} \mathrm{e}$ $\mathrm{D}_{\mathrm{Geo}}$ é significativa, favorecendo a interpretação neutra também para morfologia craniana, por outro o mesmo não pode ser dito sobre a correlação $D_{M o r} \mid D_{G e o}$ da parcela "América Central-Sul”. Em outras palavras, os resultados obtidos aqui indicam que na América do 
Norte crânios e moléculas evoluíram de maneira neutra ao passo que nas Américas Central e do Sul apenas moléculas evoluíram dessa maneira.

A conclusão acima é difícil de ser interpretada quando se consideram os resultados divulgados na literatura especializada, que afirmam que estudos sobre afinidades entre populações humanas, baseados em dados craniométricos, são congruentes com os resultados baseados em análises de locos gênicos neutros (Roseman, 2004, Harvati \& Weaver, 2006, Smith, 2009, von Cramon-Taubadel, 2009a, 2009b).

Uma das possíveis explicações para o fenômeno observado pode estar associada a respostas evolutivas diferenciais entre a morfologia craniana e os haplogrupos de mtDNA. Os resultados obtidos neste experimento permitem que se levantem duas hipóteses concomitantes: 1) Que apesar de predominantemente neutra, a morfologia craniana responde também a forças seletivas; 2) Durante o processo de dispersão geográfica, as populações nativas americanas enfrentaram barreiras seletivas que afetaram crânios e não genes.

A primeira hipótese já é bastante discutida na literatura especializada, mesmo entre os autores que assumem a evolução predominantemente neutra da morfologia craniana (Roseman, 2004, Roseman \& Weaver, 2004, Harvati \& Weaver, 2006, Smith, 2009, Hubbe et al., 2009, von Cramon-Taubadel, 2009a, 2009b). Harvati \& Weaver (2006), por exemplo, demonstraram que a morfologia do neurocranio evolui de acordo com o esperado sob um ditame neutro, enquanto que a morfologia da face reflete adaptações climáticas. Os autores concluem, ainda, que diferentes regiões cranianas retêm os sinais da história evolutiva populacional (no sentido de evolução genética neutra) e adaptações climáticas de maneira diferencial, implicando em dificuldades no emprego da morfologia craniana para a reconstrução filogenética. Conclusões semelhantes foram alcançadas por Smith (2009) e Hubbe et al. (2009). Já quanto à segunda hipótese, pouco ainda pode ser discutido. Em uma revisão de como os estudos genéticos podem contribuir para as investigações de dispersões 
populacionais, Cann (2001) comenta sobre os resultados conflitantes entre análises envolvendo marcadores estritamente genéticos e outros de diferentes origens, como fósseis, línguas e remanescentes culturais, por exemplo. Considerando essa possibilidade pode-se supor que durante o processo de dispersão pela America do Sul a morfologia craniana dos primeiros colonizadores foi sujeita a forças evolutivas diferentes daquelas a que foram os nativos que ficaram na América do Norte, refletindo essa aparente diferença revelada pelas análises das duas parcelas populacionais. Infelizmente, com as amostras esqueletais humanas hoje disponíveis é muito difícil avançar no teste dessa hipótese.

O terceiro experimento executado neste trabalho reforça a ideia de que a morfologia craniana é representada por um mosaico envolvendo traços neutros e traços seletivos. Os resultados obtidos quando todas as 22 populações foram consideradas. Conforme pode ser observado na figura que ilustra o resultado obtido quando todas as 22 populações são consideradas, medidas da região nasal da face e medidas relacionadas à largura da base do crânio são as que se apresentam mais correlacionadas ao padrão evolutivo neutro. Interpretação semelhante é alcançada quando apenas a parcela América do Norte é testada. Esses resultados são parcialmente congruentes aos obtidos por Smith (2009), embora aponte certa discrepância aos descritos por Harvati e Weaver (2006) e Hubbe et al. (2009). Assim como encontrado nos resultados aqui obtidos, esses autores também demonstraram que a morfologia craniana humana retém traços evolutivos neutros e traços evolutivos seletivos. Entretanto, os autores concluíram que os traços mais afastados do sinal de neutralidade são os relativos à face, justamente os que melhor se ajustaram ao modelo neutro neste trabalho. Novos estudos, com bancos de dados mais verticalizados para essa questão, serão necessários para compreender essa diferença.

Finalmente, os resultados do terceiro experimento reservam ainda uma última importante consideração: quando apenas as populações da América Central-Sul são analisadas, apenas duas medidas craniométricas podem ser consideradas neutras. Esse resultado explica, em parte, por que se nota uma pequena diferença entre os resultados 
obtidos quando se considera América como um todo e América do Norte. Outra interpretação favorecida por esse resultado é a hipótese de que, nas Américas Central e do Sul, os ditames seletivos foram muito mais severos do que os ocorridos na América do Norte.

Em suma, a análise de todos os resultados gerados pelos experimentos aqui empreendidos permite concluir que quando consideramos os Nativos Americanos como um todo pode-se admitir que a morfologia craniana apresenta assinatura evolutiva neutra e segue, em geral, um padrão de diferenciação compatível com o modelo de Isolamento por Distância. Essa conclusão é especialmente forte para América do Norte. Por outro lado, quando as Américas Central e do Sul são consideradas, marcadores moleculares e morfológicos não seguem a mesma direção: enquanto mtDNA apresenta forte aderência com o esperado num regime de evolução neutra, a morfologia craniana parece ser significantemente afetada por outras forças evolutivas.

Já o segundo bloco de investigações conduzidas, a caracterização da diversidade craniana humana a partir da análise exploratória de seus padrões de correlação e de variância/covariância, não permitiu afirmações tão contundentes. A abordagem adotada, de se explorar a amostra total em diferentes níveis de organização, ou, em outras palavras, metapopulações, evidenciou que as diferenças entre os diferentes grupos não apresentam magnitudes suficientemente expressivas para a aceitação de um modelo alternativo à evolução neutra como explicação para a diversidade morfológica observada no crânio humano. Talvez, a melhor explicação para a compreensão de tal processo resida, de fato, na compreensão da dinâmica populacional das séries amostradas, algo inimaginável quando o objeto de estudo é fóssil.

População é um conceito que se insere entre duas diferentes entidades biológicas de particular interesse ao estudo dos processos evolutivos, o indivíduo e a espécie (Mayr, 1970). Sua importância reside no fato de que é no nível populacional que as mudanças genéticas, das mais diversas origens, ocorrem e passam de uma geração à outra. Como destacado ao 
longo da introdução desta tese, são exatamente essas mudanças estruturais que representam a ocorrência do processo evolutivo.

Classicamente, populações geograficamente circunscritas e geneticamente diferenciadas são tratadas como raças ou subespécies (Smith et al., 1997), embora a estruturação populacional humana observada em uma série de traços fenotípicos e polimorfismos gênicos possa levar à conclusão de que, virtualmente, toda população possa ser distinguida de uma outra (Templeton, 1999). Esse raciocínio leva à ideia de populações locais como sendo as únicas entidades evolutivas supraindividuais, em detrimento dos agrupamentos e associações realizados de acordo com critérios geográficos por exemplo.

Os resultados apresentados corroboram, ao menos parcialmente, essa afirmação pois, apesar da aparente estase evolutiva na diversificação da morfologia craniana humana, ao menos dois grandes padrões morfológicos no planeta, emergiram das análises. Vale ressaltar que devido à abrangência do conceito de população, informações adicionais sobre a história evolutiva das populações, como cronologias e filiações linguísticas, por exemplo, podem ser incorporadas às definições e delimitações de um grupo. Bernardo e colaboradores (2011) demonstraram essa propriedade empiricamente, solucionando as afinidades morfológicas de populações sul-americanas após utilizar informações sobre antiguidade (cronologia) e filiação cultural (troncos linguísticos) para o estabelecimento e configuração das populações em estudo.

Voltando ao tema central deste trabalho, para a investigação dos padrões de modularidade, integração e covariância da morfologia craniana humana alguns resultados obtidos são de especial importância. Destaque entre esses resultados deve ser dado à expressiva quantidade de correlações estatisticamente significativas obtidas entre os dois tipos de interações investigadas, as correlações entre matrizes $\mathrm{M}$ e $\mathrm{C}$, e entre $\mathrm{M}$ e $\mathrm{V} / \mathrm{CV}$. Respectivamente, os coeficientes de correlação de Pearson considerados significativos para as 
duas interações foram 161 e 131, numericamente expressivos uma vez que o critério utilizado para a aceitação de significância após o teste de Mantel (1967) foi de p $\leq 0,025$.

A análise da interação entre as matrizes $\mathrm{C}$ e $\mathrm{M}$ indicou a face como o módulo desenvolvimental com maior integração de caracteres, com destaque à sub porção oral no nível funcional. As figuras relativas à esses resultados indicam as regiões de ocorrência desses módulos. Isso significa que em termos morfocranianos a face, com ênfase na região oral, evolui como um complexo unitário, com todos os seus traços interagindo harmonicamente, entre as populações humanas estudadas. Assim, seguindo o raciocínio exposto ao longo da introdução deste trabalho, esses resultados sugerem que a face, compreendendo a região oral, tem seus diferentes traços morfológicos coordenados pelos mesmos complexos gênicos e, devido à detecção de correlações significativas em todas as interações populacionais testadas, pode-se supor que todas as populações apresentam esses mesmos complexos.

Os resultados obtidos despertam, também, a atenção para dois outros módulos: o neurocrânio (nível desenvolvimental) e o basicrânio (nível funcional). Ambos não obtiveram correlações significativas para as populações estudadas, o que levanta questionamentos sobre o significado biológico deste fenômeno. Duas possíveis explicações emergem imediatamente desta situação: i) deficiência de acuidade dos módulos representados nas respectivas matrizes M; ii) absoluta ausência de integração nestes módulos. Ambas as possibilidades deverão ser melhor investigadas, através de novos métodos de análise e detecção de modularidade e integração (Pucciarelli et al., 2006, Goswami \& Polly, 2010) e da inclusão de um maior número de populações em estudo. Uma análise que deverá emergir dessa questão é a busca por novas propostas modulares, uma vez que as utilizadas neste trabalho foram as classicamente utilizadas por Marroig \& Cheverud (2001) e González-José et al. (2004).

Depreendeu-se, também, que é difícil estabelecer uma tendência central às distribuições dos coeficientes de correlação para cada módulo morfocraniano humano. Isso sugere que, entre as populações estudadas, e considerando-se os módulos selecionados, há 
pouca, ou quase nenhuma, coesão modular indicando que, embora presentes, os módulos apresentam-se pouco integrados entre si. Tal nível de integração, de acordo com Porto e colegas (2009) está relacionado à magnitude de integração morfológica, e pode ser mensurado pelo coeficiente de determinação modular.

De acordo com Oliveira e colaboradores (2009), o nível geral de correlação, medido pelo coeficiente de determinação, varia, entre os Catarrhini (incluindo aí humanos modernos) entre 0,04 e 0,28, com uma média de 0,12. Valores semelhantes são obtidos para as amostras analisadas, variando de 0,14 a 0,32, assumindo o valor 0,23 para quando todos os indivíduos foram analisados conjuntamente. Tais valores indicam que os coeficientes obtidos para as matrizes de populações humanas pouco diferem daqueles obtidos para outros grupos da ordem59 Catarrhini. Evolutivamente essa semelhança pode indicar um relativo estado de estase evolutiva entre essa categoria de mamíferos, embora a magnitude desses coeficientes ainda necessitem de uma investigação mais verticalizada.

As análises realizadas sobre as interações entre as matrizes $\mathrm{M}$ e as matrizes $\mathrm{V} / \mathrm{CV}$ seguiram as mesmas estratégias adotadas para as comparações entre $\mathrm{M}$ e C. As maiores quantidades de correlações significativas obtidas entre essas interações ocorreu para os módulos neurocraniano e facial, no nível desenvolvimental, e para o módulo oral, no nível funcional. Isso quer dizer que face e neurocrânio covariam na morfologia craniana das populações analisadas, isto é, quando um desses módulos apresenta mudanças ou outro também muda.

A análise da distribuição dos coeficientes de correlação obtidos entre $\mathrm{M} \mathrm{e} \mathrm{V/CV} \mathrm{indica}$ que, excetuando-se a curva representativa do módulo zigomático-temporal (linha vermelha), todas as outras apresentam-se de maneira bastante semelhante, com medidas de tendência central (média) praticamente sobrepostas, entre 0,2 e 0,25. Esses resultados favorecem a interpretação de que, de maneira geral, os módulos cranianos evoluem conjuntamente,

\footnotetext{
${ }^{59}$ Segundo Groves (2005), a posição taxonômica atualmente aceita para o grupo Catarrhine é a Parvordem (Parvordem Catarrhine). Juntamente com Infraordem, Parvordem é uma posição taxonômica entre Ordem e Família (Sibley et al., 1988).
} 
modelando o formato do crânio de maneira integrada. González-José e colaboradores, utilizando parcialmente o mesmo banco de dados e aplicando técnicas analíticas cooptadas de Marroig \& Cheverud (2001) e Ackermann (2002), chegou a resultados bastante semelhantes aos aqui apresentados.

Finalmente, de maneira análoga à que foi executada para os coeficientes obtidos das comparações entre $\mathrm{M}$ e $\mathrm{C}$, foram calculadas as médias das matrizes de $\mathrm{V} / \mathrm{CV}$ de cada uma das populações em estudo e da metapopulação agregando todos os indivíduos da análise. Nota-se que em termos de $\mathrm{V} / \mathrm{CV}$ nenhuma população supera o valor obtido quando toda a amostra é considerada como uma única população. Isso indica que, como um todo, a humanidade é mais variável do que quando considerada em partes, ou populações isoladas. Embora esse resultado seja favorável ao que pode ser intuído a partir da simples visualização das populações humanas, ele pode ser considerado contrário aos trabalhos que preconizam o nível intrapopulacional como o grande detentor da variabilidade morfocraniana humana (Relethford \& Blangero, 1990; Relethford, 1994, 2002).

Ao contrário do que se esperava a partir da contextualização teórica dos conceitos de módulo, integração e padrão de covariância da morfologia craniana humana, a inferência histórico-populacional das séries amostradas não ocorreu de maneira exitosa a partir das análises propostas e realizadas.

Ainda em relação aos resultados inesperados das análises aqui desempenhadas, é impossível não citar o desacordo observado entre distâncias geográficas e duas categorias, ou métricas, do grau de diversificação morfocraniana humana. A implicação direta desse desacordo reside na dificuldade em se atribuir associações e agrupamentos populacionais sem que seja adotado um critério ad hoc. Como as interações entre diferentes níveis hierárquicos são imprescindíveis para diferentes análises de evolucionabilidade (Ackermann, 2002, 2005; Oliveira, 2009), tal ponto de conflito também parece não ter solução, ao menos 
imediata, uma vez que as relações geográficas são as mais comumente utilizadas como estimadores ou "proxy" de histórias evolutivas.

Em relação à investigação dos padrões de evolucionabilidade abordados, três são os pontos que merecem algum destaque: i) o padrão de correlação entre os módulos cranianos; ii) o padrão de variância/covariância entre os módulos cranianos; iii) a interação entre esses padrões.

Os resultados aqui obtidos e discutidos permitem sugerir que com exceção do neurocrânio (desenvolvimental) e do basicrânio (funcional) todos os outros módulos analisados mostram-se coesos entre si, apresentando maior ou menor grau de correlação entre os caracteres presentes dentro de cada módulo. Já do ponto de vista integrativo, a face, com destaque para a região, ou módulo, oral, mostrou-se a região anatômica mais conservada e integrada da morfologia craniana humana.

O padrão de Variância/Covariância observado através dos resultados gerados indica que, de maneira geral, a morfologia craniana, independentemente do grau de modularidade e integração apresentado pelas diferentes regiões anatômicas do crânio descreve um padrão unitário, sugerindo que o crânio humano responde às pressões que resultam em alterações morfológicas de maneira coesa e integral, isto é, o crânio, do ponto de vista da variação e covariação dos caracteres, funciona, ou evolui, com todas as características agindo conjuntamente.

A interação entre essas duas características da morfologia craniana humana, o padrão de Correlação e o de Variância/Covariância, permite a proposta de um modelo geral explanatório para os mecanismos de mudanças morfológicas do crânio. Admitindo a forte correlação observada no módulo facial, é razoável supor que esse módulo seja o mais conservado do ponto de vista evolutivo e também o que mais sofre ações de mecanismos evolutivos. Assim, por apresentar maior correlação entre suas diferentes características morfológicas, a face responde mais prontamente às mudanças morfológicas. 
Em contrapartida, quando analisados sob o ponto de vista do padrão de variância/covariância entre os módulos cranianos, pode-se sugerir que todos, incluindo aí o módulo facial e seus componentes, apresentam alto grau de covariância, o que significa que quando um módulo, ou uma área, sofre mudanças os outros módulos ou regiões também as sofrem, com maior ou menor intensidade, dependendo da amplitude da covariação entre elas. Assim, é possível sustentar a ideia de que quando o módulo da face sofre uma pressão que resulte em alteração de sua morfologia, os outros módulos cranianos acompanham essas alterações, remodelando o formato do crânio como um todo (com exceção de alguns módulos, como já discutido ao longo do texto).

A observação do papel desempenhado pela integração da face nos processos de diversificação entre hominoides (Ackermann, 2005), entre H. neanderthalensis e $H$. sapiens (Roseman et al., 2011) e entre os humanos modernos (Roseman, 2004), favorece esta interpretação. Essa relação entre o módulo facial e os outros módulos cranianos deverá ser intensivamente explorada, com técnicas analíticas mais precisas, bancos de dados melhor estruturados e testes de hipóteses mais específicas, para a discussão dos padrões de evolucionabilidade e possibilidades (restrições) fenotípicas. 



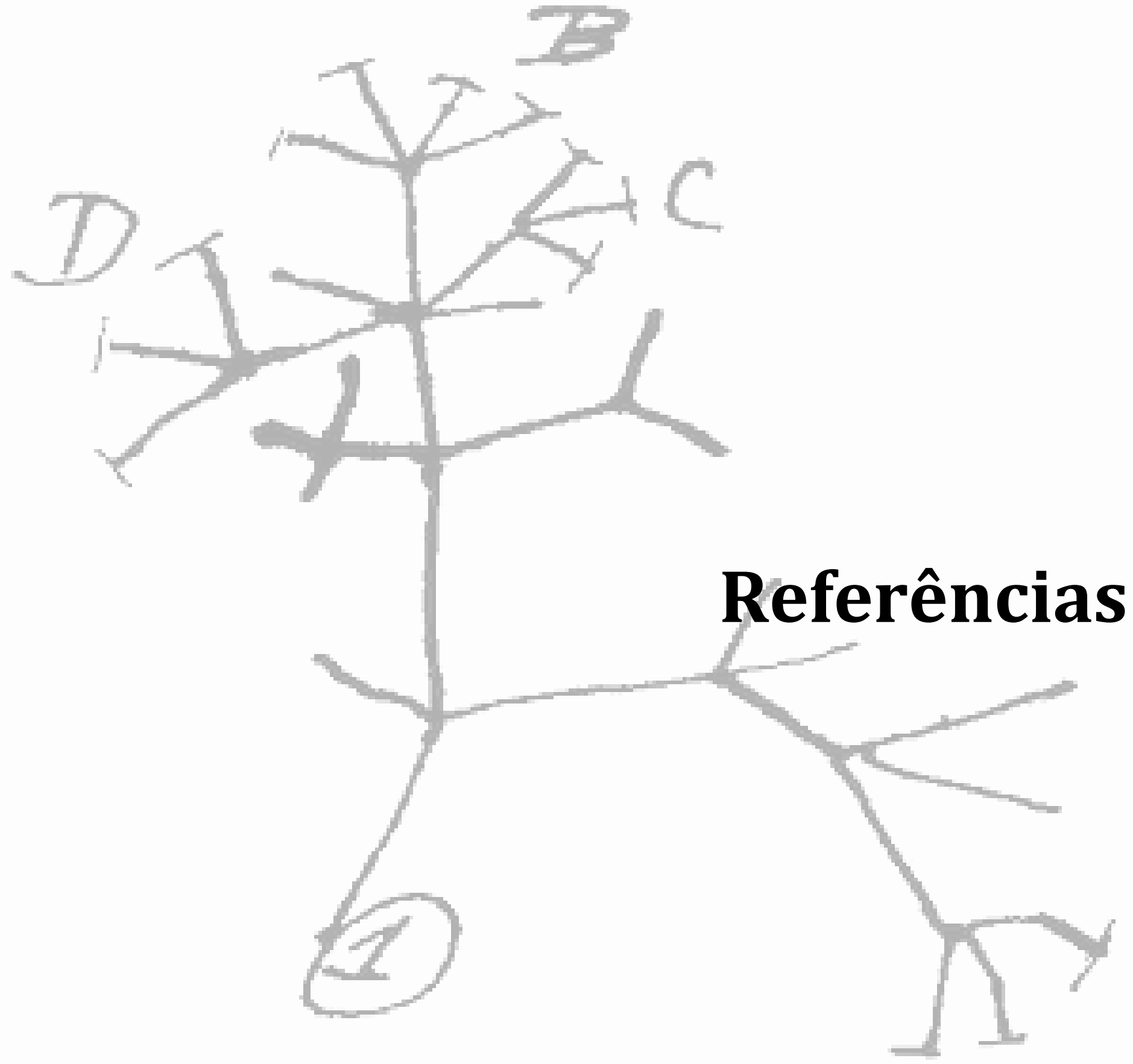



Ackermann, R. R. (2002). Patterns of covariation in the hominoid craniofacial skeleton: implications for paleoanthropological models. Journal of Human Evolution, 42: 167-187.

Ackermann, R. R. (2005). Ontogenetic integration of the hominoid face. Journal of Human Evolution, 48: 175-197.

Águilla, F. J., Águilla, G. (1993). Atlas de cefalometria. São Paulo: Pancast.

Almeida, T. F. (2011). Análise da dispersão das populações nativas americanas: uma abordagem genético-fisiográfica. Dissertação de Mestrado. Instituto de Biociências, Universidade de São Paulo.

AMNH. (2011). American Museum of Natural History Database. Disponível em <http://anthro.amnh.org/research>, acessado no período entre 09/08/2011 e 09/02/2012.

Amorim, D. S. (2002). Fundamentos de Sistemática Filogenética. Ribeirão Preto: Holos Editora.

Andaman \& Nicobar Emerald Islands. (2011). History - The British Regime. Disponível em <http://tourism.andaman.nic.in/welcome.html>, acessado em 17/08/2011.

Arias, M. C., Francisco, F. de O., Silvestre, D. (2003). O DNA mitocondrial em estudos populacionais e evolutivos de meliponíneos. In: Melo, G. A. R., Alves-dos-Santos, I (ed.). Apoidea Neotropica: Homenagem aos 90 anos de Jesus Santiago Moure. Criciúma: Editora UNESC, 305-309.

Arnaiz-Villena, A., Parga-Lozano, C., Moreno, E., Areces, C., Rey, D., Gomez-Prieto, P. (2010). The Origin of Amerindians and the Peopling of the Americas According to HLA Genes: Admixture with Asian and Pacific People. Current Genomics, 11: 103-114.

Arthur, W. (1984). Mechanisms of Morphological Evolution: A combined genetic, developmental and ecological approach. 1st edition. Chichester: John Wiley \& Sons.

Arthur, W. (2001). Developmental drive: An important determinant of the direction of phenotypic evolution. Evolution and Development, 3: 271-278.

Atuí, J. P. V. (2005). Morfologia craniana de ameríndios brasileiros recentes e suas implicações para a questão da ocupação do Novo Mundo: uma análise exploratória. Dissertação de Mestrado. Instituto de Biociências, Universidade de São Paulo.

Ballard, J. W., Kreitman, M. (1995). Is mitochondrial DNA a strictly neutral marker? TRENDS in Ecology \& Evolution, 10(12): 485-488.

Barbujani, G. (2007). A invenção das raças. São Paulo: Editora Contexto.

Barbujani, G., Magagni, A., Minch, E., Cavalli-Sforza, L. L. (1997). An apportionment of human DNA diversity. Proceedings of the National Academy of Sciences of the USA, 94: 4516-4519.

Bar-Yosef, O. (2011). Climatic Fluctuations and Early Farming in West and East Asia. Current Anthropology, 54(Supplement 4): 175-193.

Bass, W. M. (1987). Human osteology: a laboratory and field manual. 3rd edition. Columbia: Missouri Archaeological Society.

Beals, K. L. (1972). Head form and climatic stress. American Journal of Physical Anthropology, 37: 85.

Beals, K. L., Smith, C. L., Dodd, S. M. (1984). Brain Size, Cranial Morphology, Climate, and Time Machines. Current Anthropology, 25(3): 301-330. 
Beaumont, M. (2005). Adaptation and speciation: what can FST tell us? TRENDS in Ecology and Evolution, 20(8): 435-440.

Beerli, P., Edwards, S. V. (2002). When Did Neanderthals and Modern Humans Diverge? Evolutionary Anthropology, Suppl 1: 60-63.

Beiguelman, B. (1995). Dinâmica dos Genes nas Famílias e nas Populações. 2a edição. Ribeirão Preto: Sociedade Brasileira de Genética.

Beldade, P., Koops, K, Brakefield, P. M. (2002) Developmental constraints versus flexibility in morphological evolution. Nature, 416: 844-847.

Belwood, P. (2011). Holocene Population History in the Pacific Region as a Model for Worldwide Food Producer Dispersals. Current Anthropology, 54(Supplement 4): 363-378.

Bennington, J. B., Bambach, R. K. (1996). Statistical testing for paleocommunity recurrence: Are similar fossil assemblages ever the same? Palaeogeography, Palaeoclimatology, Palaeoecology, 127: 107-133.

Berg, R. L. (1960). The ecological significance of correlation pleiades. Evolution, 14: 171-180.

Bernardo, D. V. (2007). Afinidades morfológicas intra e extra-continentais dos Paleoíndios de Lagoa Santa: Uma nova abordagem. Dissertação de Mestrado. Instituto de Biociências, Universidade de São Paulo.

Bernardo, D. V., Almeida, T. F., Neves, W. A., Hanihara, T. (2009). Global human population structuring seen from craniometric data. 78th Annual Meeting of the American Association of Physical Anthropologists. March, 31 - April, 4 2009, Chicago, Illinois.

Bernardo, D. V., Neves, W. A. (2009). Diversidade morfocraniana dos remanescente ósseos humanos da Serra da Capivara: implicações para a origem do homem americano. Fumdhamentos, 8: 94-106.

Bernardo, D. V., Strauss, A., Neves, W. A., Okumura, M. (2011). Measuring skulls: Getting into the biological realm of the settlement of the New World. In: Vialou, D. (ed). Peuplements et préhistoire en Amériques. Paris: Comité des travaux historiques et scientifiques, 31-41.

Berry, A., Berry, R. J. (1967). Epigenetic variation in the human cranium. Journal of Anatomy, 101(2): 361-379.

Betti, L., Balloux, F., Amos, W., Hanihara, T. \& Manica, A. L. (2009). Distance from Africa, not climate, explains whitin-population phenotypic diversity in humans. Proc $R$ Soc $B, 276$ : 809-814.

Betti, L., Balloux, F., Hanihara, T. \& Manica, A. (2010). The relative role of drift and selection in shaping the human skull. American Journal of Physical Anthropology, 141(1): 76-82.

Biddle, M., Kjølbye-Biddle, B. (1992). Repton and the Vikings. Antiquity, 66: 36-51.

Bolnick, D. A. W., Smith, D. G. (2003). Unexpected patterns of mitochondrial DNA variation among Native Americans from the Southeastern United States. American Journal of Physical Anthropology, 122: 336-354.

Bonatto, S. L., Salzano, F. M. (1997a). A single and early migration for the peopling of the Americas supported by mitochondrial DNA sequence data. Proceedings of the National Academy of Sciences of the USA, 94: 1866-1871. 
Bonatto, S. L., Salzano, F. M. (1997b). Diversity and Age of the Four Major mtDNA Haplogroups, and Their Implications for the Peopling of the New World. American Journal of Human Genetics, 61: 1413-1423.

Boucher, B. J. (1955). Sex differences in the fetal sciatic notch. Journal of Forensic Medicine, 2(1): 5154.

Boucher, B. J. (1957). Sex differences in the fetal pelvis. American Journal of Physical Anthropology, 15(4): 581-600.

Bowler, P. J. (2005). Variation from Darwin to the Modern Synthesis. in: Hallgrímsson, B., Hall, B. K. (editors). Variation: A Central Concept in Biology. 1st edition. New York: Academic Press, 9-27.

Brace, C. L., Nelson, A. R., Seguchi, N., Oe, H., Sering, L., Qifeng, P., Yongyi, L., Tumen, D. (2001). Old World souce of the first New World human inhabitants: a comparative craniofacial view. Proceedings of the National Academy of Sciences of the USA, 98(17): 10017-10022.

Bradley, B. J. (2008). Reconstructing phylogenies and phenotypes: a molecular view of human evolution. J. Anat., 212: 337-353.

Bräuer, G. (1988). Osteometrie. In: Knußmann, R. (editor). Anthropologie. Handbuch der vergleichenden Biologie des Menschen. Stuttgart: Gustav Fischer, 160-232.

Broca, P. (1875). Instructions craniologiques et craniométriques. Mem de la Soc d'Anthrop de Paris, 2: $1-203$

Brockmeier, L. L., Kromrey, J. D., Hogarty, K. Y. (2003). Nonrandomly Missing Data in Multiple Regression Analysis: An Empirical Comparison of Ten Missing Data Treatments. Multiple Linear Regression Viewpoints, 29(1): 8-29.

Brown, M. D., Hosseini, S. H., Torroni, A., Bandelt, H., Allen, J. C., Schurr, T. G., Scozzari, R., Cruciani, F., Wallace, D. C. (1998). mtDNA haplogroup X: an ancient link between Europe, Western Asia and North America? American Journal of Human Genetics, 63: 1852-1861.

Bruzek, J. (2002). A Method for Visual Determination of Sex, Using the Human Hip Bone. American Journal of Physical Anthropology, 117: 157-168.

Buxton, L. H. D., Morant, G. M. (1933). The essential craniological technique. J Roy Anthrop Inst, 63: 19-47.

Callegari-Jacques, S. M. (2003). Bioestatística-princípios e aplicações. Porto Alegre: Artmed.

Cann, R. L. (2001). Genetic Clues to Dispersal in Human Populations: Retracing the Past from the Present. Science, 291: 1742-1748.

Cann, R. L., Stoneking, M., Wilson, A. C. (1987). Mitochondrial DNA and human evolution. Nature, 325: 31-36.

Carroll, S. B. (1995). Homeotic genes and the evolution of the chordates. Nature, 376: 479-485.

Carroll, S. B. (2001). The big picture. Nature, 409: 669.

Carroll, S. B. (2008). Evo-Devo and an Expanding Evolutionary Synthesis: A Genetic Theory of Morphological Evolution. Cell, 134: 25-36. 
Carson, E. A. (2006). Maximum Likelihood Estimation of Human Craniometric Heritabilities. American Journal of Physical Anthropology, 131: 169-180.

Cavalli-Sforza, L. L., Menozzi, P., Piazza, A. (1994). The History and Geography of Human Genes. Princeton: Princeton University Press.

Cheverud, J. M. (1982). Phenotypic, genetic, and environmental morphological integration in the cranium. Evolution, 36: 499-516.

Cheverud, J. M. (1984). Quantitative genetics and developmental constraints on evolution by selection. Journal of Theoretical Biology, 110: 155-171.

Cheverud, J. M. (1988). A comparison of genetic and phenotypic correlations. Evolution, 42: 958-968.

Cheverud, J. M. (1996a). Developmental Integration and the Evolution of Pleiotropy. American Zoologist, 36: 44-50.

Cheverud, J. M. (1996b). Quantitative genetic analysis of cranial morphology in the cotton-top (Saguinus oedipus) and saddle-back (S. fuscicollis) tamarins. Journal of Evolutionary Biology, 9: 5-42.

Cheverud, J. M., Dow, M. M., Leutenegger, W. (1985). The quantitative assessment of phylogenetic constraints in comparative analyses: sexual dimorphism in body weight among primates. Evolution, 39: 1335-1351.

Cheverud, J. M., Marroig, G. (2007). Comparing covariance matrices: random skewers method compared to the common principal components model. Genetics and Molecular Biology, 30(2): 461-469.

Clark, J. D., Dunn, J. E., Smith, K. G. (1993). A multivariate model of female black bear habitat use for a geographic information system. Journal of Wildlife Management, 57(3): 519-526.

Cockerham, C. C., Weir, B. S. (1984). Covariances of relatives stemming from a population undergoing mixed self and random mating. Biometrics, 40: 157-164.

Cohen, D. J. (2011). The Beginnings of Agriculture in China. Current Anthropology, 54(Supplement 4): 273-293.

Cohen, M. N., Wood J. W., Milner, G. R. (1994). The Osteological Paradox Reconsidered. Current Anthropology, 35(5): 629-637.

Collis, D. R. F. (editor). (1990). Arctic Languages. Paris: United Nations Educational, Scientific and Cultural Organization.

Coltrain, J. B., Hayes, M. G., O'Rourke, D. H. (2006). Current Anthropology, 47(3): 537-548.

Comrie, B., Matthews, S., Polinsky, M. (1996). O Atlas das Línguas. Lisboa: Editorial Estampa.

Corruccini, R. S. (1973). Size and shape in similarity coefficients based on metric characters. American Journal of Physical Anthropology, 38: 743-754.

Cowal, L. S., Pastor, R. F. (2008). Dimensional variation in the proximal ulna: evaluation of a metric method for sex assessment. American Journal of Physical Anthropology, 135: 469-478.

Darroch, J. N., Mosimann, J. E. (1985). Canonical and principal components of shape. Biometrika, 72: 241-252. 
Darwin, C. R. (1859). On the origin of species by means of natural selection or the preservation of favoured races in the struggle for life. The 150th anniversary landmark edition. Londres: Penguin Books.

Dawkins, R. (1976). The Selfish Gene. Oxford: Oxford University Press.

Dayal, M. R. Spocter, M. A., Bidmos, M. A. (2007). An assessment of sex using the skull of black South Africans by discriminant function analysis. Homo- Journal of Comparative Human Biology, 59(3): 209-221.

de Queiroz, K., Good, D. A. (1997). Phenetic Clustering in Biology: A Critique. The Quarterly Review of Biology, 72(1): 3-30.

Deberneva, O. A., Sukernik, R. I., Volodko, N. V., Hoseini, S. H., Lott, M. T., Wallace, D. C. (2002). Analysis of mitochondrial DNA diversity in the Aleuts of the Commander Islands and its implications for the genetic history of Beringia. American Journal of Human Genetics, 71(2): 415-421.

Devor, E. J. (1987). Transmission of human craniofacial dimensions. J Craniofac Genet Dev Biol, 7: 95106.

Diniz Filho, J. A. F. (2002). Métodos filogenéticos comparativos. Ribeirão Preto: Holos Editora.

DIVA-GIS (2005). Geographic information system grom biodiversity research. version 7.1.7. http://www.diva-gis.org.

Dobzhansky, T. (1937). Genetics and the Origin of Species. New York: Columbia University Press.

Dobzhansky, T. (1956). What is an adaptative trait. American Naturalist, 90: 337-347.

Donner, A. (1982). The Relative Effectiveness of Procedures Commonly Used in Multiple Regression Analysis for Dealing with Missing Values. The American Statistician, 36(4): 378-381.

Drake, L. M. Archaeological survey of seventeen abandoned mines near Bonito Lake, Lincoln County, New Mexico. Archaeology Notes No. 42. Santa Fé: Museum of New Mexico, Office of Archaeological Studies.

Duarte Junior, D. (2008). Matrizes e sistemas algébricos em engenharia. 1a edição. Rio de Janeiro: Editora Ciência Moderna.

East, E. M. (1916). Inheritance in crosses between Nicotiana langsdorffii and Nicotiana alata. Genetics, 1: 311-333.

Esri, Environmental Systems Research Institute. (1992). ArcView@ GIS. version 3.2.

Eswaran, V., Harpending, H. \& Rogers, A. R. (2005). Genomics refutes an exclusively African origin of humans. Journal of Human Evolution, 49: 1-18.

Excoffier, L. (1990). Evolution of human mitochondrial DNA: Evidence for departure from a pure neutral model of populations at equilibrium. Journal of Molecular Evolution, 30(2): 125-139.

Excoffier, L., Laval, G., Schneider, S. (2005). Arlequin (version 3.0): An integrated software package for population genetics data analysis. Evolutionary Bioinformatics Online, 1: 47-50.

Falconer, D. S., Mackay, T. F. C. (1996). Introduction to Quantitative Genetics. 4th edition. Harlow: Pearson Education Limited. 
Felsenstein, J. (1985). Phylogenies and the comparative method. American Naturalist, 125: 1-15.

Fowler, K. \& Whitlock, M. C. (1999). The variance in inbreeding depression and the recovery of fitness in bottlenecked populations. Proc. R. Soc. Ser, 266: 2061-2066.

Frankham, R. (1999). Quantitative genetics in conservation biology. Genetic Research, 74: 237-244.

Frayer, D. W., Wolpoff, M. H. (1985). Sexual Dimorphism. Annual Review of Anthropology, 14: 429473.

Freeman, S., Herron, J. C. (2009). Análise Evolutiva. 4a edição. Porto Alegre: Artmed.

Futuyma, D. J. (1998). Biologia Evolutiva. 3a edição. Ribeirão Preto: Funpec Editora.

Gillespie, J. H. (2004). Population genetics - a concise guide. 2nd edition. Baltimore: The Johns Hopkins University Press.

Glazier, A. M., Nadeau, J. H., Aitman, T. J. (2002). Finding genes that underlie complex traits. Science, 298: 2345-2349.

González-José, R., Abadías, N. M., Martín, A. G., Neves, W., Pucciarelli, H. M., Hernández, M. (2006). Análisis morfogeométrico de cuatro cráneos antiguos del valle de México: Peñón III, Metro Balderas, Chimalhuacán y Cueva del Tecolote. Cuicuilco, 37(13): 105-127.

González-José, R., Van der Molen, S., González-Pérez, E., Hernández, M. (2004). Patterns of Phenotypic Covariation and Correlation in Modern Humans as Viewed From Morphological Integration. American Journal of Physical Anthropology, 123: 69-77.

Google Inc. (2011). Google earth version 6.1.0.5001.

Goring-Morris, A. N., Belfer-Cohen, A. (2011). Neolithization Processes in the Levant. Current Anthropology, 54(Supplement 4): 195-208.

Gottlieb, L. D. (1984). Genetics and morphological evolution in plants. The American Naturalist, 123(5): 681-709.

Gould, S. J. \& Eldredge, N. (1993). Punctuated equilibrium comes of age. Nature, 366: 223-227.

Gould, S. J. (1989). A developmental constraint in Cerion, with comments on the definition and interpretation of constraint in evolution. Evolution, 43: 516-539.

Gould, S. J., Lewontin, R. C. (1979). The spandrels of San Marco and the Panglossian paradigm: A critique of the adaptationist programme. Proceedings of the Royal Society of London, 205(B): 581598.

Gould, S. J., Vrba, E. S. (1982). Exaptation - A Missing Term in the Science of Form. Paleobiology, 8(1): 4-15.

Green, R. E., Krause, J., Briggs, A. W., Maricic, T., Stenzel, U., Kircher, M., Patterson. N., Li, H., Zhai, W., Fritz, M. H., Hansen, N. F., Durand, E. Y., Malaspinas, A., Jensen, J. D., Marques-Bonet, T., Alkan, C., Prüfer, K., Meyer, M., Burbano, H. A., Good, J. M., Schultz, R., Ayinuer, A., Butthof, A., Höber, B., Höffner, B., Siegemund, M., Weihmann, A, Nusbaum, C., Lander, E. S., Russ, C., Novod, N., Affourtit, J., Egholm, M., Verna, C., Rudan, P., Brajkovic, D., Kucan, Z., Gušic, I., Doronichev, V. B., Golovanova, L. V., Lalueza-Fox, C., de la Rasilla, M., Fortea, J., Rosas, A., Schmitz, R. W., Johnson, P. L. F., Eichler, E. E., Falush, D., Birney, E., Mullikin, J. C., Slatkin, M., Nielsen, R., Kelso, J., Lachmann, M., Reich, D., Pääbo, S. (2010). A Draft Sequence of the Neandertal Genome. Science, 328: 710-722. 
Grine, F. E., Bailey, R. M., Harvati, K., Nathan, R. P., Morris, A. G., Henderson, G. M., Ribot, I., Pike, A. W. G. (2007). Late Pleistocene human skull from Hofmeyr, South Africa, and modern human origins. Science, 315: 226-229.

Guglielmo-Matessi, C. R., Gluckman, P., Cavalli-Sforza, L. L. (1979). Climate and the evolution of skull metrics in man. American Journal of Physical Anthropology, 50: 549-564.

Hallgrímsson, B., Brown, J. J. Y., Hall, B. K. (2005). The Study of Phenotypic Variability: An Emerging Research Agenda for Understanding the Developmental-Genetic Architecture Underlying Phenotypic Variation. in: Hallgrímsson, B., Hall, B. K. (editors). Variation: A Central Concept in Biology. 1st edition. New York: Academic Press, 525-551.

Hallgrímsson, B., Hall, B. K. (2005). Variation and Variability: Central Concepts in Biology. in: Hallgrímsson, B., Hall, B. K. (editors). Variation: A Central Concept in Biology. 1st edition. New York: Academic Press, 1-7.

Hallgrímsson, B., Lieberman, D. E., Liu, W., Ford-Hutchinson, A. F., Jirik, F. R. (2007). Epigenetic interactions and the structure of phenotypic variation in the cranium. Evolution \& Development, 9(1): 76-91.

Handley, L. J., Manica, A., Goudet, J., Balloux, F. (2007). Going the distance: human population genetics in a clinal world. TRENDS Genetics, 23: 432-439.

Hanihara, T. (1993a). Population prehistory of East Asia and the Pacific as viewed from craniofacial morphology: The basic populations in East Asia, VII. American Journal of Physical Anthropology, 91: 173-187.

Hanihara, T. (1993b). Craniofacial features of Southeast Asians and Jomonese: A reconsideration of their microevolution since the late Pleistocene. Anthropological Science, 101: 25-46.

Hanihara, T. (1996). Comparison of Craniofacial Features of Major Human Groups. American Journal of Physical Anthropology, 99: 389-412.

Hanihara, T. (2000). Frontal and facial flatness of major human populations. American Journal of Physical Anthropology, 111: 105-134.

Hanihara, T. (2008). Morphological variation of major human populations based on nonmetric populations based on nonmetric dental traits. American Journal of Physical Anthropology, 136: 169182.

Hanihara, T., Dodo, Y., Kondo, O., Nara, T., Doi, N., Sensui, N. (1999). Intra and interobserver errors in facial flatness measurements. Anthropological Science, 107: 25-39.

Hanihara, T., Ishida, H. (1995). Evolutionary significance of facial flatness in Australian Aborigines and neighbouring populations. Perspectives in Human Biology, 1: 85-98.

Hansen, T. F. (2003). Is modularity necessary for evolvability? Remarks on the relationship between pleiotropy and evolvability. BioSystems, 69(2-3): 83-94.

Hansen, T. F., Houle, D. (2008). Measuring and comparing evolvability and constraint in multivariate characters. Journal of Evolutionary Biology, 21(5): 1201-1219.

Harrington, J. (1996). The Lime-Burning Industry in Victoria: An Occupance Approach. Australasian Historical Archaeology, 14: 19-24.

Hartl, D. L. (2008). Princípios de Genética de População. 3a edição. São Paulo: Funpec-Editora. 
Hartl, D. L., Clark, A. G. (2010). Princípios de Genética de Populações. 4a edição. Porto Alegre: Artmed.

Harvati, K., Weaver, T. D. (2006). Human Cranial Anatomy and the Differential Preservation of Population History and Climate Signatures. The Anatomical Record, 288A: 1225-1233.

Hawks, J., Hunley, K., Lee, S., Wolpoff, M. (2000). Population bottlenecks and Pleistocene human evolution. Mol. Biol. Evol., 17(1): 2-22.

Hennig, W. (1965). Phylogenetic Systematics. Annu. Rev. Entomol, 10: 97-116.

Hennig, W. (1966). Phylogenetic Systematics. Urbana: University of Illinois Press.

Hey, J. (1997). Mitochondrial and Nuclear Genes Present Conflicting Portraits of Human Origins. Mol. Biol. Evol., 14(2): 166-172.

Heywood, V. H., McNeill, J. (1964). Phenetic and phylogenetic classification. Nature, 203: 1220-1224.

Hijmans, R. J., Guarino, L., Jarvis, A., O'Brien, R., Mathur, P., Bussink, C., Cruz, M., Barrantes, I., Rojas, E. (2005). Diva-Gis software. Disponível em <http://www.diva-gis.org>, acessado em: 08/02/2011.

Hill, W. G. (1996). Sewall Wright's Systems of Mating. Genetics, 143: 1499-1506.

Hiscock, P. (2008). Archaeology of Ancient Australia. New York: Routledge.

Horai, S., Muruyama, K., Hayasaka, K., Matsubayashi, S., Hattori, Y., Fucharoen, G., Harihara, S., Park, K. S., Omoto, K., Pan, I. (1996). mtDNA Polymorphism in East Asian Populations, with Special Reference to the Peopling of Japan. American Journal of Human Genetics, 59: 579-590.

Howells, W. W. (1973). Cranial variation in man. A study by multivariate analysis of patterns of difference among recent human populations. Papers of Peabody Museum of Archaeology and Ethnology. Cambridge: Harvard University Press.

Howells, W. W. (1989). Skull shapes and the map. Craniometric analysis in the dispersion of modern Homo. Papers of Peabody Museum of Archaeology and Ethnology. Cambridge: Harvard University Press.

Howells, W. W. (1995). Who's who in skulls. Papers of Peabody Museum of Archaeology and Ethnology, vol. 82. Cambridge: Harvard University Press.

Howells, W. W. (1996). Howells' Craniometric Data on the Internet. American Journal of Physical Anthropology, 101: 441-442.

Hubbe, M., Hanihara, T., Harvati, K. (2009). Climate Signatures in the Morphological Differentiation of Worldwide Modern Human Population. The Anatomical Record, 292: 1720-1733.

Hubbe, M., Oviedo, M., Torres-Rouff, C. (2011). Estado de conservación y contextualización cronológica de la colección osteológica Gustavo Le Paige. Estudios Atacameños, 41: 29-44.

Hull, D. (1970). Contemporary systematic philosophies. Ann. Rev. Ecol. Syst., 1: 19-54.

Hünemeier, T., Gómez-Valdés, J., Ballesteros-Romero, M., de Azevedo, S., Martínez-Abadías, N., Esparza, M., Sjøvold, T., Bonatto, S. L., Salzano, F. M., Bortolini, M. C., González-José, R. (2012). Cultural diversification promotes rapid phenotypic evolution in Xavánte Indians. Proceedings of the National Academy of Sciences of the USA, 109(1): 73-77. 
Hunley, K. L., Cabana, G. S., Merriwether, D. A., Long, J. C. (2007). A Formal Test of Linguistic and Genetic Coevolution in Native Central and South America. American Journal of Physical Anthropology, 132: DOI 10.1002/ajpa.20542.

Hunley, K., Long, J. C. (2005). Gene flow across linguistic boundaries in Native American populations. Proceedings of the National Academy of Sciences of the USA, 102: 1312-1317.

Inglez, M. (2010). Avaliação de métodos métricos e não-métricos para a assignação de sexo em esqueletos humanos. Trabalho de Conclusão de Curso. Universidade Presbeteriana Mackenzie.

Jeffreys, A. J., Wilson, V., Thein, S. L. (1985). Hypervariable 'minisatelite' regions in human DNA. Nature, 316: 76-79.

Johnson, C. M. (2007). A Chronology of Middle Missouri Plains Village Sites. Washington: Smithsonian Intitution Scholarly Press.

Johnson, L. A. S. (1970). Rainbow's end: the quest for an optimal taxonomy. Systematic Zoology, 19: 203-239.

Jones, M. P. (1996). Indicator and Stratification Methods for Missing Explanatory Variables in Multiple Linear Regression. Journal of the American Statistical Association, 91(433): 222-230.

Kemp, B. M., Malhi, R. S., McDonough, J., Bolnick, D. A., Eshleman, J. A., Rickards, O., MartinezLabarga, C., Johnson, J. R., Lorenz, J. G., Dixon, E. J., Fifield, T. E., Heaton, T. H., Worl, R., Smith, D. G. (2007). Genetic Analysis of Early Holovene Skeletal Remains From Alaska and its Implications for the Settlement of the Americas. American Journal of Physical Anthropology, 132: 605-621.

Kherumian, R. (1949). Répertoire des points craniométriques et anthropométriques. Rev de Morphophysiologie humaine, 2: 22p.

Kidd, K. K., Rajeevan, H., Osier, M. V., Cheung, K. H., Deng, H., Druskin, L., Heinzen, R., Kidd, J. R., Stein, S., Pakstis A. J., Tosches, N. P., Yeh, C. C., Miller, P. L. (2003). ALFRED - the Allele FREquency Database. Disponível em <http://alfred.med.yale.edu>.

Kidwell, S. M., Fürsich, F. T., Aigner, T. (1986). Conceptual Framework for the Analysis and Classification of Fossil Concentrations. Palaios, 1: 228-238.

Kimmerle, E. H., Ross, A., Slice, D. (2008). Sexual dimorphism in America: Geometric Morphometric Analysis of Craniofacial Region. Journal of Forensic Sciences, 53(1): 54-57.

Kirschner, M., Gerhart, J. (1998). Evolvability. Proceedings of the National Academy of Sciences of the USA, 95: 8420-8427.

Kitson, E. (1931). A study of the Negro crania skull with special reference to the crania from Kenya Colony. Biometrika, 23: 271-314.

Klingenberg, C. P. (1998). Heterochrony and allometry: The analysis of evolutionary change in ontogeny. Biological Reviews, 73: 79-123.

Klingenberg, C. P. (2005). Developmental Constraints, Modules, and Evolvability. in: Hallgrímsson, B., Hall, B. K. (editors). Variation: A Central Concept in Biology. 1st edition. New York: Academic Press, 219-247.

Klingenberg, C. P. (2008). Morphological Integration and Developmental Modularity. The Annual Review of Ecology, Evolution, and Systematics, 39: 115-132. 
Klug, W. S., Cummings, M. R., Spencer, C. A., Palladino, M. A. (2010). Conceitos de Genética. 9a edição. Porto Alegre: Artmed.

Konigsberg, L. W. (2012). L. W. Konigsberg's Home Page: W. W. Howells' Craniometric Data. Disponível em <http://konig.la.utk.edu/howells.htm>, acessado em 11/03/2012.

Krogman, W. M. (1978). The Human Skeleton in Forensic Medicine. Springfield: Thomas Book.

Lahr, M. M. (1995). Patterns of Modern Human Diversification: Implications for Amerindian Origins. Yearbook of Physical Anthropology, 132(4): 605-621.

Lahr, M. M. (1996). The origin of modern human diversity: a study of cranial diversity. 1st edition. Cambridge: Cambridge University Press.

Lampert, R. J., Steele, D. (1993). Archaeological Studies at Bomaderry Creek, New South Wales. Records of the Australian Museum, Supplement, 17: 55-75.

Lande, R. (1982). A quantitative genetic theory of life history evolution, Ecology, 63: 607-615.

Lander, E. S., Botstein, D. (1989). Mapping Mendelian Factors Underlying Quantitative Traits Using RFLP Linkage Maps. Genetics, 121: 185-199.

Legendre, P. (2000). Comparison of permutation methods for the partial correlation and partial Mantel tests. Journal of Statistical Computation and Simulation, 67(1): 37-73.

Lewis, C. M., Tito, R. Y., Lizárraga, B., Stone, A. C. (2004). Land, Language, and Loci: mtDNA in Native Americans and the Genetic History of Peru. American Journal of Physical Anthropology, 127: 351360.

Lewis, R. Q. (1983). El Mundo Arqueológico del Cnl. Federico Diez de Medina. La Paz: Rolando Diez de Medina.

Lewontin, R. C. (1972). The apportionment of human diversity. In: Dobzhansky, T., Hecht, M. K., Steere, W. C. (editors). Evolutionary Biology 6. New York: Appleton-Century-Crofts, 381-398.

Lieberman, D. E. (2008). Speculations about the selective basis for modern human craniofacial form. Evolutionary Anthropology, 17: 55-68.

Lieberman, D. E. (2011). The Evolution of the Human Head. Cambridge: Harvard University Press.

Little, R. J. A. (1988). Missing-data adjustments in large Surveys. Journal of Business \& Economic Statistics, 6(3): 287-296.

Little, R. J. A. (1992). Regression With Missing X's: A Review. Journal of the American Statistical Association, 87(420): 1227-1237.

Liu, H., Prugnolle, F., Manica, A. \& Balloux, F. (2006). A geographically explicit genetic model of worldwide human-settlement history. American Journal of Human Genetics, 79: 230-237.

Londoño, E. (1988). La conquista del cacicazgo de Bogotá. Boletín Cultural y Bibliográfico, 16(25): 414.

Lourandos, H. (1968). Dispersal of Activities - the East Tasmanian Aboriginal Sites. Papers and Proceedings of the Royal Society of Tasmania, 102(2): 41-46. 
Lynch, M. (1990). The rate of morphological evolution in mammals from the standpoint of the neutral expectation. The American Naturalist, 136(6): 727-741.

Lynch, M. (1991). Methods for the analysis of comparative data in evolutionary biology. Evolution, 45: $1065-1080$.

Mahalanobis, P. C. (1936). On the generalized distance in statistics. Proceedings of the National Institute of Science of India, 2(1): 49-55.

Malhi, R. S., Breece, K. E., Shook, B. A. S., Kaestle, F. A., Chatters, J. C., Hackenberger, S., Smith, D. G. (2004). Patterns of mtDNA diversity in northwestern North America. Human Biology, 76(1): 33-54.

Malhi, R. S., Eshlerman, J. A., Greenberg, J. A., Qeiss, D. A., Shook, B. A. S., Kaestle, F. A., Lorenz, J. G., Kemp, B. M., Johnson, J. R., Smith, D. G. (2002). The Structure of Diversity within New World Mitochondrial DNA Haplogroups: Implications for the Prehistory of North America. American Journal of Human Genetics, 70: 905-919.

Malhi, R. S., Mortensen, H. M., Eshleman, J. A., Kemp, B. M., Lorenz, J. G., Kaestle, F. A., Johnson, J. R., Gorodezky, C., Smith, D. G. (2003). Native American mtDNA prehistory in the American Southwest. American Journal of Physical Anthropology, 120: 108-124.

Malhi, R. S., Schultz, B. A., Smith, D. G. (2001). Distribution of Mitochondrial DNA Lineages among Native American tribes of Northeastern North America. Human Biology, 73(1): 17-55.

Manica, A., Amos, W., Balloux, F., Hanihara, T. (2007). The effect of ancient population bottlenecks on human phenotypic variation. Nature, 448: 346-349.

Mantel, M. (1967). The detection of disease clustering and a generalized regression approach. Cancer Research, 27: 209-20.

Marroig, G., Cheverud, J. M. (2001). A comparison of phenotypic variation and covariation patterns and the role of phylogeny, ecology, and ontogeny during cranial evolution of New World monkeys. Evolution, 55(12): 2567-2600.

Marshall, F., Weissbrod, L. (2011). Domestication Processes and Morphological Change. Current Anthropology, 54(Supplement 4): 397-413.

Martin, R. (1928). Lehrbuch der Anthropologie in systematischer darstellung. Vol. 2, Kraniologie, Osteologie. Jena: Gustav Fischer.

Martin, R., Saller, K. (1957). Lehrbuch der Anthropologie. Stuttgart: Gustav Fischer Verlag.

Martinez, V. W. P., Martinez, R. M. P. (2007). Tama Chullpa - Él Cementerio Prehispánico de la Comunidad Culli Culli Alto, en el Altiplano de la Jurisdicción de Sica Sica, Bolivia. La Paz: Conservation International.

Martínez-Abadías, N., Esparza, M., Sjøvold, T., González-José, R., Santos, M., Hernández, M. (2009). Heritability of human cranial dimensions: comparing the evolvability of different cranial regions. Journal of Anatomy, 214: 19-35.

Martins, E. P., Hansen, T. F. (1997). Phylogenies and the comparative method: a general approach to incorporating phylogenetic information into the analysis of interspecific data. American Naturalist, 149: 646-667. 
Maynard Smith, J., Burian, R., Kauffman, S., Alberch, P., Campbell, J., Goodwin, B., Lande, R., Raup, D., Wolpert, L. (1985). Developmental Constraints and Evolution: A Perspective from the Mountain Lake Conference on Development and Evolution. Quarterly Review of Biology, 60: 265-287

Mayr, E. (1969). Principles of systematic zoology. New York: McGraw-Hill.

Mayr, E. (1970). Populations, Species, and Evolution. An Abridgment of Animal Species and Evolution. 2nd edition. Cambridge: Harvard University Press.

Mayr, E. (1974). Cladistic analysis or cladistic classification? Z. zool. Syst. Evolut, 12:: 94-128.

Mayr, E. (1982). The Growth of Biological Thought: Diversity, Evolution and Inheritance. 1st edition. Cambridge: Harvard University Press.

Mayr, E. (1983). How to Carry Out the Adaptationist Program? The American Naturalist, 121(3): 324334.

Mayr, E. (2001). What evolution is. 1st edition. New York: Basic Books.

Mayr, E. (2005). Foreword. in: Hallgrímsson, B., Hall, B. K. (editors). Variation: A Central Concept in Biology. 1st edition. New York: Academic Press, xvii.

Mayr, E. (2006). Uma ampla discussão: Charles Darwin e a gênese do moderno pensamento evolucionário. Ribeirão Preto: Funpec Editora.

McDougall, I., Brown, F. H., Fleagle, J. G. (2005). Stratigraphic placement and age of modern humans from Kibish, Ethiopia. Nature, 433: 733-736.

242 Mendes, C. T. (2005). DNA mitocondrial na Amazônia Brasileira: Estrutura Genética Regional e Inferências Continentais. Tese de Doutorado, Faculdade de Medicina de Ribeirão Preto, Universidade de São Paulo.

Merriwether, D. A., Ferrell, R. E. (1996). The four founding lineage hypothesis for the New World: a critical reevaluation. Mol. Phylogenet. Evol., 5: 241-246.

Merriwether, D. A., Hall, W. W., Vahlne, A., Ferrell, R. E. (1996). mtDNA variation indicates Mongolia may have been the source for the founding population for the New World. American Journal of Human Genetics, 59: 204-212.

Merriwether, D. A., Rothhammer, D. A., Ferrel, R. E. (1995). Distribution of the four founding lineage haplotypes in Native Americans suggests a single wave of migration for the New World. American Journal of Physical Anthropology, 98(4): 411-430.

Mesa, N. R., Mondragón, M. C., Soto, I. D., Parra, M. V., Duque, C., Ortíz-Barrientos, D., García, L. F., Velez, I. D., Bravo, M. L., Múnera, J. G., Bedoya, G., Bortolini, M., Ruiz-Linares, A. (2000). Autosomal, mtDNA, and Y-Chromosome Diversity in Amerinds: Pre- and Post-Columbian Patterns of Gene Flow in South America. American Journal of Human Genetics, 67: 1277-1286.

Meyer, D. (1994). Árvores evolutivas humanas: uma discussão sobre inferência filogenética. Dissertação de Mestrado. Instituto de Biociências, Universidade de São Paulo.

Miles, D. B., Dunham, A. E. (1993). Historical perspectives in ecology and evolutionary biology: the use of phylogenetic comparative analysis. Annual Review of Ecology and Systematics, 24: 587-619.

Mingoti, S. A. (2005). Análise de dados através de métodos de estatística multivariada. Uma abordagem aplicada. 1a edição. Belo Horizonte: Editora UFMG. 
Mitteroecker, P., Bookstein, F. (2008). The evolutionary role of modularity and integration in the hominoid cranium. Evolution, 62(4): 943-958.

Moore-Jansen, P. M., Ousley, S. D., Jantz, R. L. (1994). Data collection procedures for forensics skeletal material: reports of investigations \#48. Knoxville: The University of Tennessee.

Morey, D. F., Crothers, G. M., Stein, J. K., Fenton, J. P., Herrmann, N. P. (2002). Indian Knoll, an Archaic Shell Midden in West-Central Kentucky. Geoarchaeology, 17(6): 521-553.

Mundfrom, D. J., Whitcomb, A. (1998). Imputing Missing Values: The Effect on the Accuracy of Classification. Multiple Linear Regression Viewpoints, 25: 13-19.

Nei, M., Roychoudhury, A. K. (1974). Genetic variation within and between the three major races of man, caucasoids, negroids and mongoloids. American Journal of Human Genetics, 26: 421-443.

Nell, J. V., Gershowitz, H., Spielman, R. S., Migliazza, E. C., Salzano, F. M., Oliver, W. J. (1977). Genetic Studies of the Macushi and Wapishana Indians. Human Genetics, 37: 207-219.

Neves, W. A. (1988). Uma proposta pragmática para cura e recuperação de coleções de esqueletos humanos de origem arqueológica. Boletim do Museu Paraense Emilio Goeldi, Série Antropologia, 4(1): 3-26.

Neves, W. A., Bernardo, D. V., Okumura, M. M. M. (2007b). A origem do homem americano vista a partir da América do Sul: uma ou duas migrações? Revista de Antropologia, 50(1): 9-44.

Neves, W. A., Bernardo, D. V., Okumura, M., Almeida, T. F., Strauss, A. (2011). Origem e dispersão dos Tupiguarani: o que diz a morfologia craniana? Boletim do Museu Paraense Emílio Goeldi. Ciências Humanas, 6(1): 95-122.

Neves, W. A., Hubbe, M. (2005). Cranial morphology of early Americans from Lagoa Santa, Brazil: Implications for the settlement of the New World. Proceedings of the National Academy of Sciences of the USA, 102(51): 18309-18314.

Neves, W. A., Hubbe, M., Correal, G. (2007a). Human skeletal remains from Sabana de Bogotá, Colombia: a case of paleoamerican morphology late survival in South America? American Journal of Physical Anthropology, 133: 1080-1098.

Neves, W. A., Powell, J. F., Prous, A., Ozolins, E. G., Blum, M. (1999). Lapa Vermelha IV Hominid 1: Morphological affinities of the earliest known american. Genetics and Molecular Biology, 22(4): 461-469.

O'Rourke, D. H., Hayes, M. G., Carlyle, S. W. (2000). Spatial and temporal stability of mtDNA haplogroup frequencies in native North America. Human Biology, 72(1): 15-34.

Offenbecker, A. M. (2011). Diet, Disease, and Developmental Defects: Examining the Role of Environmental Stress in the Etiology of Skeletal Anomalies. Dissertação de Mestrado. North Carolina State University.

Oksanen, J., Blanchet, F. G., Kindt, R., Legendre, P., Minchin, P. R., O'Hara, R. B., Simpson, G. L., Solymos, P., Stevens, M. H. H., Wagner, H. (2011). Vegan: Community Ecology Package. R package version 2.0-2. Disponível em <http://CRAN.R-project.org/package=vegan>, acessado em $02 / 06 / 2011$.

Oliveira, F. B. de (2009). Evolução do crânio de macacos do Velho Mundo: uma abordagem de genética quantitativa. Tese de Doutorado. Instituto de Biociências, Universidade de São Paulo. 
Olson, E. C., Miller, R. L. (1958). Morphological integration. 1st edition. Chicago: University of Chicago Press.

Otto, P. A. (2008). Genética de poblaciones humanas. 1a. ed. Posadas: Editorial Universitária de la Universidad Nacional de Misiones.

Owen, T., Henneberg, M., Pate, F. D. (2006). Aboriginal stature in South Australia: A 10,000-year history. Anthropological Review, 69: 3-13.

Pagel, M. D. (1999). Inferring the historical patterns of biological evolution. Nature, 401: 877-884.

Pakendorf, B., Stoneking, M. (2005). Mitochondrial DNA and Human Evolution. Annu. Rev. Genomics Hum. Genet., 6: 165-183.

Parichy, D. M. (2005). Variation and Developmental Biology: Prospects for the Future. in: Hallgrímsson, B., Hall, B. K. (editors). Variation: A Central Concept in Biology. 1st edition. New York: Academic Press, 475-498.

Park, M. A. (1996). Biological Anthropology. Mountain View: Mayfield Publishing Company.

Parker, G. (1995). Atlas da História do Mundo. São Paulo: Empresa Folha da Manhã S/A.

Pearson, K. (1896). Mathematical Contributions to the Theory of Evolution. III. Regression, Heredity, and Panmixia. Philosophical Transactions of the Royal Society of London, 187: 253-318.

Perego, U. A., Achilli, A., Angerhofer, N., Accetturo, M., Pala, M., Olivieri, A., Kashani, B. H., Ritchie, K. H., Scozzari, R., Kong, Q., Myres, N. M., Salas, A., Semino, O., Bandelt, H., Woodward, S. R., Torroni, A. (2009). Distinctive Paleo-Indian Migration Routes from Beringia Marked by Two Rare mtDNA Haplogroups. Current Biology, 19: 1-8.

Pereira, F., Soares, P., Carneiro, J., Pereira, L., Richards, M. B., Samuels, D. C., Amorim, A. (2008). Mol. Biol. Evol., 25(12): 2759-2770.

Pereira, L., Freitas, F., Fernandes, V., Pereira, J. B., Costa, M. D., Costa, S., Máximo, V., Macaulay, V., Rocha, R., Samuels, D. C. (2009). The Diversity Present in 5140 Human Mitochondrial Genomes. American Journal of Human Genetics, 84: 628-640.

Perez, S. I., Monteiro, L. R. (2009). Nonrandom factors in modern human morphological diversification: a study of craniofacial variation in southern south American populations. Evolution, 63(4): 978-993.

Petrukhin, K. E., Speer, M. C., Cayanis, E., Bonaldo, M. de F., Tantravahi, U., Soares, M. B., Fischer, S. G., Warburton, D., Gilliam, T. C., Ott. J. (1993). A Microsatellite Genetic Linkage Map of Human Chromosome 13. Genomics, 15: 76-85.

Pigliucci, M., Kaplan, J. (2000). The fall and rise of Dr Pangloss: adaptationismo and the Spandrels paper 20 years later. TREE, 15: 66-70.

Piperno, D. R. (2011). The Origins of Plant Cultivation and Domestication in the New World Tropics. Current Anthropology, 54(Supplement 4): 453-470.

Porto, A., Oliveira, F. B., Shirai, L. T., De Conto, V., Marroig, G. (2009). The Evolution of Modularity in the Mammalian Skull I: Morphological Integration Patterns and Magnitudes. Evolutionary Biology, 36(1): 118-135. 
Pretorius, E., Steyn, M., Scholtz, Y. (2006). Investigation Into the Usability of Geometric Morphometric Analysis in Assessment of Sexual Dimorphism. American Journal of Physical Anthropology, 129: 64-70.

Price, T. D., Bar-Yosef, O. (2011). The Origins of Agriculture: New Data, New Ideas. Current Anthropology, 54(Supplement 4): 163-174.

Price, T. D., Turelli, M., Slatkin, M. (1993). Peak shifts produced by correlated response to selection. Evolution, 47: 280-290.

Prugnolle, F., Manica, A., Balloux, F. (2005). Geography predicts neutral genetic diversity of human populations. Current Biology, 15(5): 159-160.

R Development Core Team. (2010). R: A language and environment for statistical computing. Vienna: R Foundation for Statistical Computing, ISBN 3-900051-07-0, Disponível em <http://www.Rproject.org>, acessado em 13/04/2010.

Ramachandran, S., Deshpande, O., Roseman, C. C., Rosenberg, N. A., Feldman, M. W. \& CavalliSforza, L. L. (2005). Support from the relationship of genetic and geographic distance in human populations for a serial founder effect originating in Africa. Proceedings of the National Academy of Sciences of the USA, 102(44): 15942-15947.

Rand, D. M. (2001). The Units of Selection on Mitochondrial DNA. Proceedings of the National Academy of Sciences of the USA., 32: 415-448.

Ray, N. (2005). A geographical information system tool to compute effective distances among samples. Proceedings of the National Academy of Sciences of the USA, 5: 177-180.

Reich, D., Green, R. E., Kircher, M., Krause, J., Patterson, N., Durand, E. Y., Viola, B., Briggs, A. W., Stenzel, U., Johnson, P. L. F., Maricic, T., Good, J. M., Marques-Bonet, T., Alkan, C., Fu, Q., Mallick, S., Li, H., Meyer, M., Eichler, E. E., Stoneking, M., Richards, M., Talamo, S., Shunkov, M. V., Derevianko, A. P., Hublin, J., Kelso, J., Slatkin, M., Pääbo, S. (2010). Genetic history of an archaic hominin group from Denisova Cave in Siberia. Nature, 468: 1053-1060.

Reich, D., Patterson, N., Campbell, D., Tandon, A., Mazieres, S., Ray, N., Parra, M. V., Rojas, W., Duque, C., Mesa, N., García, L. F., Triana, O., Blair, S., Maestre, A., Dib., J. C., Bravi, C. M., Bailliet, G., Corach, D., Hünemeier, T., Bortolini, M. C., Salzano, F. M., Petzl-Erler, M. L., Acuña-Alonzo, V., Aguilar-Salinas, C., Canizales-Quinteros, S., Tusié-Luna, T., Riba, L., Rodríguez-Cruz, M., LopezAlarcón, M., Coral-Vazquez, R., Canto-Cetina, T., Silva-Zolezzi, I., Fernandez-Lopez, J. C., Contreras, A. V., Jimenez-Sanchez, G., Gómez-Vázquez, M. J., Molina, J., Carracedo, Á., Salas, A., Gallo, C., Poletti, G., Witonsky, D. B., Alkorta-Aranburu, G., Sukernik, R. I., Osipova, L., Fedorova, S. A., Vasquez, R., Villena, M., Moreau, C., Barrantes, R., Pauls, D., Excoffier, L., Bedoya, G., Rothhammer, F., Dugoujon, J., Larrouy, G., Klitz, W., Labuda, D., Kidd, J., Kidd, K., Di Rienzzo, A., Freimer, N. B., Price, A. L., Ruiz-Linares, A. (2012). Reconstructing Native American population history. Nature, doi:10.1038/nature11258.

Reis, E. (2001). Estatística multivariada aplicada. Lisboa: Edições Sílabo.

Relethford, J. H. (1994). Craniometric variation among modern human populations. American Journal of Physical Anthropology, 95: 53-62.

Relethford, J. H. (1998). Genetics of modern human origins and diversity. Annual Review of Anthropology, 27: 1-23. 
Relethford, J. H. (2002). Apportionment of Global Human Genetic Diversity Based on Craniometrics and Skin Color. American Journal of Physical Anthropology, 118: 393-398.

Relethford, J. H. (2004a). Global patterns of isolation by distance based on genetic and morphological data. Human Biology, 76: 499-513.

Relethford, J. H. (2004b). Rmet v.5.0. Oneonta: State University of New York. Disponível em <http://employees.oneonta.edu/relethjh/programs/>, acessado em 11/05/2010.

Relethford, J. H., Blangero, J. (1990). Detecting of differential gene flow patterns of quantitative variation. Human Biology, 62: 5-25.

Revell, L. J. (2009). Size-correction and principal components for interspecific comparative studies. Evolution, 63(12): 3258-3268.

Revell, L. J. (2012). phytools: an R package for phylogenetic comparative biology (and other things). Methods in Ecology and Evolution, 3: 217-223.

Ridley, M. (2006). Evolução. 3a edição. Porto Alegre: Artmed.

Rightmire, G. P. (1970). Bushman, Hottentot and South African Negro crania studied by distance and discrimination. American Journal of Physical Anthropology, 33: 169-195.

Roff, D. A., (1995). The estimation of genetic correlations from phenotypic correlations - a test of Cheverud's conjecture. Heredity, 74: 481-490.

Roseman, C. C. (2004). Detecting interregionally diversifying natural selection on modern human cranial form by using matched molecular and morphometric data. Proceedings of the National Academy of Sciences of the USA, 101(35): 12824-12829.

Roseman, C. C., Weaver, T. D. (2004). Multivariate apportionment of global human craniometric diversity. American Journal of Physical Anthropology, 125: 257-263.

Roseman, C. C., Weaver, T. D. (2007). Molecules versus morphology? Not for the human cranium. BioEssays, 29: 1185-1188.

Rosenberg, N. A., Mahajan, S., Ramachandran, S., Zhao, C., Pritchard, J. K., Feldman, M. W. (2005). Clines, clusters, and the effect of study design on the inference of human population structure. PLoS Genetics, 1(6) e70: 660-671.

Rosenberg, N. A., Nordborg, M. (2002). Genealogical trees, coalescent theory and the analysis of genetic polymorphisms. Nature. DOI: 10.1038/nrg795.

Rosenberg, N. A., Pritchard, J. K., Weber, J. L., Cann, H. M., Kidd, K. K., Zhivotovsky, M. W., Feldman, M. W. (2002). Genetic structure of human populations. Science, 298: 2381-2384.

Roth, V. L. (2005). Variation and Versatility in Macroevolution. in: Hallgrímsson, B., Hall, B. K. (editors). Variation: A Central Concept in Biology. 1st edition. New York: Academic Press, 455-474.

Rowley-Conwy, P. (2011). Westward Ho! The Spread of Agriculture from Central Europe to the Atlantic. Current Anthropology, 54(Supplement 4): 431-451.

Ruiz-Pesini, E., Mishmar, D., Brandon, M., Procaccio, V., Wallace, D. C. (2004). Effects of Purifying and Adaptive Selection on Regional Variation in Human mtDNA. Science, 303: 223-226.

Russell, J. C. (1965). Recent Advances in Medieval Demography. Speculum, 40(1): 84-101. 
Saitou, N., Nei, M. (1987). The Neighbor-joining Method: A New Method for Reconstructing Phylogenetic Trees. Mol. Biol. Evol., 4(4): 406-425.

Sax, K. (1923). The association of size differences with seed-coat pattern and pigmentation in Phaseolus vulgaris. Genetics, 8: 552-560.

Sayavongkhamdy, T., Bellwood, P., Bulbeck, D. (2000). Recent archaeological research in Laos. IndoPacific Prehistory Association Bulletin, 19: 101-110.

Schneider, H. (2003). Métodos de Análise Filogenética. 2a. Edição. Ribeirão Preto: Holos Editora.

Seguchi, N., McKeown, A., Schmidt, R., Umeda, H., Brace, C. L. (2011). An alternative view of the peopling of South America: Lagoa Santa in craniometric perspective. Anthropological Science, 119(1): 21-38.

Seguchi, N., Nelson, A. R., Austin, S., Brace, C. L. (2005). Early South Americans in craniofacial metric perspective: Lagoa Santa. American Journal of Physical Anthropology, 40(Suppl.), 187.

Serre, D. \& Pääbo, S. (2004). Evidence for gradients of human genetic diversity within and among continents. Genome Research, 14: 1679-1685.

Shinoda, K., Adachi, N., Gullen, S., Shimada, I. (2006). Mitochondrial DNA analysis of ancient Peruvian highlanders. American Journal of Physical Anthropology, 131(1): 98-107.

Simielli, M. E. (2000). Geoatlas. São Paulo: Editora Ática.

Simpson, G. G., Roe, A., Lewontin, R. C. (2003). Quantitative Zoology. Mineola: Dover Publications.

Slatkin, M., Hudson, R. R. (1991). Pairwise compariosons of mitochondrial DNA sequences in stable and exponentially growing populations. Genetics, 129: 555-562.

Slice, D. E. (2005). Modern morphometrics. In: Slice, D. E. (editor). Modern morphometrics in physical anthropology. New York: Springer, 1-46.

Smith, K. K. (1997). Comparative patterns of craniofacial development in eutherian and methaterian mammals. Evolution, 51: 1663-1678.

Sneath, P. H. (1957). The application of computer to taxonomy. Journal of General Microbiology, 17: 201-226.

Snustad, D. P., Simmons, M. J. (2008). Fundamentos de genética. 4a. Edição. Rio de Janeiro: Guanabara Koogan.

Sokal, R. R., Camin, J. H. (1965). The Two Taxonomies: Areas of Agreement and Conflict. Systematic Zoology, 14(3): 176-195.

Sokal, R. R., Rohlf, F. J. (2012). Biometry. 4th edition. New York: W. H. Freeman and Company.

South African Government Information. (2011). About SA - History. Disponível em <http://www.info.gov.za/aboutsa/history.htm>, acessado em 17/05/2011.

Sparks, C. S., Jantz, R. L. (2002). A reassessment of human cranial plasticity: Boas revisited. Proceedings of the National Academy of Sciences of the USA, 99(23): 14636-14639. 
Stamm, A. C., Pignatari, S., Sebusiani, B. B., Galati, M. C., Mitsuda, S., Haetinger, R. G. (2002). Cirurgia endoscópica nasossinusal e da base do crânio guiada por computador. Revista Brasileira de Otorrinolaringologia, 68(4): 502-509.

Starikovskaya, Y. B., Sukernik, R. I., Schurr, T. G., Kogelnik, A. M., Wallace, D. C. (1998). mtDNA Diversity in Chukchi and Siberian Eskimos: Implications for the Genetic History of Ancient Beringia and the Peopling of the New World. American Journal of Human Genetics, 63: 1473-1491.

StatSoft, Inc. (2007). STATISTICAC (data analysis software system). Version 8.0, <www.statsoft.com>.

Steadman, D. W., Kirch, P. V. (1990). Prehistoric extinction of birds on Mangaia, Cook Islands, Polynesia. Proceedings of the National Academy of Science of USA, 87: 9605-9609.

Steegman, A. T. J. (1970). Cold adaptation and the human face. American Journal of Physical Anthropology, 32: 243-250.

Steele, D. G., Bramblett, C. A. (1988). The Anatomy and Biology of the Human Skeleton. College Station: Texas A\&M University Press.

Steppan, S. J., Phillips, P. C., Houle, D. (2002). Comparative quantitative genetics: evolution of the G matrix. TRENDS in Ecology \& Evolution, 17(7): 320-327.

Stringer, C. (2003). Out of Ethiopia. Nature, 423: 692-695.

Stringer, C. B. \& Andrews, P. (1988). Genetic and fossil evidence for the origin of modern humans. Science, 239: 1263-1268.

Stuiver, M., Polach, H. A. (1977). Reporting of 14C Data. Radiocarbon, 19(3): 355-363.

Tagaya, A. (1989). Development of a Generalized Discriminant Function for cross-population determination of sex from long bones of the arm and leg. Canadian Society of Forensic Science, 22(2): 159-175.

Tattersall, I. (2009). The Fossil Trail. Second Edition. New York: Oxford University Press.

Taylor, I. (1890). The origin of the Aryans. New York: Scribner \& Welford.

"Templeton, A. R. (1993). The "'Eve""' hypotheses: a genetic critique and reanalysis. American Anthropologist, 95: 51-72."

Templeton, A. R. (1999). Human races: a genetic and evolutionary perspective. American Anthropologist, 100(3): 632-650.

Templeton, A. R. (2002) Out of Africa again and again. Nature, 416: 45-51.

Templeton, A. R. (2005). Haplotype Trees and Modern Human Origins. Yearbook of Physical Anthropology, 48: 33-59.

Templeton, A. R. (2010). Coherent and incoherent inference in phylogeography and human evolution. Proceedings of the National Academy of Sciences of the USA, 107(14): 6376-6381.

Torroni, A., Bandelt, H., Macaulay, V., Richards, M., Cruciani, F., Rengo, C., Martinez-Cabrera, V., Villems, R., Kivisild, T., Metspalu, E., Parik, J., Tolk, H., Tambets, K., Foster, P., Karger, B., Francalacci, P., Rudan, P., Janicijevic, B., Rickards, O., Savontaus, M., Huoponen, K., Laitinen, V., Koivumäki, S., Sykes, B., Hickey, E., Novelletto, A., Moral, P., Sellitto, D., Coppa, A., Al-Zaheri, N., Santachiara- 
Benerecetti, S., Semino, O., Scozzari, R. (2001). A Signal, from Humam mtDNA, of Postglacial Recolonization in Europe. American Journal of Human Genetics, 69: 844-852.

Tourism and Travellers New Zealand Government Agencies. (2011). Origins of people Moriori. Disponível em <http://www.teara.govt.nz/en/moriori/1>, acessado em 05/07/2011.

Ulm, S., Reid, J. (2000). Index of dates from archaeological sites in Queensland. Queensland Archaeological Research, 12: 1-128.

Valentin, J. L. (2000). Ecologia numérica: uma introdução à analise multivariada de dados ecológicos. Rio de Janeiro: Intersciência.

Vallois, H. V. (1965). Anthropometric techiniques. Current Anthropology, 6(2): 127-143.

Vanzolini, P. E. (1993). Métodos estatísticos elementares em sistemática zoológica. São Paulo: Editora Hucitec.

Veyre-Goulet, S. A., Mercier, C., Robin, O., Guérin, C. (2008). Recent human sexual dimorphism study using cephalometric plots on lateral teleradiography and Discriminant Function Analysis. Journal of Forensic Sciences, 53(4): 786-789.

Viet, N. (2005). The Da But Culture: evidence for cultural development in Vietnan during the Middle Holocene. Indo-Pacific Prehistory Association Bulletin, 25: 89-93.

Vilanova, J. (1875). Ciencia Prehistorica. Revista Europea, 69: 637-640

von Cramon-Taubadel, N., Lycett, S. J. (2008). Brief communication: human cranial variation fits iterative founder effect model with African origin. American Journal of Physical Anthropology, 136: 108-113.

von Cramon-Taubadel, N., Weaver, T. D. (2009). Insights From a Quantitative Genetic Approach to Human Morphological Evolution. Evolutionary Anthropology, 18: 237-240.

Wagner, G. P., (1996). Homologues, natural kinds and evolution of modularity. American Zoology, 36: $36-43$

Wagner, G. P., Altenberg, L. (1996). Complex adaptations and the evolution of evolvability. Evolution, 50: 967-976.

Wagner, G. P., Pavlicev, M., Cheverud, J. M. (2007). The road to modularity. Nature Reviews Genetics, 8: 921-931.

Walker, P. L. (2005). Greater Sciatic Notch Morphology: Sex, Age, and Population Differences. American Journal of Physical Anthropology, 127: 385-391.

Wang, S., Lewis, C. M., Jakobsson, M., Ramachandran, S., Ray, N., Bedoya, G., Rojas, W., Parra, M. V., Molina, J. A., Gallo, G., Mazzotti, G., Poletti, G., Hill, K., Hurtado, A. M., Labuda, D., Klitz, W., Barrantes, R., Bortolini, M. C., Salzano, F. M., Petzl-Erler, M. L., Tsuneto, L. T., Llop, E., Rothhammer, F., Excoffier, L., Feldman, M. W., Rosenberg, N. A., Ruiz-Linares, A. (2007). Genetic variation and population structure in Native Americans. Plos Genetics, 3(11):e185.

Ward, J. H. (1963). Hierarchical grouping to optimize an objective function. Journal of the American Statistical Association, 58(301): 236-244.

Washburn, S. W. (1963). The study of race. American Anthropologist, 65: 521-531. 
Weaver, T. D., Roseman, C. C., Stringer, C. B. (2007). Were neandertal and modern human cranial differences produced by natural selection or genetic drift? Journal of Human Evolution, 53(2): 135145.

Weidenreich, F. (1947). Facts and speculations concerning the origin of Homo sapiens. American Anthropologist, 49(2): 187-203.

Weiss, E., Zohary, D. (2011). The Neolithic Southwest Asian Founder Crops. Current Anthropology, 54(Supplement 4): 237-254.

Whitlock, M. C. (2002). Selection, load and inbreeding depression in a large metapopulation. Genetics, 160: 1191-1202.

Wilkie, A. O. M., Morriss-Kay, G. M. (2001). Genetics of craniofacial development and malformation. Nature Reviews Genetics, 2: 458-468.

Williams, F. L., Belcher, R. L., Armelagos, G. J. (2005). Forensic misclassification of ancient Nubian crania: Implications for assumptions about human variation. Current Anthropology, 46: 340-346.

Wilson, E. O. (1975). Sociobiology: The New Synthesis. Cambridge: The Belknap Press of Harvard University Press.

Wolpoff, M. H. (1968). Climatic influence on the nasal aperture. American Journal of Physical Anthropology, 29: 405-423.

Wolpoff, M. H., Hawks, J., Caspari, R. (2000). Multiregional, Not Multiple Origins. American Journal of Physical Anthropology, 112: 129-136.

Wolpoff, M. H., Spuhler, J. N., Smith, F. H., Radov?i?, J., Pope, G., Frayer, D. W., Eckhardt, R. Clark, G. (1988). Modern human origins. Science, 241: 772-773.

Wood, J. W., Milner, G. R., Harpending, H. C., Weiss, K. M. (1992). The Osteological Paradox: Problems of Inferring Prehistoric Health from Skeletal Samples. Current Anthropology, 33(4): 343370.

Wright, L. E., Yoder, C. J. (2003). Recent Progress in Bioarchaeology: Approaches to the Osteological Paradox. Journal of Archaeological Research, 11(1): 43-70.

Wright, S. (1921a). Systems of Mating. IV. The effects of selection. Genetics, 6: 162-166.

Wright, S. (1921b). Systems of Mating. V. General considerations. Genetics, 6: 167-178.

Wright, S. (1943). Isolation by distance. Genetics, 28: 114-138

Wright, S. (1965). The interpretation of population structure by F-statistics with special regard to systems of mating. Evolution, 19(3): 395-420.

Wright, S. (1984). Evolution and the genetics of populations, volume 4. Chicago: Chicago University Press.

Wu, R., Ma, C., Casella, G. (2007). Statistical Genetics of Quantitative Traits. Linkage, Maps, and QTL. 1st edition. New York: Springer.

Xing, Y. Z., Tan, Y. F., Hua, J. P., Sun, X. L., Xu, C. G., Zhang, Q. (2002). Characterization of the main effects, epistatic effects and their environmental interactions of QTLs on the genetic basis of yield traits in rice. Theoretical and Applied Genetics, 105: 248-257. 
Yamaguchi, B. (1973). Facial flatness measurements of the Ainu and Japanese crania. Bulletin of National Science Museum, 16: 161-171.

Young, D. E. (1986). The paleoindian skeletal material from Horn Shelter, number 2, in central Texas: an analysis and perspective. Dissertação de Mestrado. Texas A \& M University.

Zelditch, M. L. (2005). Developmental Regulation of Variability. in: Hallgrímsson, B., Hall, B. K. (editors). Variation: A Central Concept in Biology. 1st edition. New York: Academic Press, 249-276.

Zelditch, M. L., Bookstein, F. L., Lundrigan, B. L. (1992). Ontogeny of Integrated Skull Growth in the Cotton Rat Sigmodon fulviventer. Evolution, 46(4): 1164-1180.

Zelditch, M. L., Bookstein, F. L., Lundrigan, B. L. (1993). The ontogenetic complexity of developmental constraints. Journal of Evolutionary Biology, 6: 121-141.

Zelditch, M. L., Lundrigan, B. L., Sheets, H. D., Garland, T. (2003). Do precocial mammals develop at a higher rate? A comparison of rates of skull development in Sigmodon fulviventer and Mus musculus domesticus. Journal of Evolutionary Biology, 16: 708-720.

Zeng, Z. B. (1994). Precision mapping of quantitative trait loci. Genetics, 136: 1457-1468. 